EISSN: $2706-7947$ ISSN: 2077- 4613

DOI: 10.36632/mejas/2021.11.3.56

Journal homepage: www.curresweb.com

Pages: 694-773

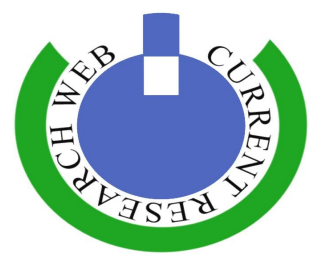

\title{
Effectiveness of Biofertilizers for Enhancing Nutrients Availability in Rhizosphere Zone, Stimulate Aggregate Formation and Their Effects by Climatic Changes
}

\author{
${ }^{1}$ Abou Seeda, M.A Yassen, A.A, ${ }^{2}$ Abou El-Nour, E.A.A, and ${ }^{1}$ Sahar, M. Zaghloul \\ ${ }^{I}$ Plant Nutrition Dept., National Research Centre, 33 El Buhouth St., 12622 Dokki, Giza, Egypt. \\ ${ }^{2}$ Fertilization Tech. Dept., National Research Centre, 33 El Buhouth St., 12622 Dokki, Giza, Egypt
}

Received: 15 June 2021 Accepted: 10 Sept. $2021 \quad$ Published: 20 Sept. 2021

\begin{abstract}
Land degradation is a major threat to the food security, with increasing world population the agricultural land is declining and degrading. Biofertilization with Fungi and bacterial inoculate, and their combination with organic fertilizers can be a promising approach for recovering degradation of the soil, minimizing the extensive use of chemical fertilizers. Biofertilization can enhance the bioavailability of nutrient for plant growth, though; fixation, chelation as well as improving the physical characteristics of soil aggregation by their execration of hydrophobins and Glomalin protein. The mechanisms of microbial inoculate in the provision or mobilization of nutrients in degraded land is a key for their success in field applications. Microbes are important, for improving the physical characteristics as well as reinstating the soil fertility of degraded soils. Such mechanisms may help in the developer of innovative cost-effective management practices in order to improve the soil fertility and crop production in degraded soils. The role of bacterial and fungal inoculated in combination with organic materials could have a potential for restoration of soils degradation due to the effectiveness of organic matter that can fulfill the nutrient demand. Applications of bio-fertilizaters generally reduce the excessive use of chemical fertilizers. Several researchers reported that endophytes bacterial play a very crucial role in enhancing and promoting plant growth and resilience against abiotic and biotic stress. For enhancing nutrient availability, biomass production, leaf area, hydraulic activity, chlorophyll content, shoot and root ratio, there is a growing need to improve nutrients use efficiency in the soil in an eco-friendly manner, that can be achieved by the application of microbial nutrients solubilizes. Physical characteristics of soils provide by the plant rhizosphere and their microbial communities for a long time, the presence of plants with symbiotic fungal community always encourage the formation of stable macro-aggregates.
\end{abstract}

Keywords: biofertilizers,PGPR, plant microbiota, soil fertility,crop productivity,soil aggregates, sustainable agriculture.

\section{Introduction}

The global human population is increasing continuously, that has propelled up to 7 billion at present Godfray et al., (2010); Glick, (2015). At this projected growth rate, the world population will rise to about 9.5 billion by 2050, thus, exerting immense pressure on food supplies Glick, (2015). FAO (2009), reported that global food demands in coming decades will raise by about $70 \%$, that will enhance the need of intensively growing agricultural crops Godfray et al., (2010); Tilman et al., (2011). To encounter this issue, soils are cultivated with extractive crops, which depleted the nutrient reserves that had led to negative balance of nutrients and soil degradation van Lynden and Odeman, (1998); Glick, (2015). Fig. (1). This can be defined as physico-chemical and biological deterioration of soil environment through anthropogenic activity leading to a serious decline in soil productivity and fertility Dregne, (2002). The other dominant form of soil degradation are erosion and salinity, where the causative factors for former type include improper agricultural practices, deforestation and overgrazing van Lyndenand Odeman, (1998). 

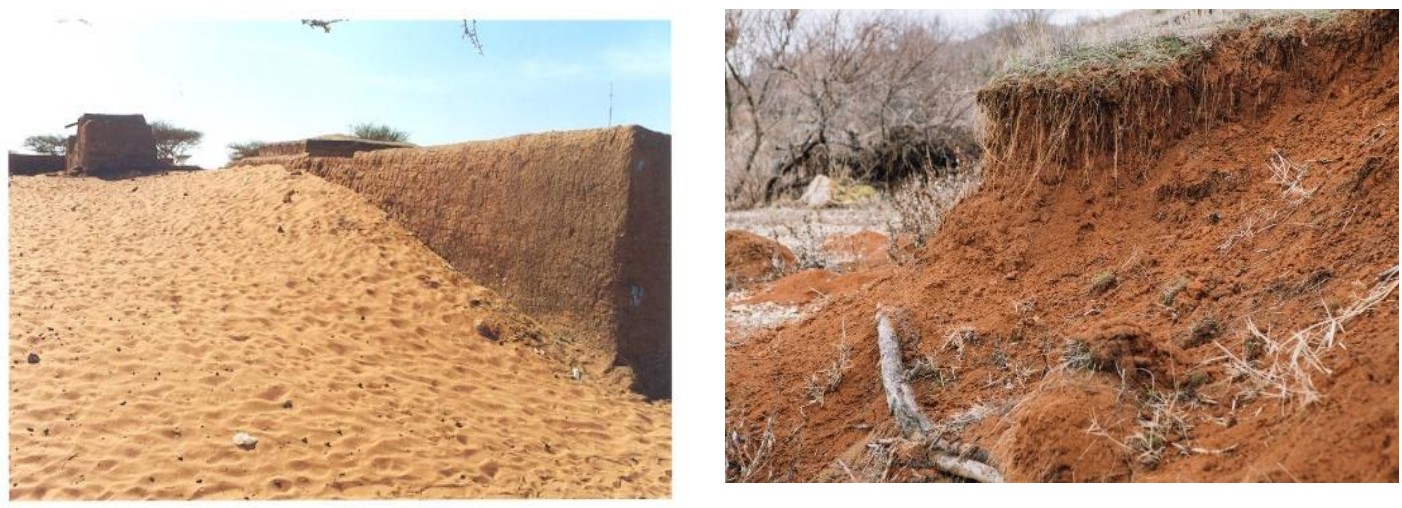

Fig. 1: Illustrated the abusive behavior over the last 150 years has caused tremendous damage to the earth's topsoil resulting in vast land degradation such as erosion, deforestation, waterlogging and a decline in soil fertility. Land degradation has become a critical global issue because of its harmful effects on agronomic productivity, the ecosystem, as well as its impact on food security along with the quality of everyday life.

These practices degrade $38 \%$ of the world agricultural land, $21 \%$ permanent pasture and $18 \%$ forests and woodlands (Oldeman et al., 1990; Utuk and Daniel, 2015). Of the total degraded cropland, pasture and woodland, Oldeman et al., (1990) categorized as lightly (9\%), moderately (10\%) and strongly (4\%) degraded soils. Light and moderately degraded soils are suit-able for local farming with reduced agricultural functions. A large decline in productivity of such soils and their restoration is possible with changes in farm management practices whereas severely degraded soil virtually lose their productivity and their original biotic functionality Fig. (2),

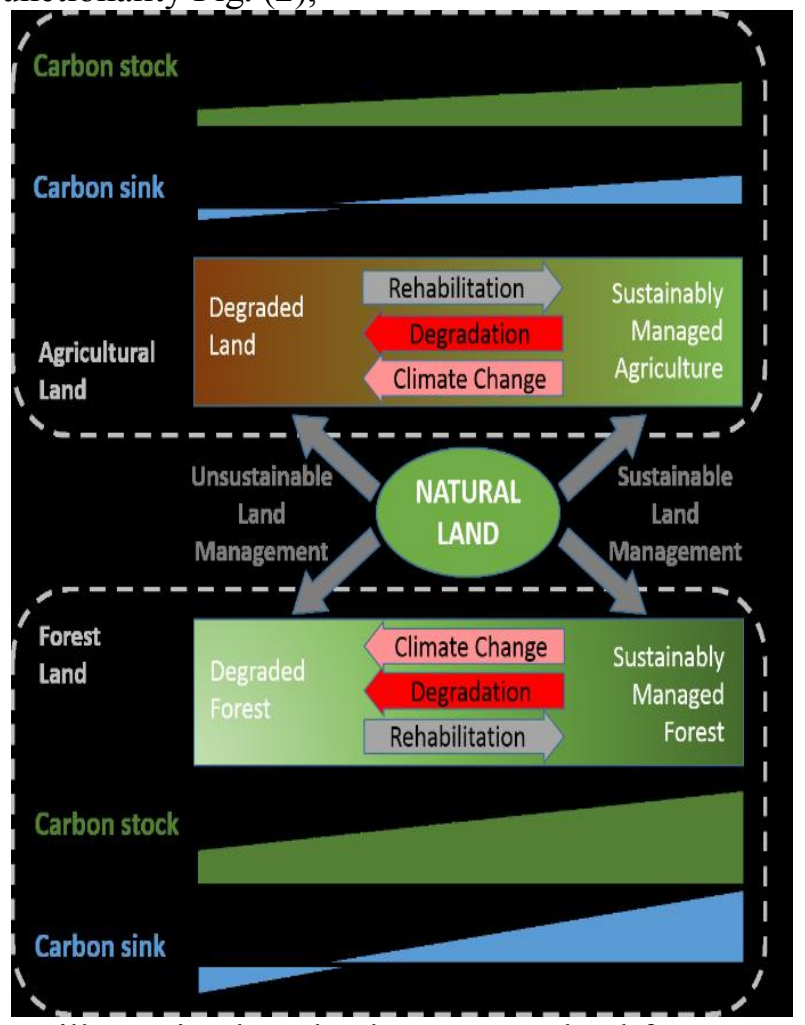

Fig. 2: Conceptual diagram illustrating how land use moves land from a natural to a used state. How the land is managed in response to climate change determines sustainable or degraded outcome. Climate change can exacerbate many degradation processes and introduce novel ones (e.g., permafrost thawing or biome shifts), hence, management needs to respond to climate impacts in order to avoid, reduce or reverse degradation. The types and intensity of human land use and climate change impacts on natural lands affect their carbon stocks and their ability to operate as carbon sinks. In managed agricultural lands, degradation typically results in reductions of 
soil organic carbon stocks, which also adversely affects land productivity and carbon sinks. In forestland, reduction in biomass carbon stocks alone is not necessarily an indication of a reduction in carbon sinks. Sustainably managed forest landscapes can have a lower biomass carbon density but the younger forests have a higher growth rate, and therefore contribute stronger carbon sinks, than natural forests

Oldeman et al., (1990); Utuk and Daniel, (2015). In former soils, removal of organic matter and nutrient rich layer of soil profile causes nutrient depletion, the loss of soil fertility, structure and water holding capacity Montgomery, (2007). Production of agricultural crops on such soil strongly depends on the nutrient availability and good soil structure for supporting plant growth. Nitrogen $(\mathrm{N})$, phosphorus $(\mathrm{P})$, potassium $(\mathrm{K})$ and iron $(\mathrm{Fe})$ are key nutrients that play a major role in crop production on degraded soils. As most of the soils in the world are known to be deficient in aforementioned nutrients, there will be a great demand of chemical fertilizers to fulfill nutrients deficiency. The global requirement of chemical fertilizers (N, P, K and other macronutrients) is expected to reach 194 million tons by the year of 2016 as reported by FAO (2012). Manufacturing of the chemical fertilizers to meet this demand requires a huge number of nonrenewable resources. Excessive use of chemical fertilizers has also contributed to soil and air pollution (greenhouse gaseous emissions) as well as water eutrophication in eutrophication in many parts of the world Fig. (3), (4).

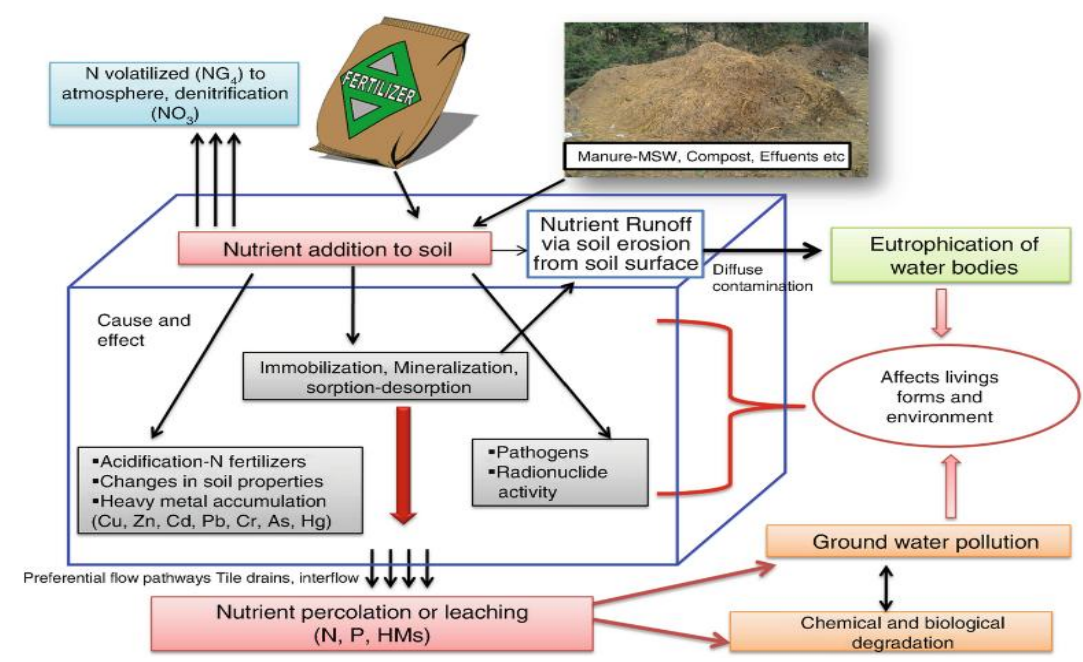

Fig. 3: Illustrates the transformation of contaminants in inorganic and organic fertilizer in soil ecosystem

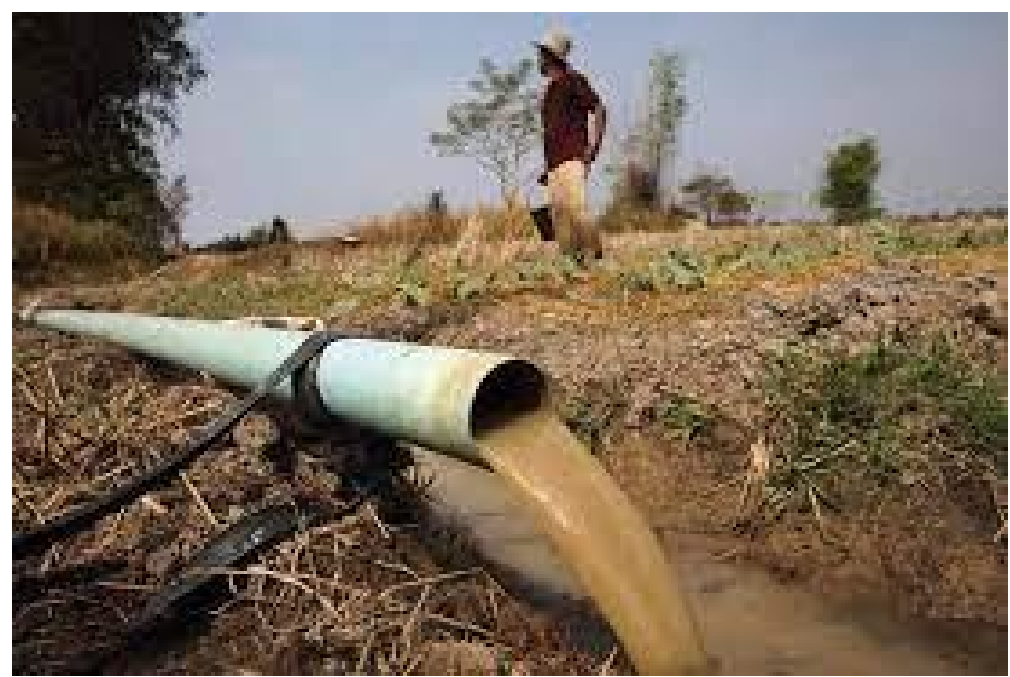

Fig. 4: Illustrates the excessive use of chemical fertilizers has also contributed to Water eutrophication in many parts of the world 
Therefore, efforts are necessary to fine out alternative, innovative, environmentally friendly options to reduce the use of costly and non-environmentally friendly chemical fertilizers. In this context, microbes (i.e., bacteria and fungi) naturally occurring in soil or supplied as bio-fertilizers, could represent a promising approach to increase nutrients bioavailability and improve soil structure Fig (5), (6)

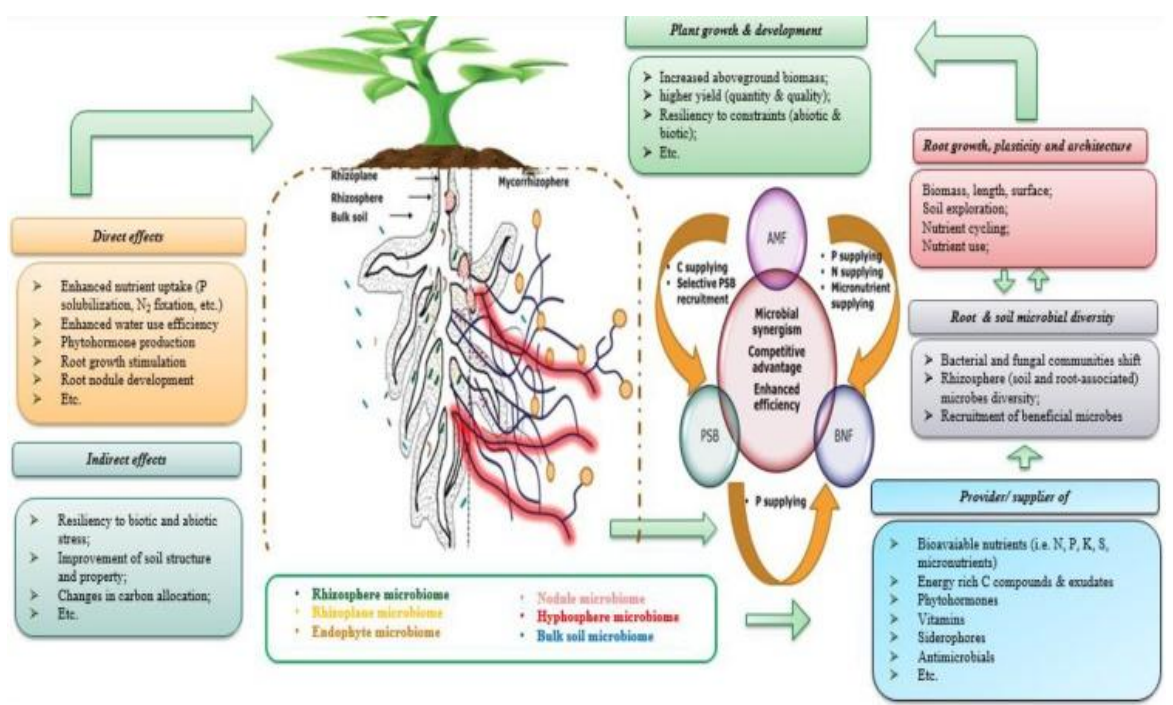

Fig. 5: Conceptual overview illustrating the role of $\mathrm{P}$ solubilizing microorganisms (PSMs) in enhancing $\mathrm{P}$ mineral fertilizers eco-efficiency. PSM increase bioavailable $\mathrm{P}$ either directly by the production of low molecular weight organic acids, thus chelating through their carboxylic groups, cations attached to insoluble $\mathrm{P}$, or indirectly by synthetizing bioactive molecules (phytohormones, siderophore, antibiotics, etc.) which improve plant vitality and resilience to biotic and abiotic stress and ultimately leads to better nutrients uptake and agronomic yield after Bargaz et al., (2018)

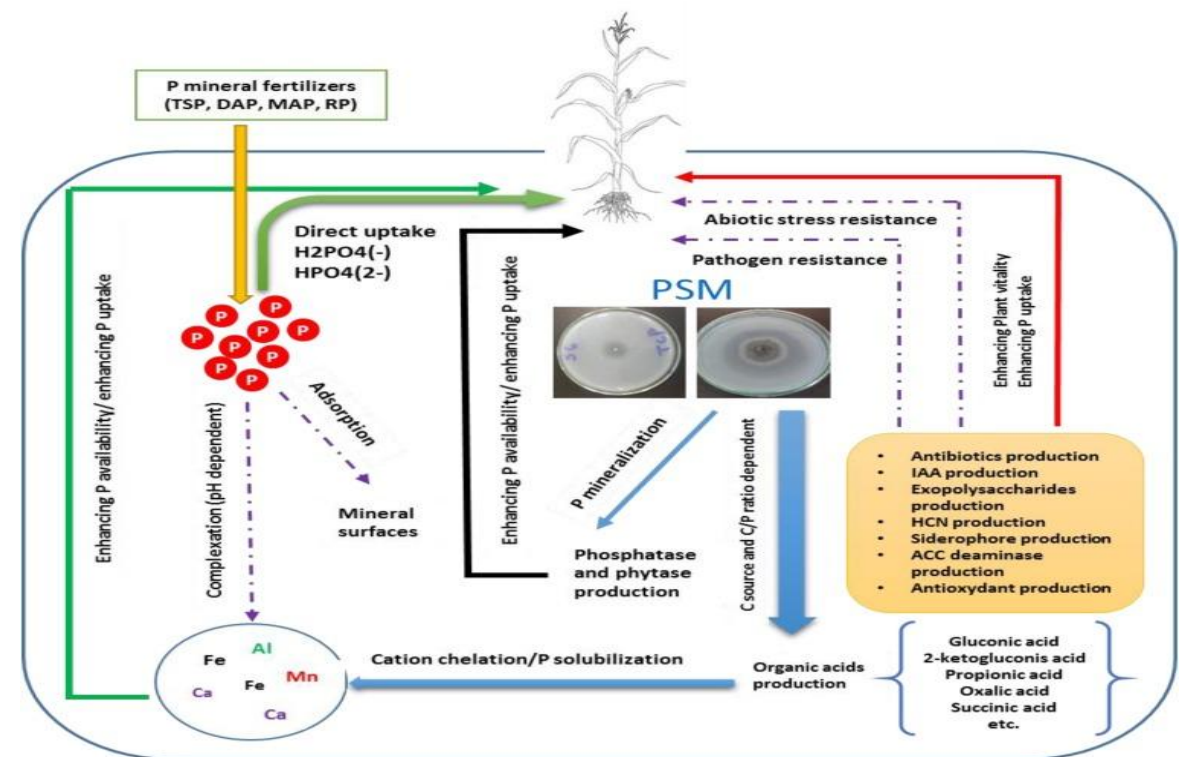

Fig. 6: Simplified illustration of the microbial consortia concept highlighting beneficial rhizosphere PGPM and their direct (i.e., nutrients uptake via fixing N2, solubilizing P, producing plant growth promoting (PGP) substances like indole acetic acid, gibberellin, and cytokinin, etc.) and indirect effects (i.e., alleviation and/or protection against biotic and abiotic constraints) on root growth, symbiotic (rhizobial and mycorrhizal, etc.) and aboveground (plant growth, productivity, etc.) plant performance. Heterogeneity of the rhizosphere and root beneficial microbiome influences root growth and plasticity of root architecture that lead to effective exploration of soil and thus efficient nutrient uptake with positive consequences on growth and yield of the plant host. After Bargaz et al., (2018) 
A number of innovative and efficient technologies has been adopted such as smart irrigation systems, smart fertilizers i.e., slow-release fertilizer and enhanced efficiency fertilizers (EEFs), etc., integrated fertilization, and diseases biocontrol strategies as well as diverse imaging- and sensing-based technologies that provide highly valuable information for monitoring and securing crop productivity. Agricultural microbial biotechnology through the integration of beneficial plant-microbe and microbiome interactions may represent a promising sustainable solution to improve agricultural production Timmusk et al., (2017) Fig (7).

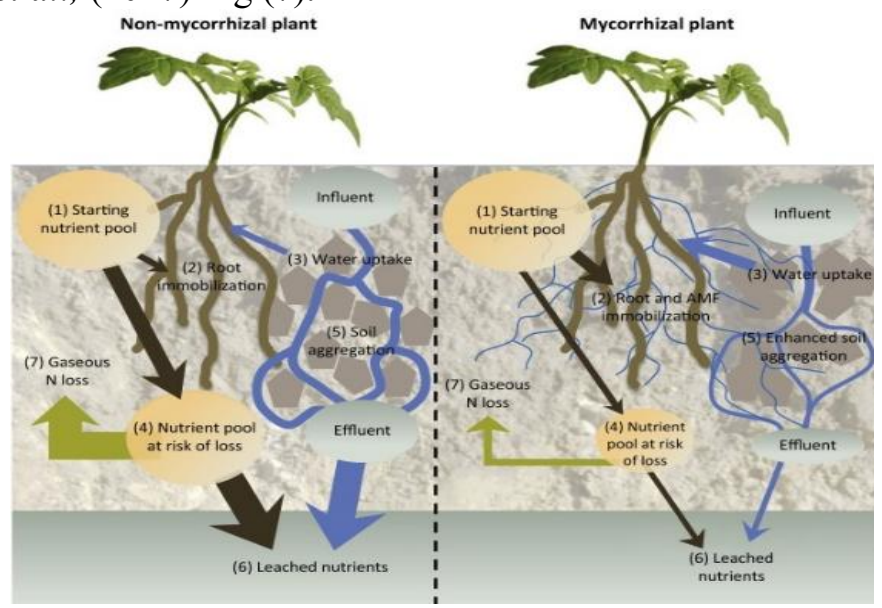

Fig. 7: Illustrates a microbial community that populates in the rhizosphere is aided by a plant's root exudates. Maintaining a plant's health is a key factor in its continued existence. As minute as rhizospheric microbes are, their importance in plant growth depending on plants for nutrients and other necessary requested

Advances in genomic, post-genomic, biochemistry, ecology, and symbiotic interactions of beneficial microbial strains have led to the development and commercialization of efficacious microbial products (biofertilizers, bio stimulants, bio pesticides, and plant growth promoting PGP ) with proven success to improve crops' yield and adaptation to environmental changes, and inputs of carbon and energy Timmusk et al., (2017) Umesha et al., (2018)

Bacterial and fungal inocula and organic amendments could be considered as a potential option to incorporate in crop integrated nutrient management strategy of degraded soils Medina, et al., (2010); Chaer et al., (2011). These inocula can exploit, translocate, mineralize and mobilize soil P, K , Fe reserves, increase organic matter or fix $\mathrm{N}$ from the atmosphere Figueiredo et al., (2011b); Ahemad and Kibret, (2014); Leifheit et al., (2014); Nguyen and Bruns, (2015); Owen et al., (2015).According to van der Heijden et al., (2008), arbuscular mycorrhizal(AM) fungi and biological $\mathrm{N}$ fixing bacteria annually contribute $5-20 \%$ to the total $\mathrm{N}$ demand of grassland and savannah. The contribution of AM fungi to temperate and boreal forests is $80 \%$ whereas total $\mathrm{P}$ acquired by plants through bacteria and fungi was $75 \%$. The basic mechanisms through which bacteria and fungi promote nutrients bioavailability include $\mathrm{N}$ fixation, $\mathrm{P}, \mathrm{K}$ and Fe mobilization through phosphorous.

The positive impacts of microbial-based biofertilizers on growth and yield of staple crops may be limited to a single nutrient element such as $\mathrm{N}$ but also to several nutrients due to arbuscular mycorrhizal fungi (AMF) Bardi and Malusà, (2012). Moreover, the development of microorganisms' consortium that is a polymicrobial mixture that contains several microbial strains belonging to different functional groups may strongly promote plant growth, yields, and healthy agro ecosystems Arora et al., (2011); Malusa et al., (2012). Success in constructing effective polymicrobial formulations with multiple modes of action depends on how functional, complementary, and synergic the candidate strains are Malusa et al., (2012); Reddy and Saravanan, (2013). Inoculation with mixed cultures of Penicillium spp. and AM fungi induced positive and synergistic effects (especially enhanced plant nutrition and growth) in cereals and legumes Kucey, (1983); Osorio and Habte, (2001); Babana and Antoun, (2007). Positive impacts on legume crops have also been observed when co-inoculating with Rhizobium spp. and Penicillium Downey and van Kessel, (1990); Rice et al., (2000), rhizobia with AMF Farzaneh et al., (2009); Wang et al., (2011), Rhizobium and P solubilizing-bacteria Alagawadi and Gaur, (1988), or even with the tripartite inoculation with AMF-Rhizobium-P-solubilizing fungus Meng et al., (2015); 
Zhu R.F. et al., (2016). Multifunctional microbial consortia may also involve free-living NF bacteria as well as different PGP rhizobacteria with higher abilities to maximize plant growth, yield and efficient $\mathrm{N}$ uptake Lisette et al., (2003); Wu et al., (2005); Malusa et al., (2007); Adesemoye et al., 2009; Vassilev et al., (2015), reduction of organic acids and siderophores Nitrogen Fixation Both symbiotic and non-symbiotic BNF constitute a major input of $\mathrm{N}$ in agro ecosystems and may provide an ecologically acceptable complement or substitute for mineral N fertilizers Peoples et al., (1995), (2009); Herridge et al., (2008); Lazali and Bargaz, (2017). However, BNF is often limited under low soil nutrient availability, notably $P$ that is required at sufficient rates during the BNF process Schulze and Drevon, (2005); Alkama et al., (2012). More particularly, high P requirements were found to be more critical in N2-fixing (NF) legumes than in non-symbiotic plants whose growth rely on mineral N sources Serraj and Adu- Gyamfi, (2004); Schulze and Drevon, (2005); Sulieman and Tran, (2015). Generally, in soils containing only a small fraction of $\mathrm{P}$ that is readily available, plant growth and associatedmetabolic pathways would be greatly impaired, which makes necessary the application of mineral $\mathrm{P}$ fertilizers to replenish the soil as to immediately satisfy plant requirements for better growth and yield Richardson et al., (2009).

Much information is available about the important role of mineral $\mathrm{P}$ fertilization in plant growth processes, including nutrient uptake $(\mathrm{Ca}, \mathrm{Mg}, \mathrm{Zn}, \mathrm{Cu}, \mathrm{Mn}$, and $\mathrm{Fe}$, etc.), photosynthesis, root development, root hair formation, nodulation, BNF, and particularly as an energy source for the latter biological process Fig. (8) Israel, (1987); Drevon and Hartwig, (1997); Gordon et al., (1997); Nielsen et al., (2001); Hogh-Jensen et al., (2002); Nziguheba et al., (2016 ). Plant N nutrition, with emphasis on legume crops such as faba bean, common bean, and cowpea, may be affected positively in response to an adequate $\mathrm{P}$ nutrition that has positive consequences on robust root systems, vigorous seedlings, ammonium assimilation into amino acids, and ureides, as well as synthesis of mitochondrial and symbiosome membranes for functional NF nodules Fageria et al., (1995); Schachtman et al., (1998); Nyoki and Ndakidemi, (2014a); Tairo and Ndakidemi, (2014); Sulieman and Tran, (2015). This is of particular importance for NF legumes whose nodule formation, nodule functioning, and the energy costs related to NF greatly depend on the P status in plant and nodule tissues Vardien et al., (2016). Moreover, the fact that root-nodules are strong $\mathrm{P}$ sinks, with nodule $\mathrm{P}$ concentrations often exceeding those of roots and shoots also indicates the important role of $\mathrm{P}$ in the legume symbiosis processes Schulze and Drevon, (2005); Bargaz et al., (2012); Nyoki and Ndakidemi, (2014a).

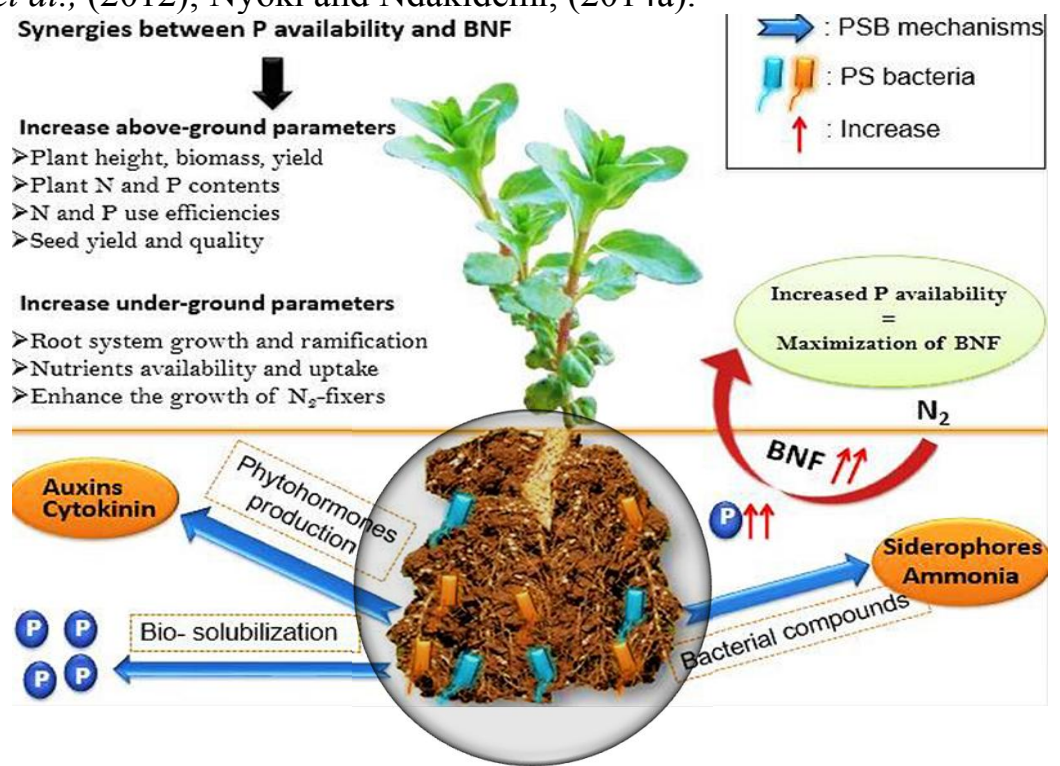

Fig. 8: Interactions between PSB and legumes nodulated roots and their effects on nutrients availability and the overall plant growth parameters

One of the important mechanisms exerted by PSB is the production of plant growth regulators such as auxins, cytokinins, gibberellins, and ethylene Anand et al., (2016). These molecules are known to promote root growth and make available previously inaccessible pools of $\mathrm{P}$ and this, in turn, contributes to fulfilling indirectly the energy costs of the BNF process Zaidi et al., (2010). Several researchers found high concentrations of auxin in root nodules, which confirms the vital role of this 
hormone in nodule formation and functioning Mathesius et al., (1998); Van Noorden et al., (2006) Fig. (9).

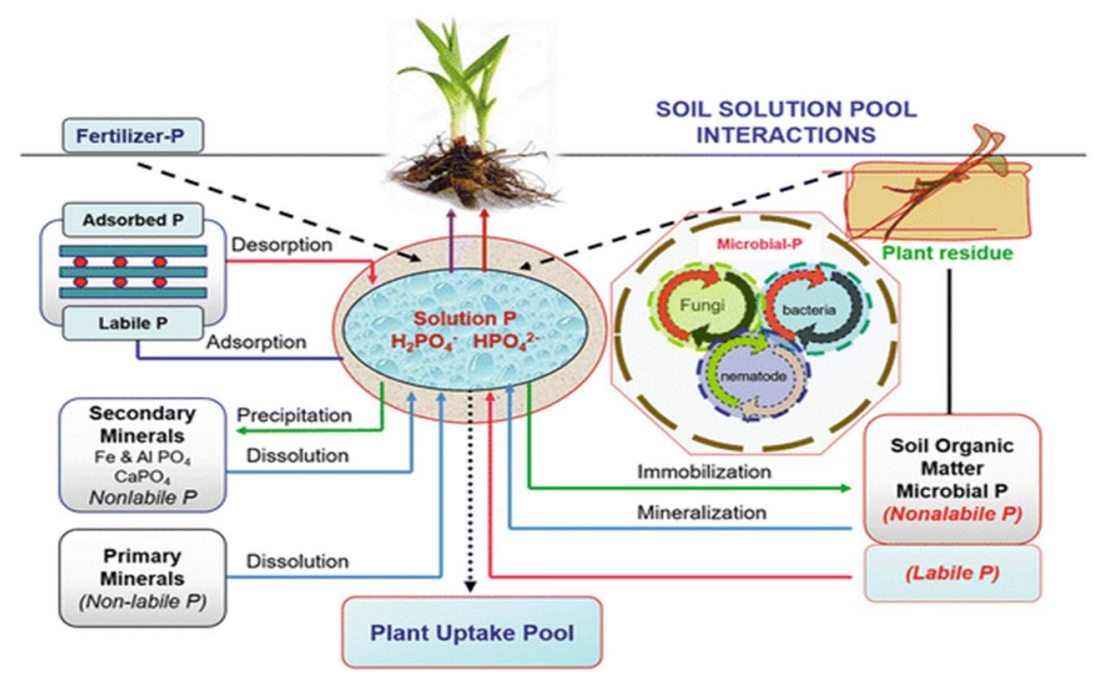

Fig. 9: Represents a diagram explaining hormones regulate nodulation at different stages Legumes release flavonoids to trigger rhizobia to produce lipochitooligosaccharides, termed Nod factors (NFs). NFs are detected by two LysM domain receptor-like kinases and initiate the symbiosissignaling pathway in plants. Calcium spiking and root hair deformation are early responses in host plants to NFs. Curled root hair entraps the rhizobia, which enters the root tissue of host plants through a specific path, called an "infection thread". Auxin signaling initiates this infection thread and cytokinin signaling is required for infection thread elongation. ABA, ethylene, GA and JA all negatively regulate calcium spiking and infection thread formation. This symbiotic signal induces cortex cell division and initiates nodule organogenesis. Auxin and cytokinin are key regulators of cortical cell proliferation and differentiation and are essential for further nodule development. However, ethylene, GA, JA, ABA and BRs suppress nodule formation and development. Interestingly, SA and BRs have opposite effects on the formation of determinate and indeterminate nodules.

Rao (2014) reported that co-inoculation of AMF (Glomus fasciculatum) along with rhizobia significantly improved nodulation, BNF, shoot $\mathrm{N}$ and $\mathrm{P}$ content and yield of soybean. Likewise, Qureshi et al., (2012) reported that co-inoculation of mash bean (Vigna mungo L.) with Rhizobium and a $\mathrm{P}$ solubilizing strain (Bacillus sp.) increased plant growth not only due to P solubilizing Fig. (10) and N2fixation abilities but also due to their capacity to produce auxin .Fig.(11). They also reported that microbial auxin altered endogenous hormonal level, which in turn increased root length, root biomass, number of nodule and number of infection sites, which further resulted in increased plant growth. This corroborates with findings by Ahmad et al., (2019) who showed that co-inoculation of mung bean plants with Bacillus aryabhattai S10 and Bacillus subtilis ZM63 increased nodulation, plant growth, and the nutritional status of the tested plants. The increment of nodulation parameters was likely attributed to the improved formation of nodules through the increased surface area of rhizobial infection during nodulation 


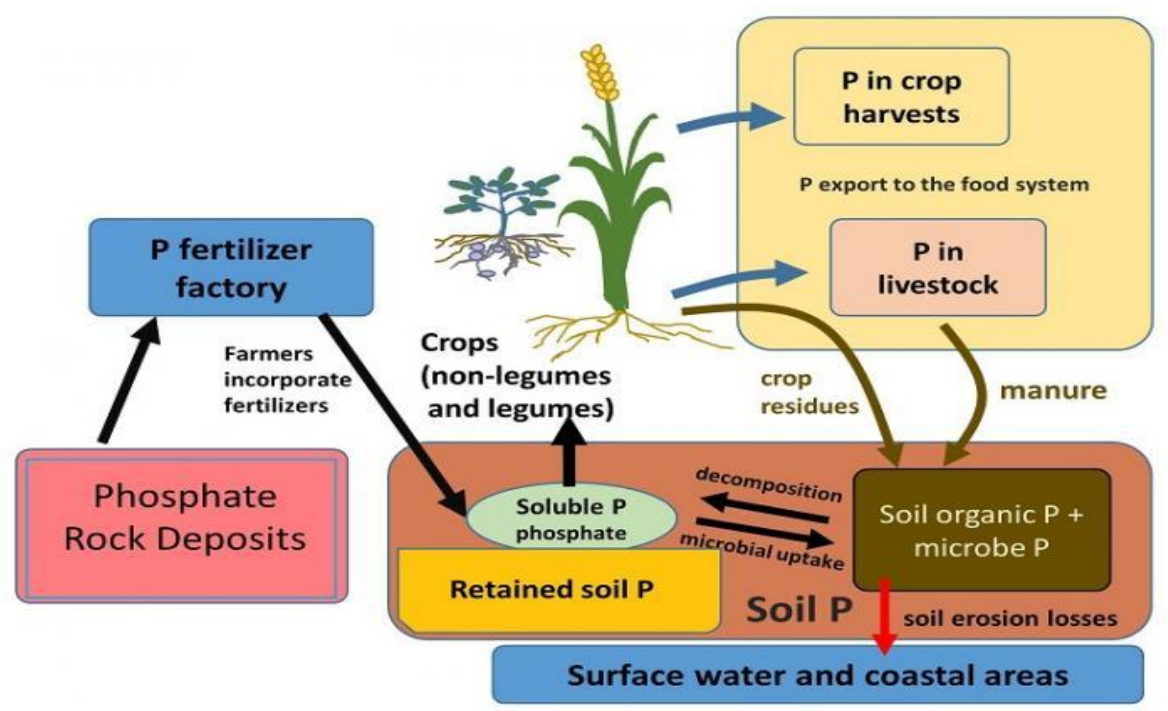

Fig. 10: An overview phosphorus cycle, Improving Plant Phosphorus (P) Acquisition by Phosphate Solubilizing...

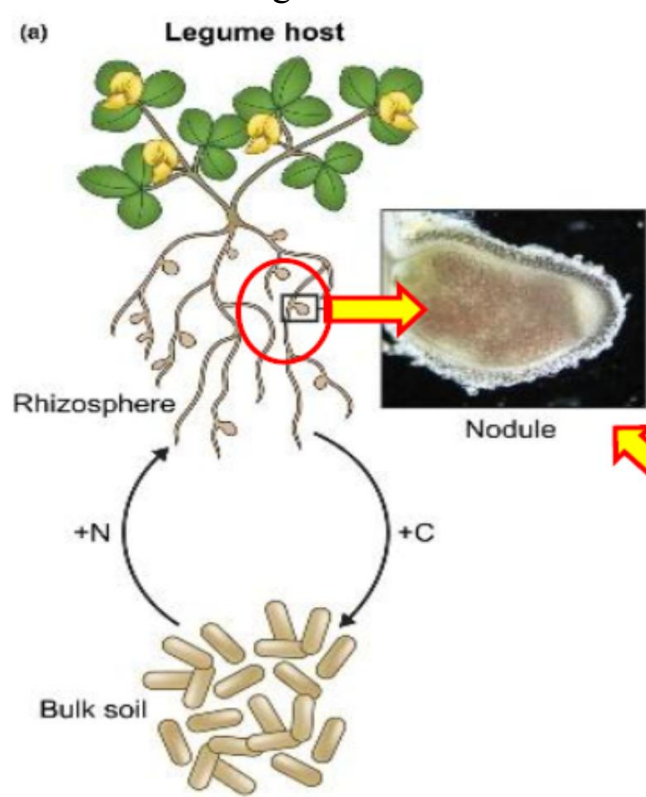

Rhizobial bacteria (b)

Identification method

Fluorescent tag

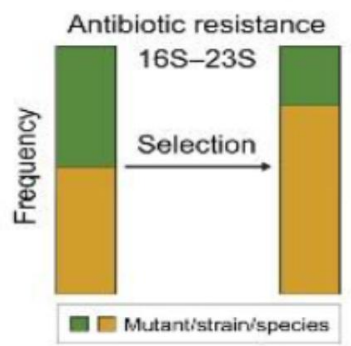

(c) Mixed inocula metric

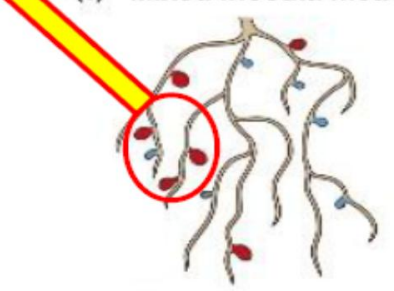

- $\square$ Mutant/strain/species
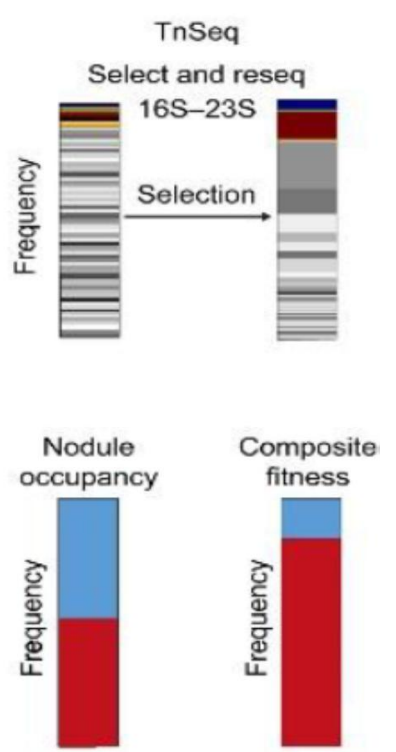

Fig. 11: Rhizobial fitness in the legume-rhizobia mutualism. (a) The major environments experienced by rhizobia in nature. $\mathrm{N}$, ammonia $(\mathrm{NH} 3)$; $\mathrm{C}$, malate (C4H6O5). (b) Examples of pairwise and more complex mixed-inoculation experiments. (c) Illustration of the difference between nodule occupancy (proportion of nodules inhabited by each rhizobial lineage) and composite fitness (relative representation of a rhizobial lineage across all pooled nodules). Nodule photo. After Liana T. Burghardt (2020)

After Liana (2020), reported that most plant-microbe interactions are facultative, with microbes experiencing temporally and spatially variable selection. How this variation affects microbial evolution is poorly understood. Given its tractability and ecological and agricultural importance, the legumerhizobia nitrogen fixing symbiosis is a powerful model for identifying traits and genes underlying bacterial fitness. New technologies allow high-throughput measurement of the relative fitness of bacterial mutants, strains and species in mixed inocula in the host, rhizosphere and soil environments. Considering how host genetic variation $\left(G^{*} G\right)$, other environmental factors $(G * E)$, and host lifecycle variation may contribute to the maintenance of genetic variation and adaptive trajectories of rhizobia and, potentially, other facultative symbionts. Lastly, I place these findings in the context of developing beneficial inoculants in a changing climate. Several researchers reported that the mutualism between 
rhizobial bacteria and leguminous plants has long been used to study the functional genetic basis of biological nitrogen $(\mathrm{N})$ fixation and the evolutionary ecology of mutualisms Heath and Grillo, (2016). This relationship is vital for plant productivity and nutrient cycling in both agricultural and natural systems Ciais et al., (2013). In nature, rhizobia experience a complex series of selective environments. The symbiotic interaction begins when seeds germinate. As legume roots grow, the rhizobia living in the soil colonize the root surface; only a tiny fraction of these rhizobia will invade plant tissue via root hairs and initiate nodule development (Fig. 1a). As the nodule develops, the invading rhizobial population expands and begins to fix N2 into NH3 in exchange for resources, including photosynthate. The specificity and functional details (e.g. how rhizobia enter roots) of these interactions vary widely. The extent to which these details influence the evolution of the mutualism itself is an active area of research Sachs et al., (2018). Regardless, evolutionary changes in rhizobial populations that have measurable effects on rhizobial and host traits can occur over the timescale of a few host generations either through shifts in the frequency of lineages or through de novo mutations Tang et al., (2012); Hollowell et al., (2016).

Mixed-inoculation of soybean plants with Rhizobium, Enterobacter and PSM (not identified) increased plant biomass, weight and length of pods as well as root nodulation parameters. The latter being a consequence of increased production of auxin and gibberellin by the combined action of the tested microbes, subsequently leading to increased cell division and elongation. Eventually, increasing the overall plant growth, yield and productivity Yasmeen and Bano, (2014). Similarly, Figueiredo et al., (2008) stated that cytokinin produced by a PSB strain (Paenibacillus polymyxa DSM36) could influence BNF in common bean plants, most likely through the stimulation of rhizobial growth, nodule development and the number of infections in roots . This corroborates with findings by Elkoca et al., (2008) who revealed that production of plant growth regulators by Bacillus subtilis (OSU-142) and Bacillus megaterium (M-3) increased root system growth which in turn increased the number of infection sites. Moreover, Kannapiran and Ramkumar (2011) reported that black gram (Phaseolus mungo) $\mathrm{N}$ status was enhanced following inoculation with several bacteria amongst two PSB strains (Pseudomonas aeruginosa and Bacillus sp). In fact, these positive effects were attributed to several metabolites produced by the tested bacteria, such as siderophores, $\mathrm{HCN}$, auxin and ammonia.

Other traits related to extensive rooting system and their spatial distribution, hyper-nodulation, root exudates, rhizosphere acidification, and heterogeneity are among the most important plant-related belowground traits that contribute to higher nutrient use efficiency Fig. (12).

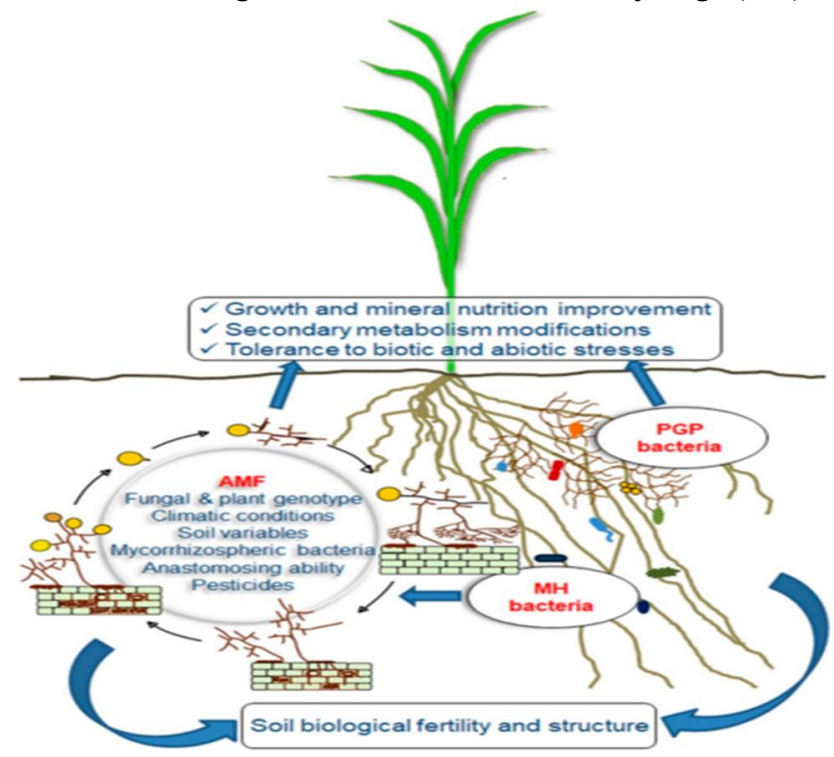

Fig. 12: Illustrates effect of arbuscular mycorrhizal fungi (AMF) and beneficial bacteria on plant performance and soil fertility. The beneficial effects of mycorrhizal fungi (AMF) and bacteria on root architecture nutrient use efficiency. On the left: a visual representation of the AMF life cycle and factors affecting the different AMF developmental stages; on the right: mycorrhizal helper $(\mathrm{MH})$ and plant growth promoting (PGP) bacteria synergistically interacting with AMF. 
Regarding $\mathrm{P}$, these traits may substantially contribute in alleviating the sensitivity of NF plants to low $\mathrm{P}$ availability through ensuring large amount of P-dependent carbon and energy turnover required during the NF process Schulze, (2004); Serraj and Adu-Gyamfi, (2004); Schulze and Drevon, (2005). Moreover, exploiting beneficial microbial traits involved in higher P solubilization would positively influence $\mathrm{P}$ uptake in addition to multiple advantages attributed to the production of plant growthpromoting substances which could indirectly influence the efficiency of BNF Kucey et al., (1989); Afzal et al., (2010). Inoculation of soybean plants with both a P-solubilizing (Bacillus) and NF (Bradyrhizobium) strains improved symbiotic traits related to growth of nodules and roots, aboveground biomass, total $\mathrm{N}$ and grain yield Ming et al., (2003); Afzal et al., (2010). However, despite positive responses on improved growth, nutrient use efficiency ( $\mathrm{N}$ and $\mathrm{P})$, and stable yield, all were demonstrated due to microbial application and mineral supply. In addition to this, organopolysaccharides and proteins (Glomalin, mucilage's and hydrophobins) are also produced that help to promote soil aggregate stability Mortimer et al., (2008); Glick, (2012); Caesar-Tonthat et al., (2014); Nguyen and Bruns, (2015); Owen et al., (2015).

Bacteria, fungi, carry out these processes. Later group of microbes form a symbiotic association with legume roots infected by $\mathrm{N}$ fixing bacteria that increase $\mathrm{P}-$, micro and other macronutrients for plant uptake as well as mitigate the effect of water and salt stress Sánchez-Díaz et al., (1990);Nadeem et al., (2009). Free living and symbiotic bacteria enhance plant growth by providing $\mathrm{N}$ through atmospheric $\mathrm{N}_{2}$ fixation and produce (phyto)-hormone (auxins, cytokinins and gibberellins) in addition to anti-microbial molecules to protect the crops from diseases Khan, (2005). In the past, agriculturists had immensely practiced the application of earthworms and organic fertilizers to improve the soil fertility (Rashid et al., (2013); Shah et al., (2013); Rashid et al., (2014b), (2014a). Both practices prove to be beneficial for soil nutrient management of agro ecosystems. However, earthworm enhanced greenhouse gaseous emissions Lubbers et al., (2013), and their successful functioning was achieved at an expense of maintaining their healthy population in soil. Such high maintenance costs would directly affect the price index of the crops.

Another possibility would be to improve the soil fertility by enriching the soil with microorganisms such as bacteria and fungi Fig. (13).

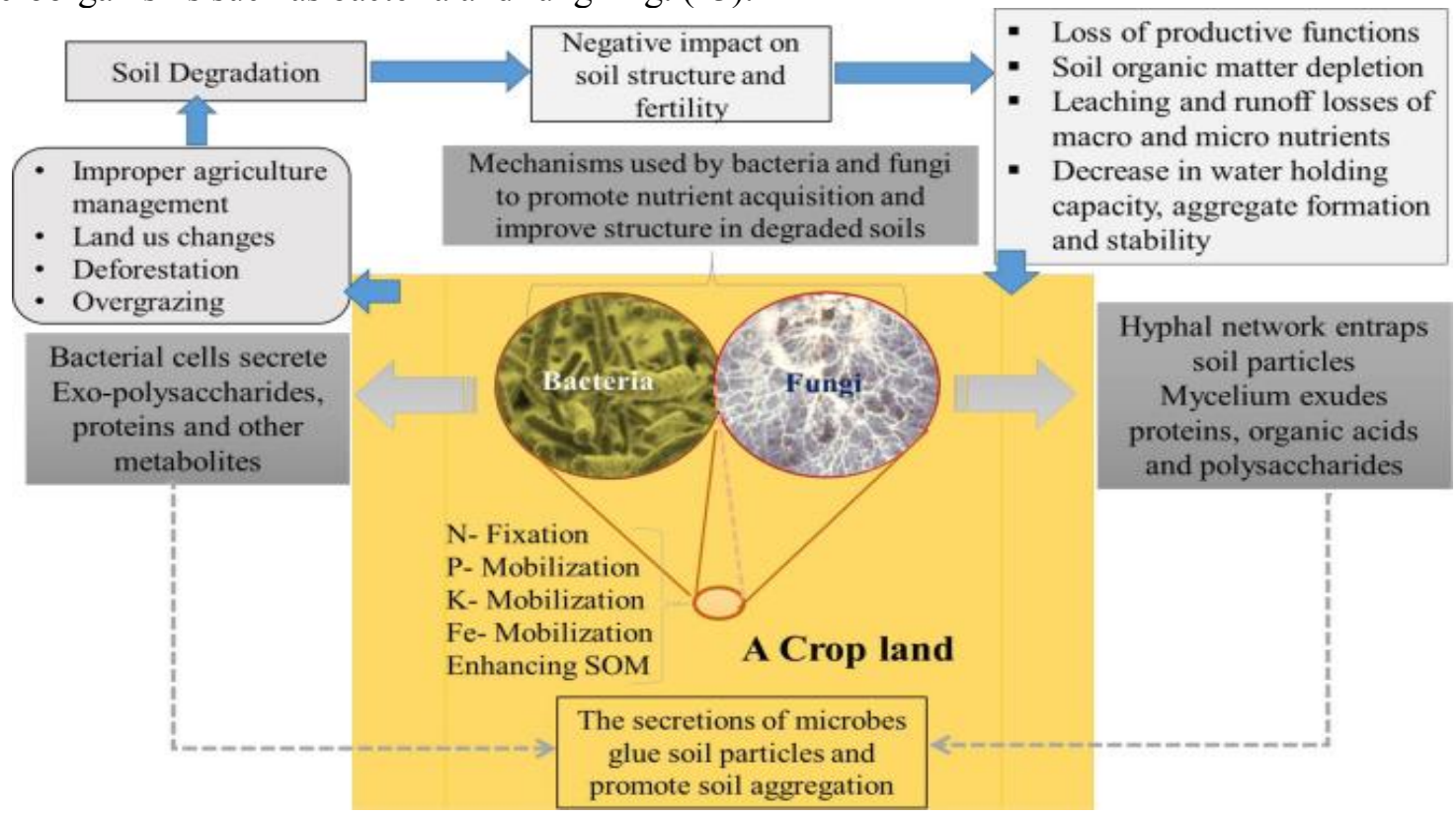

Fig. 13: Illustrates a mechanism used by bacteria and fungi to improve soil organic matter (SOM), nutrient availability and aggregation

These microorganisms are omnipresent and found in various components of earth such as water and soil. Bacteria and fungi are known to improve soil structure by promoting the formation of soil aggregates and pores within Degens, (1997); Miller and Jastrow, (2000) Fig.(14). 


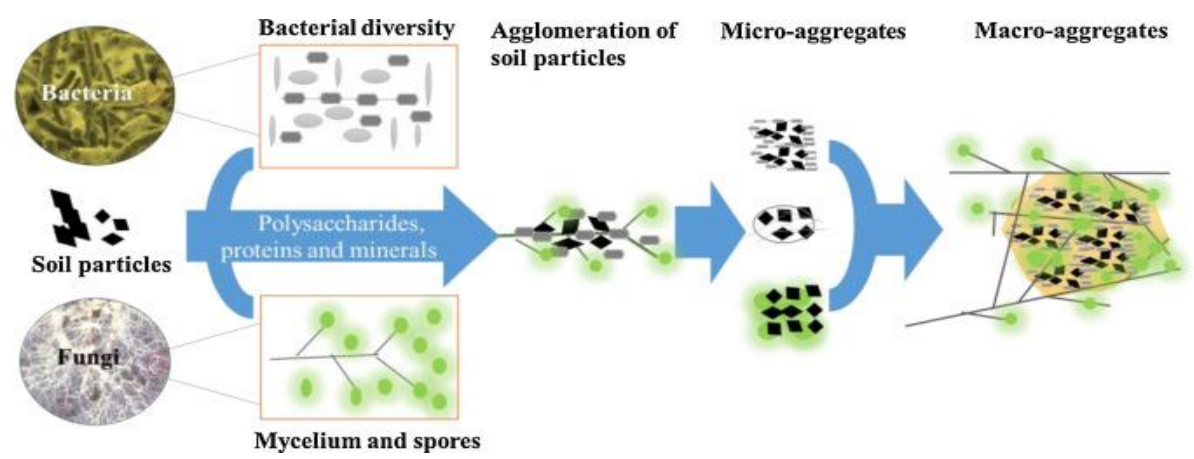

Fig. 14: Diagram illustrate the role of bacterial and fungal inocula for improving of Soil structure

Fungal cells release mucilaginous exudates that are mainly composed of extracellular surface polysaccharides; cell wall polysaccharides and somatic or intracellular polysaccharides located inside the cytoplasmic membrane. Extracellular polysaccharides are mainly responsible for the formation of aggregates, which are beneficial for improving porosity and aeration in soil, Degens, (1997) Fig. (15).s
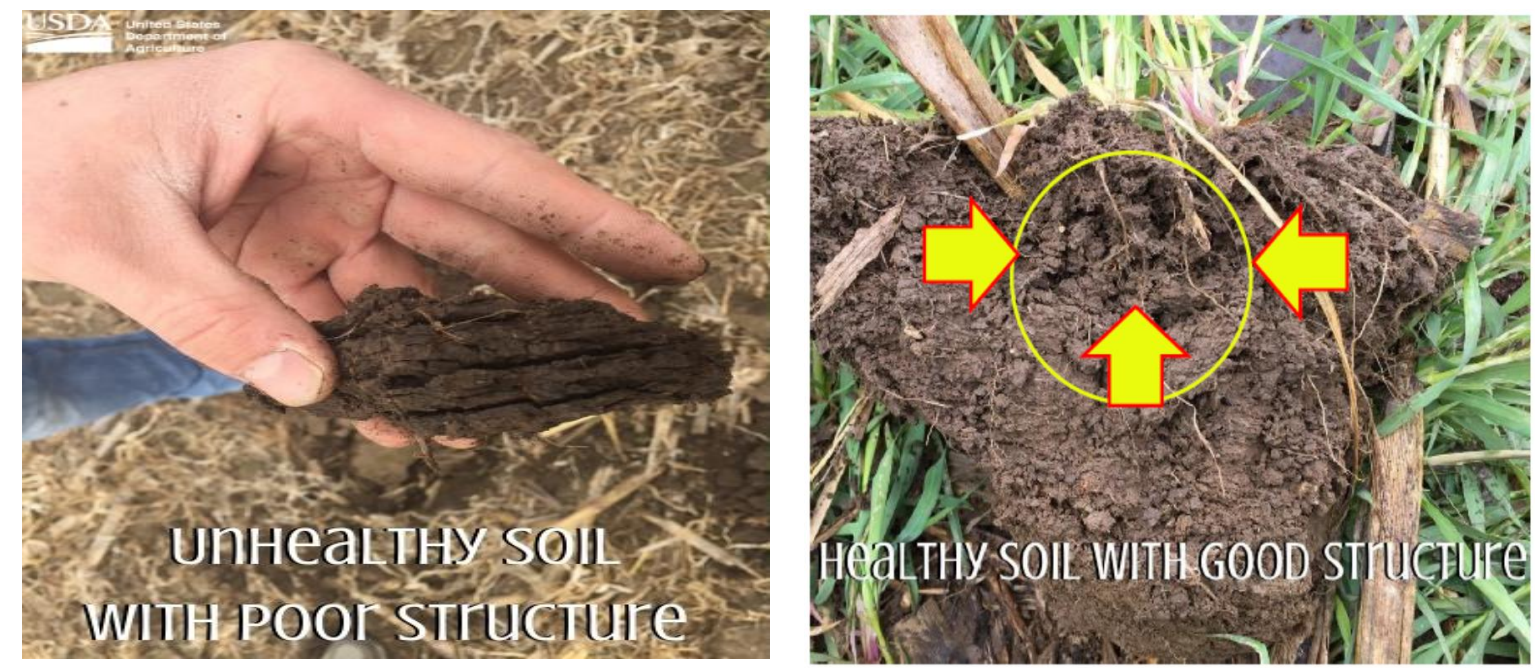

Fig. 15: Illustrates the importance of root architecture for improving soil structure

Endophytic bacteria can perform various nutrient transformations, thanks to their versatile enzymatic systems crucial in nutrient recycling and metabolism Jamir et al., (2019). The transformation of atmospheric $\mathrm{N}_{2}$ through biological nitrogen fixation (BNF) is important to the plants and in restoring soil fertility. BNF is a microbial mediated process that involves converting atmospheric $\mathrm{N}_{2}$ in the presence of nitrogenase enzyme complex into ammonia and nitrate Khare and Yadav (2017).

Nitrogen is considered a major growth-limiting nutrient in plants. The microbes involved in this kind of nutrient conversion are referred to as diazotrophs. According to Nag et al., (2020), some diazotrophs can fix nitrogen in association with their host plants, while others can do so in their freeliving state.

Some symbiotic bacterial endophytes induce physiological and structural modifications of plant roots leading to the establishment of specialized structures known as nodules. For instance, legume plants usually establish specific associations with soil rhizobacteria that can sequester $\mathrm{N}_{2}$ as ammonia using root nodules. These include Bradyrhizobium, Rhizobium, All rhizobium, Sinorhizobium, and Mesorhizobium Koskey 

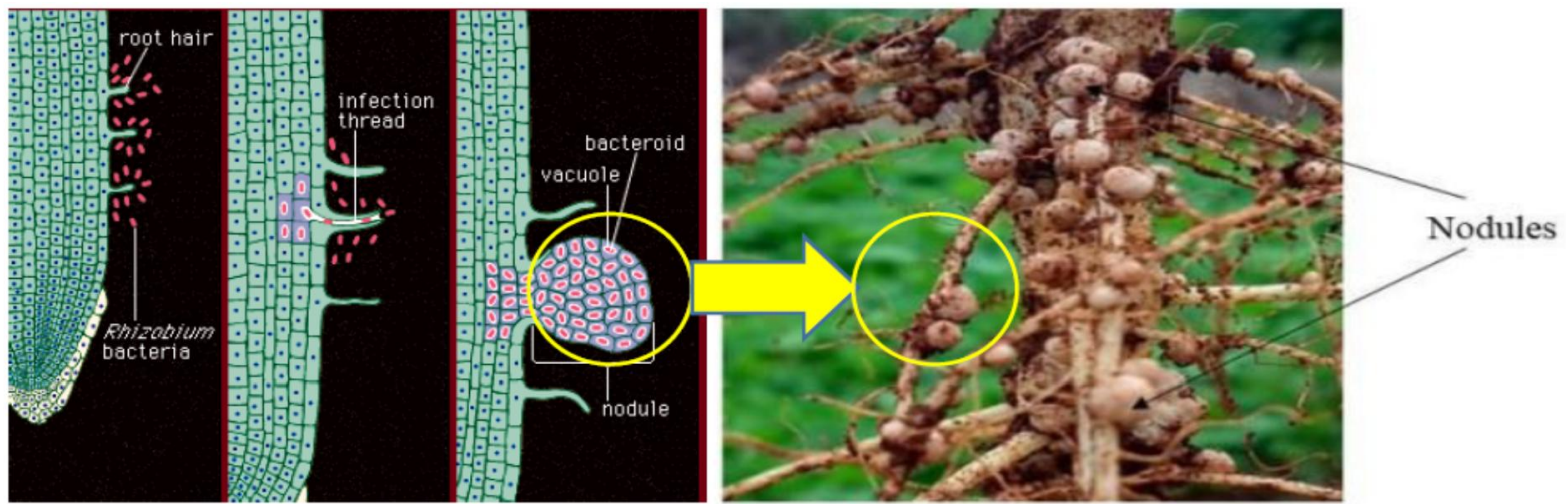

Fig. 16: A root of a field grown cowpea plant showing root nodules after colonization by effective nitrogen-fixing endophytic bacteria. Image courtesy of the Future Leaders-African Independent Researchers (FLAIR) project titled; using root-associated microorganisms to enhance sustainable crop production and resilience of smallholder agro ecosystems to climate change.

Koskey et al., (2017), Tak and Gehlot (2019). Other soil microorganisms such as actinomycetes and cyanobacteria in cycads and lichens also have been reported to fix nitrogen through the formation of symbiotic associations Dahal et al., (2017). Symbiotic associations tend to work efficiently because the $\mathrm{N}$ fixed by the bacteria is directly transferred to the host plant and in return, the photosynthetically fixed carbon and other metabolites benefit the bacterial symbiont Jamir et al., (2019). However, there are nitrogen-fixing bacteria that are non-symbionts and do not induce nodulation unlike rhizobia Fig. (16). these bacteria have the ability to thrive on the nutrients and energy derived from the roots of the host plant. According to Afzal et al., Afzal et al., (2019) and Njeru et al., (2020), associative nitrogenfixing endophytes can promote plant growth and health in nitrogen-limited soils compared to other rhizospheric microorganisms. Similarly, endophytic bacteria that are nitrogen fixers can enhance nitrogen accumulation in plants growing in nitrogen-deficient soils as described by Gupta et al., Gupta et al., (2013). The success of culturable N-fixing endophytes in promoting plant growth in poor field conditions indicates the reliability of the endophytes in delivering low-cost ecosystem services for farmers. However, less endophytic bacteria that have enzymatic ability to carry out BNF compared to the total endophytic bacterial population.

\section{Environmental sanitation}

\section{1- Biofertilizers for nutrients bioavailability in degraded soils}

The diverse community of endophyte and rhizobacteria is a critical resource in enhancing plant growth and resistance against abiotic and biotic stress. These microbes include various bacterial communities dominated by Proteobacteria, Bacteroidetes, Actinobacteria and Firmicutes, Fig (17).

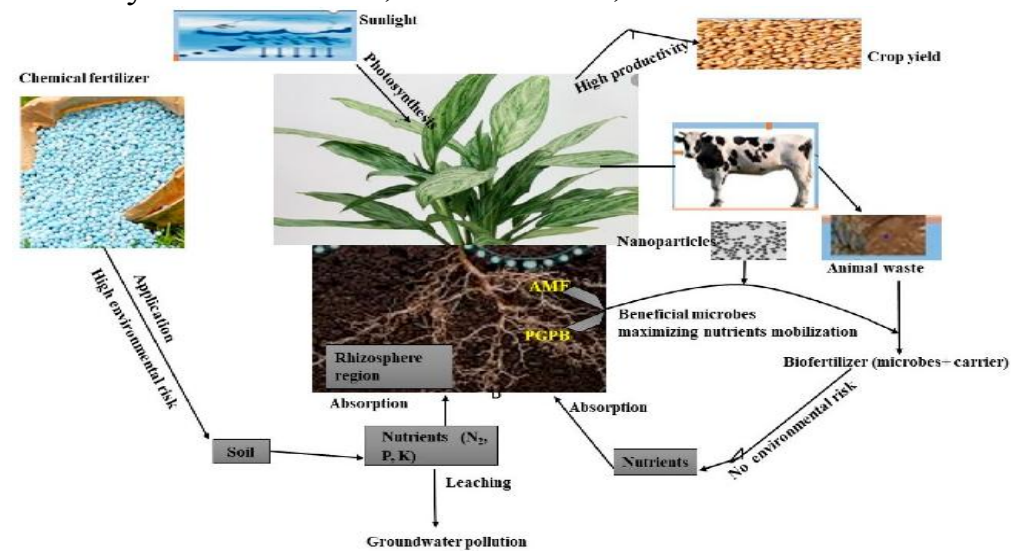

Fig. 17: Overview of rhizosphere as the bottleneck in controlling nutrient uptake by plants through the application of chemical and biofertilizer; Arbuscular mycorrhiza fungi (AMF), Plant growthpromoting rhizobacteria (PGPR). 
They inhabit and proliferate in plant tissues forming beneficial associations compared to other microbes residing in the exospheric region. Despite the demonstration of the presence of bacterial endophytes in crops, their role in supporting nutrient bioavailability and acquisition in degraded soils is largely unexplored. In addition, the practical application of these microbial communities in the field has not been demonstrated. A comprehensive understanding of plant-endophyte interactions will help restore degraded soils and plant nutrient acquisition in resource-limiting field environments.

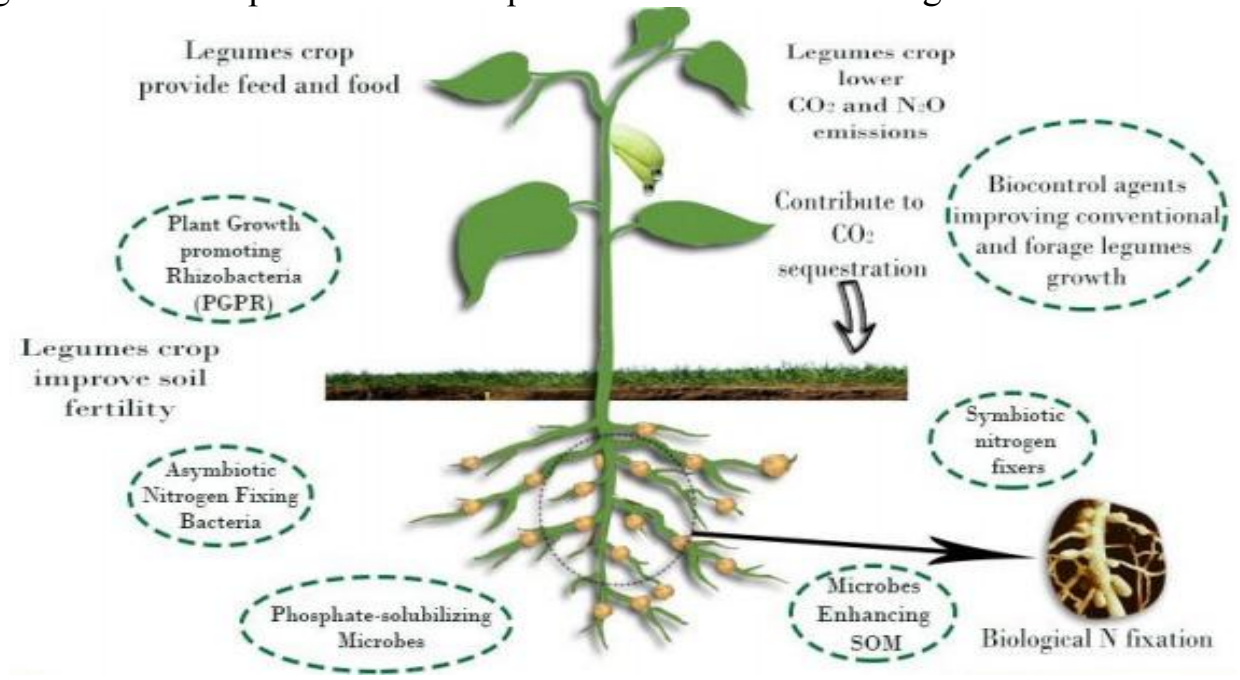

Fig. 18: A complex interaction of legume microbiota depicting colonization, diversity, functionality and abundance in both below- and above- ground plant organs. SOM: soil organic matter; N: nitrogen.

Anthropogenic farming practices such as the use of chemical fertilizers to restore degraded soils have proved to be detrimental to soil structure, function and soil biodiversity. Recent studies in soil and root structure suggest that the rhizosphere and endophytic bacterial communities could potentially be used to enhance crop production Fig. (18).

Endophytic microbes play a key role in modulation of metabolism in plants, stimulation of plant growth, and aid in plant adaptation to environmental stress using phytohormones signaling. The use of rhizosphere and endophytic bacteria can significantly reduce the amount of agrochemicals that contribute to environmental pollution Fig. (19). In the context of the changing climatic conditions, some beneficial rhizospheric and endophytic bacterial communities enhance adaptation and resilience, thereby promoting sustainable farming systems.

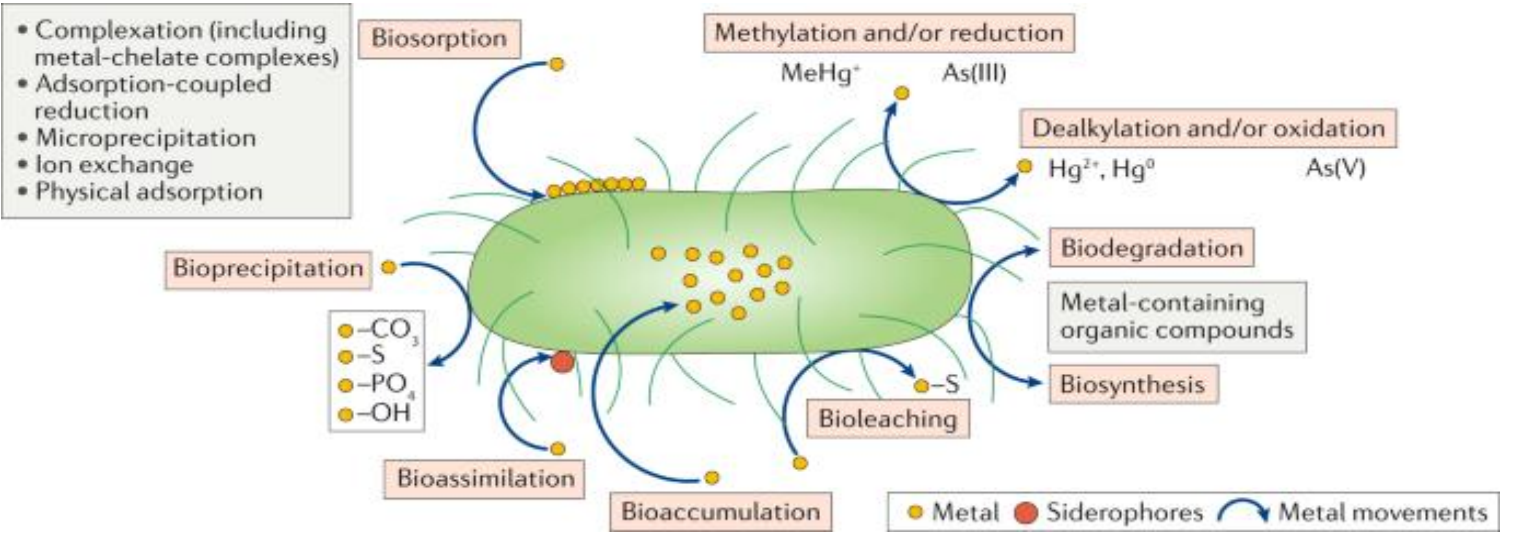

Fig. 19: Illustrates the role of bacterial bioremediation of heavy metals contamination. (A) Bacterial bio sorption of heavy metals through cell surface adsorption, extracellular precipitation and intracellular accumulation. (B) Bacterial heavy metal remediation through siderophore formation. This is aided by the formation of siderophore-metal complexes and membrane protein-mediated metal transport. (C) Bacterial heavy metal remediation through biosurfactants 
production. Biosurfactants undergo sorption, desorption at the soil-water-heavy metal matrix, and lead to the precipitation of heavy metals.

The current review addresses the concepts, challenges, and roles of the bacterial endophytes and rhizobacteria as components of the plant microbiota, and their prospective use in reclamation of degraded soil environments Fig. (19).

Land degradation is a worldwide problem caused by number of human induced processes that result in loss of soil fertility and productivity. The major causes of the land degradation includes deforestation, improper agricultural practices, (intensive cultivation, unbalanced fertilization, poor quality irrigation and chemical inputs in the form of fertilizers or pesticides) and industrialization Dregne (2002). Moreover, Dlamini et al., (2014) have associated land degradation with decrease in soil organic carbon and $\mathrm{N}$ stocks. According to estimation by Bai et al., (2008), about $40 \%$ of the world agricultural soils are seriously degraded whereas $24 \%$ area of the productive soils is still under continuous degradation. This requires special attention to figure out alternative and sustainable nutrient management techniques that can reinstate the fertility of such soils.
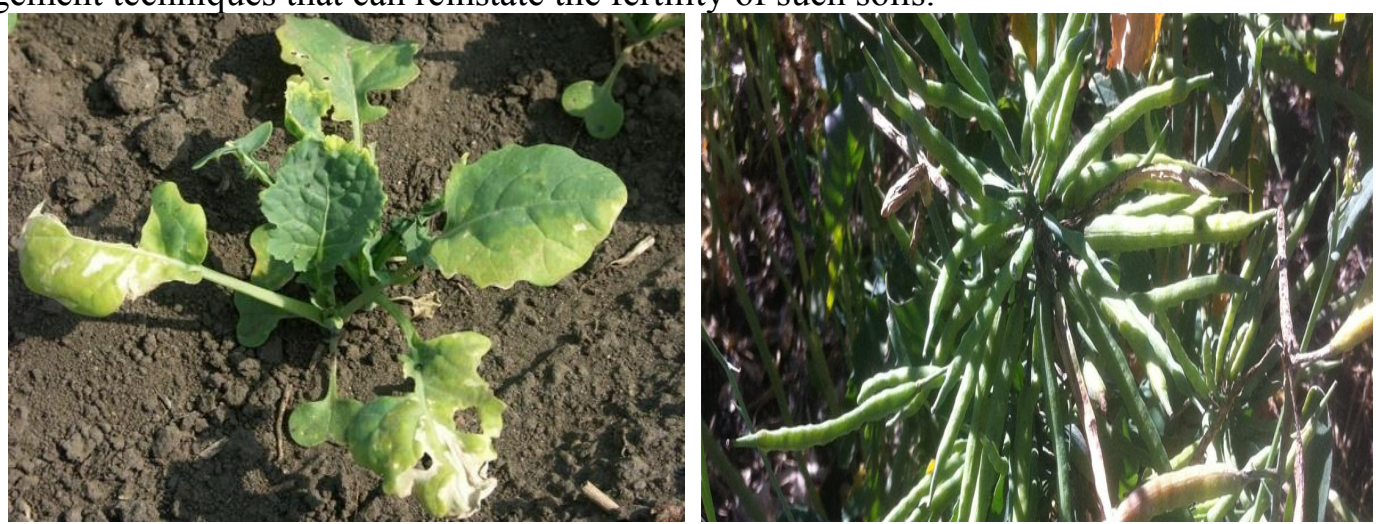

Fig. 20: Illustrates the effect of herbicide carryover can cause crop injury ranging from minimal to complete crop loss. Increased acreage of canola and new herbicide options in other rotation crops have created more opportunities for carryover damage. Minimizing risks and being aware of symptoms to properly identify damage to best manage this potential challenge.

\subsection{Soil degradation}

Agricultural land degradation caused by anthropogenic activities such as excessive use of inorganic fertilizers and pesticides, continuous cultivation of exhaustive crops such as cereals, and the emergence of destructive phytopathogens have contributed to the decline in crop productivity Fig. (20).

According to Kopittke et al., (2019). the leading cause of soil degradation is the loss of soil fertility that becomes a risk factor to crop production. Moreover, Singh et al., (2020) indicated that the advances in sustainable crop production have been challenged mainly by soil degradation, depletion of soil organic matter, demographic development, and climate change. Since the green revolution period, crop production has been characterized by the use of chemical fertilizers, heavy farm machineries, intensive tillage, high-yielding crop varieties, and use of pesticides that are recalcitrant to biodegradation. However, these practices have ruined soil ecology and disrupted the key plant-microbe interactions beneficial in soil fertility restoration Altieri et al., (2018). The use of beneficial biological agents and their derivatives in sustainable agriculture is gaining popularity with the recent advances in molecular technology. This is because they are eco-friendly, versatile, and can enhance crop productivity in a wide range of environments despite the changing climatic conditions Kumar et al., (2017). The microbial component in the plant endosphere and rhizosphere form beneficial associations with plants that can improve crop productivity Ali et al., (2017). They promote plant resilience to various abiotic and biotic factors that limit growth and production Kumar and Verma (2018). These microbes can live either internally or externally on the host plant tissues. For instance, rhizospheric bacteria inhabit plant roots within the soil, and epiphytic bacteria inhabit plant leaf surfaces.

Kumar et al., (2017), reported that plants and microbes are the important components of ecosystem, and their interactions help in regulating the biogeochemical cycle in the environment. Plantassociated microorganisms include bacteria, fungi, viruses, and some algae. They may be endophytic 
and/or epiphytic depending upon their location on the host plants. Endophytic bacteria are plantassociated bacteria that live in the internal tissues of the plant without harming the host plant. They have an important role in plant growth promotion, as they directly or indirectly promote plant growth. They do it by inhibiting the growth of plant pathogens, and/or by producing various secondary metabolites. They are used in the agricultural sector as an eco-friendly alternative tool that helps to improve crop yield. Detection of plant defense response and identification of compounds synthesized by root endophytes are an effective means for their utilization in the agriculture sector as biofertilizers. Therefore, it is important to study the diversity of root endophytic microbial community, endophytehost plant interactions and their colonization, and their activity for successful application in agricultural lands. Here, in this review, the potential of the root endophytic microbial community, colonization, and role in the improvement of plant growth has been explained. This could mark the potential use of endophytes for the benefit of plant growth and enhanced yield.

These microbes use host plants for their growth, colonization, and proliferation; however, they offer a variety of benefits to the hosts. Colonization of microorganisms on host plants takes place through air, water, and insects, or they may be present in germinating plant parts. Endophytic microbial interactions influence the internal part, while epiphytic microbial interactions influence the exterior surface of the plants. These microbes are not harmful to the plants; however, they secrete some beneficial substances that may help in plant growth promotion, resistance to pathogenic microbes, removal of harmful contaminants, and production of secondary metabolites Fig.(21).

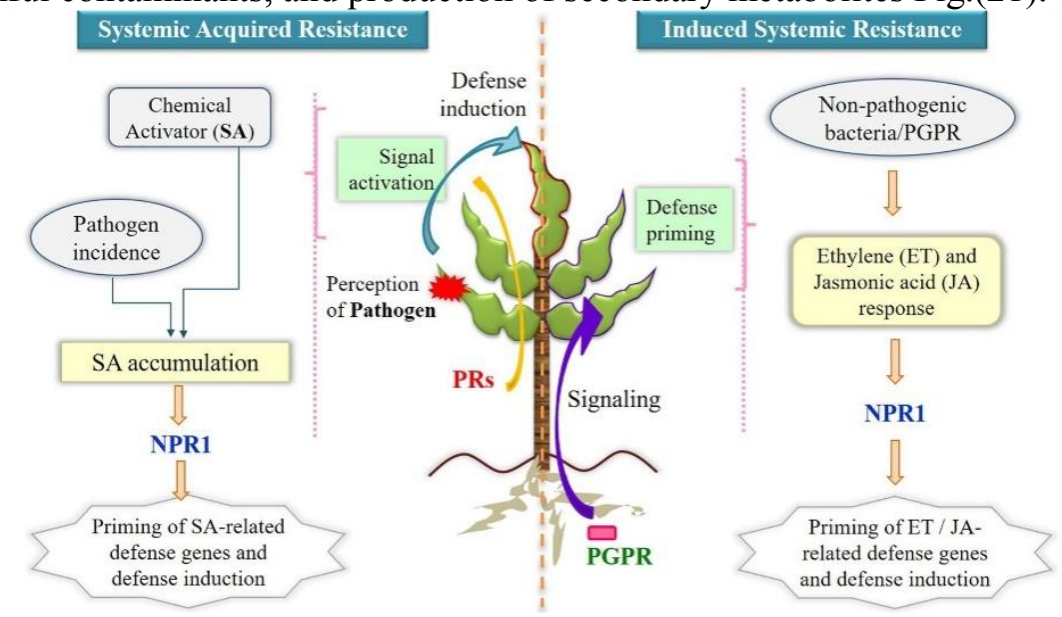

Fig. 21: Illustrates the mechanism of SAR and ISR utilizing phytohormones for inducing defense responses upon microbial incidence. Systemic acquired resistance involves salicylic acid accumulation after perception of pathogen by plants (in red) and expression of pathogenesisrelated proteins in resistant tissues (upper leaf with dark red border) for inducing defense actions, whereas in induced systemic resistance, nonpathogenic plant growth-promoting rhizobacteria enable defense responses via ethylene and jasmonic acid priming process. NPR1 is the positive regulator of salicylic acid in SAR and is needed in downstream processes of ethylene signaling in ISR. SAR, systemic acquired resistance; ISR, induced systemic resistance; SA, salicylic acid; ET, ethylene; JA, jasmonic acid; PRs, pathogenesis related genes; PGPR, plant growth-promoting rhizobacteria; NPR1, non-expresser of PR genes. After Kanchan Vishwakarma et al., (2020)

In such a way, microbes contribute in agricultural crop improvement, food safety, and industries they also stated that beneficial effects of microbial interactions between microorganisms and host plant with their function are important to address the agro ecological importance of endophytic and epiphytic microbes. The colonization and proliferation of plant growth promoting endophytes (PGPE) are well recognized for their importance in the enhancement of plant growth by providing a number of growth regulators/hormones, synthesis of 1-aminocycloprop ane-1-carboxylic acid (ACC) deaminase, assailable essential nutrients and by reducing disease through suppressing growth of pathogens Doty (2008); Aravind et al., (2010); Zhang et al., (2011b); Phetcharat et al., (2012). Some of the beneficial aspects and outcomes of microbial interactions are described in the Fig. (22) Ma et al., (2016). 


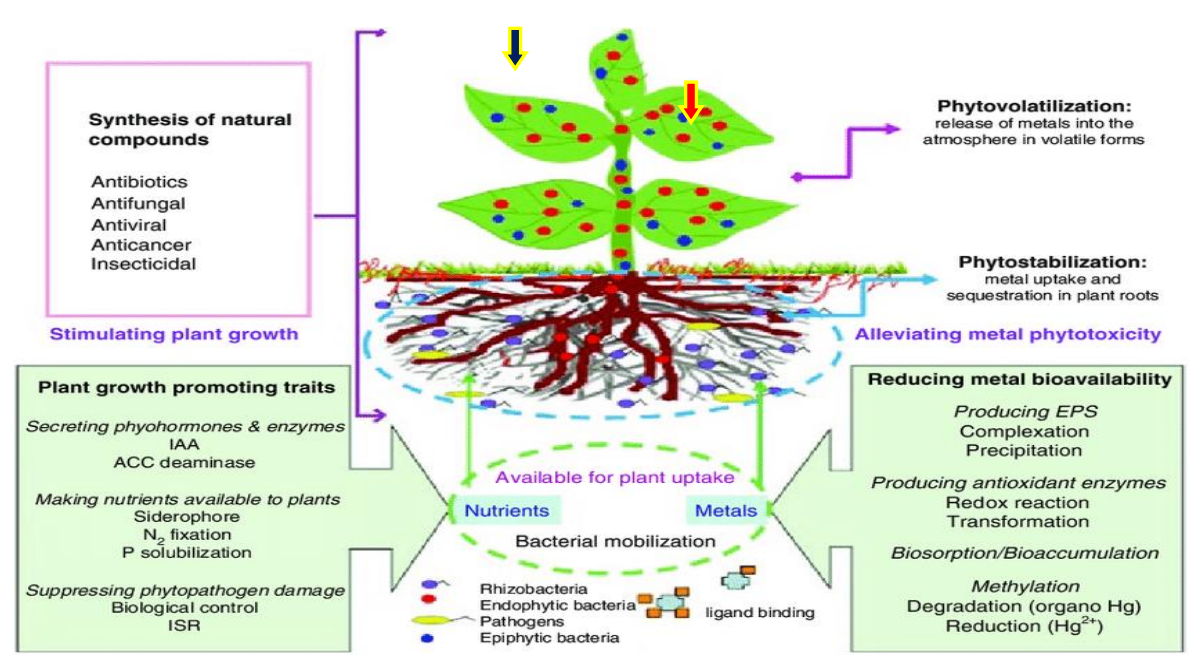

Fig. 22: Diagrammatic representation of plant growth-promoting activities and production of certain beneficial metabolites/compounds by plant-associated bacteria. Abbrev. IAA: indole-3-acetic acid, $A C C$ : 1-aminocyclopropane-1-carboxylic acid, ISR: induced systemic resistance, EPS: extracellular polymeric substances. after Ma et al.,(2016).

Such interaction may be beneficial since bioaugmentation with such endophytic moreover; epiphytic microbes possessing multiple plant growth promoting traits including metal resistance/accumulation/detoxification/ transformation/sequestration can diminish the metal phytotoxicity and alter the phyto-availability of heavy metals in contaminated soils Fig. (22), Rajkumar et al., (2009); Weyens et al., (2009); Ma et al., (2011). This makes these microbes and the host plants as a perfect choice for phytoremediation studies. Furthermore, there are many ecological factors which strongly influence the diversity of epiphytic growth and persistence at different spatial locations in different plant species and at different geographical locations Hietz (2005); Cruz-Angón et al., (2009).

The role of plant-associated bacteria in enhancing crop production and soil fertility has been widely studied Glick (2020). The role of bacterial endophytes in the restoration of degraded soils and crop production Fig. (23). On degraded soils, it has not been possible to replicate on the actual field conditions the successes of plant-endophytic interactions seen in laboratory experiments.
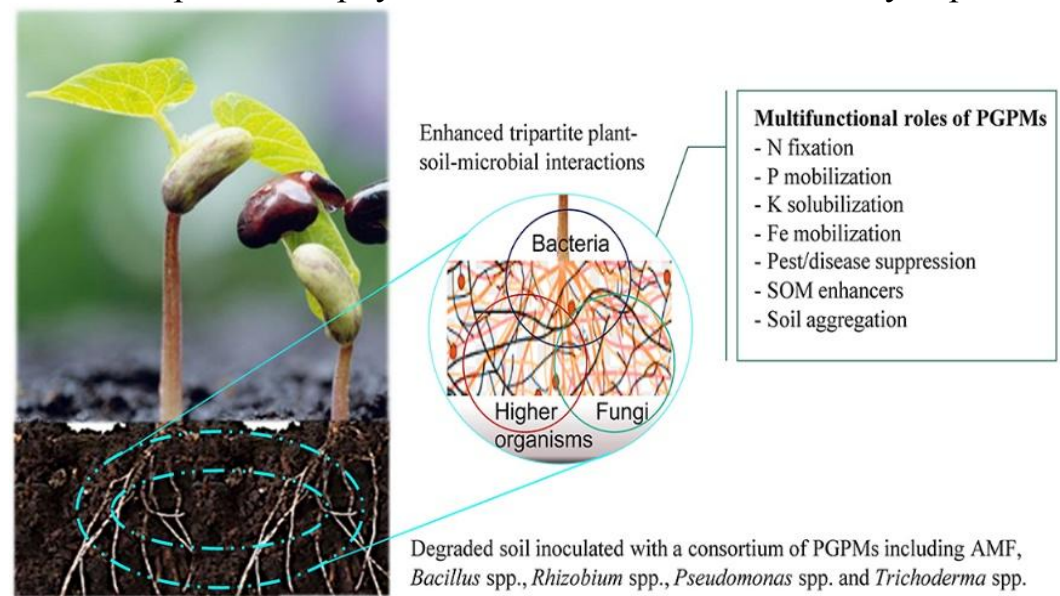

Fig. 23: Illustrates plant growth promoting microorganisms (PGPMs) play a significant role in provision of beneficial ecosystem services in resource-limiting smallholder farming systems. Together with crops such as legumes (Phaseolus vulgaris L.), they form multifunctional interactions that enhance nutrient availability and uptake, pest and disease suppression, soil organic matter (SOM) accumulation and formation of soil aggregates, that collectively increase crop productivity .After Gilbert et al., (2021)

Rhizobacteria refer to plant growth-promoting bacteria that exist in the rhizosphere Fig. (24). The rhizosphere consists of the narrow zone of soil influenced by plant root system where maximum microbial activities occurs Verma et al., (2019). The rhizosphere zone is an ecological niche that 
provides a rich source of nutrients and energy for plant growth. The rhizobacteria are abundant plant partners in the rhizosphere, but they differ in their roles in plant growth promotion. Various interactions occur between plants and rhizobacteria in the rhizosphere.

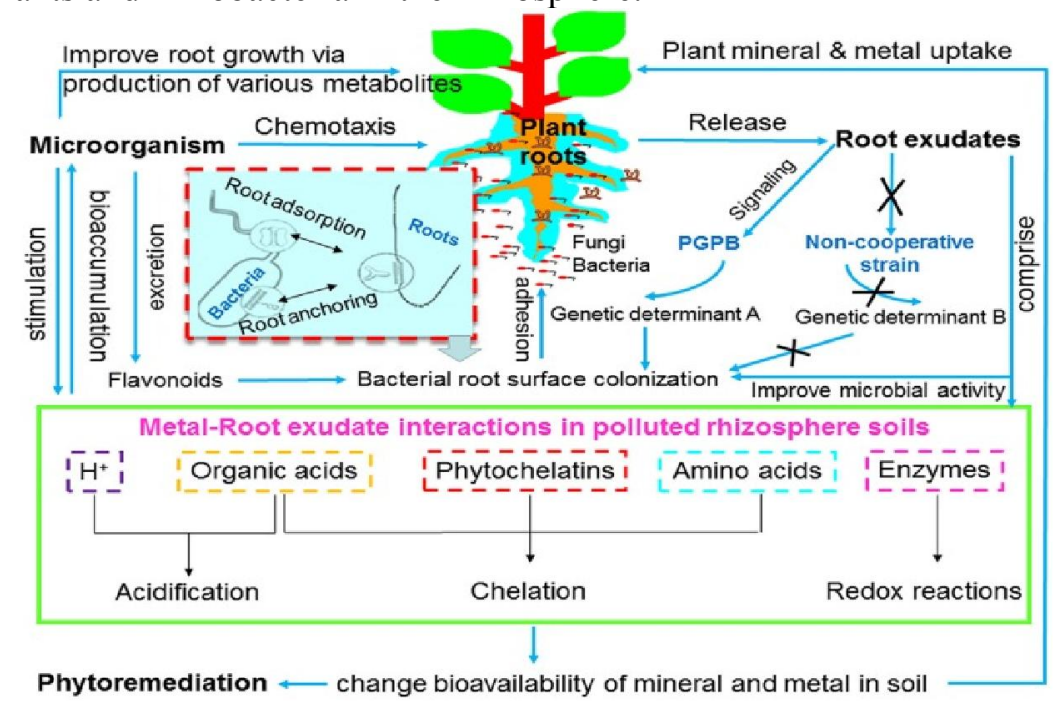

Fig. 24: Represents a schematic overview of mechanisms of plant-microbe-metal interaction

These interactions are important, and involve of signals between the rhizobacteria and the plant roots that regulate their biochemical activities Bhattacharyya and Jha DK (2012). The rhizobacteria are crucial in the rhizosphere for nutrients cycling, carbon sequestration, and ecosystem functioning that promote plant growth, yield and nutrition. Various bacteria genera have been utilized as plant growthpromoting rhizobacteria (PGPR) and include Burkholderia, Pseudomonas, Arthrobacter, Bacillus, Serratia, Micrococcus, Chromobacterium, Erwinia, Azospirillum, Caulobacter, Agrobacterium, and Azotobacter Verma et al., (2019). The rhizobacteria produce plant growth modulating phytohormones such as ethylene, gibberellins, and auxins. Other important metabolites include production of siderophores, enzymes, organic acids, antibiotics, biosurfactants, nitric oxide, and osmolytes Fig. (25).

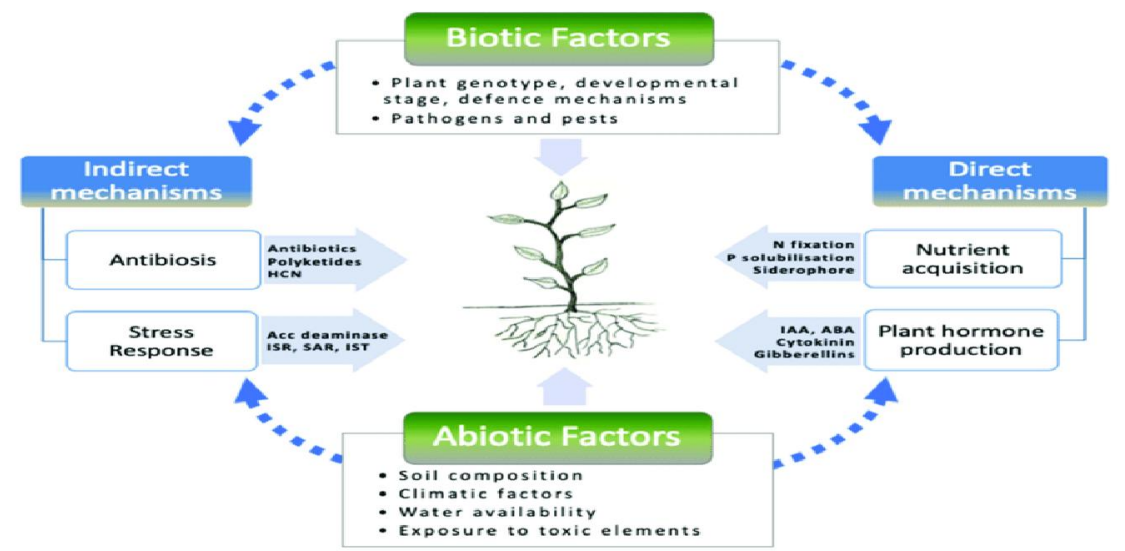

Fig. 25: Illustrates biotic and abiotic factors influencing plant- plant growth-promoting rhizobacteria (PGPR) interactions in the rhizosphere. After Karivaradharajan et al., (2020)

The metabolites are responsible for improving nutrients uptake, tolerance to abiotic stress, nitrogen fixation, suppression of pathogenic organisms Pii et al., (2015) Bacterial endophytes are also referred to as plant growth-promoting rhizobacteria $(P G P R)$ and are believed to be part of the group of bacteria that occupy the rhizosphere Prasad, et al., (2019) Some studies have defined bacterial endophytes as bacteria that do not harm the plant but can be isolated inside surface-sterilized plant materials Liu et al., (2017) These bacteria have adaptive abilities to invade and colonize their host Liu et al., (2017). Endophytic bacteria enhance growth by establishing synergistic interactions with the host plant or antagonistic interactions with soil pathogens Eljounaidi et al., (2016). These inter-microbe and plant-microbe interactions play a crucial role in the restoration of degraded land into an agriculturally 
productive landscape through various complex biochemical mechanisms. Moreover, bacterial endophytes can potentially exert greater beneficial effects on the host plants compared to other plantassociated bacteria. It has been reported that bacterial endophytes have undergone a longer evolutionary selection over many generations and are well adapted to the host plant Ullah et al., (2019). In addition, they are inherited and can be transferred through seeds, making them more compatible and effective in inducing plant growth promotion Kumar and Verma (2018). This inheritability factor is important in selecting adaptive and effective endophytes associated with a specific plant of agricultural importance, especially in plant breeding and tackling climate change-related challenges. Their capacity to tolerate and induce resilience against biotic and abiotic stresses in plants can be exploited to solve edaphic and pathogen-related challenges facing the crop production sector. Pandey et al., (2019) reported that, various benefits associated with endophytes could be more conspicuous when the plants are subjected to adverse environmental stress. Habitat-imposed stress triggers plant-microbial signaling, which forms a complex communication pathway that promotes ecological interactions between individual organisms leading to better adaptation of the host plant to the disturbed environment. Endophytic bacteria enable their host to outcompete other plants such as weeds by enhancing the production of allelopathic biomolecules with antagonistic effects against competitors Rabiey et al., (2019) Fig. (26).

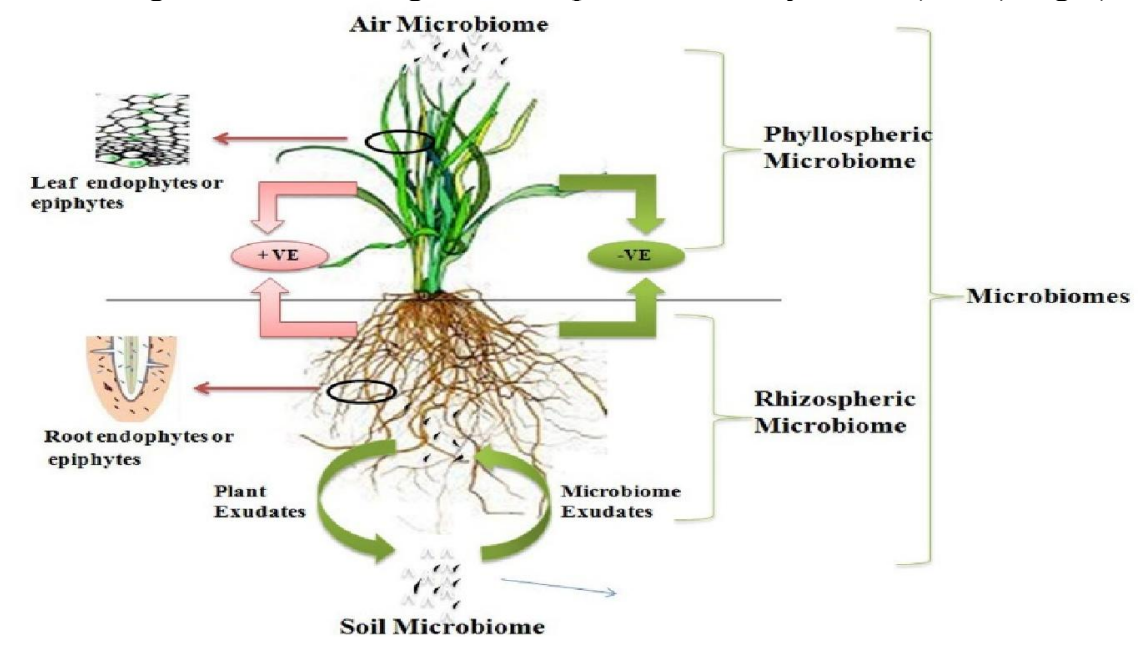

Fig. 26: Illustrates a possible route of entry of allelopathic substances to the surrounding environment from the allelopathic plants. Modified from Chick and Kielbaso (1998)

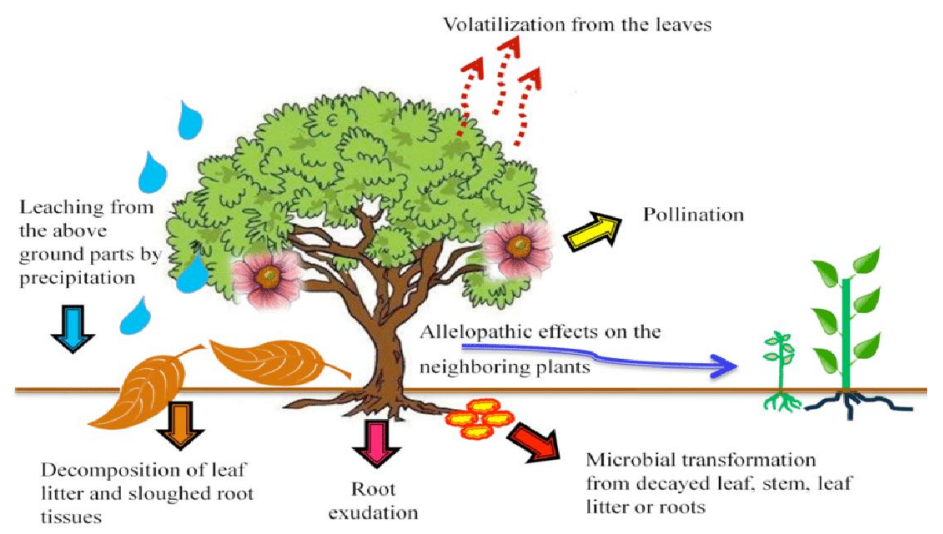

Fig. 27: Represents the plant-microbe interaction in different microbiome.

Notably, host plants are also able to "choose" their microbial partners that enable them to gain maximum benefits from the interactions Griffiths et al., (2020). Bacterial endophytes, affect host plant development positively without any noticeable harm while suppressing any pathogen that may invade the plant zhang et al., (2019). In return, the endophytic microbes benefit and use the plant endosphere as a unique and safe haven that is unperturbed by the harsh climatic conditions that could harm and affect their functionality Le Cocq et al., (2017). Besides, most endophytic bacteria exhibit a biphasic life cycle where they alternate between the soil and plant environment, thus surviving between seasons Singh et al., (2017) Fig. (27). 
Microflora is an aggregation of several types of microbes to form heterogeneous communities that are necessary components in several ecological niches and composed of distinct proportions of various microorganisms. Microorganisms of microflora do not live isolated or independently, but in its place these populations actively interact with other biological members of the ecosystem within their ecological niche. These microbial interactions may take place with any of biological form such as animal-microbe interaction, microbe-microbe interaction, plant-microbe inter- action, etc. Plants provide an excellent ecosystem for microbial interactions. The plant provides the variable environment to the microorganisms from aerial plant part to the stable root system for the interactions. Based on location of plant-microbe interaction, the microbes can be divided in two groups, phyllospheric microorganisms that interact with the aerial leaf surface of plants and rhizospheric which interact with roots of plants. Phyllospheric microorganisms are adapted to low humidity and high irradiation, helps to protect plants from airborne pathogens. Rhizosphere of plants is a nutritionally rich zone due to deposition of nutrition rich compounds such as amino acid, organic acid, vitamins, sugars, etc. secreted by the roots. There is a pictorial presentation of various microbiome in Fig. (26) Showing both phyllospheric and rhizospheric microorganisms. The nutritional enriched environment around roots creates a favorable environment for the growth of soil microorganisms, which includes rhizosphere and the rhizoplane soil microbial communities. A number of microorganisms interact with different plant tissues or cells with various level of dependence. These interactions may be beneficial, harmful, or neutral for one or both the organisms based on these attribute plant-microbe interactions are known as a mensalism (neutral- negative), antagonism (negative-positive), commensalism (neutral-positive), competition (negative-negative), mutualism (positive-positive), and neutralism (neutral-neutral). The commensalism or mutualism are more frequent interactions found in plants, in which either one or both species gain benefit from the relationship respectively Campbell, (1995). Mycorrhiza and genus Rhizobium symbionts are best example of mutualism interaction. There are a number of superb reviews reporting present research on plant-microbe interaction at the molecular level, plant responses to quorum-sensing signals from microbial communities, applications of plant-microbe interaction, microflora responses toward transgenic plants and other rhizospheric interactions Bauer and Mathesius, (1998); Singh et al., (2004); Sørensen and Sessitsch, (2007); Fillion, (2008); Ryan et al., (2008). The examination and understanding of these plant-microbe interactions help to figure out the insights of mechanism that may direct us to understand such concerns. These sustainable resources will be ecofriendly and helpful to clean up the pollution and gaseous effect on a global scale. Other bacteria establish symbiotic structures such as nodules from legumes that harbour diverse bacterial strains. Interestingly, only the rhizobia responsible for nitrogen fixation are well known, while other bacterial endophytes are poorly studied Afzal et al., (2019). Some studies on root nodule microbiome have shown more complex nodule microbial occupants than expected, Velázquez et al., (2017), Sharaf et al., (2019).

\subsection{Fertility of degraded soil recovered by bacterial and fungal.}

Combination of bacteria or fungi inocula with organic materials were used by Medina et al., (2004); Mengual et al.,(2014 a,b) Leifheit et al., (2015),in order to recover the degraded soil to obtain promising results. Leifheit et al., (2015) using fungal inoculum with organic residues to increase soil aggregation and their stability in pot experiment while Mengual et al., (2014a, b) stated that, Pavailability, total $\mathrm{N}$ and other microbiological and biochemical parameters gradually increase with coapplication of bacterial inocula and composted sugar beet in small field. Recently combined effects of bacterial and fungal inocula and cover crops increased phosphorous mobilization and soil organic matter in subtropical red soils during a time duration of six months Cui et al., (2015). They found that the soil organic matter tends to increase phosphorous by about $5.2 \%(17.97 \pm 1.02$ vs. $17.07 \pm 1.05$ g. $\mathrm{kg}^{-1}$ ) relative to control, however results were not statistically significant while inoculation of AM fungi further enhanced this parameter by $5.4 \%(18.94 \pm 1.03$ vs. $17.97 \pm 1.02, \mathrm{P}>0.05)$ from Phosphorous. Moreover, in this study moderately labile organic $\mathrm{P}$ was also increased from control $(302.8 \pm 4$ vs. $272.5 \pm 9.2, \mathrm{P}=0.05)$. This form of $\mathrm{P}$ strongly influences the phosphomonoesterases enzyme activity Cui et al., (2015). Hydrolytic enzymes released by soil inoculants are main drivers of carbon, $\mathrm{N}$ and $\mathrm{P}$ cycling hence they play a key role in hastening the nutrients cycling in soils for plant growth Burns et al., (2013) Fig. (28). Thus, a combined application of organic amendments, cover crops, fungal and bacterial inocula could be a good approach for the sustainable restoration of degraded soil that is not considered yet under field conditions. In above discussion, it had been highlighted that 
direct application and symbiotic interactions of bacterial and fungal inocula with crops and organic fertilizers could be used as an emerging tool for restoring and recovering degraded lands. Therefore, adequate selection for the combined application of diverse communities of bacteria, fungi and organic fertilizers could be a key to restore and reinstate the degraded ecosystems.

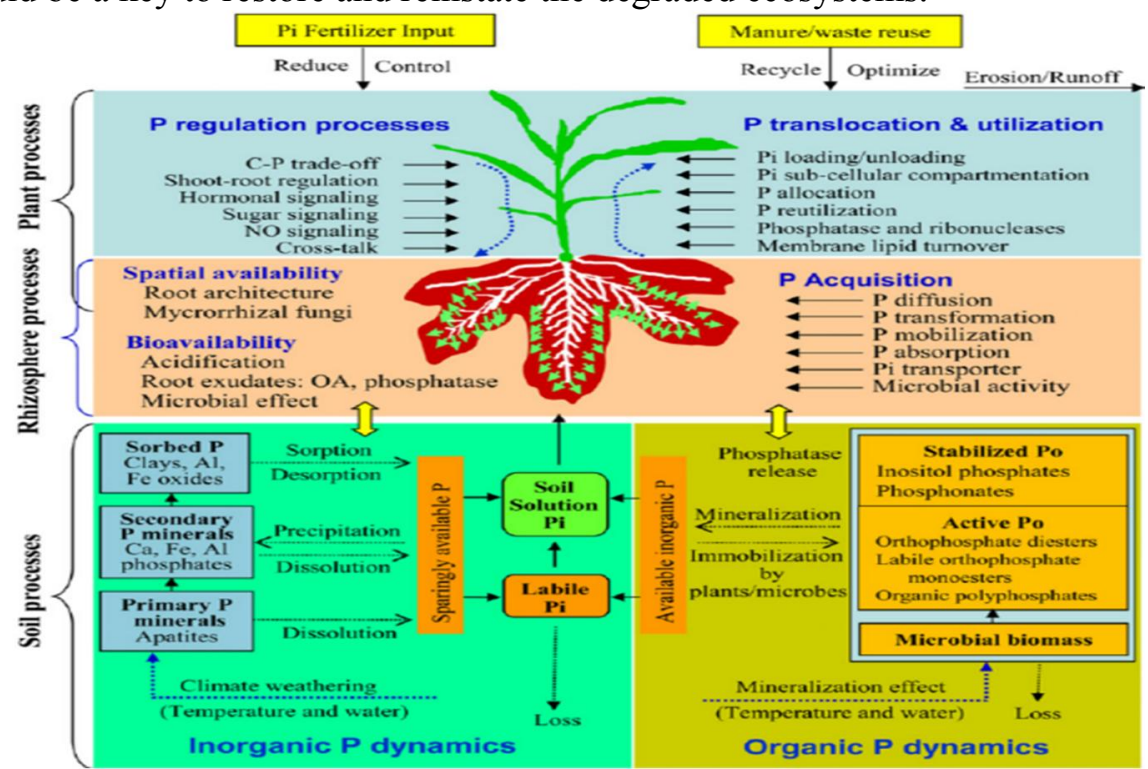

Fig. 28: Illustrates the dynamics phosphorous in the soil/rhizosphere-plant continuum. C-P, Carbon- P; $\mathrm{NO}$, nitric oxide; OA, organic acids.

\subsection{Functions of biofertilizers in rhizosphere zone}

Species of bacteria and fungi play a key role for improving soil fertility, these microbes gradually increase organic matter, helping the availability of $\mathrm{N}, \mathrm{P}, \mathrm{K}$ and $\mathrm{Fe}$ in soil as reported by several researchers, Egamberdiyeva and Höflich, (2004); Caesar-Tonthat et al., (2014); Leifheit et al., (2015).

Additionally, they also produce organic acids for the mobilization of nutrients and facilitate their plant uptake from the rhizosphere zone. However, chemical fertilization in agro-ecosystems can be greatly reduced the fertility status of soil Figueiredo et al., (2011a). Glick, (2012), Fig. (29).

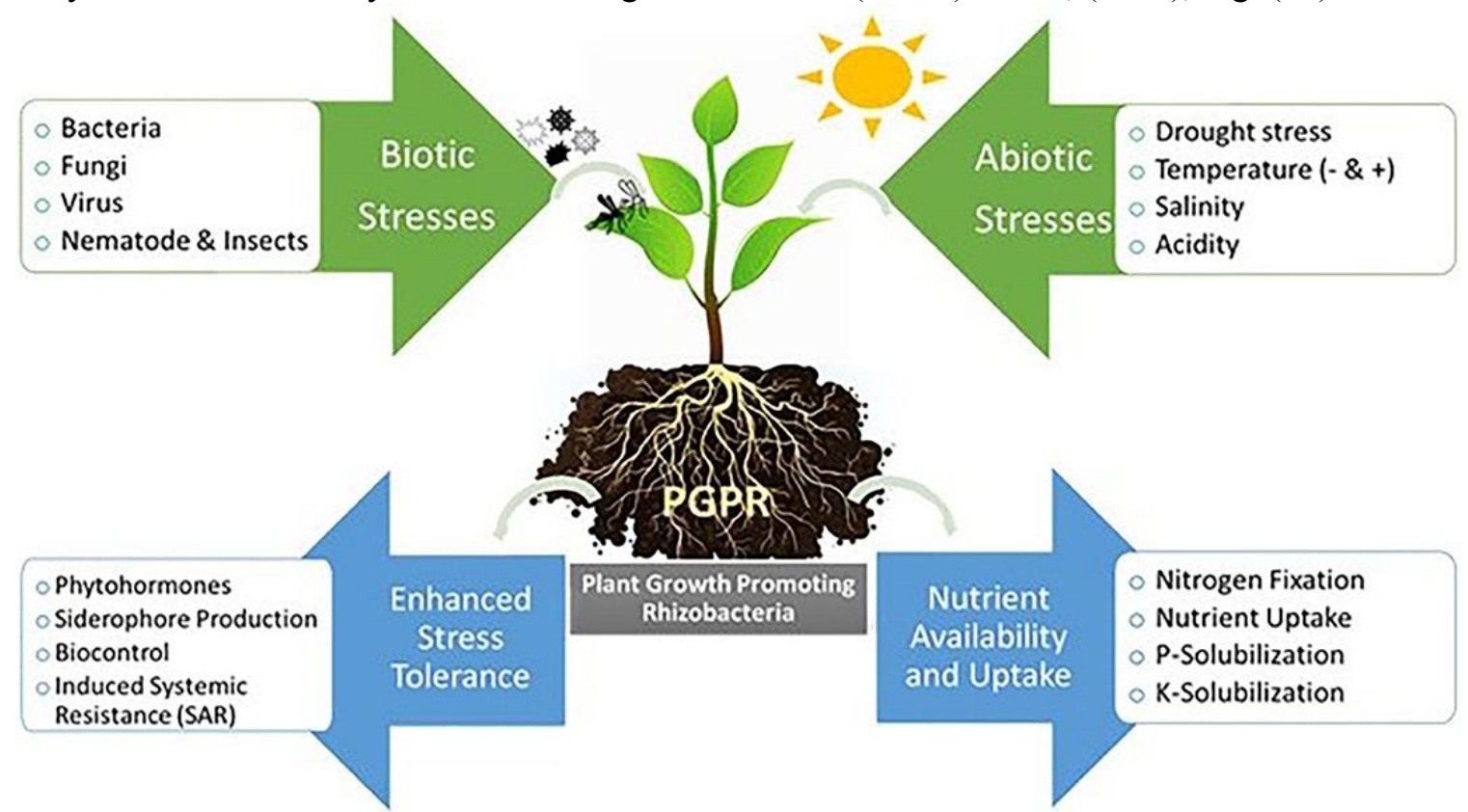

Fig. 29: Represents different mechanisms of plant growth promoting rhizobacteria in plant rhizosphere

Soil rhizosphere harbors an active, diverse, and complex bacterial community associated with plants. Bacterial endophytes have been isolated in most of the plants studied; their adaptive traits in 
plant tissues are poorly as reported by Thiergart- et al., (2020). Increasing microbial functional diversity positively influences plant traits through the enhanced provision of agro- ecosystem services associated with soil fertility, productivity and overall plant health Liu et al., (2017). Distinctively, type and growth stages of plant material used were gradually influence their composition Mahmood et al., (2019). Hong et al., (2019) carried out metagenomics analyses at different plant ages and reported a high variation of PGPRs, including endophytes, colonizing a 3-year old Panax ginseng plant. Different plant species have been reported to have different bacterial endophytes despite growing in the same environment Santoyo et al., (2016). Ding et al., Barraza et al., (2020), who reported that host plant species followed by sampling time and location of the plant materials are the most important determinants when selecting an endophytic community also observed. Their distribution along the plant tissues could also differ with some endophytes concentrating on the roots while others on the stem and leaves Barraza et al., (2020). Vertical evolutionary inheritance through seeds or stem cuttings also affects the predominant endophytic bacterial species present. Besides, the type of soil used to grow the plants also affects endophytic diversity Ding et al., (2013) Fig. (30 ). This means the same plant species could have very diverse bacterial endophytes while growing in different agricultural soils.

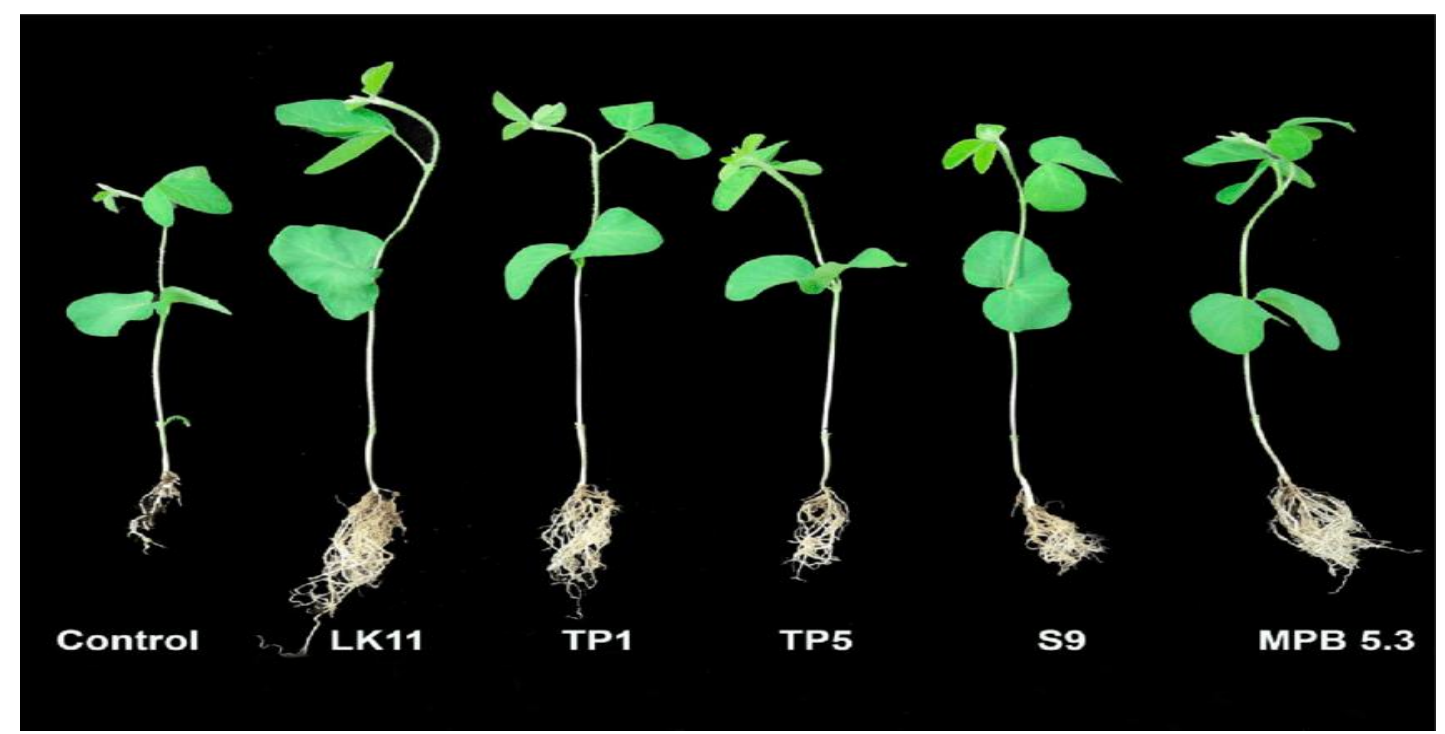

Fig. 30: Illustrates treatment s of soybean plants with bacterial endophytes $L K 11, T P 1, T P 5, S 9$, and $M P B 5.3$, isolated from arid land-inhabiting plants. Endophytes with or without IAA production ability were inoculated onto soybean to analyze the growth-promoting effect under normal conditions in crop plants. The experiment was repeatedly conducted under controlled greenhouse conditions. Plants shown here are representative of the treatment replications from three repetitions of the experiment. From left to right, control-without any treatment and plants inoculated with LK11, TP1, TP5, S9, and MPB5. After Sajjad Asafa et al., (2017)

Sajjad Asafa et al.,(2017), reported that five bacterial endophytes LK11 (Sphingomonas sp. LK11), TP5 (Bacillus subtilis), MPB5.3 (B. subtilis subsp. Subtilis), S9 (B. subtilis subsp. Subtilis), and TP1 (Serratia marcescens) were isolated from arid land-dwelling plants under normal conditions for determining and evaluating the potential plant growth-promoting action (PPGPB) of bacterial endophytes, based on morphological characteristics particularly after isolation and purification. They observed that Phytohormonal analysis of these endophytes predicted indole acetic acid (IAA) production were $12.31 \pm 0.45,6.8 \pm 0.59$, and $10.5 \pm 1.02 \mu \mathrm{M} / \mathrm{mL}$ in the culture of LK11, MPB5.3, and TP1, respectively. Under controlled greenhouse conditions, these endophytes were inoculated into soybean, and their growth promoting characteristics were compared with those of non-phytohormonesproducing endophytes. In terms of plant growth promotion, among IAA-producing endophytes, LK11 and TP1 greatly improved physiological characteristics such as shoot /root length, fresh /dry weight, and chlorophyll contents. However, the non-phytohormones-producing endophytes TP5 and S9 did not show a growth-promoting effect. Based on these results, plants inoculated with LK11 and TP1 along with a control were subjected to endogenous hormonal analysis and showed a significant increase in 
abscisic acid (457.30-398.55 vs. 205.93 ng/g D.W.) and a decrease in jasmonic acid content (50.0785.07 vs. $93.90 \mathrm{ng} / \mathrm{g}$ D.W.), respectively. Total gibberellin content was found to significantly increase in endophyte-inoculated plants (155.43-146.94 ng/g D.W.) as compared to those in controls (113.76 ng/g D.W.). Bacterial endophytes might be used to enhance crop plant physiological characteristics isolated from arid land-inhabiting plants under normal conditions.

\subsection{Potential benefits of endophytic bacteria for advancing yield.}

Different endophytic and rhizospheric bacteria have distinctive strategies for enhancing plant growth and yield in the soil. The distinct biotic activities of these bacteria make them vital components for nutrient restoration in sustainable farming systems Ahemad and Kibret (2014), Olubukola etal (2021) reported that interactions between microorganisms and host plants determine the growth and development as well as the health of the host plant. Various microbial groups inhabit the rhizosphere, each with its peculiar function. The survival of each microbial group depends largely on its ability to colonize the plant root and outcompete the native organisms. The role of the rhizospheric microbiome in enhancing plant growth has not been fully maximized Fig. (31).

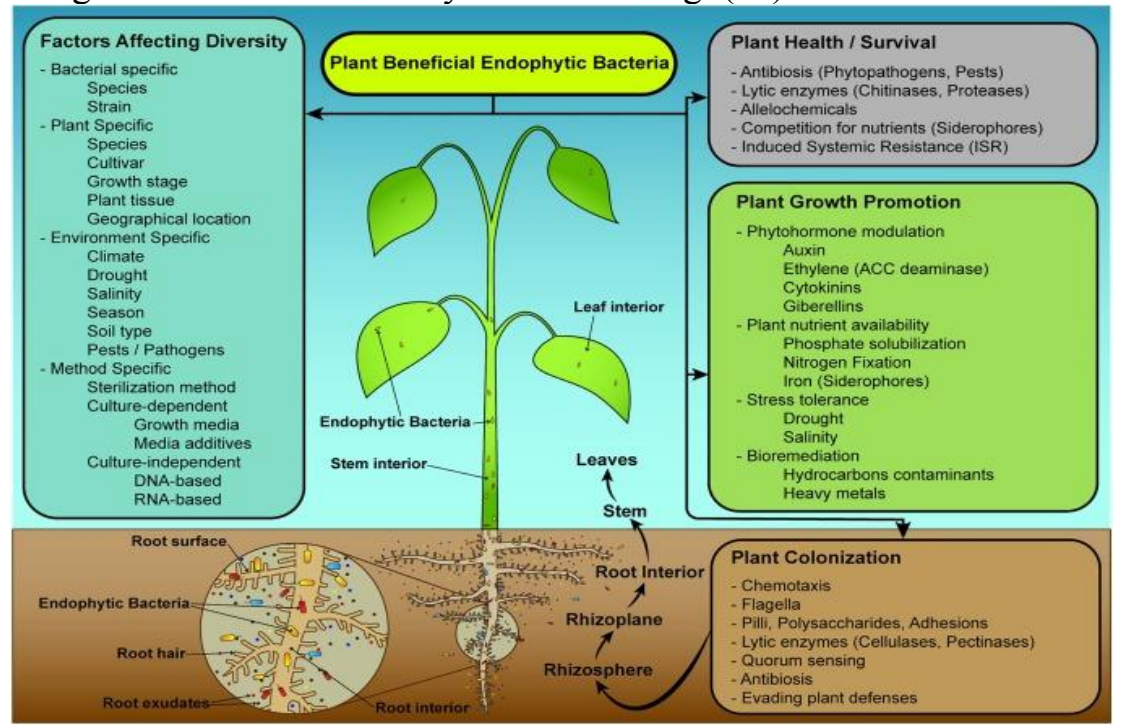

Fig. 31: Illustrates the Potential benefits of endophytic bacteria for advancing yield. These benefits have been shown to include increase in seed germination rate, root growth, yield, leaf area, chlorophyll content, nutrient uptake, protein content, hydraulic activity, tolerance to abiotic stress, shoot and root weights and heights, bio-control, and delayed sense-cence. After PérezMontano et al., (2014)

Pérez-Montano et al., (2014) stated that plant growth-promoting rhizobacteria (PGPR) are freeliving bacteria that actively colonize plant roots, exerting beneficial effects on plant development. It may (a) promote the plant growth either by using their own metabolism (solubilizing phosphates, producing hormones or fixing nitrogen) or directly affecting the plant metabolism (increasing the uptake of water and minerals), enhancing root development, increasing the enzymatic activity of the plant or "helping" other beneficial microorganisms to enhance their action on the plants or, (b) may promote the plant growth by suppressing plant pathogens. These abilities are of great agriculture importance in terms of improving soil fertility and crop yield, thus reducing the negative impact of chemical fertilizers on the environment. An understanding of the complexities of microbial interactions and factors affecting their assembly in the community is necessary to benefit maximally from the cooperation's of various microbial communities for sustainable crop production. Factors affecting microbial diversity in the rhizosphere, microbiome part of the changes in the microbial communities around the rhizosphere are influenced by abiotic and biotic factors Patel et al., (2015). The composition of plant microbiome and other soil environments specifies the duties performed by host plants in differentiating its colonizers Berendsen et al., (2012). Nonetheless, plant genotypes have shown to be the main driver in providing direction of the rhizosphere microbial diversities Marques et al., (2014) Zancarini et al., (2012). Some of the factors that affect microbial diversity in the rhizosphere microbiome such as type of plant, 
pathogenic invasion, free-living Protists, (climatic changes) such as increasing temperature of the soil, soil Salinity, high doses of nitrogen level may suppresses microbial respiration, changing of land use from natural habitat to agricultural and irrigation with wastewater. Udaya Kumar et al., (2021) stated that, plant root is the primary site of interaction between plants and associated microorganisms and constitutes the main components of plant microbiome that influence crop production Fig. (32).

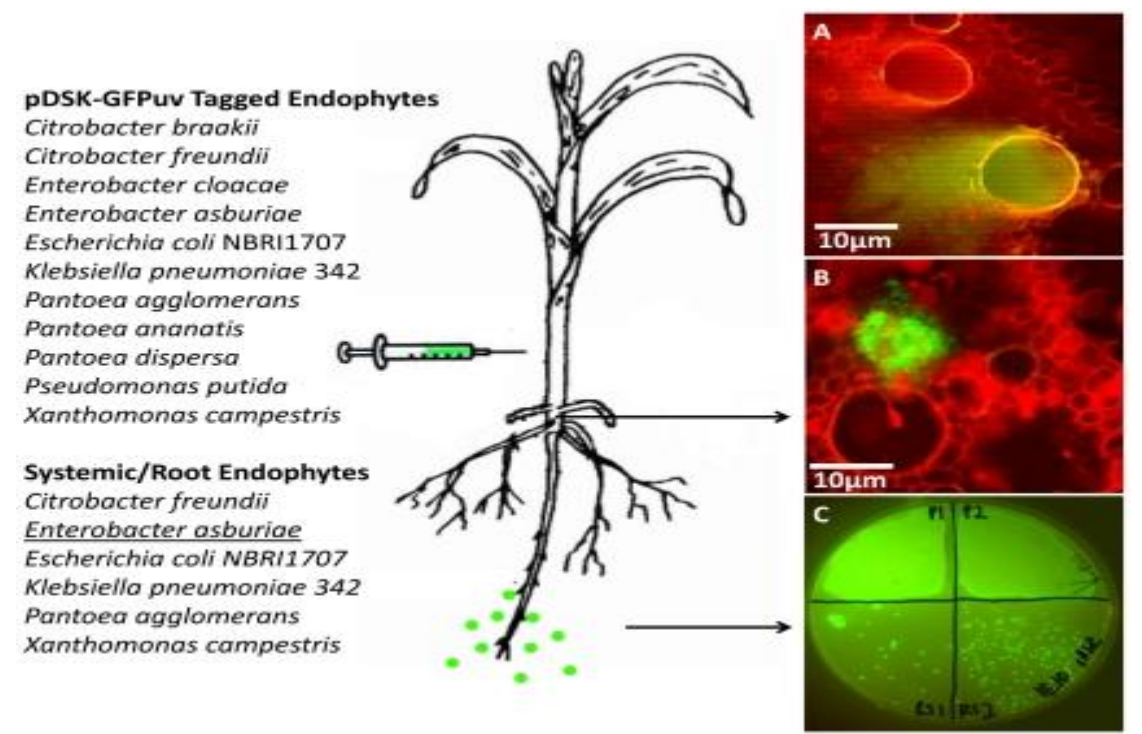

Fig. 32: Represents eleven endophytes indicated were successfully tagged with GFP (pDSK-GFPuv, KanR) and injected into maize stems. Six endophytes indicated migrated to roots and persisted for $>5$ days as shown by fluorescence microscopy and culturing from macerated root tissues onto R2A Kanamycin media. (A) Panteoa agglomerans shown spilling out of a metaxylem vessel. (B) Enterobacter asburiae spilling out of root vascular tissue. (C) Culturing confirmed that E. asburiae was present in the roots of two plants (top two quadrants) as well as in their rhizospheres (bottom two quadrants). After David Johnston-Monje and Manish N. Raizada (2011).

David Johnston-Monje and Manish N. Raizada (2011), stated that endophytes are non-pathogenic microbes living inside plants. Four different teosinte and 10 different maize varieties were screened for endophytic bacteria by culturing, cloning and DNA fingerprinting using terminal restriction fragment length polymorphism (TRFLP) of 16S rDNA, Principle Component Analysis of TRFLP. They observed that seed endophyte community composition varied in relation to plant host phylogeny. However, a core microbiota of endophytes was conserved in Zea seeds across boundaries of evolution, ethnography and ecology. The majority of seed endophytes in the wild ancestor persist today in domesticated maize, though ancient selection against the hard fruitcase surrounding seeds may have altered the abundance of endophytes. Four TRFLP signals including two predicted to represent Clostridium and Paenibacillus species were conserved across all Zea genotypes, while culturing showed that Enterobacter, Methyl bacteria, Pantoea and Pseudomonas species were widespread, with c-proteobacteria being the prevalent class. Twenty-six different genera were cultured, and these were evaluated for their ability to stimulate plant growth, grow on nitrogen-free media, solubilize phosphate, sequester iron, secrete RNAse, antagonize pathogens, and catabolize the precursor of ethylene, produce auxin and acetoin /butanediol. Of these traits, phosphate solubilization and production of acetoin/butanediol were the most commonly observed. An isolate from the giant Mexican landrace Mixteco, with 100\% identity to Burkholderia phytofirmans, significantly promoted shoot potato biomass. GFP tagging and maize stem injection confirmed that several seed endophytes could spread systemically through the plant. One seed isolate, Enterobacter asburiae, was able to exit the root and colonize the rhizosphere.

The endophytic bacteria in the root zone have an important role in plant growth promotion. Diverse microbial communities inhabit plant root tissues, and they directly or indirectly promote plant growth by inhibiting the growth of plant pathogens, producing various secondary metabolites. Mechanisms of plant growth promotion and response of root endophytic microorganisms for their 
survival and colonization in the host plants are the result of complex plant-microbe interactions. Endophytic microorganisms also assist the host to sustain different biotic and abiotic stresses. Better insights are emerging for the endophyte, such as host plant interactions due to advancements in 'omic' technologies, which facilitate the exploration of genes that are responsible for plant tissue colonization. Consequently, this is informative to envisage putative functions and metabolic processes crucial for endophytic adaptations. Detection of cell signaling molecules between host plants and identification of compounds synthesized by root endophytes are effective means for their utilization in the agriculture sector as biofertilizers. In addition, it is interesting that the endophytic microorganism colonization influences the relative abundance of indigenous microbial communities and suppresses the deleterious microorganisms in plant tissues. Natural products released by endophytes act as biocontrol agents and inhibit pathogen growth. The symbiosis of endophytic bacteria and arbuscular mycorrhizal fungi (AMF) affects plant symbiotic signaling pathways, root colonization patterns, and phytohormones synthesis. In this review, the potential of the root endophytic community, colonization, and role in the improvement of plant growth has been explained in the light of intricate plant-microbe interactions. Fig. (33), they produce extracellular fluids such as organic acids that solubilize nutrients for easy absorption by plants Chhabra and Dowling (2017).

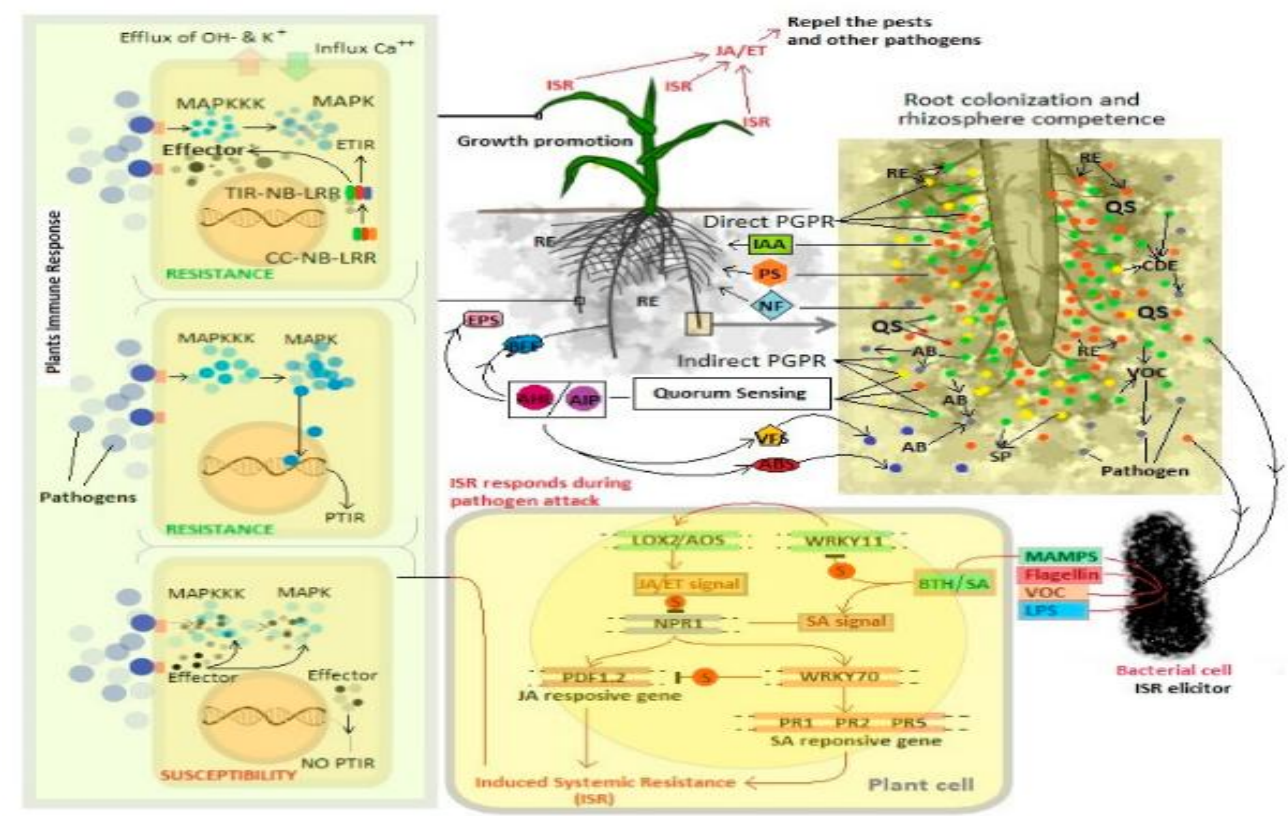

Fig. 33: Mode of Action of Endophytic PGPR can enhance plant growth by employing one or more of these mechanisms microbial interactions at the root zone, and cellular responses of the host plant. Abbreviations: (JA/ET) : Jasmonate / Ethylene,(SA) : Salicylic acid, (AB) : Antibiotic, (ABS): Antibiosis, (RE): Root exudates, (VOCs) : Volatile organic compounds, (VFS): Virulence factor secretion, (CDE) : Cell wall degrading enzymes, (BFF): Biofilm formation, (PS) : Phosphate solubilization, (SP) : Siderophore production, (NF) : Nitrogen Fixation, (QS) : Quorum sensing, (BTH): Benzothiadiazol, (LPS): Lipopolysaccharide, (IAA): Indole acetic acid, (S): Suppression, (PTIR): Pathogen Triggered Immune Response, (NB) : Nucleotide binding, (CC) : Coiled coil, (LRR) : Leucine rich repeats. After Udaya Kumar et al., (2021)

Other endophytic bacteria indirectly promote plant growth through biocontrol mechanisms such as competition for nutrients, release of lytic enzymes, and the induction of plant defense mechanisms Liu, et al., (2017). This is supported by the findings of Devi, et al., (2017), where the application of Bacillus spp. induced systemic resistance and nutrient competitive advantage in inoculated potato plants. The inter-specific plant-microbial interaction process starts with the establishment of communication between the host plant and microorganism. This is made possible by the production of specific compounds in the root exudates that aid signaling and recognition. The type of root exudates significantly determines the composition of microbiota in the rhizosphere colonizing the plant Zhalnina, et al., (2018). Through a series of complex signal mediated communications, bacterial endophytes can 
gain entry into the root's endosphere such as nodules in the case of legumes. Apart from water and temperature, plants in terrestrial environments are strongly constrained by nutrients availability. Notably, plants in different ecosystems respond to changes in the concentration of one or more soil nutrients and endophytes can play a key role in balancing soil nutrients, enhancing nutrient acquisition, and plant growth Adesemoye et al., (2017). In degraded soil, for instance, there is low availability of minerals such as $\mathrm{P}$ and Fe for plant absorption. Acquisition of such nutrients can be enhanced by the use of bacterial endophytes that releases phytosiderophores responsible for Fe chelation and carboxylate exudates required for P mobilization Singh et al., (2018), Ku et al., (2019)

Nitrogen $(\mathrm{N})$ is often lost through leaching or emission thus limiting its availability in most of the cultivated soils Abou seeda et al., (2020). Phosphorus (P), potassium (K) and sulphur are generally limited in degraded soils. Under nutrient limited conditions, these nutrients affect the $\mathrm{N}_{2}$-fixation by reducing the growth of $\mathrm{N}$-fixing bacteria, nodule formation and functioning, as well as affecting host plant growth. Divito and Sadras (2014). Nodule production, activity and their number are limited more than plant shoot biomass in response to the deficiency of P, K and sulphur Abou seeda et al., (2020) Fig. (33).

Moreover, Phosphorous limitation in soil decreases the activity of nitrogenase enzyme in Nfixing bacteria, because both autotrophic and heterotrophic bacteria require high ATP for cellular N2fixation Reed et al., (2007, (2011; Pérez et al., (2014), Abou seeda et al., (2020).. Similar to nutrient deficiency, soil moisture is another major factor that influences nodule formation or retardation of nodule growth Fig (34). Water availability in soil is related to water holding capacity that is very low in degraded soil Montgomery, (2007). According to Sinclair et al., (1987) water, limiting conditions severely affect nodule formation in soybean crop. Thus in-degraded soils, $\mathrm{N}_{2}$-fixation and other related functions (decomposition, mineralization, enzymes or organic production) of microbes are severely affected due to loss of fertility and water holding capacity. Soil microbes adapt various strategies to cope with such deficiencies.

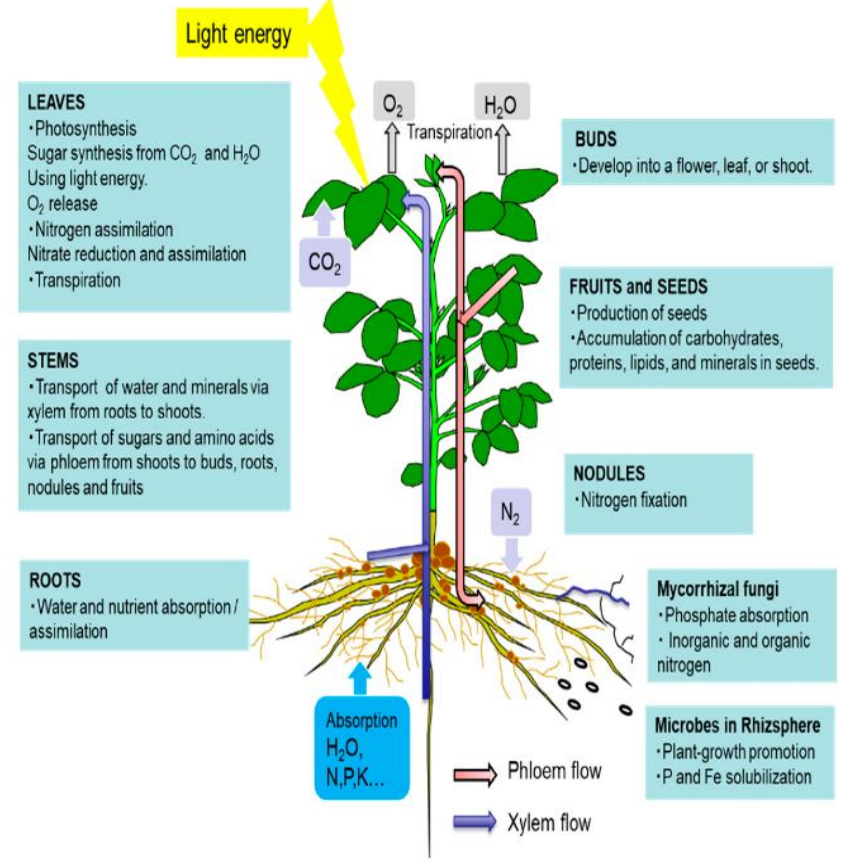

Fig. 34: Represents an overview of the $\mathrm{C}$ and $\mathrm{N}$ flow among plant organs. Plants use the xylem and phloem system to exchange nutrients and the information on the status of water and mineral nutrient acquisition by the root system and the growth requirements of the shoot organs. The $\mathrm{C}$ flow from shoots supports roots, symbionts (i.e., fungi and bacteria) that provide plants with nutrients and other benefits, and young (sink) organs, such as buds, flowers, and fruits, via the phloem (noted in red arrow). Xylem (noted in blue arrow) conveys water and nutrient from the roots to the rest of the plant and provides physical support. Several of the displayed systems may occur independently in nature (e.g., nodules, mycorrhizal fungi, and plant growthpromoting rhizobacteria (PGPR)) and/or may not be present at the same time on the root. Bud, flower, and fruit differentiation and development may appear sequentially on the shoots. 


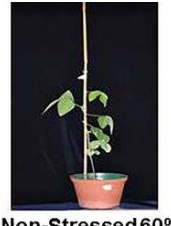

Non-Stressed $60 \%$ Drought $60 \%$

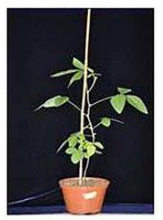

Non-Stressed $40 \%$

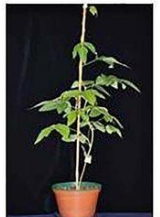

Non-Stressed $30 \%$ Drought $30 \%$

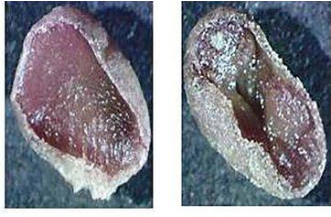

Non-Stressed $60 \%$ Drought $60 \%$

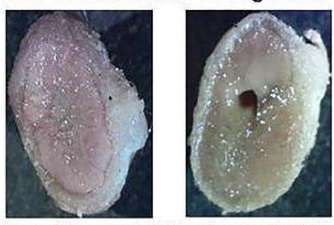

Non-Stressed $40 \%$ Drought $40 \%$

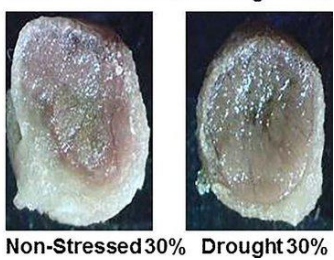

Fig. 35: Illustrates, Soybean growth under non-stress and drought-stress: (A) Soybean growth under non-stress and drought-stress conditions. (B) Crown nodule cross sections of non-stressed nodules and of drought-stressed nodules exposed to different degrees of drought $(60 \%, 40 \%$ and $30 \% \mathrm{~m} \mathrm{WHC}$ ). Plants age was 56 days (60\% MWHC), 67 days (40\% MWHC) and 75 days (30\% MWHC) after sowing

Although $\mathrm{N}$ is present abundantly in atmosphere in the form of diatomic $\left(\mathrm{N}_{2}\right)$ molecule, but its structure makes $\mathrm{N}_{2}$ molecule inert. However, reduction of $\mathrm{N}_{2}$ molecule into $\mathrm{N}$ is a complex process that requires input of huge amount of energy Postgate, (1982). Prokaryotic microorganisms known as diazotrophs fix atmospheric $\mathrm{N}_{2}$ in the form of ammonia $\left(\mathrm{NH}_{3}\right)$ through their normal metabolic process Riggs et al., (2001); Galloway et al., (2008). These microbes are free living organisms present in the bulk soil Reed et al., (2011) that mainly includes Cyanobacteria, Proteobacteria, Archaea, and firm cutes Demba Diallo et al., (2004); Duc et al., (2009). Some of these organisms (Azotobacter and Azoarcus genera) are also present at comparable densities in the rhizosphere and bulk soil. However, there are other bacteria from genera Herbaspirillum and Azospirillum that colonize only in the rhizosphere Mrkovackiand Milic, (2001); Malik et al., (2002); Bashan et al., (2004); Bashan and and De-Bashan, (2010). Rhizobia has the capability to infect roots and induce the formation of root nodules Stacey, (2007). Therefore in the field of $\mathrm{N}$ fixation, most of the researchers specially focus on rhizobium-legume symbiosis due to higher impact on primary productivity of the agricultural ecosystem Rengel, (2002). The establishment of this association results in the formation of highly specialized organ called 'nodules' that are formed on the intracellular root of symbionts, on which bacteria colonize. Such bacteria mainly belong to the family Rhizobiaceae that develop a highly specific interaction with the infected root. This interaction consists of several stages, which involves the exchange of complex signals between the bacterium and plant Sprent et al., (1989). Bacteria fix $\mathrm{N}_{2}$ through a complex enzyme system called nitrogenase Kim and Rees, (1994) and this enzyme system exists as two separable components; $(\boldsymbol{A})$ nitrogenase reductase (Fe-protein) and $(\boldsymbol{B})$ nitrogenase metal cofactor. The former enzyme serves as an exclusive electron donor with high reducing power whereas the later (substrate reduction component) accepts the electrons energy and convert inert $\mathrm{N}_{2}$ molecule into $\mathrm{NH}_{3}$ Fig. (36).

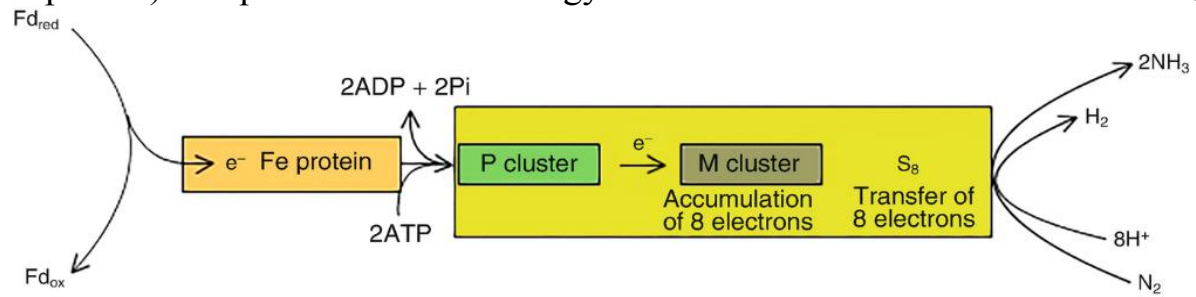

Fig. 36: Illustrates a diagram of molecular nitrogen reduction by nitrogenase. $\mathrm{N}_{2}$ binding site is present in $\mathbf{M}$ cluster which should accumulate eight electrons $\left(\mathbf{8} \mathbf{e}^{-}\right)$before $\mathbf{N}_{\mathbf{2}}$ is reduced to $\mathbf{N H}_{\mathbf{3}}$. In the initial stage, possibly two $\mathbf{H}^{+}$might bind with the active site resulting in release of $\mathbf{H}_{2}$ 
In order to produce 1.0 mole of $\mathrm{NH}_{3}, 16$ moles of adenosine triphosphate (ATP) is required by these microbes Hubbell and Kidder, (2009), who obtain this energy by oxidizing organic molecules. Free-living bacteria must obtain this amount of ATP from other organisms, while photosynthetic microbes (cyanobacteria) use self-generated energy from photosyn thesis process Fig. (37) .

Yaniv et al., (2021) reported that live cyanobacteria could produce photocurrent in bio-photo electrochemical cells (BPECs) that can be exploited for clean renewable energy production. Electron transfer from cyanobacteria to the electrochemical cell was proposed to be facilitated by small molecule(s) mediator(s) whose identity (or identities) remain unknown. The mechanism of electron transfer in the BPEC by identifying the major electron mediator as NADPH in three cyanobacterial species. They observed that an increase in the concentration of NADPH secreted into the external cell medium (ECM) is obtained by both illumination and activation of the BPEC. Elimination of NADPH in the ECM abrogates the photocurrent while addition of exogenous $\mathrm{NADP}^{+}$significantly increases and prolongs the photocurrent production. $\mathrm{NADP}^{+}$is thus the first non-toxic, water-soluble electron mediator that can functionally link photosynthetic cells to an energy conversion system and may serve to improve the performance of future BPECs. Other microbes like associative and symbiotic nitrogenfixer get these compounds from the rhizosphere of their host plant Hubbell and Kidder, (2009). Postgate, (1998).

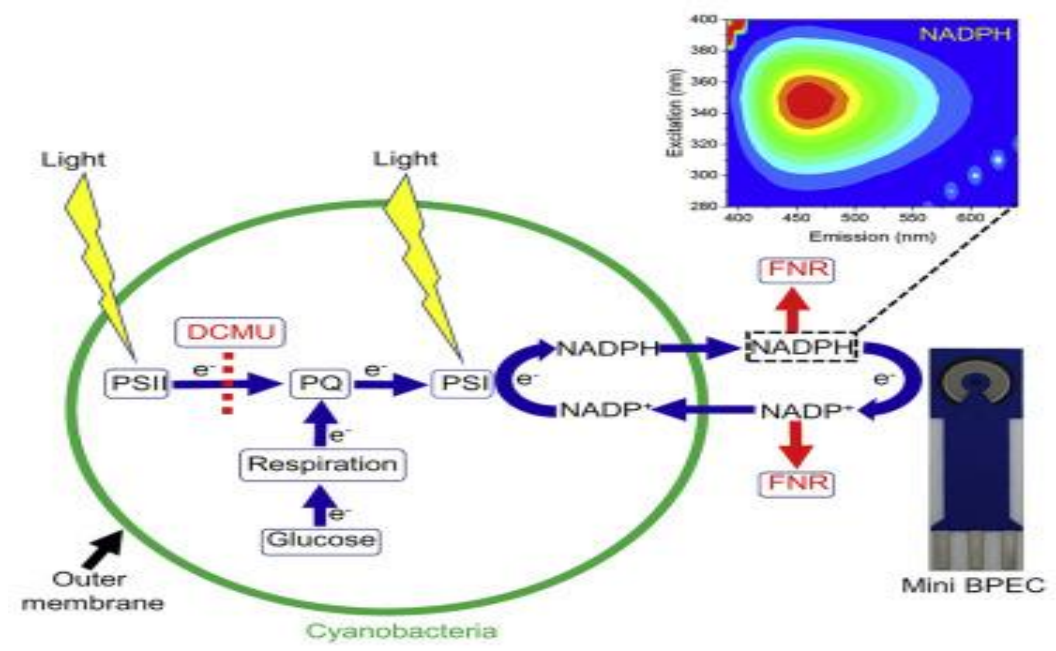

Fig. 37: Schematic depiction of the main electron transport pathway in cyanobacterial BPECs the electron transport originates from the respiratory pathway that reduces the PQ pool and continues downstream to PSI that under illumination reduces NADP + to NADPH. NADPH exits the stroma (cytoplasm) and outer membrane to the ECM and reduces the graphite anode. It then re-enters the cyanobacterial cells to accept more electrons from PSI. Yellow flash shapes indicate the light illumination that is absorbed in the photosystems. Green arrows represent the directionality of the electron transport pathway. Black arrows indicate the internal and outer cell membranes. A dashed line represents the electron blockage between PSII and the plastoquinone pool (PQ) in the presence of DCMU. Red arrows represent the binding of NADP+ and NADPH to exogenous FNR that prevent them from reducing the anode or reentering the cell and in this manner abrogate the current production. After Yaniv et al., (2021)

\subsection{The roles of biofertilizers in resisting plant stress}

Productivity of plant generally is threatened through increasing biotic and abiotic stresses across the globe, of which some are related to climate change while others are anthropogenic Grover, et al., (2011). The incidences of extreme events like the emergence of plant diseases and pests, frost, heat waves, intense rains coupled with floods, and severe drought are increasingly being witnessed globally Raza, et al., (2019). These incidences are expected to continue increasing due to climatic changes and their impacts are through to severely affect the livelihoods of many people particularly in developing countries. The only option is plant breeding has been utilized to produce genotypes that can tolerate stresses but their success in the field has been limited and is not guaranteed to hold the changing future climatic conditions Msimbira and Smith (2020). In this context, soil microorganisms have unique traits 
that can reduce the severity of the incidences and promote sustainable crop production. The endophytic bacteria and rhizobacteria have shown a high capability of enhancing crop growth and yield by inducing tolerance traits against different forms of stress Omomowo and Babalola (2019) Fig. (38). These microbes exhibit multifaceted functional traits and can colonize and firmly establish themselves in the plant tissues, thereby positively influencing plant growth and survival.

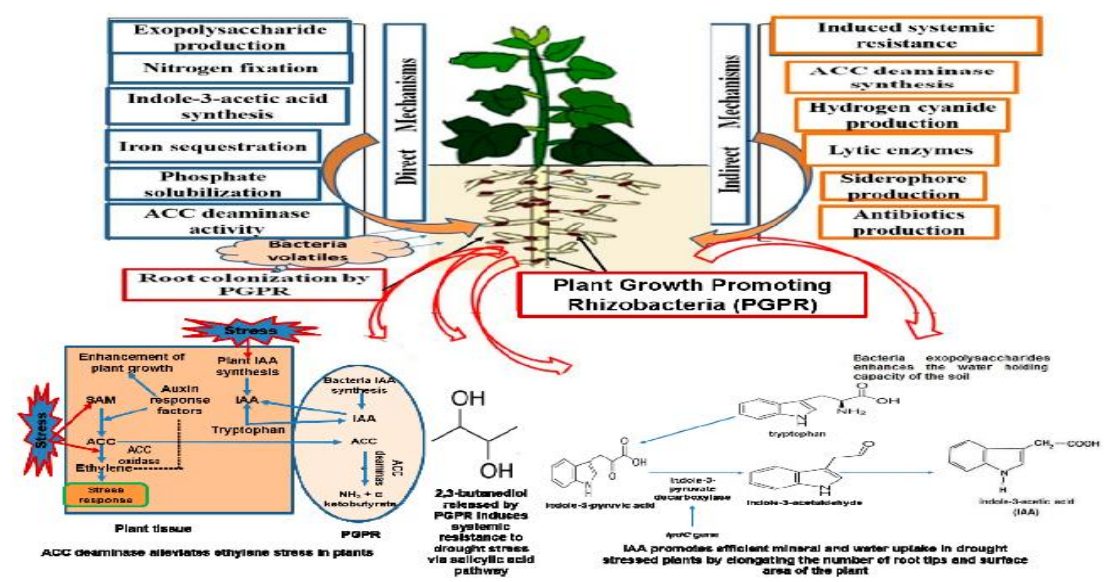

Fig. 38: Represents a diagram of mechanisms used by PGPR in alleviating drought stress and plant growth promotion

Studies have shown that endophytic bacteria can increase the supply of nutrients to their host plants to enable them to manage stress and suppress plant nematodes and insect pests Eid, et al., (2019). Furthermore, can also reduce disease severity and suppress weed growth, thus, improving plant resilience under stress conditions Kim, et al., (2019). According to Gorai et al., (2020), plants with high endophytic and rhizospheric microbial diversity are more resilient to environmental stress as opposed to endophytic-free plants. Additionally, Vigani et al., Vigani, et al., (2019) suggested that endophytic bacteria could sustain their host plants against different forms of stress by developing resistance "power". Endophytic microbes synthesize various secondary metabolites or anti-stress like metabolites that activate the host plant's stress management mechanisms. Some of those metabolites include phytohormones (ethylene and abscisic acid), enzymes (superoxide dismutase and catalase), and organic osmolytes such as glycine, butane and proline Chandran et al., (2020). Some endophytes induce the production of reactive oxygen as scavenger species that deal with free radicals, while others trigger antagonistic actions and defensive pathways to suppress phytopathogens Dubey, et al., (2020). However, Hashem, et al., (2019) warn of possible toxin production by endophytes while suppressing plant stress and hence it would be imperative to rigorously test different metabolites that they produce for animal and human safety. Endophytic bacteria and rhizobacteria also confer stress resilience via induction of plant immune fitness, and biocontrol of destructive insects, pests and phytopathogens. Biological control is described as a mechanism of protecting plants against phytopathogens through the production of bacteriocins, lytic enzymes, antibiotics and siderophores. Endophytic inoculation has been shown to suppress fungal, bacterial, and viral diseases Tewari et al., (2019). Bacillus amyloliquefaciens have shown high potential as a biocontrol agent against powdery mildew in tobacco plants Jiao et al., (2020). Similarly, verticillium wilt disease in cotton that is caused by Verticillium dahliae has been suppressed significantly by the application of Enterobacter spp. in pot and field experiments Berg and Hallmann (2007). According to Beneduzi et al., (2012), rhizosphere and endophytic bacteria suppress diseases by inducing systemic resistance, which is a defensive mechanism developed by plants after stimulation. The use of bacterial endophytes that produce antibiotics in the host makes them very efficient in combating plant pathogens Chandran et al., (2020). Examples of antibiotic compounds are lipopeptides biosurfactants that are synthesized by Bacillus spp. and Pseudomonas spp. According to Wang et al., Wang et al., (2020), antibiotic compounds isolated from different bacterial endophytes affect other organisms by inhibiting cell wall synthesis and ribosomes' small subunit formation Wang et al., (2020). Azospirillum spp. produces plant metabolites and hormones such as auxins in retaliation to stress conditions like carbon limitation, drought stress Chandran et al., (2020), and high acidity and salinity Cassán et al., (2014) Fig.(39). 


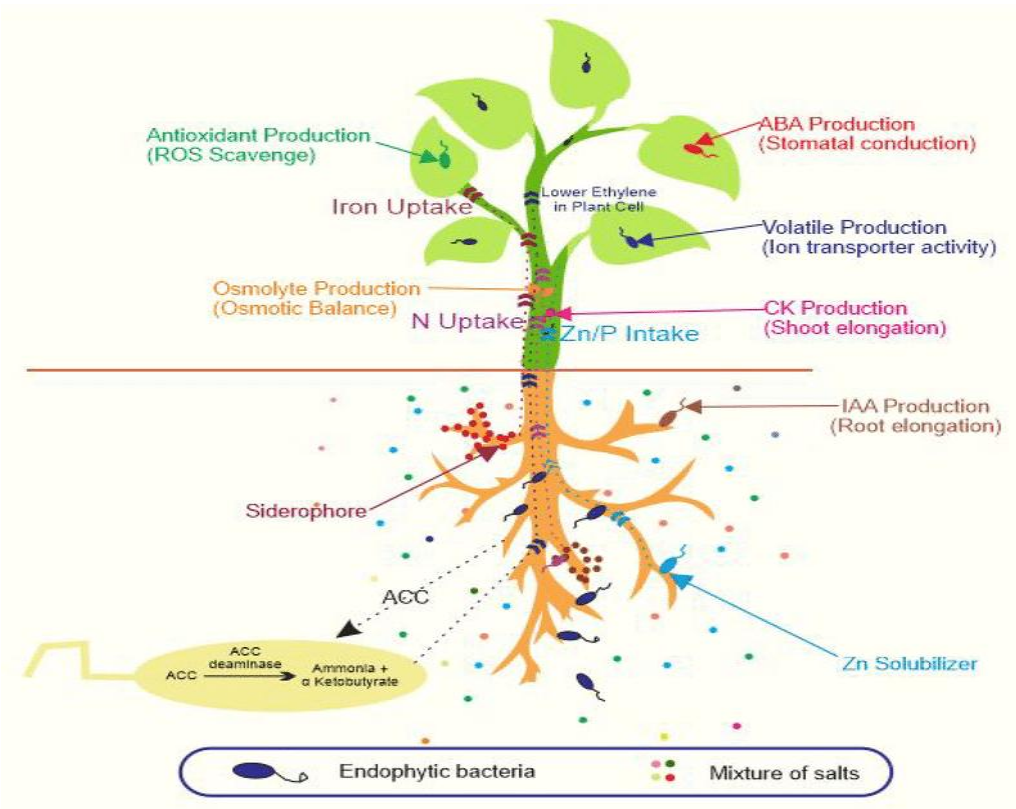

Fig. 39: Illustrates the role of endophytic bacteria in induced salt tolerance by plants. Endophytic bacteria with plant growth-promoting potential counter stress by releasing osmotic pressure, eliminating toxic substances, increasing hormone production such as indole acetic acid (IAA) and cytokines (CK) further enabling plants to recover from stress and to grow normally. Enhanced root-to-shoot communication improves water and nutritional balance, source-sink relationships and stomatal conductance. Stimulating osmolyte accumulation, carbohydrate metabolism and anti-oxidant activity delays leaf senescence, which in turn contributes to photosynthesis After Anukool Vaishnav et al., (2018)

Role of Endophytic bacteria in the adaptation of agricultural crops to saline stress have been successfully used to overcome the negative effect of salts and to enhance plant growth under stress conditions. The beneficial effects provoked by endophytes are osmotic adjustment, detoxification, phytohormones regulation and nutrient acquisition in plants that account for alleviating the effects of salt stress Fig. (39).

Anukool Vaishnav, et al., (2018), stated that endophytes may also enter plants via stomata present on leaves and young stems, lenticels present in the periderm of stems, and roots and germinating radicals and seeds Compant et al., (2010). The mode of endophytic colonization is also categorized into obligate, facultative and passive. Obligate bacteria are present only in seeds and can colonize the whole plant. Facultative bacteria are derived from the soil and, when finding suitable conditions, they colonize plants. Some bacteria enter plants via wounds and cracks, known as the passive mode of colonization. In addition, Rhizobia spp. are also endophytes that colonize the internal plant tissues and form nodules, where the nitrogen fixation process is carried out. Compant et al., (2005), (2008) demonstrated that an endophytic bacterium, Burkholderia phytofirmans, produced endo glucanase and endopolygalacturonase compounds that are involved in localized cell wall degradation and help in bacterial entry through cracks and movement of bacterial cells across the endodermis into the xylem, followed by subsequent colonization of the root interior. These different modes of entry for endophytic bacteria Fig. (40) 


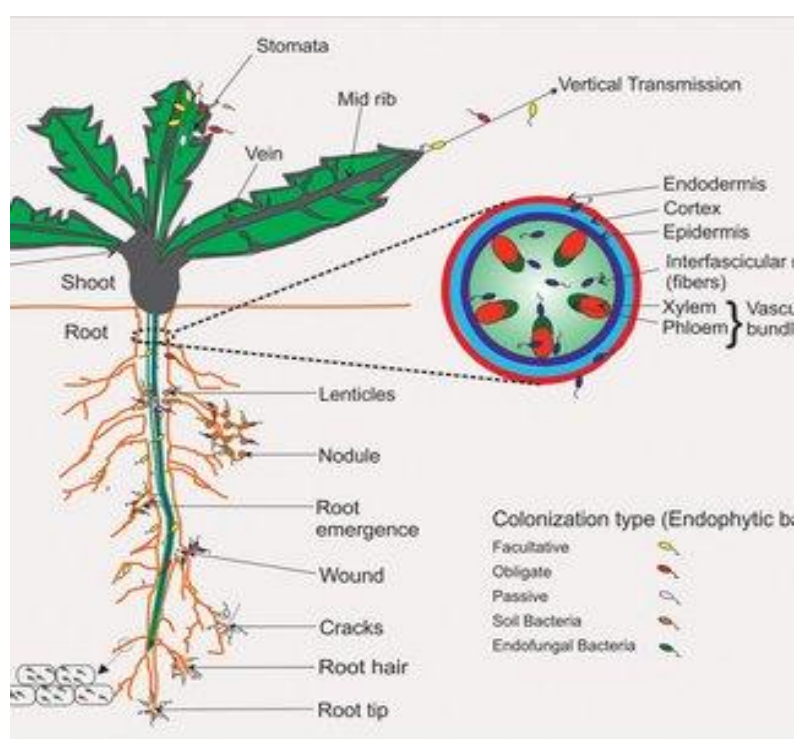

Fig. 40: The mode of entry of endophytic bacteria into different parts of plant tissues. Firstly, they enter through roots, that is, primary and lateral root hair cells, root crack, wounds and nodules. Secondly, they attach to the stomata present in leaves. Endophytic bacteria of one plant gain access to another plant via vertical transmission. After Anukool Vaishnav etal (2018)

Endophytic bacteria and other rhizobacteria can mitigate environmentally induced stresses and enhance plant survival under challenging environmental conditions. These roles are expected to be more relevant with the increasingly adverse effects of climate change on soil quality, health and food production Vardharajula et al., (2017). However, the activity and effectiveness of endophytes depends on plant species, growth stage, age, and other plant genotypic properties, and most importantly, the changing environmental conditions Chaparro et al., (2014).

\subsection{Phosphate solubilization}

Plants require phosphorus $(\mathrm{P})$ as an essential nutrient for growth and development. The deficiency of $\mathrm{P}$ availability in the rhizosphere is a major limiting factor for plant growth. $\mathrm{P}$ is involved in important plant-metabolic processes such as respiration, biosynthesis of macromolecules, energy transfer, and photosynthesis Fig. (41), Mitran, et al., (2018).

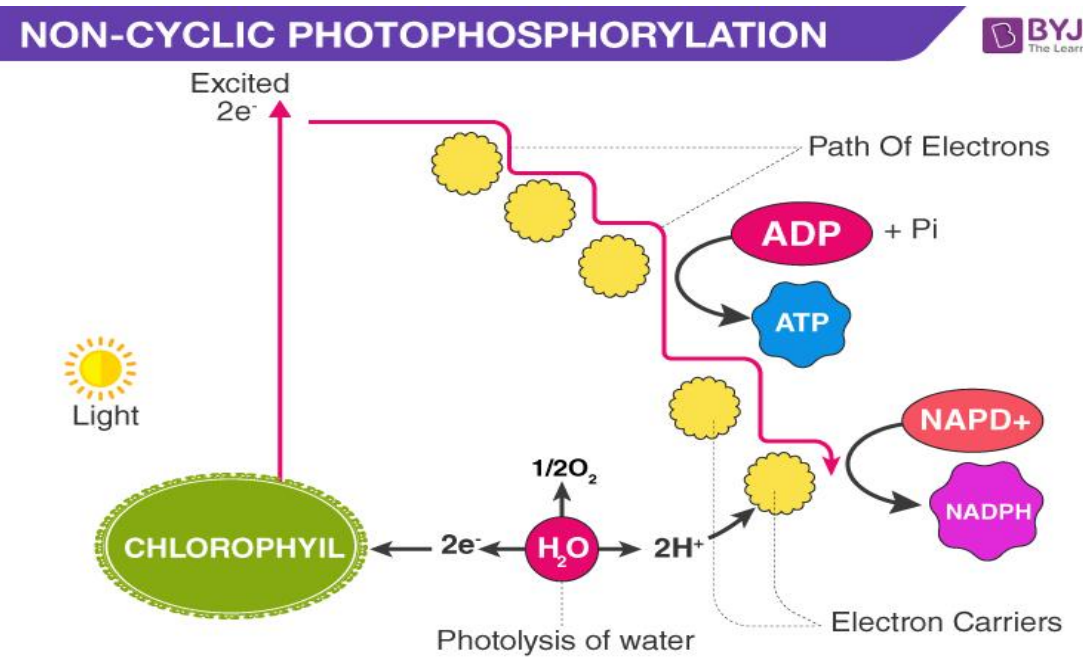

Fig. 41: Represents the photophosphorylation process, which results in the movement of the electrons in a cyclic manner for synthesizing ATP molecules, is called cyclic photophosphorylation, that accomplish the ADP to ATP for immediate energy for the cells. Which taking place in the thylakoid membrane and uses photosystem I and the chlorophyll P700. 
Phosphorus in the soil is often in forms that are unavailable for plant uptake and hence cannot support plant growth. According to Alori et al., (2017), about 95\% of phosphate in the soil is immobilized, insoluble, and/or precipitated into minerals like rock phosphate and tricalcium phosphate. Interestingly, phosphorus applied using inorganic fertilizers end up forming complexes with the soil and hence becoming unavailable for plant absorption Penn and Camberato (2019). To increase P availability in the soil, mineralization and solubilization of phosphate through biological processes are required. These processes are carried out effectively by phosphate solubilizing bacteria, which are part of endophytic bacteria colonizing the plants and rhizosphere Alori et al., (2017). Among the most effective groups of solubilizes include Pseudomonas, Enterobacter, Bacillus, Mesorhizobium, Rhizobium, Achromobacter, and Acinetobacter Suman et al., (2016), Penn and Camberato (2019). Endophytic bacteria promote $\mathrm{P}$ availability by solubilizing the insoluble $\mathrm{P}$ forms using mechanisms such as organic acid production, acidification, ion exchange and chelation Walia, et al., (2017), Fig. (42).

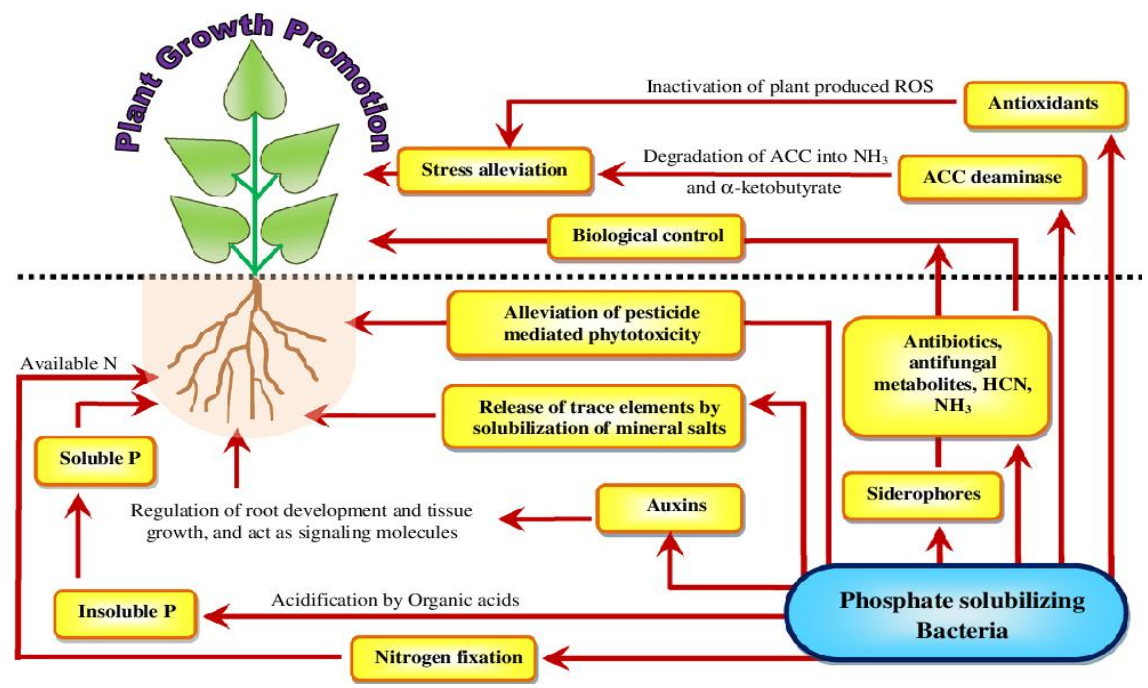

Fig. 42: Illustrates the mechanisms of phosphate-solubilizing bacteria mediated plant growth promotion. ROS reactive oxygen species, ACC 1-aminocyclopropane-1- carboxylate, NH3 ammonia, HCN hydrogen cyanate, IAA indole-3-acetic acid, P phosphate. After Ahemad. (2014).

Ahemad (2014), stated that phosphate-solubilizing bacteria for phosphorus availability for plant growth and development. Generally, substantial amount of phosphorus (P) occurs in soil ranging from 400 to $1,200 \mathrm{mg} / \mathrm{kg}$ of soil, either in mineral forms, e.g., apatite, hydroxyapatite and oxyapatite, or organic forms such as, inositol phosphate (soil phytate), phosphomonoesters, phosphotriesters and phosphotriesters Ahemad et al., (2009). However, the concentration of soluble forms of P in soil is usually $1 \mathrm{mg} / \mathrm{kg}$ or less Goldstein (1994). In addition, it has a very limited bioavailability to growing plants due to high reactivity of phosphate ions in soils. To circumvent this deficiency, phosphatic fertilizers are applied in soils. Nevertheless, most of the applied P in the forms of fertilizers is precipitated; consequently, a very small fraction is available for absorption by plants. As an eco-friendly and economical alternative to provide substantial amount of soluble $\mathrm{P}$ to plants for growth promotion is the exploitation of P solubilization and mineralization traits of PSB. Additionally, PSB not only protect plants from phytopathogens through the production of antibiotics, HCN, phenazines and antifungal metabolites, etc. Upadhayay and Srivastava (2012); Singh et al., (2013), but also promote plant growth through $\mathrm{N}_{2}$ fixation He et al., (2010), siderophore production Ahemad and Khan (2012a, b), phytohormones secretion Misra et al., (2012); Oves et al., (2013) and lowering ethylene levels Jiang et al., (2008); Kumar et al., (2009).

Other endophytic bacteria enhance P solubilization by secretion of complexes in the soil that mineralize organic phosphorus Etesami and Adl (2020). For instance, Burkholderia sp. synthesizes tartaric, citric and oxalic acids that are largely involved in phosphorus solubilization Kong and Hong (2020). During vermicomposting, inoculation of plants using Herbaspirillum seropedicae, Bacillus 
spp., and Burkholderia silvatlantica increases P availability and phosphatase activity dos Santos, et al., (2018) Fig. (43).

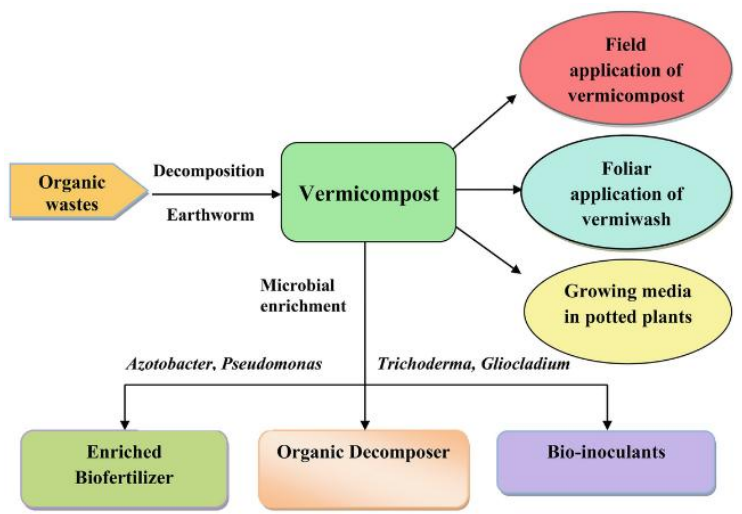

Fig. 43: Illustrates schematic diagram of vermicompost production Vermicompost is a good source of nitrogen $(\mathrm{N})$, phosphorus $(\mathrm{P})$, potassium $(\mathrm{K})$ as well as vitamins, antibiotics, humic acid

Vermicompost is a nutrient-rich, microbiologically active organic amendment that is obtained in the form of castings of ingested biomass by earthworms after undergoing physical, chemical, and microbial transformations. Vermicompost is a combination of the earthworm casts, partially decomposed bedding materials, seeds or cocoons, humic substances, and associated microorganisms that is stabilized to small particles of a peat-like material with high porosity, and with more waterholding capacity and low $\mathrm{C} / \mathrm{N}$ ratio with a very large surface area, which facilitate holding and retaining plant nutrients Dominguez (2004). Vermicompost is a good source of nitrogen (N) Bansal and Kapoor (2000), phosphorus (P) Pramanik et al., (2007), and potassium (K) as well as vitamins, antibiotics, humic acid Pramanik et al., (2007), N-fixing and P-solubilizing bacteria, enzymes such as protease, amylases, lipases, cellulases, and chitinase, and growth promoting substances such as auxins and gibberellins Sinha et al., (2009); Lazcano and Dominguez (2011). The process of breaking down complex organic substrates into a stabilized humus-like substance through the action of earthworms is called vermicomposting.

Besides, bacterial endophytes can assimilate solubilized $\mathrm{P}$, hinder soil $\mathrm{P}$ fixation, and promote adsorption of phosphate into the host plant under phosphate limiting conditions, thus, making it more available for the plants Arif, et al., (2017). Therefore, endophytic bacteria can be used as potential biofertilizers for restoring soil fertility in degraded soils. They are part of the most promising sustainable interventions in agriculture due to their effectiveness and environmentally friendly nature. Because of their efficient interventions in $\mathrm{P}$ solubilization, endophytes remain the most viable biological resource systems that have been identified to date. They have been proven to solubilize inorganic $\mathrm{P}$ into available forms such as orthophosphate improving plant growth and yield in degraded soils Alori et al., (2017).

\subsection{Potassium bioavailability}

Potassium (K) not only provides resilience to both abiotic and biotic stresses, but also plays a key role in plant metabolic and physiological processes Fig. (44). Unfortunately, over $90 \%$ of $\mathrm{K}$ in the soil is unavailable for plant absorption necessitating searching for effective endophytic bacteria and rhizobacteria that solubilize the crucial mineral. Intensive farming, especially in developing countries where farmers do not put adequate strategies to replenish the lost soil $\mathrm{K}$ nutrient after a harvest Liu, et al., (2017), further depletes the limited availability of $\mathrm{K}$ in the soil Bahadur, et al., (2016). 


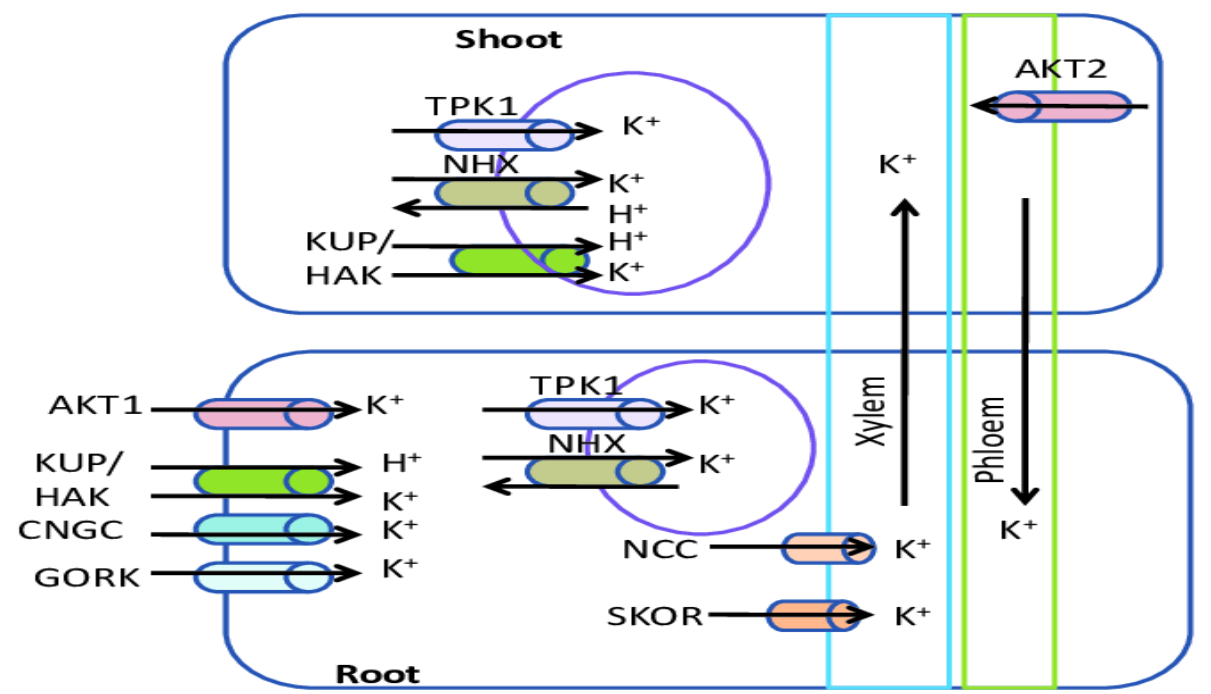

Fig. 44: Illustrates a key role of potassium in plant metabolic and physiological processes. AKT, Arabidopsis (Shaker-type) K+ channel: CNGC: cyclic nucleotide-gated channel; GORK: guard cell Outward rectifying $\mathrm{K}+$ channel; HAK/KUP: high affinity $\mathrm{K}+$ transporters; KAT: Arabidopsis (Shaker type) K+ channel; NCC: non-selective cation channels; NHX: $\mathrm{Na}+$ proton exchanger; SKOR: stelar Outward rectifying K+ channel; TPK: tonoplast two-pore K+ channel. After Ahmad et al., (2014)

According to Minden and Olde Venterink (2019), K deficiency worldwide is considered a major setback in crop production Abou seeda et al., (2020). The fact that farmers apply inorganic fertilizers without knowing the exact standard amount required worsens the situation. Continuous use of chemical fertilizers is environmentally undesirable and a costly affair in maintaining soil fertility status. Therefore, to sustain crop production, it is important to improve $\mathrm{K}$ availability by finding alternative sustainable ways. It has been demonstrated that some endophytic bacteria establish a functional relationship with plants that is holistic in nature and contributes to K bioavailability Liu, et al., (2017). Endophytic bacteria can free potassium from insoluble soil minerals and they are referred to as Ksolubilizing bacteria (KSB). A large diversity of bacterial endophytes that can also carry out $\mathrm{K}$ solubilization includes; Burkholderia spp. Acidithiobacillus ferrooxidans, Flavobacterium spp. Bacillus circulans, Bacillus mucilaginosus, Paenibacillus spp. and Bacillus edaphicus Kumar et al., (2015). The $B$. mucilaginosus and B. edaphicus have demonstrated high capabilities in $\mathrm{K}$ solubilization from Kbearing minerals Teotia, et al., (2016), Meena, et al., (2016) These microbes are known to utilize mechanisms such as chelation, production of organic acids, complexation, acidolysis, exchange reactions and lowering soil $\mathrm{pH}$ to cause the dissolution of $\mathrm{K}$ in the soils Masood and Bano (2016). Several studies have shown that KSBs, under controlled and field conditions, can improve crops' germination, growth, uptake of nutrients, and yields Meena, et al., (2016), Shrivastava et al., (2016). The use of endophytic and rhizospheric bacteria in $\mathrm{K}$ solubilization may not entirely fulfill the $\mathrm{K}$ requirements for the plants as compared to the use of inorganic $\mathrm{K}$ fertilizers Kour, et al., (2020) Fig. (45). 


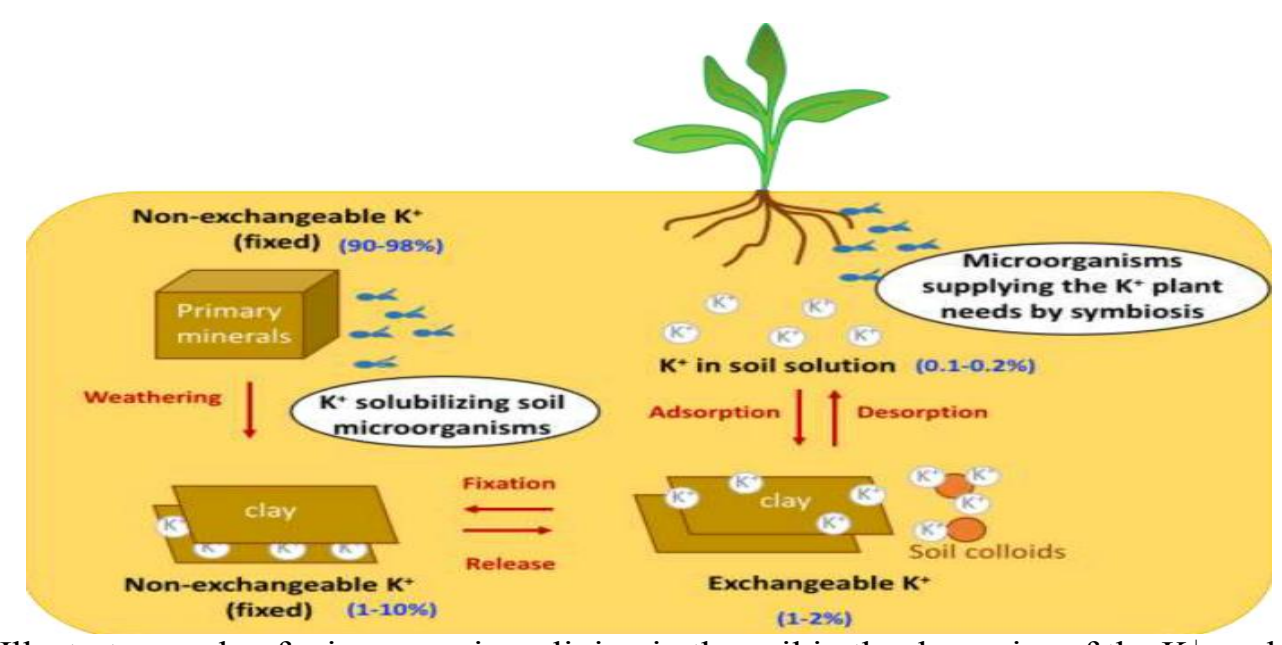

Fig. 45: Illustrates a role of microorganisms living in the soil in the dynamics of the $\mathrm{K}^{+}$cycle. Scheme depicting the microbial strategies to improve $\mathrm{K}^{+}$plant nutrition: $\mathrm{K}^{+}$solubilizing microorganisms and microorganisms establishing symbiotic associations with plants.

However, K availability can be enhanced significantly by the novel approach of using rhizobacteria which are eco-friendly and can greatly cut the use of inorganic fertilizers in crop production Shrivastava et al., (2016). For instance, some K solubilizing bacteria that have been used to improve agricultural soils and productivity of specific crops include Pseudomonas and Bacillus spp. in sorghum (Sorghum bicolor), Pseudomonas spp., Bacillus spp., Micrococcus spp. and Enterobacter spp. in common beans (Phaseolus vulgaris), Mesorhizobium ciceri and P. jessenii in chickpea (Cicer arietinum) Nagpal, et al., (2020), Bacillus, Paenibacillus kribbensis, Stenotrophomonas and Pseudomonas in wheat (Triticum aestivum) Masood and Bano (2016). Bacillus circulans in Oranges (Citrus sinensis), and Bacillus spp., Azotobacter spp., Pseudomonas spp. and Mesorhizobium spp. in various legumes Zahedi (2016), Granada, et al., (2018). The use of endophytic bacteria in the restoration of $\mathrm{K}$ degraded soils is considered an attractive and pragmatic intervention for sustainable crop production. According to Etesami et al., (2017) K bacterial solubilizes are valued resources for lessening $\mathrm{K}$ deficiencies in degraded agricultural soils. However, there is still grossly inadequate experimental evidence on their effectiveness in degraded field conditions. Additionally, studies by Khan, et al., (2017) shows that the approach is not well utilized due to lack of sufficient information and awareness in communities practicing agriculture for their livelihood.

\subsection{Micronutrient mobilization}

Plant growth-promoting rhizobacteria (PGPR) are naturally occurring soil bacteria able to benefit plants by improving their productivity and immunity. These bacteria are associated with the rhizosphere, the part of soil under the influence of plant roots and their exudates, Gray and Smith (2005). The best-known mutualistic symbiotic bacteria are the rhizobia, which establish symbiotic associations with leguminous crop plants, fixing atmospheric nitrogen for the plant in certain root structures known as nodules. Other examples of mutualistic bacteria associated with plants are Frankia, which induces the formation of nodules in actinorrhizic plants, such as Alnustrees, where bacterial nitrogen fixation takes place. Several PGPR have been used worldwide as biofertilizers, contributing to increasing crop yields and soil fertility and hence with the potential to contribute to more sustainable agriculture and forestry Khalid et al., (2009). According to Malusá and Vassilev (2014), a biofertilizer is "the formulated product containing one or more microorganisms that enhance the nutrient status of the plants by either replacing soil nutrients and/or by making nutrients more available to plants and/or by increasing plant access to nutrients. Nonetheless, there are other bacteria able to promote plant growth through other mechanisms, such as the production of phytohormones, environmental stress relief, or the prevention of plant diseases.

Siderophores are organic compounds whose main function is to chelate the ferric iron Fe (III)) from the environment. Microbial siderophores also provide plants with $\mathrm{Fe}$, enhancing their growth when Fe is limiting Crowley (2006) but the exact mechanisms of Fe supply to the plant are not well understood Ahmed and Holmstrom (2014). Siderophores from endophytic Streptomyces promote 
Azadirachtaindica plant growth Verma et al., (2011). Rhizobial strains able to produce siderophores have been reported to be potential biofertilizers, improving the production of carrots, lettuce, peppers and tomatoes Garcia-Fraile et al., (2012) Flores-Felix et al., (2013) Fig. (46).

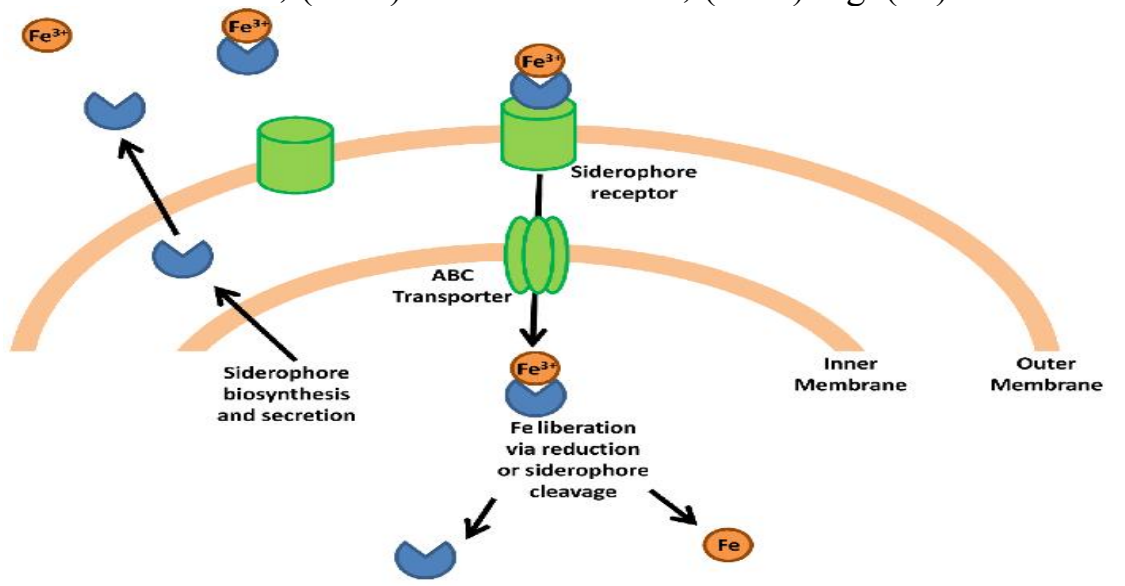

Fig. 46: Illustrates the schematic represents a generic siderophore-mediated iron acquisition system based on common features in Gram-negative species. Siderophores are synthesized and secreted from the bacterial cell where they capture free iron or strip iron complexed to host proteins. The siderophore-iron complex binds a siderophore-specific receptor on the bacterial cell surface and is transported through the extracellular membrane. An ABC transporter transports the siderophore-iron complex into the cytoplasm where the complex is dissociated via reduction or enzymatic cleavage of the siderophore, releasing the iron atom into the intracellular iron pool

One siderophore-producing Phyllobacterium strain promotes the growth and quality of strawberries Flores-Felix et al., (2015). Micronutrient availability in the rhizosphere is influenced by the complex microbe-plant micronutrient interactions. Comprehensive studies of these interactions will improve our understanding of the rhizosphere effects influencing growth and nutrition of plants in the environments with low availability of $\mathrm{Zn}, \mathrm{Mn}$ and other micronutrients. This knowledge will allow integration of abiotic and biotic factors into dynamic agricultural ecosystems that will underpin production of crops with improved micronutrient nutrition as a cornerstone of sustainable agriculture and biofortification for nutrition of susceptible human populations Ma, (2005). Sharma et al., (2003); Vansuyt et al., (2007) Machuca et al., (2007); Miethke and Marahiel, (2007).

Generally, siderophores have high affinity to form complexes with $\mathrm{Fe}^{3+}(1: 1)$. Uptake of the complexes by the cell membrane of both Gram positive and negative bacteria reduces $\mathrm{Fe}^{3+}$ to $\mathrm{Fe}^{2+}$. Later cell membrane expel these ions from the siderophores into the cell Boukhalfa andCrumbliss, (2002) by linking its inner and outer membranes, a mechanism called "gating". Siderophores solubilize iron from unavailable minerals or organic compounds in iron-limited condition Indiragandhi et al., (2008) Fig. (45). Therefore producing extra cellular siderophores which deprive pathogenic organisms produced under $\mathrm{Fe}$ limited condition and form complexes with other heavy metals $(\mathrm{Zn}, \mathrm{Pb}, \mathrm{In}, \mathrm{Cu}, \mathrm{Ga}, \mathrm{Cd}$ and Al) Schalk et al., (2011) and radionuclides including U and Np (Kiss and Farkas, (1998); Neubauer et al., (2000). Heavy metals encourage the bacteria to produce siderophores that chelate the metal to increase Fe availability in the rhizosphere of these soils Wang et al., (2002), elevating heavy metal by phytoextraction through enhancing the activity of antioxidants.

\section{Importance of microorganisms for soil aggregation}

Allison (1968) defined an aggregate as a "naturally occurring cluster or group of soil particles in which the forces holding the particles together are much stronger than the forces between adjacent aggregates". Brewer (1964) considered an aggregate as having an identifiable morphological boundary that distinguishes it from its neighbors. There have many papers describing of the ways in which these aggregates are formed Fig. (47). 


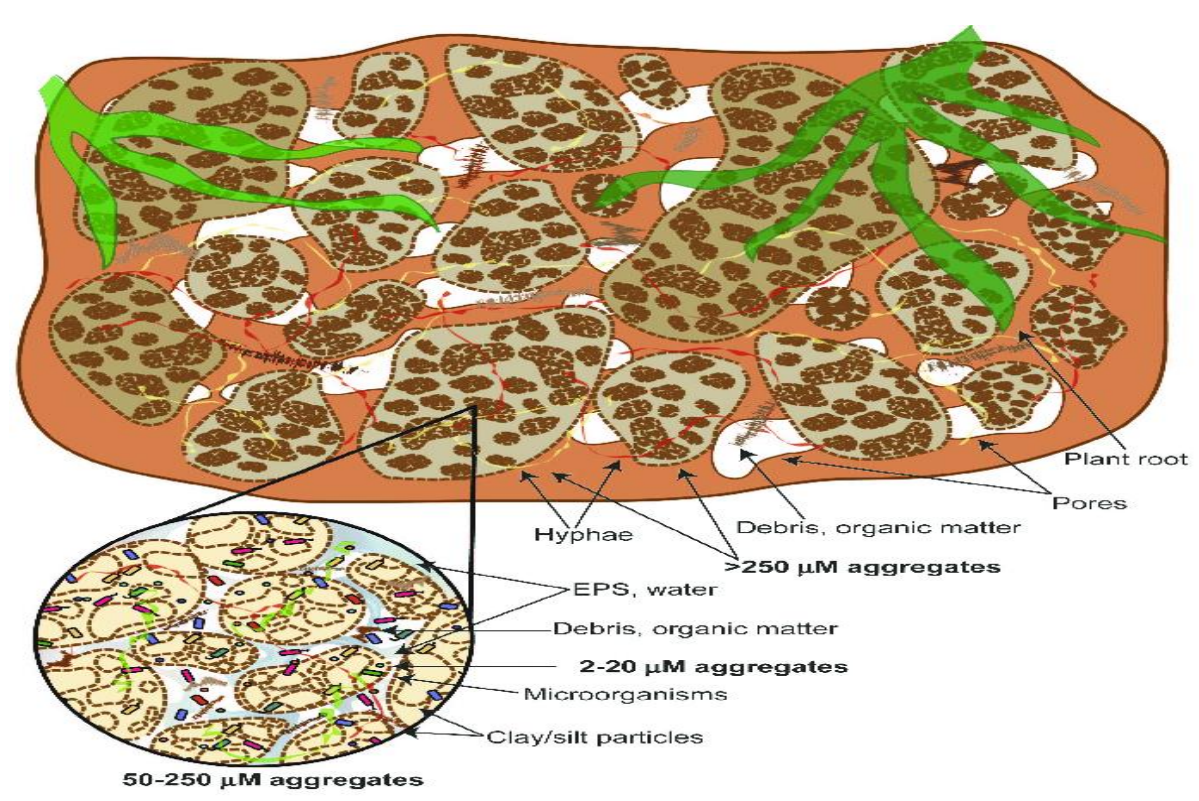

Fig. 47: Represents a diagram of the hierarchical model of soil aggregate classification. Larger aggregates are composed of smaller units, which are formed from even smaller aggregates

These models describe the mechanisms that form and stabilize aggregates: the orientation of the mineral particles, the attractions between these particles, the interactions between these particles and the soil microorganisms and the production of aggregating agents by these microorganisms Emerson (1959); Harris et al., (1963); Dexter (1988) cited by Oades and Waters (1991).

The most important strategies proposed for maintaining and improving soil fertility are those that target the physical properties of the soil. The abundance and stability of the aggregates are critical for several soil functions.

- Plant growth Hamblin (1985); Letey (1985),

- Resistance to erosion Barthès and Roose (2002)

- Soil organic matter turnover Feller and Beare (1997); Chotte et al., (1998); Puget et al., (2000); Six et al., (2001),

- The abundance, activity and diversity of organisms, both mesofauna Quénéhervé and Chotte (1996) and microflora Elliott (1986); Gupta and Germida (1988); Kabir et al., (1994); Chotte et al., (2002).

Consequently, it is still very important to determine the factors controlling the processes of formation and stabilization of aggregates Fig. (48). The importance of soil microorganisms for soil aggregation has been regularly reviewed Griffiths (1965); Lynch and Bragg (1985); Robert and Chenu (1992).
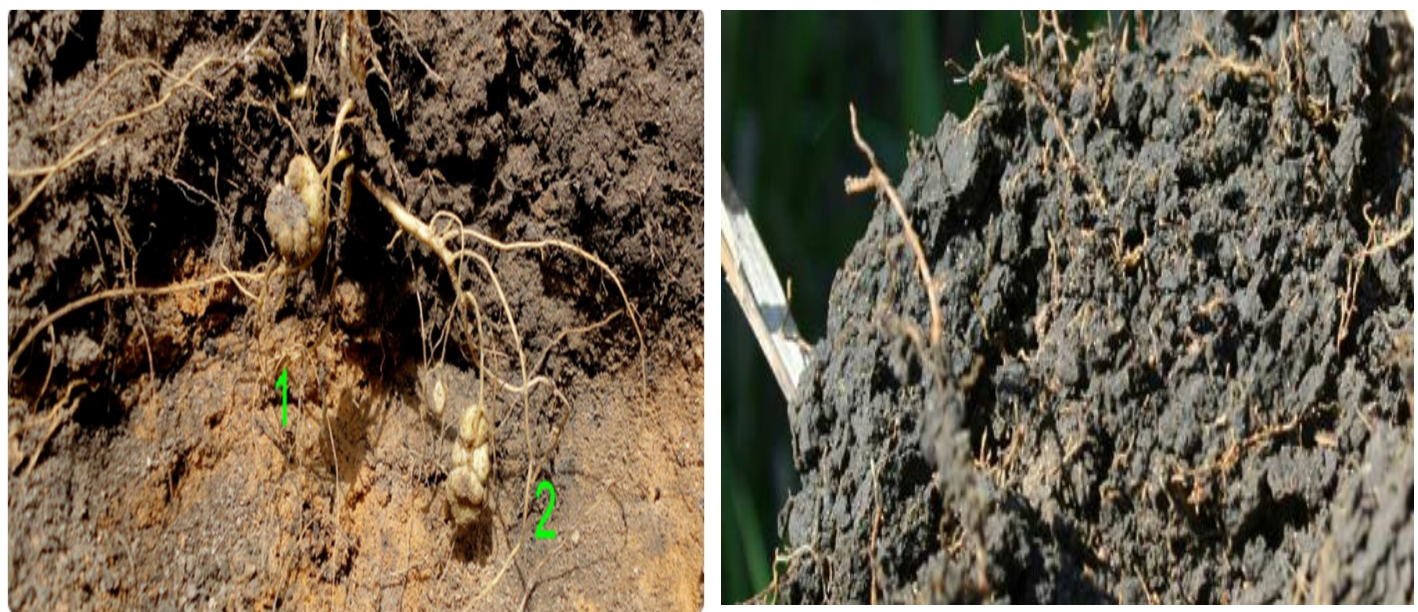

Photo 48: The stability of aggregate is the ability of a soil to regulate the movement and storage of air and water throughout the soil profile. The more stable the soil's aggregates, the more productive the soil. 


\subsection{The role of microorganisms for improving soil structure.}

Many methods have been used to characterize the particle structure of a soil reviewed by DiazZorita et al., (2002). The most commonly used methods; however, use a sieving process to separate the soil particles physically. The sieving may be carried out on a soil sample maintained at its natural humidity level, on a soil sample rewetted by capillary action, on a soil sample immersed in water or on a soil sample dried and then rewetted. In these methods, the air trapped in the pores by the water and rapid wetting exerts a force on the solid mass, causing it to disperse. If the soil is rewetted slowly, the air can escape and so there is less force than when the soil is rewetted rapidly. It should be noted that some authors recommend more vigorous methods, such as using agitator beads, which are particularly useful for studying microaggregates in 2:1 clay soils (e.g., Vertisols; Jocteur Monrozier et al., (1991). There are a number of papers in the literature which show the effect of increasingly vigorous dispersion on the destruction of macro aggregates (> $250 \mu \mathrm{m}$; Cambardella and Elliott (1986); Elliott (1986); Bossuyt et al., (2001). Therefore, the method used for separating the aggregates must be specified when describing the role of soil microorganisms in aggregation. Bossuyt et al., (2001) have observed that the formation of macro aggregates $(>2000 \mu \mathrm{m})$ in an incubated soil with the addition of organic residues in the presence of a fungicide is significantly less than in the same soil without the fungicide In a laboratory study carried out using an apparatus specially designed to measure the effect of a mycorrhizal fungus (Glomus mossae) and the effect of the host plant's roots (Sorghum bicolor) separately on soil aggregation, Andrade et al., (1998) showed that more aggregates were formed when both the roots and the fungus were present (the effect of the mycorrhizosphere). The hyphae on their own (hyphosphere) had less effect than roots on their own (rhizosphere). Although these studies illustrated the effect of fungi, other studies have shown that there is a limit to the effect of fungi on aggregation. Beyond a certain limit, further fungal growth has no further effect on aggregation Bossuyt et al., (2001).

A possible explanation of this observation may be deduced from the work of Rillig and Steinberg (2002).

In this study, the growth of mycorrhizal fungus (Glomus intraradices) hyphae and the production of a metabolite involved in the formation and stabilization of aggregates were monitored. In the no aggregated soil, which was a suboptimal growth environment for the fungus, there was little hyphal growth, but large quantities of the aggregating metabolite were produced. On the other hand, in the aggregated soil, which was more favorable for fungal growth, the opposite results were obtained with the metabolism of the fungus oriented to the production of hyphae. In the suboptimal growth environment, the fungus devotes a part of its metabolism to the production of an "organic cement" to reorganize its local environment and improve its growth conditions. In a large number of field studies, the impact of microorganisms on aggregation has been compared for different types of tillage. In a study carried out over six sites along a climatic gradient (from 380 to $1140 \mathrm{~mm} /$ year rainfall), with conventional tillage and no-tillage agro ecosystems at each site, Frey et al., (1999) found an increase in the fungal biomass and an increase in the median diameter of the aggregates in the soil. The bacterial biomass did not seem to be affected by the tillage. However, statistical analysis of the soil by the authors using the humidity of the soil as a co-variable showed that in this case the soil structure did not have an effect on the fungal biomass. This result can explained by the different metabolisms of fungi and bacteria that adapt differently to changes in the humidity of the soil Fig. (49). 


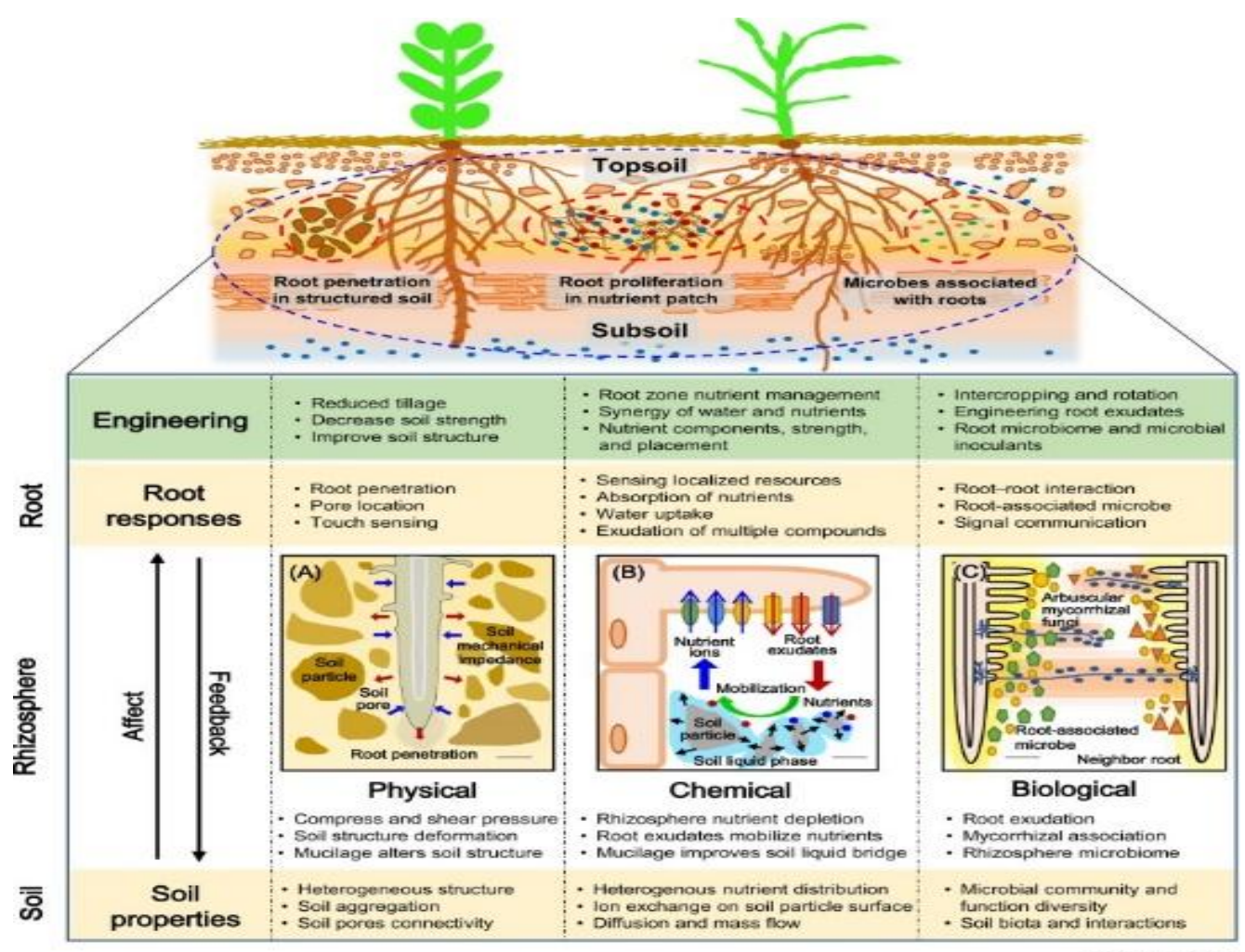

Fig. 49: Represents root architecture with strong responses to localized nutrient patches and deep rooting properties for efficient nutrient and water acquisition
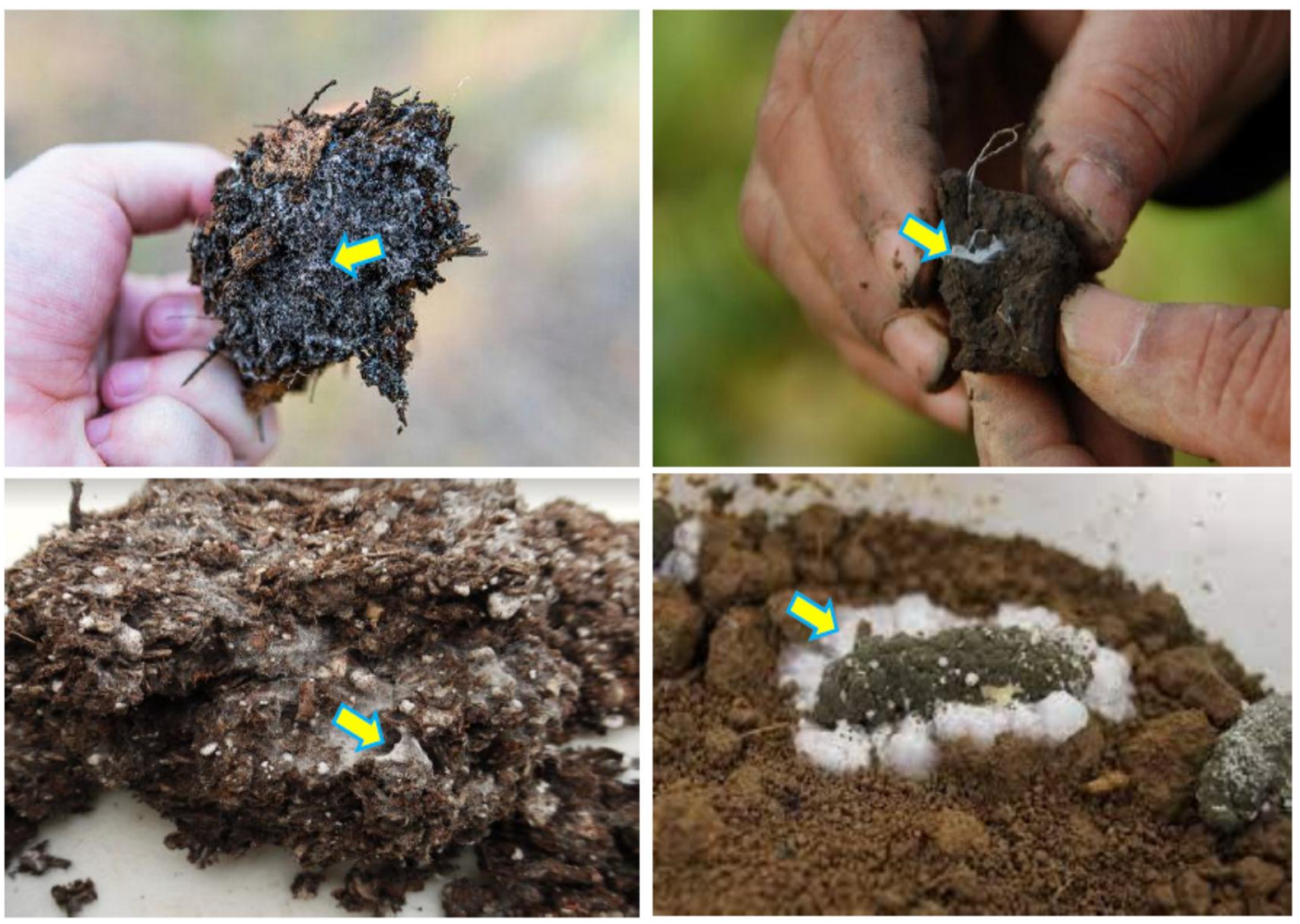

Photos 50: Illustrates the role of Fungi for improving soil structure through their metabolism of soil microorganisms forming and stabilizing soil aggregates

Fungi are known to have a metabolism more suitable than that of bacteria for colonizing the dry environments (surface of litter, pores between aggregates, etc.) Fig. (50), found in no-tillage soils 
Holland and Coleman (1987); Beare et al., (1992). The metabolism of soil microorganisms in the formation and stabilization of aggregates is, therefore, particularly important.

\subsection{Microbial metabolites responsible for soil aggregation}

The effect of mycorrhizal fungi on aggregation, Degens et al., (1996) were unable to distinguish the respective roles of fine roots and fungal hyphae on the mechanical stabilization (enmeshing) of soil particles. Baldock and Kay (1997) suggested that the structural stability of soils was strongly dependent on a fraction of the total carbon content of the soil, without giving details of this carbon pool Fig. (51).

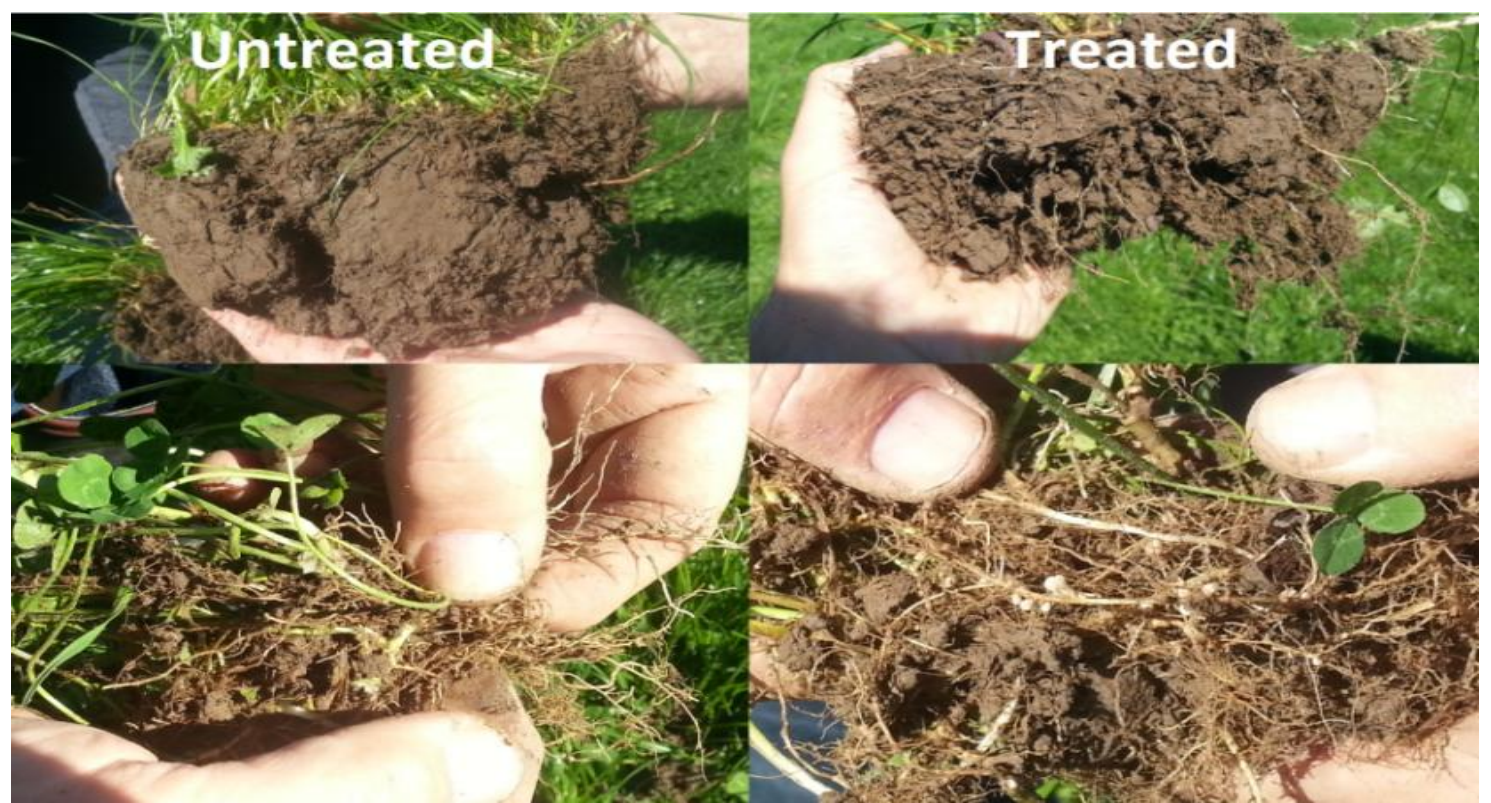

Fig. 51: Illustrates soil structure that refers to soil particles grouped together into aggregates through physical, chemical, and biological processes. Physical-chemical processes including ; Polyvalent cations like $\mathrm{Ca}^{2+}$, magnesium $\mathrm{Mg}^{2+}$ and aluminum $\mathrm{Al}^{3+}$ bind together clay particles. Biological processes including; humus, organic glues created by fungi and bacteria decomposing organic matter and by polymers and sugars excreted from roots. Fungal hyphae and fine roots stabilize aggregates

Haynes and Swift (1990); Gijsman and Thomas (1995); Baldock and Kay (1997) have reported positive correlations between the carbohydrate content and the stability of the aggregates. This correlation, however, does not prove that carbohydrates have a functional role in the aggregation process: Baldock and Kay (1997) reported that removing the carbohydrates did not alter the stability of the aggregates. In a study monitoring the formation of aggregates by microorganisms in response to the addition of starch, Guggenberger et al., (1999) found a very rapid increase in the total mass of the largest aggregates (between 250 and $800 \mu \mathrm{m}$ ) in the first 4 days.They also measured a high level of fungal growth in these aggregates, whereas the microbial biomass was mostly found in the smaller aggregates. After 4 days, the measurements showed a significant reduction in the fungal biomass without, however, a reduction in the mass of the aggregates. It would appear that while the presence of fungal hyphae provides physical binding for the soil particles.

\subsection{Polysaccharides.}

The importance of polysaccharides in the aggregation process has been recognized for several years Robert and Chenu (1992). These papers show that the most active polysaccharides in the formation of aggregates are bacterial metabolites and exudates from roots Fig. (52). 


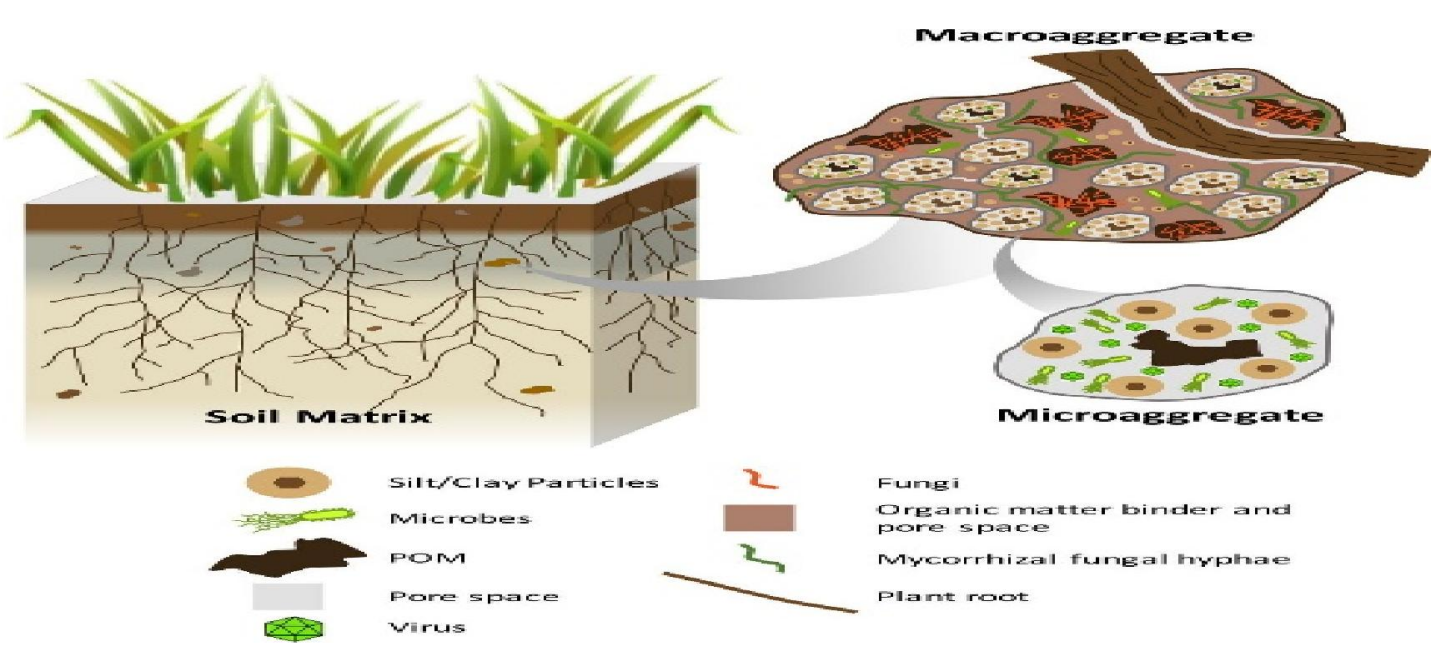

Fig. 52: Simplified schematic of soil horizon and soil macro- and microaggregates. Important properties include local chemistry, surface area, and pore sizes within and between aggregates, surface roughness, and connectivity. POM, particulate organic matter. After Regina et al., (2019).

The effectiveness of polysaccharides stems from their macromolecular structure that enables them to be adsorbed on clay particles and to glue particles together Fig. (53).
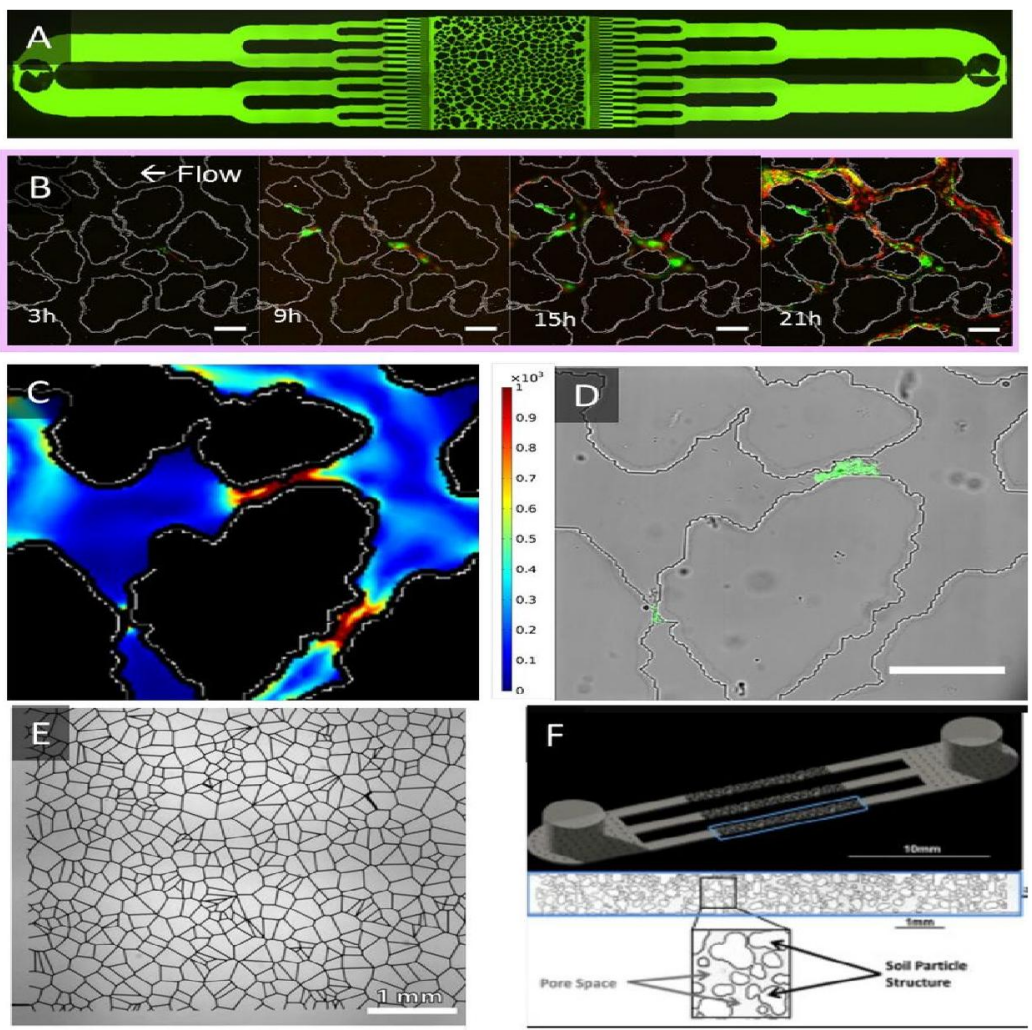

Fig. 53: Illustrates microfluidic approaches can recreate soil features for lab-based studies. (A) A heterogeneous porous medium design replicates the natural shape and distribution of sand particles. (B) Within these pore spaces, bacteria grow (green) and decay (red) under the influence of pressure-driven flow (scale bar $=100 \mathrm{~m}$ ). (C) A consistent particle layout between replicates allows the pore space hydrodynamics to be computationally simulated. (D) This system showed that a soil bacteria initially clogs pores with high shear rates (scale bar $=100$ $\mathrm{m}$ ). (E) A random pore network generated from Voronoi tessellations was used to study twophase flow underground. (F) A microfluidic design created by a particle-generating algorithm was used to study the influence of microbial extracellular polysaccharides on pore space water 
retention. For more information regarding the associated techniques, see references 124 (A to D), 125 (E), and 126 (F). After Regina et al., (2019).

The impact of polysaccharides on mineral particles is usually studied in laboratories. Chenu (1993) showed that the water retention capacity of clay particles is strongly influenced by adding polysaccharides. The strength of this effect depends on the type of polysaccharide and the properties of the clay particles. Adsorption by montmorillonite $(2: 1)$ clays results in a modification of macrostructure, which is more significant for kaolinites than for smectites. Electron microscope images and polysaccharide labeling techniques Thiery (1967) show the role-played by polysaccharides in the stabilization of microscopic aggregates Foster (1981); Feller et al., (1991); Chotte et al., (1994). For the soil as a whole, the importance of polysaccharides in the aggregation process is shown by the correlation between the quantity of aggregates that are stable in water and the quantity of polysaccharides. Many extraction methods have been used Cheshire (1979), but the correlation between stable aggregates and polysaccharides is strongest when the polysaccharides are extracted using hot water or dilute acids Haynes et al., (1991); Angers et al., (1993). In silty soil studies, Puget et al., (1999) showed the predominance of plant carbohydrates in the largest aggregates. Furthermore, this study showed that clay and silt in the stable aggregates $>50 \mu \mathrm{m}$ had high concentrations of microbial carbohydrates, confirming the hypothesis that the stability of the aggregates is partly due to the polysaccharides. Producing by microorganisms decomposing the vegetal residues trapped in the aggregates, characteristics of polysaccharides are such that many studies have been carried out on the feasibility of exploiting them. Most studies have concentrated on the selection and inoculation of the microorganisms that produce polysaccharides. Amellal et al., (1999) noticed that exopolysaccharides produce by soil inoculation with a bacterium selected from the wheat rhizosphere; Alami et al., (1997) on the effects of a rhizobium obtained from the sunflower rhizosphere, Rogers and Burns (1994) on the inoculation of soils with cyanobacteria, and show the advantages of microbiological management of the physical properties of soil.

\subsection{Glomalin}

The characterization of arbuscular mycorrhizal fungi has shown the presence of a large quantity of an organic compound secreted by the hyphae Wright and Upadhyaya (1996). This compound, which is insoluble in water, has aroused the interest of scientists because of its apparent recalcitrance. It is, therefore, to play a key role in soil stabilization Fig. (54).

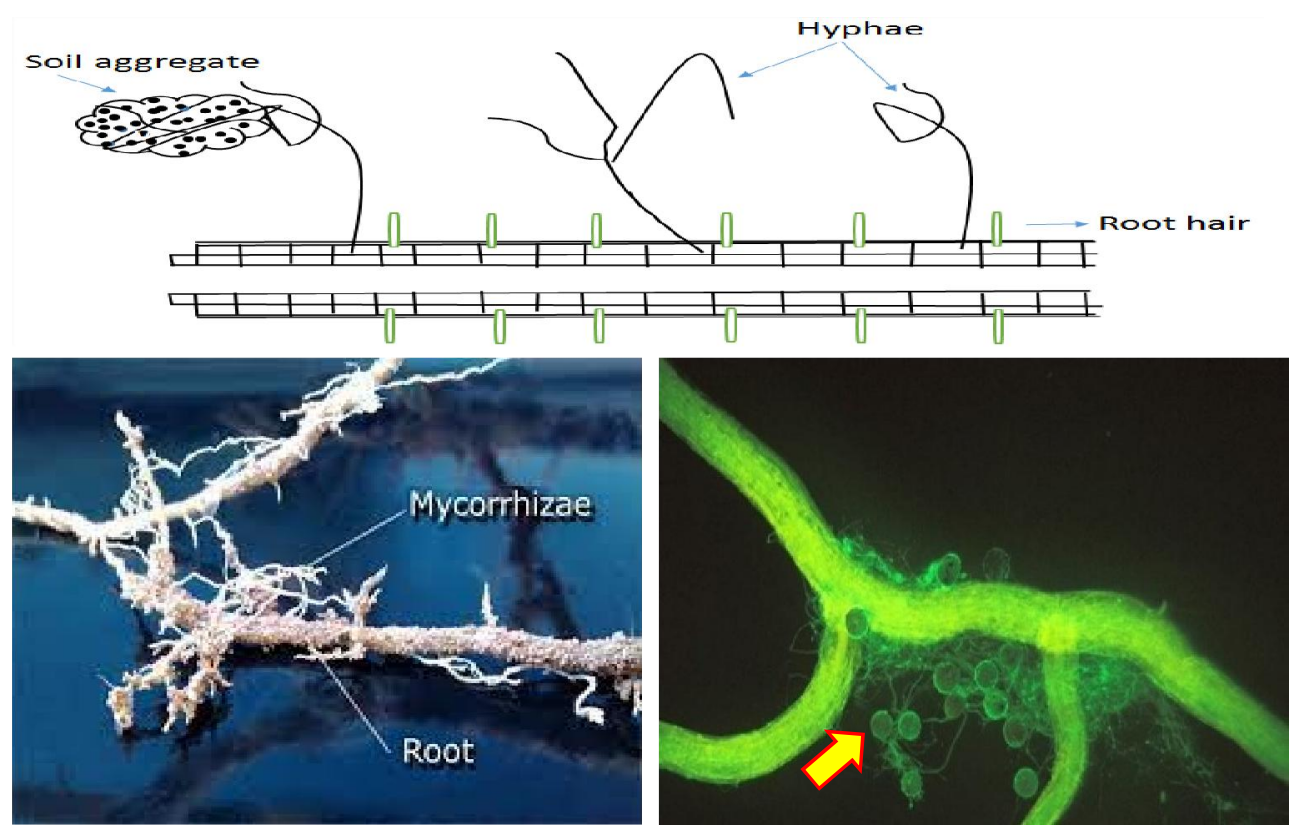

Fig. 54: Represents hyphae collect some soil particles and then coat it with Glomalin to form soil aggregates 
Glomalin is a glycoprotein produced abundantly on hyphae and spores of arbuscular mycorrhizal (AM) fungi in soil and in roots. Glomalin can contribute to as much as $27 \%$ of the soil carbon especially in temperate zone. By gluing soil particles together, this protein also helps retain other carbon containing compounds and protects them from decomposing as well Fig.(53). The early work concentrated on developing an extraction and identification method based on the methods used for proteins Wright and Upadhyaha (1998). The method relies on the extractability and solubility of the fractions of this fungal metabolite. Normally two fractions, whose solubility depends on the concentration of the solvent, are separated. One fraction is easily extractable Glomalin (EEG) and the fraction extracted with the highest concentration of solvent is total Glomalin (TG). Glomalin is a glycoprotein having N-linked oligosaccharides and tightly bound iron. It is insoluble and possibly hydrophobic in its native state Wright et al., (1996) Fig. (55).
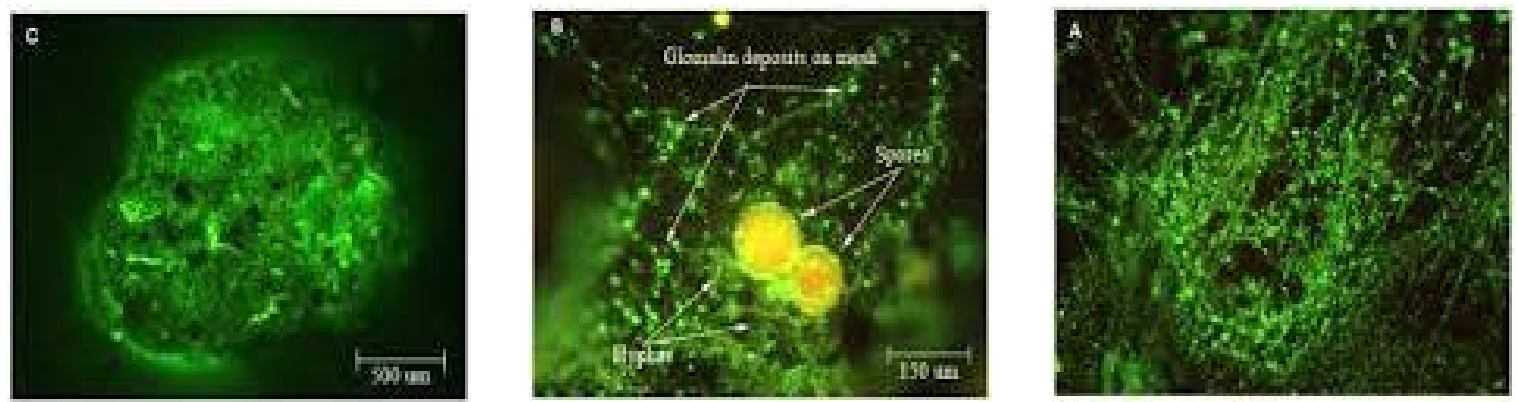

Fig. 55: Illustrates the monoclonal antibody against Glomalin is used in an immunofluorescence assay to indicate where Glomalin is located on fungal hyphae (A and $\mathbf{B}$ ), Claroideoglomus etunicathum spores $(\mathbf{B})$, and a $1 \mathrm{~mm}$ soil aggregate $(\mathbf{C})$ by binding to Glomalin and then binding to an IgM antibody conjugated to fluorescein isothiocyanate which glows green under blue light. After Kristine and Jonathan, (2013).

Glomalin can be detected in situ using immunofluorescence. Wright (2000) used a monoclonal antibody produced from Glomus intraradices and indirect immunofluorescence to detect the Glomalin on the surface of the hyphae and soil aggregates. This work showed that Glomalin is detected on the mycorrhizal hyphae and on the surface of the aggregates. A number of studies have confirmed the role of this fungal metabolite in the formation and stabilization of aggregates Wright and Upadhyaya (1998); Bird et al., (2002); Rillig and Steinberg (2002). One recent study has paid particular attention to defining the roles of root architecture, fungal hyphae and the Glomalin for aggregate stability Fig. (56). When Glomalin is extracted, its properties will certainly change. It is, therefore, difficult to assess its role in the formation and stabilization of aggregates. Rillig et al., (2002) compared the effect of several mycotrophic plants on aggregation. They used a path-model previously used to test for causal interaction among biological factors on soil stabilization Jastrow et al., (1998). They concluded that the production of Glomalin by the hyphae had a stronger effect than the direct action of enmeshing. This conclusion does not conflict with the findings that the hyphae have an effect on the formation of aggregates Tisdall and Oades (1982). 


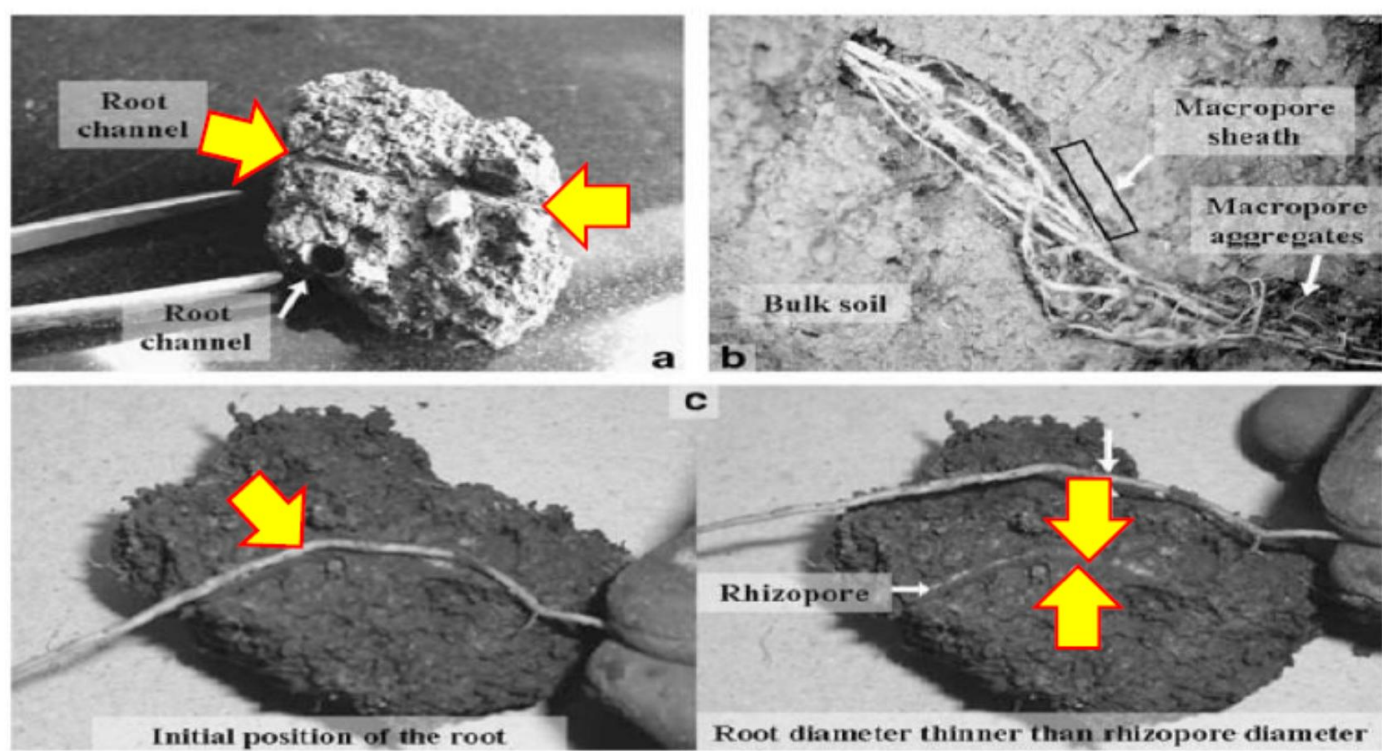

Fig. 56: Impact of root architecture for stabilization of soil aggregates

\subsection{Lipids}

Lipids play an important role in the aggregation processes is less well documented than for other compounds Capriel et al., (1990); Dinel et al., (1991). Monreal et al., (1995) compared the abundance of aggregates that were stable in water and the concentration of organic compounds (carbohydrates, lignin, lipids) in two agro ecosystems (wheat fallow rotation versus continuous wheat). The results showed that the abundance of aggregates $>250 \mu \mathrm{m}$ strongly correlated with the lipid concentration. The presence of lipids in the aggregates improves their resistance to slaking, as lipids are hydrophobic Paré et al., (1999) Fig. (57). Jiefei et al., (2019) reported that soil water repellency (SWR) could interrupt water infiltration that may decline plant growth and potentially trigger soil erosion. Until now, research has been mainly focused on understanding the mechanisms of SWR at different scales by observation and modelling studies. They also stated that Soil characteristics are strongly related to the severity of SWR, particularly in soil organic matter and soil moisture. The presence of a higher amount of hydrophobic organic compounds and lower soil moisture content lead to higher water repellency. Suggesting that the interaction at the nanoscale between organic compounds and water molecules primarily determines the persistence of SWR. The repeated alternation of drying-wetting process largely modifies the relationship between water molecules and soil particles that affects the possibility of SWR from hydrophilic in wet condition to hydrophobic in dry condition. Within ecosystem scale, vegetation and microbes are original sources of SWR-inducing compounds influencing the distribution and prevalence of SWR. Nevertheless, the challenge of global climate change, drought and warming can increase SWR. Extreme SWR induces more serious runoff and overland flow that is enhanced by intensive precipitation.

The potential for improving the physical properties of soils provided by the plant rhizosphere and its microbial community has been exploited for a long time. This improvement has been described in recent papers which underline the continuing usefulness of this approach Haynes and Beare (1997); Caravaca et al., (2002a, b), (2003). These papers show clearly that the presence of plants with their natural or introduced symbiotic fungal community encourages the formation of stable macroaggregates. However, the physical properties of soils improved by using non-mycotrophic plants. Haynes and Beare (1997) observed the same increase in the quantity of stable aggregates in the presence of mycotrophic and non-mycotrophic plants. The stimulation of saprophytic fungal communities by the root exudates partly explains this result 


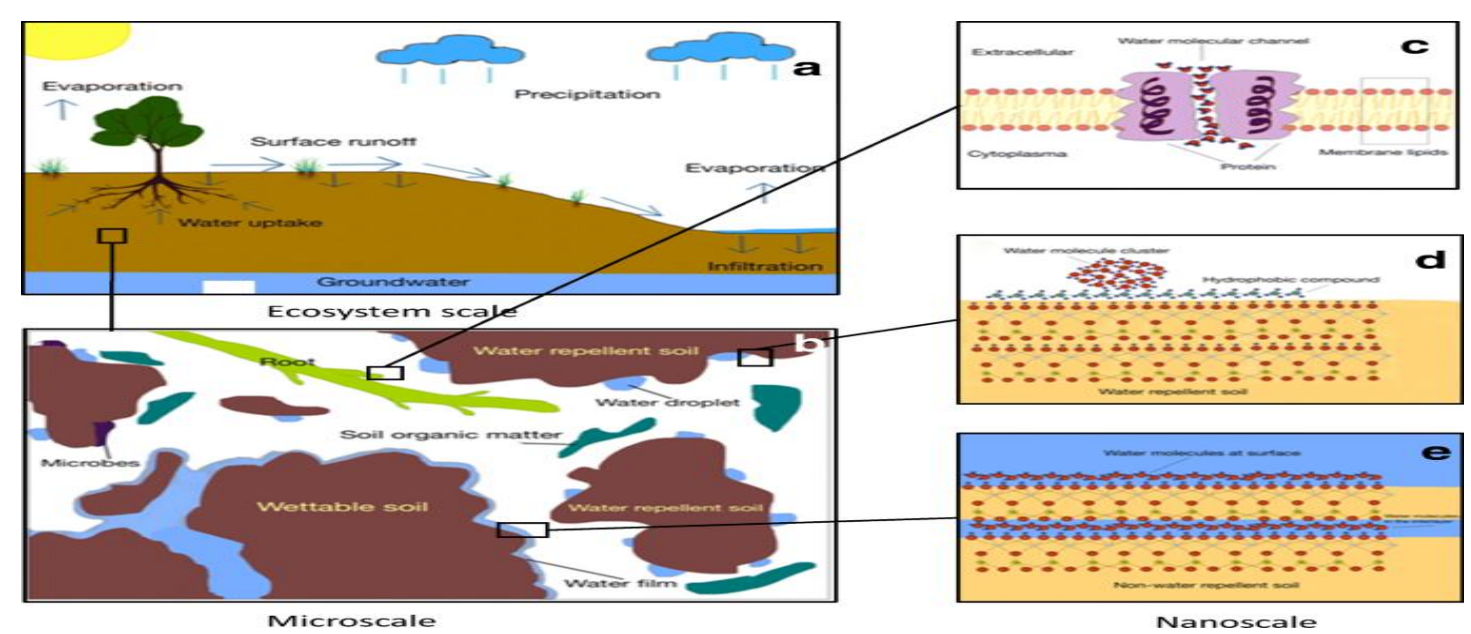

Fig. 57:A:The infiltration of surface water is interrupted by the occurrence of SWR that declines soil water content and impact the water and nutrient uptake of plants. It may enhance evaporation and surface runoff that would potentially influence the whole ecosystem. B: In soil, due to the irregular distribution of soil organic matter derived from plants and microbes, water repellent soil represents a heterogeneous wetting pattern. Water droplets scatter on hydrophobic surfaces and soil water forms a water film on wettable surface. $\mathbf{C}$ : Water can rapidly pass a water channel made of proteins (Aquaporin) on the membrane of plant root cell. D: The water molecules orientate when passing this transmembrane water channel Tajkhorshid et al., (2002); Reichow et al., (2013). Hydrophobic compounds coating the particle of clay soil (kaolinite) surface resist water molecules that cluster on the surface. $\mathbf{E}$ : Water molecules can distribute evenly on the soil surface without the occurrence of hydrophobic compound. After Jiefei et al., (2019).

\subsection{Organic residues}

Organic materials has been studied to investigate the impact on aggregation Tisdall et al., (1978); Schlecht-Pietsch et al., (1994); Roldan et al., (1996); Par'e et al., (1999); Sonneleitner et al., (2003), Abou seeda (1982). Results show that organic amendments have a positive effect on aggregation. On tropical soils, Spaccini et al., (2003) reported that organic amendments proved to be an effective strategy for improving the structure of soils with low stability. However, it should be noted that this positive effect varies depending on the type of clay Denef et al., (2002). This study showed that the increase in stable aggregates $(>250 \mu \mathrm{m})$, after the addition of exogenous organic matter, is greater in a soil where the clay content is a mixture of 2:1 and 1:1 clays in comparison with the increase in soil with 1:1 clays. In a mixture of 2:1 and 1:1 clays, it is probable that electrostatic forces are added to the effects of the microbial metabolites from the decomposition of the added organic matter in forming and stabilizing the aggregates Fig. (58).

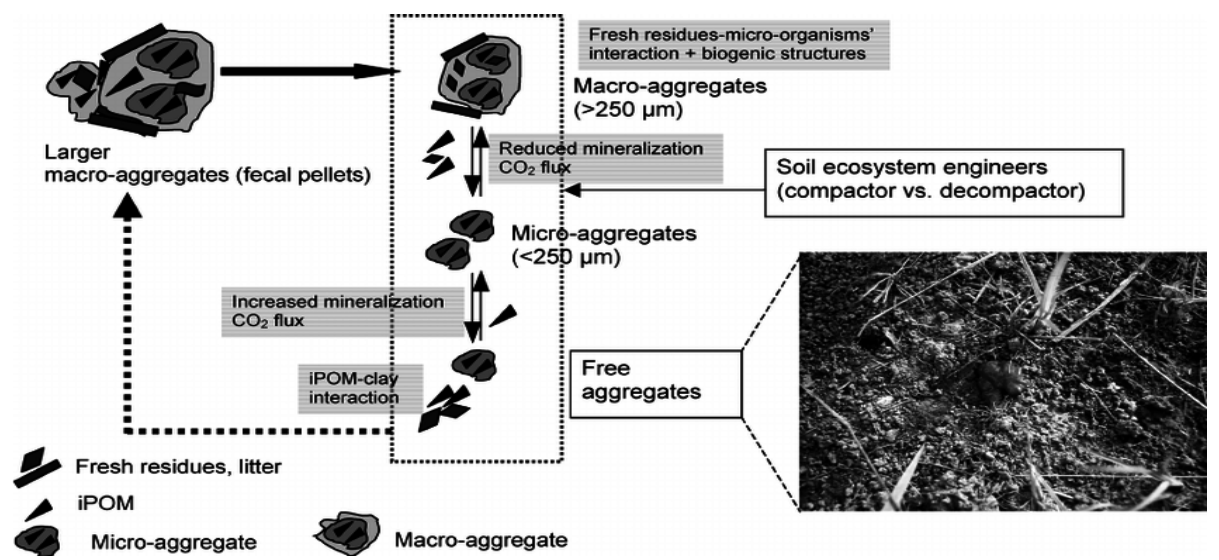

Fig. 58: Illustrates a model of aggregate formation dynamics and the role of large invertebrates (soil ecosystem engineers) in the process. The caption (from Jiménez) shows the soil surface under savanna vegetation fully covered with earthworm casts and free aggregates once these structures are destroyed by both abiotic and biotic processes. 


\section{Climate change and their effects on microorganisms}

Climate changes is forward direct and indirect effect on speed up or slow down terrestrial microbial community composition and their functions. As the temperature increases microbial community structures are altered and processes as respiration, fermentation, and methano-genesis are accelerated Fig. (59).

The impact of climate change for biotic and abiotic components are the risk of injury, illness, death from the resulting heat waves, wildfires, intense storms, floods rises, distinction, natural disasters, extreme heat, poor air quality, drought, spreading and emerging diseases are included. The effect of bacteria, fungus, algae and archea on climate

Change, are accelerate global warming through organic matter decomposition and finally increase the flux of $\mathrm{CO}_{2}$ in atmosphere Swati et al., (2014), Weiman, (2015). Microbial decomposition of soil carbon is producing a positive feedback to rising global temperatures. Microbial biomass and enzymes are powerful tool to stimulate warming because decompose carbon based organic matter efficiently and release toxic compounds to environment. At the same time, prevent climate change. Temperature directly affect enzyme activity and microbial physiological property.

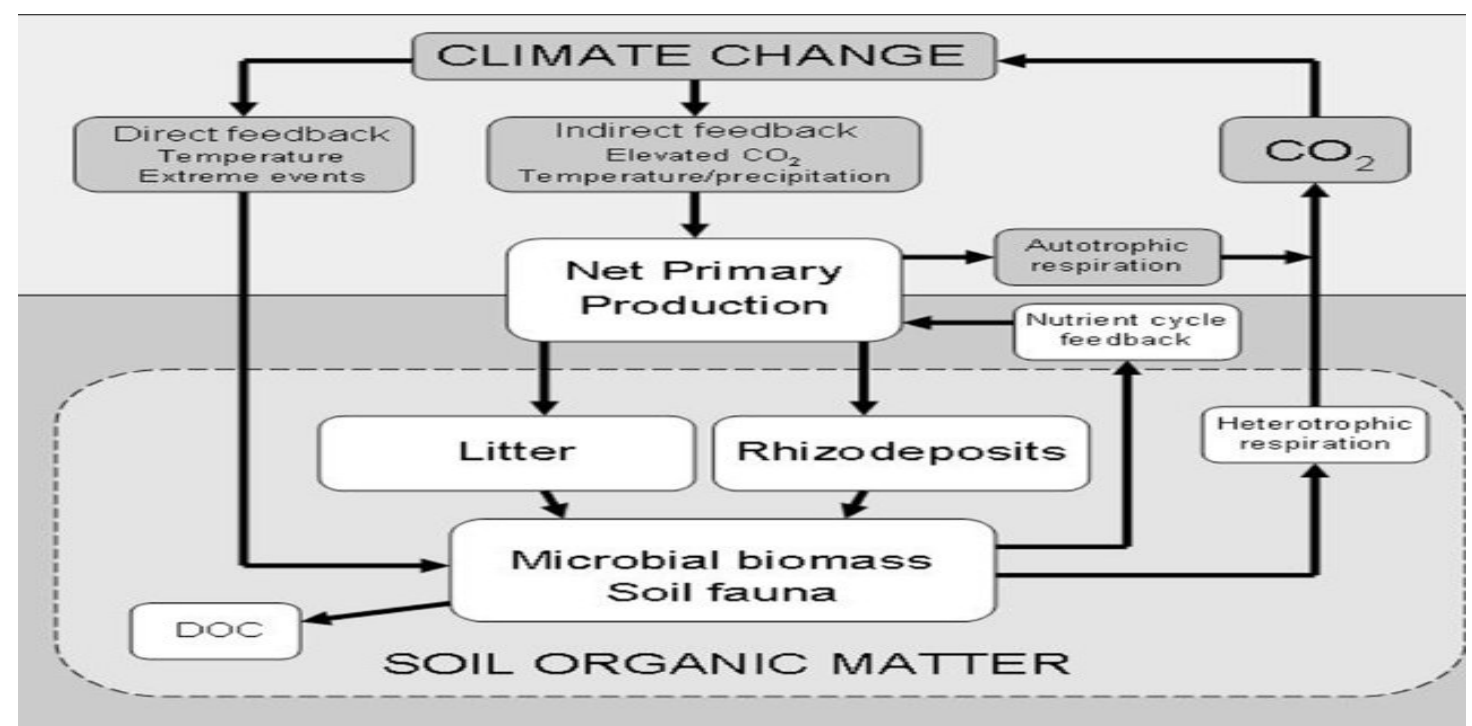

Fig. 59: Represents the direct and indirect effects of climate change on soil microbial communities and feedback to the Earth's carbon dioxide production

Efficiency of soil microorganisms in using carbon determines the soil carbon response to climate change Allison et al., (2010), Bradford et al., (2008). Microbial community composition, abundance, and function is altered when microbes are exposed to new extremes' in Environmental condition; that is environmental change or global warming/climatic disturbance has an effect on microbial ecology, ecosystem structure, and function. Moreover, significant changes also happen through over time in their functional genes and traits. This kind of effect/influence occurs under on each biogeochemical cycle. Yergeau et al., (2012), Sayer et al., (2017).

\subsection{Mechanisms to solve climate change}

Microbial processes have a central role in the global fluxes of the key biogenic greenhouse gases (carbon dioxide, methane and nitrous oxide) and are likely to respond rapidly to climate change. Microorganisms regulate terrestrial greenhouse gas flux. This involves consideration of the complex interactions that occur between microorganisms and other biotic and abiotic factors Fig. (60). 


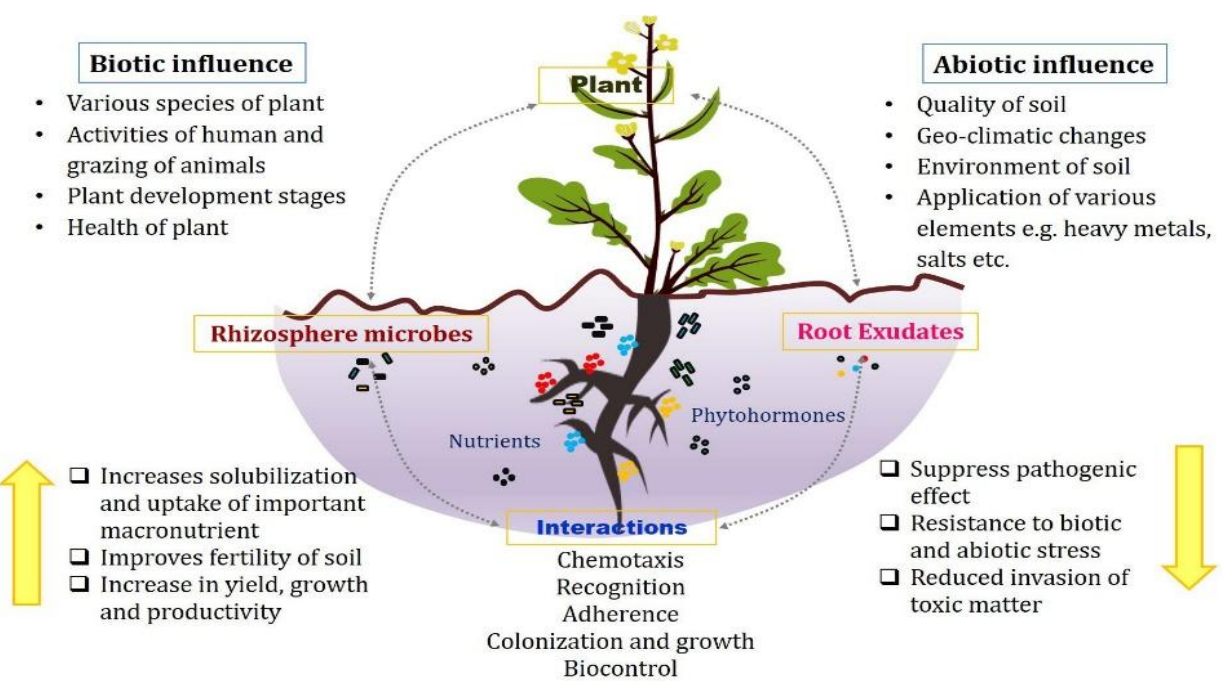

Fig. 60: Association in the rhizosphere between plant roots, microbes, and root exudates under biotic and abiotic influences.

The potential to mitigate climate change by reducing greenhouse gas emissions through managing terrestrial microbial processes is a tantalizing prospect for the future. It is widely accepted that microorganisms have played a key part in determining the atmospheric concentrations of greenhouse gases Singh et al., (2010), Zimmer (2010). The major feedback response mechanism for climate change by changing their microbial community structure and composition solve this kind of environmental problem. Simply, by using nutrient cycling processes and stimulating their functional genetic material for degrading and eliminating chemicals or gasses that leads to global warming Zhou et al., (2011). When microbial communities and biogeochemical cycles are linked together act as a good mechanism to solve climate change. Microorganisms are very important to use greenhouse gases as energy source and build their cell Singh et al., (2010) Fig. (61).

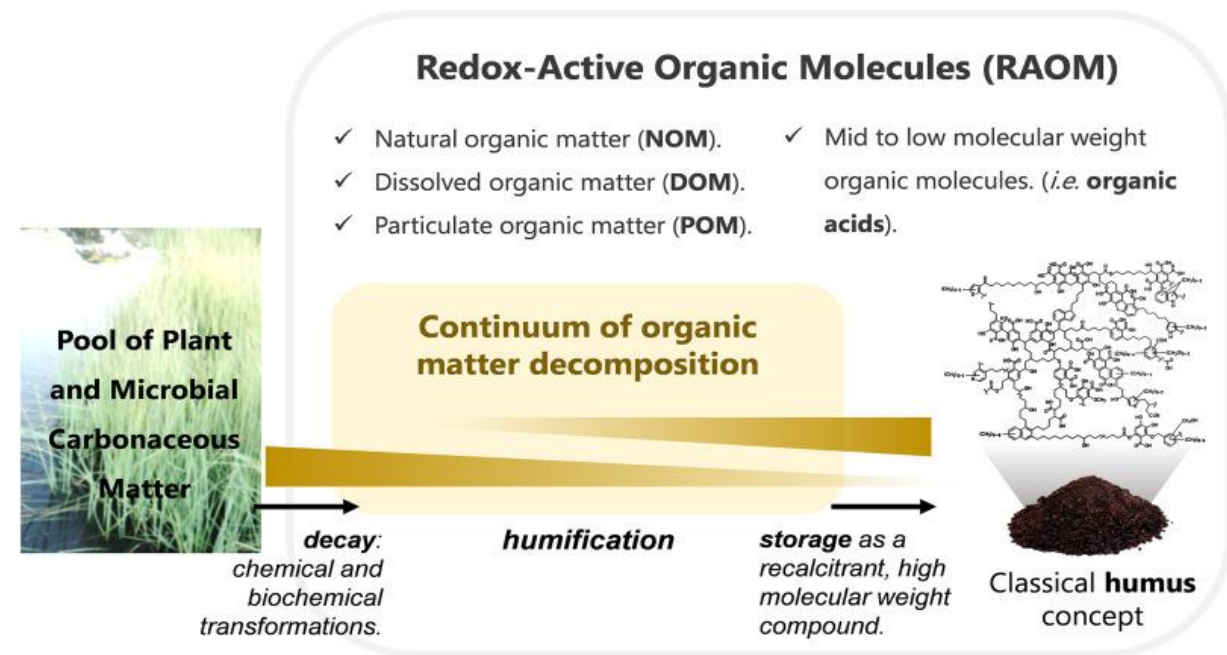

Fig. 61: Illustrates the role of humic substances in mitigating greenhouse gasses

\subsection{Microbial communities and carbon cycle}

The global carbon cycle is mainly depend on microbial communities that fix atmospheric carbon, promote plant growth, and degrade or transform organic material in the environment. Large amounts of organic carbon are currently locked in high latitude permafrost, grassland soils, tropical forests and other ecosystems. In another hand, microorganisms play key role in determining the longevity and stability of this carbon and whether or not it is released into the atmosphere as greenhouse gas that means mediate the processes of carbon cycle Weiman, (2015). Microorganisms are slow down global warming and implications for crucial ecological processes such as nutrient cycling which rely on microbial activity. This is why the microbial enzyme systems involved are viewed as key 'engines' that 
drive the Earth's biogeochemical cycles. The balance between photosynthesis and respiration dominates the terrestrial carbon cycle Fig. (62).

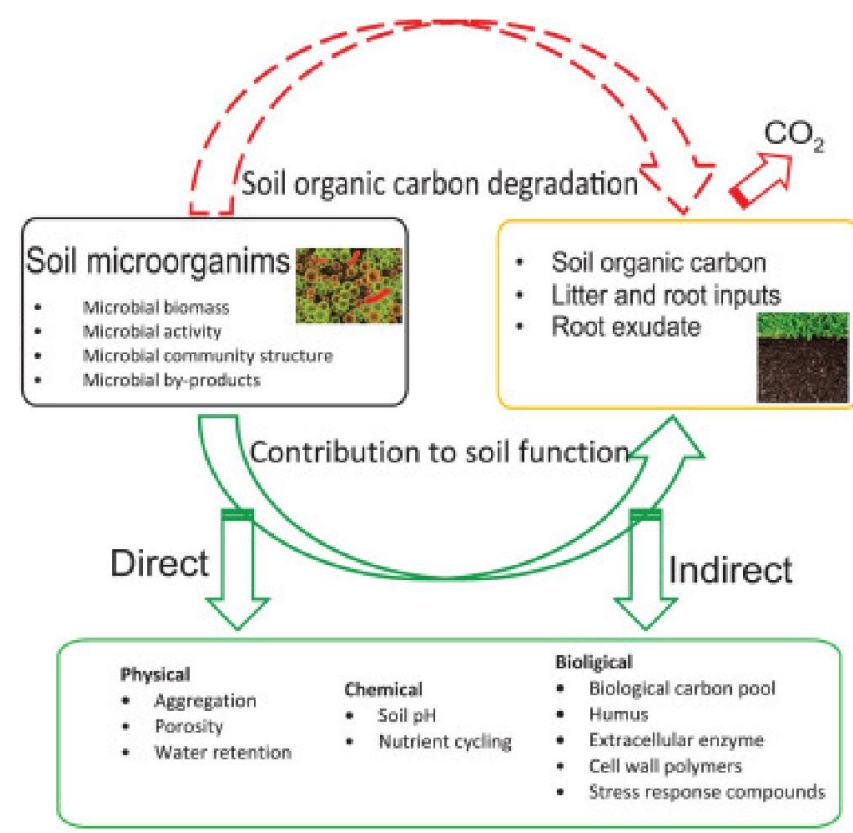

Fig. 62: Illustrates carbon cycle the microorganisms are involved in the process of breaking down and transforming dead organic material into forms that can be reused by other organisms

Carbon is transferred from the atmosphere to soil via 'carbon-fixing' autotrophic organisms such as photosynthesizing plants, photo and chemoautotrophic microorganisms these are synthesis atmospheric carbon dioxide in to organic material. Practically, microorganisms use carbons for their metabolism substrate due to these highly consume atmospheric carbon dioxide Fig. (63). Soil microorganisms essential for transfer carbon between environmental compartments to fulfil their fundamental goal mainly to achieve survival through reproduction. Thus, microbes utilize different organic and inorganic forms of carbon as carbon and energy sources. The balance between photosynthesis and respiration Prosser (2007), Falkowski et al., (2008) dominates the terrestrial carbon cycle. Carbon is also found in the earth's crust, primarily as limestone and kerogens. Chemoautotrophic is an organism obtaining its nutrition through the oxidation of non-organic compounds as opposed to the process of photosynthesis. Carbon in the earth's atmosphere exists in two main forms: carbon dioxide and methane, carbon dioxide is dissolve directly from atmosphere in to water bodies Fig. (64).

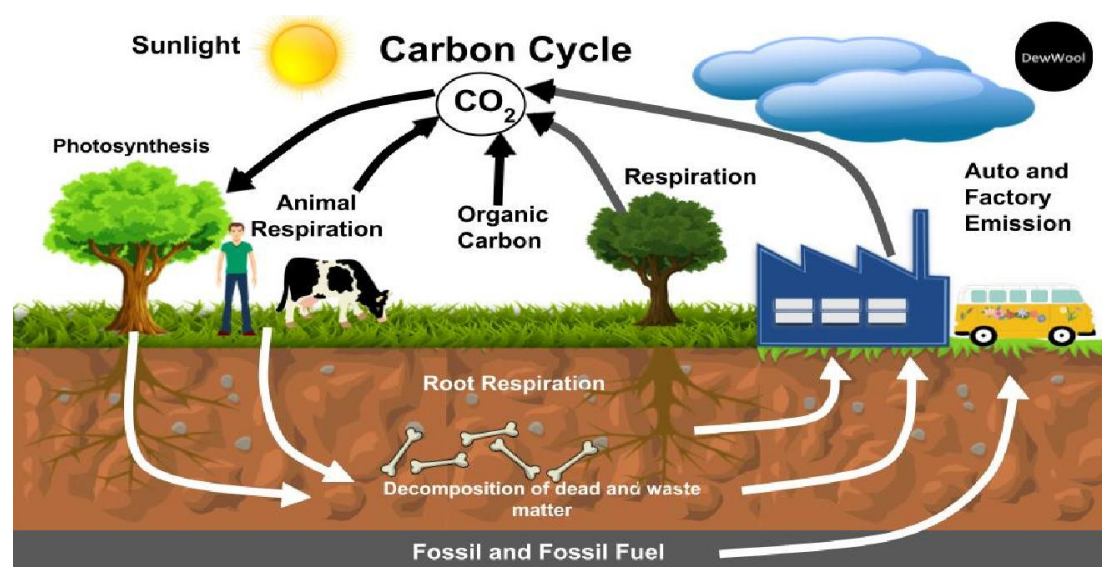

Fig. 63: Represents a global carbon cycle diagram show the pathway, the flow, and the Sources of carbon in the atmosphere. 
In addition to this, dissolving in precipitation as raindrops fall through the atmosphere. When dissolved in water, carbon dioxide reacts with water molecules and forms carbonic acid that is contribute to ocean acidity.

Microorganisms are part of a larger cycling of carbon that occurs on the global scale. The actions of microorganisms help extract carbon from non-living sources and make the carbon is available to living organisms. Much of the carbon that enters the carbon cycle is carbon dioxide. This form of carbon exists as a gas in the atmosphere, but before it can be incorporated into living organisms, it must be transformed in to usable organic form. The transformative process by which carbon dioxide is taken up from the atmospheric reservoir and "fixed" into organic substances is called carbon fixation. The bestknown example of carbon fixation is photosynthesis, a process by which energy derived from sunlight is harnessed to form organic compounds. Photosynthetic algae are important microorganisms in this regard and chemoautotrophs are mentioned. Primarily, bacteria and archae are capable of carbon dioxide conversion in to sugar form available for cell building. Some organic carbon is returned to the atmosphere as $\mathrm{CO}_{2}$ form during respiration. The rest of the organic carbon may cycle from organism to organism through in food chain. When an organism dies, bacteria decompose it and its carbon is released into the atmosphere or the soil. $\mathrm{CO}_{2}$ dissolves in the water at that time algae, plants and bacteria convert into organic carbon. Carbon may transfer between organisms from producers to consumers.
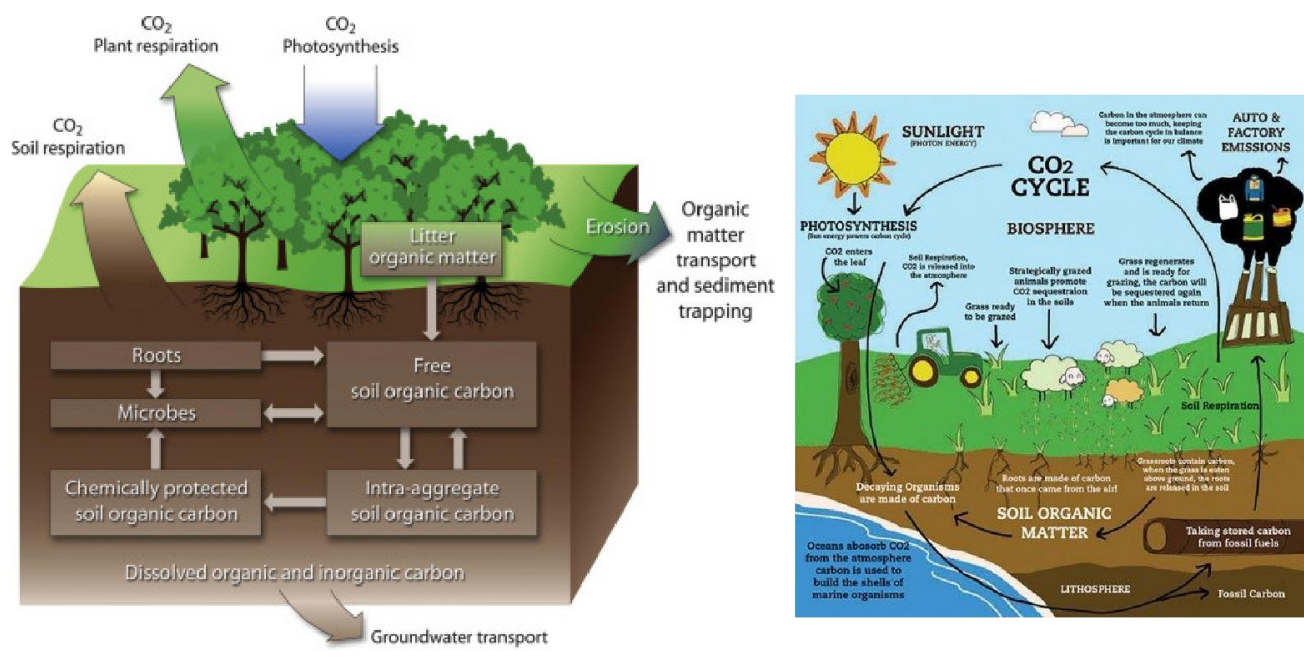

Fig. 64: Illustrates the carbon cycle

Bacteria ultimately break down their tissues and $\mathrm{CO}_{2}$ is released back into the ocean or atmosphere Zimmer (2010), Crowther et al., (2015). The cycling of carbon by variety of bacteria and fungi species occurs in aquatic habitats. Even relatively, oxygen free Zones such as in the deep mud of lakes, ponds and other water bodies can be regions where the anaerobic conversion of carbon takes place. Both types of conversion take place in the presence and the absence of oxygen. Algal involvement is an aerobic process. In anaerobic environments, microorganisms can cycle the carbon compounds to yield energy in a process known as fermentation. Other microorganisms are able to participate in the cycling of carbon. For example, green and purple sulfur bacteria are able to use the energy they gain from the degradation of a compound called hydrogen sulfide to degrade carbon compounds. Other bacteria such as Thiobacillus ferrooxidans uses the energy gained from the removal of an electron from iron containing compounds to convert carbon. Only microorganisms do the anaerobic degradation of carbon. This degradation is a collaborative effort involving numerous bacteria such as Bacteroids succinogenes, Clostridium butyricum, and Syntrophomonas sp. This bacterial collaboration is termed interspecies hydrogen transfer and finally responsible for bulk of carbon dioxide and methane is released in to atmosphere.

\subsection{Microbial communities and methane cycle}

Cycling of carbon between carbon dioxide and organic compounds are considered as ecologically significant. Both eukaryotes (plants and algae) and autotrophic bacteria (cyanobacteria) are contribute a great significance role in the fixation of carbon dioxide into organic compounds. As well, as 
consumers are used organic compounds and release carbon dioxide. Methane $\left(\mathrm{CH}_{4}\right)$ is a greenhouse gas most of the time enter to atmosphere because of microbial action. Methane consuming microorganisms are critical to maintaining a healthy climate on earth Fig. (65).

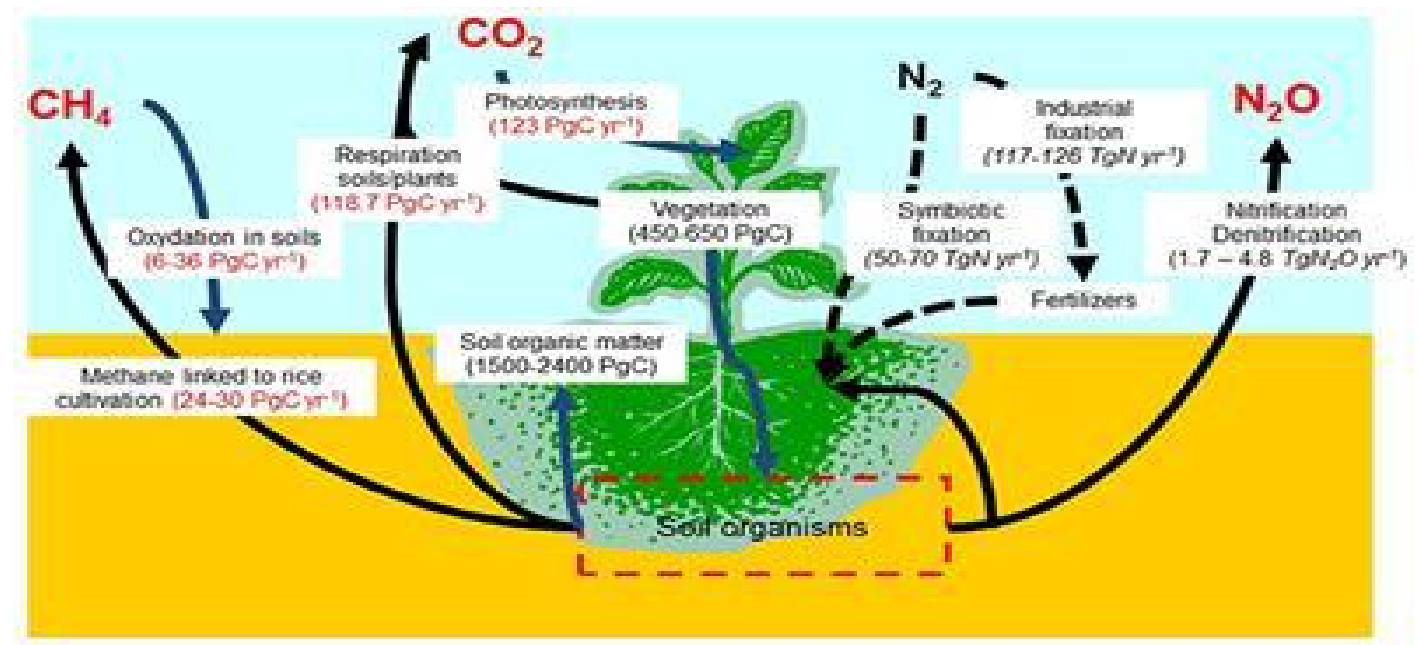

Fig. 65: Illustrates a Soil and GHGs fluxes After Ciais et al., (2013)

Bacteria use methane for metabolism as energy source Zimmerman and Labonte (2015) Gupta et al., (2014). Methanotrophic bacteria is consuming methane as their only source of energy and convert it to carbon dioxide during their digestive process. These bacteria can consume huge concentration of methane that is helpful in reducing methane emission from methane producing factories and landfills Gupta et al., (2014), Shindell et al., (2012). Microorganisms are used high amount of Methane compounds that is found at everywhere Zimmerman and Labonte (2015). In anaerobic conditions just like deep compacted mud, carbon dioxide easily changed in to methane this is accomplished by methanogenic bacteria. The conversion process needs hydrogen, yields water and energy for the methanogens. To accomplish the recycling pattern another group of methane bacteria called methane oxidizing bacteria or methanotrophs (literally "methane eaters") can convert methane to carbon dioxide. This conversion, which is an aerobic process, also yields water and energy. In the presence of oxygen, $\mathrm{CH}_{4}$ is oxidized to $\mathrm{CO}_{2}$ by Methanotrophic bacteria. The oxidation of $\mathrm{CH}_{4}$ to $\mathrm{CO}_{2}$ completes the carbon cycle. Methanotrophs tend to live at the boundary between aerobic and anaerobic environments. They have access to the methane produced by the anaerobic methanogenic bacteria, but also access to the oxygen needed for their conversion of the methane Parul et al., (2013)

Soil organic carbon (SOC) is the balance between plant inputs and biologically mediated losses. The amount of SOC is large compared to anthropogenic $\mathrm{CO} 2$ fluxes to the atmosphere that small changes in the SOC pool could have a major impact on the concentration of $\mathrm{CO}_{2}$ in the atmosphere $\mathrm{Cox}$ et al., (2000); Crowther et al., (2016). This can be seen as a threat, but also as an opportunity for possible mitigation measures. In order to be able to quantify these stocks and fluxes reliable methods are needed. Even though several models have been developed to estimate and forecast the fluxes of GHGs Parton et al., (1994); Del Grosso et al., (2008), we still need well-defined long-term field measurements to evaluate and validate their predictions. To enable this on a global scale, it is necessary to use methods that give comparable results. Standardization is a proven approach to accomplish such requirements, not only by describing complete methods, but also by developing guidelines for the use of methods that are still under development. In this paper, we evaluate the availability of required standards for quantitative assessment of the role of soil in the fluxes of GHGs and soil C stocks. Both GHGs fluxes and $\mathrm{C}$ stocks in soil are complex to measure, variable, and heterogeneous as they are governed by climate (e.g., temperature, moisture regimes, $\mathrm{N}$ deposits), soil characteristics (e.g., pH, clay content, cation exchange capacity), and for managed soils by the agricultural or forestry practices (e.g., crop and wood residues management, soil tillage, soil amendments and fertilizers, irrigation). These factors generally interact and their effects on SOC stocks and GHGs emissions are still poorly quantified Eglin et al., (2010); Fujisaki et al., (2015). Moreover, $\mathrm{C}$ and $\mathrm{N}$ cycles are closely connected as for example organic matter decay may produce $\mathrm{CO}_{2}$ but also $\mathrm{N}_{2} \mathrm{O}$ through heterotrophic nitrification and/or 
denitrification Zhang et al., (2015). Several international and European policies are now acknowledging the importance of soils, which means that proper, comparable and reliable information is needed to report on C stocks and GHGs emissions from soil. It also implies a need for consensus on the adoption and verification of mitigation options that soil can provide. Therefore, the need for standards is becoming urgent to ensure comparable estimations of $\mathrm{C}$ either stocks or GHGs emissions. Paustian et al., (2016) together with The Global Soil Partnership in its pillar 5 Montanarella and Vargas, (2012) call for harmonization of protocols, methods, measurements, and indicators for soil management to facilitate comparability and exchange of data. This paper reviews existing ISO standards and identifies the need for new ones to support climate policy requirements regarding soil processes that control $\mathrm{C}$ storage and GHGs emissions. Antonio Bispo, et al., (2017) Soil is a key compartment for climate regulation as a source of greenhouse gases (GHGs) emissions and as a sink of carbon. Thus, soil carbon sequestration strategies should be considered alongside reduction strategies for other greenhouse gas emissions. Considering this, several international and European policies on climate change are now acknowledging the importance of soils, which means that proper, comparable and reliable information is needed to report on carbon stocks and GHGs emissions from soil.

\subsection{Microbial communities and nitrogen cycle}

Nitrogen is existed in an elemental form. It is the major component of the air constituting about $78 \%$ of the gases in the earth atmosphere. There are also different nitrogen gaseous compounds that exist in the atmosphere including $\mathrm{NH}_{3}, \mathrm{NO}$ and $\mathrm{N}_{2} \mathrm{O}$. Nitrogen is in the form of a very stable molecule $\left(\mathrm{N}_{2}\right)$ which is unusable by plants and animals without fixation. Nitrogen Fixation is the process of changing atmospheric nitrogen into chemical forms that is usable by living things. $\mathrm{N}_{2}$ enters in to biosphere via biological fixation. Biological nitrogen fixation will ever totally replace industrial fixation for intensive agriculture, Rhizobium bacteria that cause formation of nodules on the roots of legumes such as soybeans and alfalfa. The bacteria are specific for certain plants for example; the species that infects soybeans will not infect alfalfa. The bacterium attaches to a root hair of the plant and in response; the plant forms a hollow thread leading into the root. Bacteria grow through this infection thread and eventually initiate formation of a nodule on the root. As much as 30 percent of the weight of a nodule may be bacteria. The plant supplies energy and nutrients for bacteria; bacteria and fungus supply nitrogen from the air in a form the plant can use through fixation. This is an example of symbiotic nitrogen fixation Anne Bernhard (2010), Vitousek et al., (2013). Specific bacteria (Rhizobium trifolium) possess nitrogenase enzymes that can fix atmospheric nitrogen into a form (ammonium ion) that is chemically useful to higher organisms As part of the symbiotic relationship, the plant convert the 'fixed' ammonium ion to nitrogen oxides and amino acids to form proteins and other molecules like alkaloids Jama et al., (2013) Fig. (66).

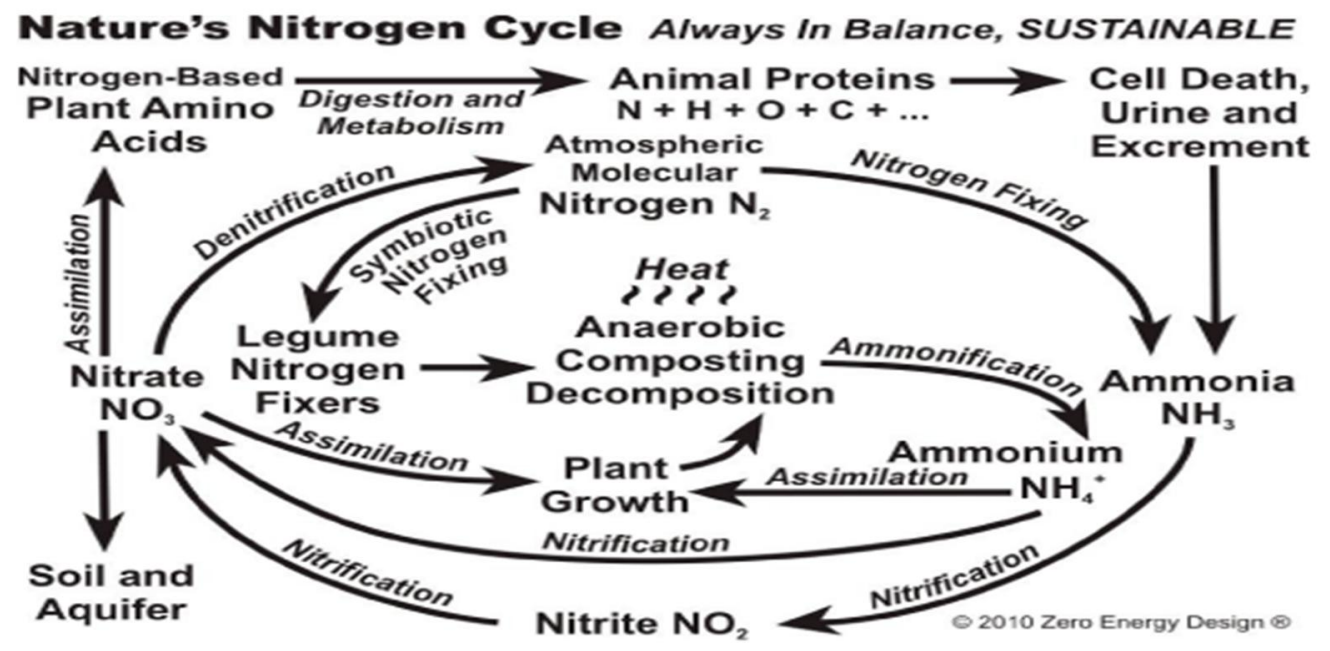

Fig. 66: Illustrates nitrogen cycle

Nitrogen cycle mainly the conversion of nitrogen from one state to another state. Most of the time microorganisms push the system in order to harvest energy or to accumulate nitrogen in a form 
needed for their growth and development. The major transformations of nitrogen are involved through the following steps.

\subsubsection{Nitrogen fixation}

The first step in the process of making/transforming nitrogen usable/taken up by plants. Microbes responsible for convert nitrogen into ammonium. Two kinds of nitrogen fixing bacteria are recognized. The first kind, the free-living (non-symbiotic) bacteria, includes cyanobacteria or blue-green algae, Anabaena, Nostoc, Azotobacter, Beijerinckia, and Clostridium. The second kind comprises the mutualistic (symbiotic) bacteria mainly Rhizobium associated with leguminous plants. Free living and symbiotic microorganisms carry out nitrogen fixation in a good manner. These Bacteria have the nitrogenase enzyme that combines gaseous nitrogen with hydrogen to produce ammonia, which is converted by the bacteria into other organic compounds Anne Bernhard (2010), Orr et al., (2011) Fig. (66) .

\subsubsection{Nitrification}

The process ammonium transformed into nitrates by living things. Nitrates are what the organisms can absorb. Soil living bacteria and other nitrifying bacteria complete the transformation of ammonia to nitrate. In the primary stage of nitrification, bacteria such as the Nitrosomonas species, which converts ammonia to nitrites $\left(\mathrm{NO}_{2}^{-}\right)$, do the oxidation of ammonium $\left(\mathrm{NH}_{4}^{+}\right)$. Other bacterial species such as Nitrobacter, are responsible for the oxidation of the nitrites into nitrates $\left(\mathrm{NO}_{3}^{-}\right)$. Ammonia is converted to nitrates or nitrites because ammonia gas is toxic to plants. Ammonium ion useful in energy source microorganisms involved in side the system. Nitrite is toxic to plant and animal. It must be immediately convert in to nitrate by different species Anne Bernhard (2010), Ward (2011), Wunderlin et al., (2012).

\subsubsection{Assimilation}

This step indicate that the mechanism of plants get nitrogen. Plants can uptake nitrates from soil by their root hairs. Eventually, it is used in cellular component production like amino acids, nucleic acids, and chlorophyll. In plants that have a symbiotic relationship with rhizobia, some nitrogen is assimilated in the form of ammonium ions directly from the nodules. Other life form also seeking nitrogen through food chain structure Singh and Kundu (2014) Fig. (66) .

\subsubsection{Ammonification:}

During the living things are died, decomposers like fungi and bacteria turn nitrogen to ammonium. Later it can reenter in the normal nitrogen cycle. In the $\mathrm{N}_{2}$ process, the nitrogen is released usually in the form of ammonia. The process is termed as ammonification or mineralization. Many types of enzymes are involved for example Gln Synthetase (Cytosolic \& Plastid), Glu 2-oxoglutarate aminotransferase (Ferredoxin \& NADH dependent) and Glu Dehydrogenase. Actually, in soil this takes the form of the ammonium ion $\left(\mathrm{NH}_{4}^{+}\right)$which has a positive charge. This charge tends to bind the nitrogen to clay minerals of the soil, an advantage in that the nitrogen is not readily lost by leaching or runoff. It has the disadvantage that it cannot easily migrate to reach plant roots for uptake Anne Bernhard (2010), Singh and Kundu (2014) Fig. (66) .

\subsubsection{Denitrification:}

At the end of cycle, extra nitrogen molecules in the soil move out to atmosphere. Denitrification is the reduction of nitrates back into the largely inert nitrogen gas $\left(\mathrm{N}_{2}\right)$ for completing cycle. Special and unique group of bacteria like Pseudomonas and Clostridium performs this kind of task. They use nitrate as an electron acceptor in the place of oxygen during respiration. The denitrifying bacteria use nitrates in the soil to carry out respiration and consequently produce nitrogen gas, which is inert and unavailable to plants. The process is takes place in the absence of oxygen commonly in waterlogged soils. Eventually, nitrate is converted to nitrogen gas and reenters to atmosphere Anne Bernhard (2010), Groffman (2012) Fig. (66) . 


\section{Conclusions}

Land degradation is a major threat to the food security, with increasing world population the agricultural land is declining and degrading. biofertilisation with Fungi, bacterial inocula, and their combination with organic fertilizers can be a promising approach for recovering degradation of the soil. Furthermore, can minimize the extensive use of chemical fertilizers. biofertilisation can enhance the bioavailability of nutrient for plant growth, though; fixation, chelation as well as improving the physical characteristics of soil aggregation by their execration of hydrophobins and Glomalin protein. The mechanisms of microbial inocula in the provision or mobilization of nutrients in degraded land is a key for their success in field applications. However, it is becoming clearer that these microbes can allow them to perform their associated functions can be a promising approach for recovering degradation. Effectiveness of bacterial endophytes particularly in modern crop production is one of the best solution for maximization used of applied fertilizers. Full understanding of the genome of endophytic bacteria, may helping and uncovering the functional genes that help them adapt to unfavorable conditions, would be a breakthrough in biotechnology and agriculture. Fertilization in crop production can be minimize and or avoid by the effectiveness of bacterial endophytes that gain entry and colonize the plant tissues and overcome the plant immune response and infer resilience to abiotic and biotic stressors such as changing climatic conditions. The practical association of bacterial endophytes with plants in the field can be explored for the potential restoration of degraded and unproductive lands. Many efforts should be required on the interaction of bacteria and fungi particularly under field conditions. Such mechanisms may helping in the developing of innovative as well as cost effective management practices in order for improving the soil fertility and crop production particularly in degraded soils. Biofertilizers in combining with organic materials may have potential effects for restoration of soils degradation. Furthermore, bacteria and fungi creating synergistic effect for nutrient acquisition and can also reduce the excessive use of chemical fertilizers as well as formation of soil aggregation and their stabilization. There is a growing need to improve nutrients use efficiency in the soil in an eco-friendly manner, that can be achieved by the application of microbial nutrients solubilizes.

\section{References}

Abiala, M.A., and A.C. Odebode, 2015. Rhizospheric Enterobacter enhanced maize seedling health and growth. Biocontrol Sci. Techn., 25: 359-372.

Abou seeda, 1982. Effect of soil conditioners on some physical properties of Egyptian soils. M.Sc. Thesis. Belgium, Gent., 1982

Abou Seeda, M.A., A.A. Yassen, E.A.A. Abou El-Nour and Sahar M. Zaghloul, 2020. Improving of phosphorus use efficiency in Plant-Soil-System. Current Science International, 09(02).

Abou Seeda, M.A., A.A. Yassen, and E.A.A. Abou El-Nour, 2020. Role of Essential Plant Nutrients and their Risk Assessment, Book, Published by Innovationinfoebooks: September 2020 Hearthrow Stockley Park, Heathrow UB11BD, UK.

Abou-el-Seoud, I.I., and A. Abdel-Megeed, 2012. Impact of rock materials and biofertilizations on P and K availability for maize (Zea Maize. under calcareoussoil conditions. Saudi J. of Biol. Sci. 19 (1): 55-63.

Adesemoye, A.O., G. Yuen, and D.B. Watts, 2017. Microbial inoculants for optimized plant nutrient use in integrated pest and input management systems, Probiotics and plant health. Singapore: Springer, $21-40$.

Adesemoye, A.O., and J.W. Kloepper, 2009. Plant-microbes' interactions in enhanced fertilizer-use efficiency. Appl. Microbiol. Biotechnol., 85: 1-12.

Adhikari, A., S. Dutta, A. Chattopadhaya, et al., 2013. Potential effects of plant growth promoting rhizobacteria (Pseudomonas fluorescens. on cowpea seedling health and damping off disease control. Afr. J. Biotechnol., 12: 1853-1861.

Afzal, I., Z.K. Shinwari, S. Sikandar, et al., 2019. Plant beneficial endophytic bacteria: Mechanisms, diversity, host range and genetic determinants. Microbiol. Res., 221: 36-49.

Afzal, A., B. Asghari, and F. Mussarat, 2010. Higher soybean yield by inoculation with N-fixing and P-solubilizing bacteria. Agron. Sustain. Dev., 30: 487-495.

Agerer, R., 2001. Exploration types of ectomycorrhizae. Mycorrhiza, 11 (2):107-114. 
Ahemad, M., and M.S. Khan, 2010a. Influence of selective herbicides on plant growth promoting traits of phosphate solubilizing Enterobacter asburiae strain PS2. Res. J. Microbiol., 5:849-857.

Ahemad, M., and M.S. Khan, 2010b. Plant growth promoting activities of phosphate-solubilizing Enterobacter asburiae as influenced by fungicides. Eur. Asian J. Biosci., 4:88-95

Ahemad, M., and M. Kibret, 2014. Mechanisms and applications of plant growth promoting rhizobacteria: Current perspective. J. King Saud Univ-Sci., 26: 1-20.

Ahemad, M., A. Zaidi, M.S. Khan, and M. Oves, 2019. Biological importance of phosphorus and phosphate solubilizing microbes. In: Khan MS, Zaidi A (eds. Phosphate solubilizing microbes for crop improvement. Nova Science Publishers Inc., New York, 1-14.

Ahemad, M., 2014. Phosphate-solubilizing bacteria-assisted phytoremediation of metalliferous soils: a review. Biotech DOI 10.1007/s13205-014-0206-0.

Ahmad, I., and F.J. Maathuis, 2014. Cellular and tissue distribution of potassium: physiological relevance, mechanisms and regulation. J. Plant Physiol., 171: 708-714.

AL Kahtani, M.D.F., A. Fouda, K.A. Attia, et al., 2020. Isolation and characterization of plant growth promoting endophytic bacteria from desert plants and their application as bioinoculants for sustainable agriculture. Agronomy, 10: 1325.

Alagawadi, A.R., and A.C. Gaur, 1988. Associative effect of Rhizobium and phosphate-solubilizing bacteria on the yield and nutrient uptake of chickpea. Plant Soil, 105: 241-246.

Alami, Y., W. Achouak, C. Marol, T. Heulin, 1997. Rhizosphere soil aggregation and plant growth promotion of sunflowers by an exopolysaccharide-producing Rhizobium sp. strain isolated from sunflower roots. Appl Environ Microbiol., 66(8):3393-3398

Ali, M.A., M. Naveed, A. Mustafa, et al., 2017. The good, the bad, and the ugly of rhizosphere microbiome. In: Kumar V, Kumar M, Sharma S, et al., (Eds): Probiotics and plant health. Singapore: Springer, 253-290.

Alkama, N., G. Ounane, and J.J. Drevon, 2012. Is genotypic variation of HC efflux under P deficiency linked with nodulated-root respiration of $\mathrm{N} 2$ fixing common bean (Phaseolus vulgaris L.)? J. Plant Physiol., 169: 1084-1089.

Allison, F.E., 1968. Soil aggregation-zone facts and fallacies as seen by a microbiologist. Soil Sci., 106:136-143.

Allison, S.D., M.D Wallenstein, and M.A. Bradford, 2010. Soil carbon response to warming dependent on microbial physiology. Nature Geosci 3: 336-340. Link: https://goo.gl/bdT73m

Aloo, B.N., B.A. Makumba, and E.R. Mbega, 2019. The potential of Bacilli rhizobacteria for sustainable crop production and environmental sustainability. Microbiol. Res., 219: 26-39.

Alori, E.T., B.R. Glick, and O.O. Babalola, 2017. Microbial phosphorus solubilization and its potential for use in sustainable agriculture. Front Microbiol., 8: 971.

Altieri, M.A., J.G. Farrell, S.B. Hecht, et al., 2018. The Agroecosystem: Determinants, resources, processes, and sustainability. Agroecology. CRC Press, 41-68.

Ambriz, E., A. Báez-Pérez, J. Sánchez-Yánez, P. Moutoglis, and J. Villegas, 2010.Fraxinus-GlomusPisolithus symbiosis: plant growth and soil aggregationeffects. Pedobiologia, 53 (6): 369-373.

Amezketa, E., 1999. Soil aggregate stability: a review. J. Sustain. Agric., 14 (2-3):83-151.

Ambrosini, A., A. Beneduzi, T. Stefanski, et al., 2012. Screening of plant growth promoting Rhizobacteria isolated from sunflower (Helianthus annuus L.) Plant Soil, 356: 245-264.

Amellal, N., F. Bartoli, G. Villemin, A. Talouizte, and T. Heulin, 1999. Effects of inoculation of EPSproducing Pantoea agglomerans on wheat rhizosphere aggregation. Plant Soil, 211:93-101

Anand, K., B. Kumari, and M.A. Mallick, 2016. Phosphate solubilizing microbes: an effective and alternative approach as biofertilizers. Int. J. Pharm. Pharm. Sci., 8: 37-40.

Andrade, G., K.L. Mihara, R.G. Linderman, and G.J. Bethlenfalvay, 1998. Soil aggregation status and rhizobacteria in the mycorrhizosphere. Plant Soil, 202:89-96

Andrade, G., K. Mihara, R. Linderman, and G. Bethlenfalvay, 1997. Bacteria from rhizosphere and hyphosphere soils of different arbuscular-mycorrhizal fungi. Plant Soil, 192 (1): 71-79.

Andreolli, M., S. Lampis, G. Zapparoli, et al., 2016. Diversity of bacterial endophytes in 3 and 15 yearold grapevines of Vitis vinifera $\mathrm{cv}$. Corvina and their potential for plant growth promotion and phytopathogen control. Microbiol. Res., 183: 42-52.

Angers, D.A., A. N'dayegamiye, and D. Cot ${ }^{\wedge}$ 'e, 1993. Tillage-induced differences inorganic matter of particle-size fractions and microbial biomass. Soil Sci. Soc. Am. J., 57:512-516. 
Anne, B., 2010. The Nitrogen Cycle: Processes, Players, and Human Impact. Nature Education Knowledge, 2: 1-9.

Antonio, B., A. Lizzi, A.A. Denis, B. Martial, B. Michel, C. Lauric, N.J.C. Rob, H. Joop, J. Knut, L. Frank, L. Caroline, M. Stanislav, M. Edith, E.M. Angus, S. Hiro, W. Yoichi and K.E. Thomas 2017. Accounting for Carbon Stocks in Soils and Measuring GHGs Emission Fluxes from Soils: Do We Have the Necessary Standards? Front. Environ. Sci., 12.

Anukool, V., K.Sh. Awadhesh, Sh. Anjney, K. Roshan, and K.C. Devendra, 2018 . Endophytic Bacteria in Plant Salt Stress Tolerance: Current and Future Prospects. Journal of Plant Growth Regulation.

Aravind, R., S.J. Eapen, A. Kumar, and K.V. Ramana, 2010. Screening of endophytic bacteria and evaluation of selected isolates for suppression of burrowing nematode (Radopholus similis Thorne. using three varieties of black pepper (Piper nigrum L.) Crop Prot., 29:318-324

Arif, M.S., S.M. Shahzad, T. Yasmeen, et al., 2017. Improving plant phosphorus (p. acquisition by phosphate-solubilizing bacteria. In: Naeem M, Ansari A, Gill S. (Eds): Essential Plant Nutrients. Springer, Cham., 513-556.

Armada, E., G. Portela, A. Roldán, and R. Azcón, 2014. Combined use of beneficial soilmicroorganism and agrowaste residue to cope with plant water limitation under semiarid conditions. Geoderma, 232: 640-648.

Arora, N.K., E. Khare, and D.K. Maheshwari, 2011. "Plant growth promoting rhizobacteria: constraints in bioformulation, commercialization, and future strategies," in: Plant Growth and Health Promoting Bacteria, Microbiology Monographs, Chap. 18, ed. D. K. Maheshwari (Berlin: Springer).

Arya, N., A. Rana, A. Rajwar, et al., 2018. Biocontrol efficacy of siderophore producing indigenous Pseudomonas strains against fusarium wilt in tomato. Natl. Acad. Sci. Lett., 41: 133-136.

Asghari, H.R., and T.R. Cavagnaro, 2012. Arbuscular mycorrhizas reduce nitrogen lossvia leaching. PLoS One, 7 (1): e29825.

Aspiras, R., O. Allen, R. Harris, and G. Chesters, 1971. The role of microorganisms in the stabilization of soil aggregates. Soil Biol. Biochem., 3 (4): 347-353.

Babana, A.H., and H. Antoun, 2007. "Effect of Tilemsi phosphate rock-solubilizing microorganisms on phosphorus uptake and yield of field-grown wheat (Triticum aestivum L.) in Mali," in First International Meeting on Microbial Phosphate Solubilization. Dev. Plant Soil Science, Vol. 102, eds E. Velázquez and C. Rodríguez-Barrueco (Dordrecht: Springer).

Bahadur, I., B.R. Maurya, A. Kumar, et al., 2016. Towards the soil sustainability and potassiumsolubilizing microorganisms. In: Meena V, Maurya B, Verma J, et al., (Eds): Potassium solubilizing microorganisms for sustainable agriculture. New Delhi: Springer, 255-266.

Bai, Z.G., D.L. Dent, L. Olsson, et al., 2008. Proxy global assessment of land degradation. Soil Use Manage., 24: 223-234.

Baldock, J.A., and B.D. Kay, 1997. Influence of cropping history and chemical treatments on the water stable aggregation of a silt loam soil. Can. J. Soil Sci., 67: 501-511

Bansal, S., and K.K. Kapoor, 2000. Vermicomposting of crop residues and cattle dung with Eisenia fetida. Bioresour. Technol., 73:95-98

Bardi, L., and E. Malusà, 2012. "Drought and nutritional stresses in plant: alleviating role of rhizospheric microorganisms," in Abiotic Stress: New Research, eds N. Haryana and S. Punj (Hauppauge: Nova Science Publishers Inc): 1-57.

Barea, J.-M., M.J. Pozo, R. Azcon, and C. Azcon-Aguilar, 2005. Microbial co-operation in the rhizosphere. J. Exp. Bot., 56 (417): 1761-1778.

Bargaz, A., K. Lyamlouli, M. Chtouki, Y. Zeroual and D. Dhiba, 2018. Soil Microbial Resources for Improving Fertilizers Efficiency in an Integrated Plant Nutrient Management System. Front. Microbiol., 9:1606.

Bargaz, A., C. Ghoulam, L. Amenc, M. Lazali, M. Faghire, and J. Abadie, 2012. A phosphoenol pyruvate phosphatase gene transcript is induced in the root nodule cortex of Phaseolus vulgaris under P deficiency. J. Exp. Bot., 63: 4723-4730.

Barraza, A., J.C. Vizuet-de-Rueda, and R. Alvarez-Venegas, 2020. Highly diverse root endophyte bacterial community is driven by growth substrate and is plant genotype-independent in common bean (Phaseolus vulgaris L.) Peer J., 8: e9423. 
Barth 'es, B., and E. Roose, 2002. Aggregate stability as an indicator of soil susceptibility to runoff and erosion; validation at several levels. Catena, 47:133-149

Bashan, Y., L.E. de-Bashan, S.R. Prabhu, et al., 2014. Advances in plant growth-promoting bacterial inoculant technology: Formulations and practical perspectives, 1998-2013. Plant Soil, 378: 1-33.

Bashan, Y., and L.E. De-Bashan, 2010. Chapter two-how the plant growth-promoting bacterium Azospirillum promotes plant growth - a critical assessment. Adv. Agron., 108: 77-136.

Bashan, Y., G. Holguin, and L.E. De-Bashan, 2004. Azospirillum-plant relationships: physiological, molecular, agricultural, and environmental advances, 1997-2003. Can. J. Microbiol., 50 (8): 521 577.

Bauer, W.D., and U. Mathesius, 2004. Plant responses to bacterial quorum sensing signals. Curr. Opin. Plant Biol., 7:429-433.

Beare, M.H., R.W. Parmelee, P.F. Hendrix, and W. Cheng, 1992. Microbial and faunal interactions and effects on litter nitrogen and decomposition in agroecosystems. Ecol. Monogr., 62:569-591 116.

Beckers, B., M. Op De Beeck, S. Thijs, et al., 2016. Performance of 16s rDNA primer pairs in the study of rhizosphere and endosphere bacterial microbiomes in metabarcoding studies. Front Microbiol., 7: 650 .

Bedine, B.M.A., M.L. Sameza, B. Iacomi, et al., 2020. Screening, identification and evaluation of Trichoderma spp. for biocontrol potential of common bean damping-off pathogens. Biocontrol. Sci. Technol., 30: 228-242.

Bedini, S., L. Avio, C. Sbrana, A. Turrini, P. Migliorini, C. Vazzana, and M. Giovannetti, 2013. Mycorrhizal activity and diversity in a long-term organic Mediterranean agroecosystem. Biol. Fert. Soils, 49 (7): 781-790.

Bedini, S., E. Pellegrino, L. Avio, S. Pellegrini, P. Bazzoffi, E. Argese, and M. Giovannetti, 2009. Changes in soil aggregation and glomalin-related soil protein content as affected by the arbuscular mycorrhizal fungal species Glomus mosseae and Glomus intraradical. Soil Biol. Biochem., 41 (7): 1491-1496.

Bender, S.F., F. Conen, H. Van, der, and M.G. eijden, 2015. Mycorrhizal effects onnutrient cycling, nutrient leaching and N 2 O production in experimental grassland. Soil Biol. Biochem., 80: 283292.

Beneduzi, A., A. Ambrosini, and L.M.P. Passaglia, 2012. Plant growth-promoting rhizobacteria (PGPR): Their potential as antagonists and biocontrol agents. Genet. Mol. Biol., 35: 1044-1051.

Berendsen, R.L., C.M. Pieterse, and P.A. Bakker, 2012. The rhizosphere microbiome and plant health. Trends Plant Sci., 17(8):478-486

Berg, G., and J. Hallmann, 2007. Control of plant pathogenic fungi with bacterial endophytes. Microbial Root Endophytes. In: Schulz BJE, Boyle CJC, Sieber TN. (Eds): Heidelberg: Springer, 9: 53-69.

Bhattacharjee, R., A. Singh, and S.N. Mukhopadhyay, 2008. Use of nitrogenfixing bacteria as biofertiliser for non-legumes: prospects and challenges. Appl. Microbiol. Biotechnol. 80: 199-209.

Bhattacharyya, P.N., and D.K. Jha, 2012. Plant growth-promoting rhizobacteria (PGPR): Emergence in agriculture. World J. Microbiol. Biotechnol., 28: 1327-1350.

Bianciotto, V., C. Bandi, D. Minerdi, M. Sironi, H.V. Tichy, and P. Bonfante, 1996. Anobligately endosymbiotic mycorrhizal fungus itself harbors obligatelyintracellular bacteria. Appl. Environ. Microbiol., 62 (8): 3005-3010.

Bird, S.B., J.E. Herrick, M.M. Wander, and S.F. Wright, 2002. Spatial heterogeneity of aggregate stability and soil carbon in semi-arid rangeland. Environ. Pollut., 116:445-455

Biswas, J.C., J.K. Ladha, F.B. Dazzo, Y.G. Yanni, and B.G. Rolfe, 2000. Rhizobialinoculation influences seedling vigor and yield of rice. Agron. J., 92 (5): 880-886.

Blaha, C.A.G., and I.S. Schrank, 2003. An Azospirillum brasilense Tn5 mutant with modified stress response and impaired in flocculation. Antonie VA Leeuwenhoek, 83 (1): 35-43.

Bona, E., G. Lingua, P. Manassero, S. Cantamessa, F. Marsano, V. Todeschini, A. Copetta, G. D’Agostino, N. Massa, and L. Avidano, 2014. AM fungi and PGP pseudomonads increase flowering, fruit production, and vitamin content instrawberry grown at low nitrogen and phosphorus levels. Mycorrhiza, 1-13.

Borie, F., R. Rubio, and A. Morales, 2008. Arbuscular mycorrhizal fungi and soilaggregation. J. Soil Sci. Plant Nutr., 8 (2): 9-18. 
Bossuyt, H., K. Denef, J. Six, S.D. Frey, R. Merckx, and K. Paustian, 2001. Influence of microbial populations and residues quality on aggregate stability. Appl. Soil Ecol., 16:195-208

Bottinelli, N., P. Jouquet, Y. Capowiez, P. Podwojewski, M. Grimaldi, and X. Peng, 2015. Why is the influence of soil macrofauna on soil structure only consideredby soil ecologists? Soil Tillage Res., 146: 118-124.

Boukhalfa, H.C., and A.L. Crumbliss, 2002. Chemical aspects of siderophore mediated iron transport. Biometals, 15 (4): 325-339.

Bradford, M.A., C.A. Davies, S.D. Frey, T.R. Maddox, J.M. Melillo, et al., 2008. Thermal adaptation of soil microbial respiration to elevated temperature. Ecol. Lett., 11: 1316-1327.

Breitkreuz, C., F. Buscot, M. Tarkka, et al., 2020. Shifts between and among populations of wheat rhizosphere Pseudomonas, Streptomyces and Phyllobacterium suggest consistent phosphate mobilization at different wheat growth stages under abiotic stress. Front Microbiol., 10: 3109.

Brewer, R., 1964. Fabric and mineral analysis of soils. Wiley, New York.

Bronick, C.J., and R. Lal, 2005. Soil structure and management: a review. Geoderma, 124: 3-22, 1.

Burns, R.G., J.L. DeForest, J. Marxsen, R.L. Sinsabaugh, M.E. Stromberger, M.D. Wallenstein, M.N. Weintraub, and A. Zoppini, 2013. Soil enzymes in achanging environment: current knowledge and future directions. Soil Biol. Biochem., 58: 216-234.

Caesar-TonThat, T.C., W.L. Shelver, R.G. Thorn, and V.L. Cochran, 2001. Generation of antibodies for soil aggregating basidiomycete detection as an early indicator of trends in soil quality. Appl Soil Ecol., 18:99-116.

Caesar-TonThat, A.J., 2002. Soil binding properties of mucilage produced by a basidiomycete fungus in a model system. Mycol. Res., 106 (08):930-937.

Caesar-TonThat, A.J., E. Espeland, U.M. Sainju, R.T. Lartey, and J.F. Gaskin, 2013. Effects of Agaricus lilaceps fairy rings on soil aggregation and microbial community structure in relation to growth stimulation of western wheatgrass (Pascopyrumsmithii. in eastern Montana rangeland. Microb. Ecol., 66 (1): 120-131.

Caesar-TonThat, T., A. Caesar, J. Gaskin, U. Sainju, and W. Busscher, 2007. Taxonomicdiversity of predominant culturable bacteria associated with microaggregatesfrom two different agroecosystems and their ability to aggregate soil in vitro.Appl. Soil Ecol., 36 (1): 10-21.

Caesar-Tonthat, T.C., W.B. Stevens, U.M. Sainju, A.J. Caesar, M. West, and J.F. Gaskin, 2014. Soilaggregating bacterial community as affected by irrigation, tillage, and cropping system in the northern great plains. Soil Sci., 179 (1): 11-20.

Cambardella, C.A., and E.T. Elliott, 1986. Methods for physical separation and characterization of soil organic matter fractions. Geoderma, 56:4449-4457.

Campbell., 1995. Prokaryotes and the Origins of Metabolic Diversity, 5thEdn, eds E.B.Brady (Reed wood City, CA: The Benjamin/Cummings Publishing Company): 502-519.

Capriel, P., T. Beck, H. Borchet, and P. Harter, 1990. Relationship between soil aliphatic fraction extracted with supercritical hexane, soil microbial biomass, and soil aggregate stability. Soil Sci Soc Am Proc., 54: 415-420.

Caravaca, F., M.M. Alguacil, D. Figueroa, J.M. Barea, and A. Roldan, 2003. Re-establishment of Retama sphaerocarpa as target species for reclamation of soil physical and biological properties in a semiarid Mediterranean area. For Ecol Manage, 182:49-58

Caravaca, F., J.M. Barea, D. Figueroa, and A. Roldan, 2002a. Assessing the effectiveness of mycorrhizal inoculation and soil compost addition for enhancing reafforestation with Olea europea subsp. sylvestris through changes in soil biological and physical parameters. Appl. Soil Ecol. 20:107-118.

Caravaca F, C Garcia, MT Hernandez, and A. Roldan, 2002b. Aggregate stability changes after organic amendment and mycorrhizal inoculation in the afforestation of a semiarid site with Pinus halepensis. Appl. Soil Ecol., 19:199-208

Carlson, J., J. Saxena, N. Basta, L. Hundal, D. Busalacchi, and R.P. Dick, 2015.Application of organic amendments to restore degraded soil: effects on soil microbial properties. Environ. Monit. Assess., 187 (3): 1-15.

Cassán, F., J. Vanderleyden, and S. Spaepen, 2014. Physiological and agronomical aspects of phytohormone production by model plant-growth-promoting rhizobacteria (pgpr. belonging to the genus Azospirillum. J. Plant Growth Regul., 33: 440-459. 
Chaer, G.M., M.F. Fernandes, D.D. Myrold, et al., 2009. Shifts in microbial community composition and physiological profiles across a gradient of induced soil degradation. Soil Sci. Soc. Am. J., 73: $1327-1334$.

Chaer, G.M., A.S. Resende, E.F.C. Campello, F. de, S.M. Aria, R.M. Boddey, 2011.Nitrogen-fixing legume tree species for the reclamation of severely degradedlands in Brazil. Tree Physiol., 31 (2): 139-149.

Chaintreuil, C., E. Giraud, Y. Prin, et al., 2000. Photosynthetic bradyrhizobia are natural endophytes of the African wild rice Oryza breviligulata. Appl. Environ. Microbiol., 66: 5437-5447.

Chakraborty, P., and P. Tribedi, 2019. Functional diversity performs a key role in the isolation of nitrogen-fixing and phosphate-solubilizing bacteria from soil. Folia Microbiol (Praha.) 64: 461470.

Chandran, V., H. Shaji, and L. Mathew, 2020. Endophytic microbial influence on plant stress responses. Microb. Endophytes, 161-193.

Chang, C.-H.Y., and S.-S. Yang, 2009. Thermo-tolerant phosphate-solubilizing microbes for multifunctional biofertilizer preparation. Bioresour. Technol., 100 (4):1648-1658.

Chaparro, J.M., D.V. Badri, and J.M. Vivanco, 2014. Rhizosphere microbiome assemblage is affected by plant development. ISME J., 8: 790-803.

Chatterjee, R., A. Roy, and R.K. Thirumdasu, 2017. Microbial inoculants in organic vegetable production: Current perspective. Microbial strategies for vegetable production, Springer International Publishing, 1-21.

Chaudhary, T., and P. Shukla, 2020. Commercial bioinoculant development: Techniques and challenges. In: Shukla P. (Eds): Microbial enzymes and biotechniques. Singapore: Springer, 5770.

Chen, Y.H., X.Z. Yang, Z. Li, et al., 2020. Efficiency of potassium-solubilizing Paenibacillus mucilaginosus for the growth of apple seedling. J. Integr. Agric., 19: 2458-2469.

Chen, X., Z. Li, M. Liu, C. Jiang, and Y. Che, 2015. Microbial community and functional diversity associated with different aggregate fractions of a paddy soil fertilized with organic manure and/or NPK fertilizer for 20 years. J. Soils Sediments, 15(2): 292-301.

Chen, Y., P. Rekha, A. Arun, F. Shen, W.-A. Lai, and C. Young, 2006. Phosphate solubilizing bacteria from subtropical soil and their tricalcium phosphate solubilizing abilities. Appl. Soil Ecol., 34 (1): 33-41.

Cheng, D.D., Z.S. Tian, L. Feng, et al., 2019. Diversity analysis of the rhizospheric and endophytic bacterial communities of Senecio vulgaris L. (Asteraceae. in an invasive range. Peer) J., 6: e6162.

Chenu, C., 1993. Clay-or-sand polysaccharide associations as models for the interface between microorganisms and soil: water-related properties and microstructure. Geoderma, 56:143-156.

Chenu, C., 1989. Influence of a fungal polysaccharide, scleroglucan, on clay microstructures. Soil Biol. Biochem., 21 (2): 299-305.

Chenu, C., G. Stotzky, P. Huang, J. Bollag, and N. Senesi, 2002. Interactions BetweenMicroorganisms and Soil Particles: An Overview. Interactions Between SoilParticles and Microorganisms: Impact on the Terrestrial Ecosystem IUPAC.John Wiley \& Sons, Ltd., Manchester, UK, 1-40.

Cheshire, M.V., 1979. Nature and origin of carbohydrates in soils. Academic Press, London.

Chhabra, S., and D.N. Dowling, 2017. Endophyte-promoted nutrient acquisition: Phosphorus and iron. In: Doty S. (Ed): Functional importance of the plant microbiome, 21-42.

Chick, T.A., and J.J. Kielbaso, 1998. Allelopathy as an inhibition factor in ornamental tree growth: implications from the literature. J. Arboric, 24: 274-279.

Chinheya, C.C., K.S. Yobo, and M.D. Laing, 2017. Biological control of the root knot nematode, Meloidogyne javanica (Chitwood. using Bacillus isolates, on soybean. Biol. Control, 109: 37-41.

Chotte, J.L., J.N. Ladd, and M. Amato, 1998. Sites of microbial assimilation and turnover of 14C soluble and particulate substrates decomposing in a clay soil. Soil Biol. Biochem., 30:205-218.

Chotte, J.L., A. Schwartzman, R. Bailly, and L. Jocteur Monrozier, 2002. Changes in bacterial communities and Azospirillum diversity in a tropical soil under 3 years and 19 years natural fallow assessed by soil fractionation. Soil Biol. Biochem., 34:1083-1092

Chotte, J.L., G. Villemin, P. Guillor'e, and L. Jocteur Monrozier, 1994. Morphological aspects of microorganism habitats in a vertisol. In: Ringrose-Voase AJ, Humphreys GS (eds. Proceedings of 
the IXth International Working Meeting on Soil micromorphology, vol 22. Developments in Soil Science, Townsville, 395-403.

Ciais, P., C. Sabine, G. Bala, L. Bopp, V. Brovkin, J. Canadell, A. Chhabra, R. DeFries, J. Galloway, M. Heimann et al., 2013. In: Stocker TF, Qin D, Plattner G-K, Tignor M, Allen SK, Boschung J, Nauels A, Xia Y, Bex V, Midgley PM, eds. Carbon and other biogeochemical cycles. Climate Change 2013: The physical science basis. Contribution of Working Group I to the Fifth Assessment Report of the Intergovernmental Panel on Climate Change. Cambridge, UK \& New York, NY, USA: Cambridge University Press.

Clark, R., R. Zobel, and S. Zeto, 1999. Effects of mycorrhizal fungus isolates on mineralacquisition by Panicum virgatum in acidic soil. Mycorrhiza, 9 (3): 167-176.

Compant, S., C. Clement, and A. Sessitsch, 2010. Plant growth-promoting bacteria in the rhizo-and endosphere of plants: their role, colonization, mechanisms involved and prospects for utilization. Soil Biol. Biochem., 42:669-678

Compant, S., H. Kaplan, A. Sessitsch, J. Nowak, E. Ait Barka, and C. Clément, 2008. Endophytic colonization of Vitis vinifera L. by Burkholderia phytofirmans strain PsJN: from the rhizosphere to inflorescence tissues. FEMS Microbiol. Ecol., 63:84e93.

Compant, S., B. Reiter, A. Sessitsch, J. Nowak, C. Clément, and E. Ait Barka, 2005. Endophytic colonization of Vitis vinifera L. by plant growth-promoting bacte- rium Burkholderia sp. strain PsJN. Appl. Environ. Microbiol., 71:1685e1693

Compant, S., A. Samad, H. Faist, et al., 2019. A review on the plant microbiome: Ecology, functions, and emerging trends in microbial application. J. Adv. Res., 19: 29-37.

Cordell, D., J.-O. Drangert, and S. White, 2009. The story of phosphorus: global food security and food for thought. Glob. Environ. Change, 19 (2): 292-305.

Cox, P.M., R.A. Betts, C.D. Jones, S.A. Spall, and I.J. Totterdell, 2000. Acceleration of global warming due to carbon-cycle feedbacks in a coupled climate model. Nature, 408: 184-187.

Crowley, D.A., 2006. Microbial Siderophores in the Plant Rhizosphere. In: Barton LL, Abadia J,editors. Iron Nutrition in Plants and Rhizospheric Microorganisms Netherlands: Springer Netherlands; 169-190.

Crowther, T.W., S.M. Thomas, D.S. Maynard, P. Baldrian, K. Covey, et al, 2015. biotic interactions mediate soil microbial feedbacks to climate change. Proc Nat Acad. Sci., 112: 7033-7038.

Crowther, T.W., K.E.O. Todd-Brown, C.W. Rowe, W.R. Wieder, J.C. Carey, M.B. Machmuller, et al., 2016. Quantifying global soil carbon losses in response to warming. Nature, 540: 104-108.

Cruz-Angón, A., M.L. Baena, and R. Greenberg, 2009. The contribution of epiphytes to the abundance and species richness of canopy insects in a Mexican coffee plantation. J. Trop. Ecol., 25:453-463.

Cui, H., Y. Zhou, Z. Gu, H. Zhu, S. Fu, and Q. Yao, 2015. The combined effects of covercrops and symbiotic microbes on phosphatase gene and organic phosphorushydrolysis in subtropical orchard soils. Soil Biol. Biochem., 82: 119-126.

D Lima, D.R.M., I.B. dos Santos, J.T.C. Oliveira, et al., 2020. Genetic diversity of N-fixing and plant growth-promoting bacterial community in different sugarcane genotypes, association habitat and phenological phase of the crop. Arch. Microbiol., 203: 1089-1105.

Dahal, B., G. NandaKafle, L. Perkins, et al., 2017. Diversity of free-Living nitrogen fixing Streptomyces in soils of the badlands of South Dakota. Microbiol. Res., 195: 31-39.

Dahal, R.H., D.K. Chaudhary, D.U. Kim, et al., 2021. Chryseobacterium antibioticum sp. nov. with antimicrobial activity against Gram-negative bacteria, isolated from Arctic soil. J. Antibiot. (Tokyo). 74: 115-123.

Dastager, S.G., C. Deepa, and A. Pandey, 2010. Isolation and characterization of novel plant growth promoting Micrococcus sp NII-0909 and its interaction with cowpea. Plant Physiol. Biochem., 48 (12): 987-992.

David, J.-M., and N.R. Manish, 2011. Conservation and Diversity of Seed Associated Endophytes in Zea across Boundaries of Evolution, Ethnography and Ecology. PLoS ONE, www.plosone.org 2 June, 6(6)e20396

Daynes, C.N., D.J. Field, J.A. Saleeba, M.A. Cole, and P.A. McGee, 2013. Development and stabilisation of soil structure via interactions between organic matter, arbuscular mycorrhizal fungi and plant roots. Soil Biol. Biochem., 57: 683-694. 
Daynes, C.N., N. Zhang, J.A. Saleeba, and P.A. McGee, 2012. Soil aggregates formed in vitro by saprotrophic Trichocomaceae have transient water-stability. Soil Biol. Biochem., 48: 151-161.

Degens, B.P., G.P. Sparling, and L.K. Abbott, 1996. Increasing the length of hyphae in a sandy soil increases the amount of water-stable aggregates. Appl. Soil Ecology, 3:149-159.

Degens, B.P., 1997. Macro-aggregation of soils by biological bonding and binding mechanisms and the factors affecting these: a review. Soil Res., 35 (3): 431-460.

Del Grosso, S.J., W.J. Parton, D.S. Ojima, C.A. Keough, T.H. Riley, and A.R. Mosier, 2008. "DAYCENT simulated effets of land use and climate on county level N loss vectors in the USA," in Nitrogen in the Environment: Sources, Problems, and Management, eds R. F. Follett and J. L. Hatfield (Amsterdam: Elsevier Science Publishers): 571-595.

Del Mar Alguacil, M., Díaz-Pereira, E., Caravaca, F., Fernández, D.A., and A. Roldán, 2009.Increased diversity of arbuscular mycorrhizal fungi in a long-term field experiment via application of organic amendments to a semiarid degraded soil. Appl. Environ. Microbiol., 75 (13): 4254-4263.

Demba Diallo, M., A. Willems, N. Vloemans, S. Cousin, T.T. Vandekerckhove, P. DeLajudie, M. Neyra, W. Vyverman, M. Gillis, and K. van der Gucht, 2004.Polymerase chain reaction denaturing gradient gel electrophoresis analysis ofthe N2-fixing bacterial diversity in soil under Acacia tortilis ssp: raddiana andBalanites aegyptiaca in the dryland part of Senegal. Environ. Microbiol., 6 (4):400-415.

Denef, K., J. Six, H. Bossuyt, S.D. Frey, E.T. Elliott, R. Merckx, and K. Paustian, 2001. Influence of dry-wet cycles on the interrelationship between aggregate, particulate organic matter, and microbial community dynamics. Soil Biol. Biochem., 33:1599-1611.

Devi, A.R., R. Kotoky, P. Pandey, et al., 2017. Application of Bacillus spp. for sustainable cultivation of potato (Solanum tuberosum L.) and the benefits, In: Islam M, Rahman M, Pandey P. et al., (Eds): Bacilli and Agrobiotechnology. Springer, Cham., 185-211.

Dexter, A.R., 1988. Advances in characterization of soil structure. Soil Tillage Res., 11:199-238

Diaz-Zorita, M., E. Perfect, and J.L. Grove, 2002. Disruptive methods for assessing soil structure. Importance of Microorganisms for Soil Aggregation 117 Soil Tillage Res., 64:3-22.

Diehl, D., 2013. Soil water repellency: dynamics of heterogeneous surfaces.Colloids Surfaces A: Physicochem. Eng. Aspects, 432: 8-18.

Dinel, H., M. Schnitzer, and G.R. Mehuys, 1991. Soil lipids: origin, nature, content, decomposition and effect on soil physical properties. In: Stotzky G (ed. Soil biochemistry, vol 6. Dekker, New York, $397-430$.

Ding, T., M.W. Palmer, and U. Melcher, 2013. Community terminal restriction fragment length polymorphisms reveal insights into the diversity and dynamics of leaf endophytic bacteria. $B M C$ Microbiol., 13: 1.

Divito, G.A., and V.O. Sadras, 2014. How do phosphorus, potassium and sulphur affectplant growth and biological nitrogen fixation in crop and pasture legumes? Ameta-analysis. Field Crops Res., 156: $161-171$.

Dlamini, P., P. Chivenge, A. Manson, and V. Chaplot, 2014. Land degradation impact onsoil organic carbon and nitrogen stocks of sub-tropical humid grasslands inSouth Africa. Geoderma, 235: 372381.

Dominguez, J., 2004. State of the art and new perspectives on vermicomposting research. In: Edwards CA (ed. Earthworm ecology. CRC Press, Boca Raton, 401-424.

Dos Santos, C.L.R., G.C. Alves, A.V. de Matos Macedo, et al., 2017. Contribution of a mixed inoculant containing strains of Burkholderia spp. and Herbaspirillum ssp. to the growth of three sorghum genotypes under increased nitrogen fertilization levels. Appl. Soil Ecol., 113: 96-106.

Dos Santos, M.L., D.L. Berlitz, S.L.F. Wiest, et al., 2018. Benefits associated with the interaction of endophytic bacteria and plants. Braz. Arch. Biol. Techn., 61: e18160431.

Doty, S.L., 2008. Enhancing phytoremediation through the use of transgenics and endophytes. New Phytol., 179:318-333

Downey, J., and Ch. van Kessel, 1990. Dual inoculation of Pisum sativum with Rhizobium leguminosarum and Penicillium bilaji. Biol. Fertl. Soils, 3: 194-196.

Dregne, H.E., 2002. Land Degradation in the Drylands. Arid Land Res. Manag., 16 (2):99-132.

Drevon, J. J., and U.A. Hartwig, 1997. Phosphorus deficiency increases the argon induced decline in nodule nitrogenase activity in soybean and alfafa. Planta, 201: 463-469. 
Driver, J.D., W.E. Holben, and M.C. Rillig, 2005. Characterization of glomalin as ahyphal wall component of arbuscular mycorrhizal fungi. Soil Biol. Biochem., 37(1): 101-106.

Du Jardin, P., 2015. Plant biostimulants: definition, concept, main categories and regulation. Sci. Horticult., 196: 3-14.

Dubey, A., M.A. Malla, A. Kumar, et al., 2020. Plants endophytes: unveiling hidden agenda for bioprospecting toward sustainable agriculture. Crit. Rev. Biotechnol., 40: 1210-1231.

Duc, L., M. Noll, B.E. Meier, H. Bürgmann, and J. Zeyer, 2009. High diversity ofdiazotrophs in the forefield of a receding alpine glacier. Microb. Ecol., 57 (1):179-190.

Egamberdiyeva, D., and G. Höflich, 2004. Effect of plant growth-promoting bacteria on growth and nutrient uptake of cotton and pea in a semi-arid region ofUzbekistan. J. Arid Environ., 56 (2): 293301.

Eglin, T., P. Ciais, S.L. Piao, P. Barre, V. Bellassen, P. Cadule, et al., 2010. Historical and future perspectives of global soil carbon response to climate and land-use changes. Tellus., 62: 700-718.

Eid, A.M., S.S. Salim, S.E. Hassan, et al., 2019. Role of endophytes in plant health and abiotic stress management. In: Kumar V, Prasad R, Kumar M, et al., (Eds): Microbiome in plant health and disease. Singapore: Springer, 119-144.

Eke, P., A. Kumar, K.P. Sahu, et al., 2019. Endophytic bacteria of desert cactus (Euphorbia trigonas Mill. confer drought tolerance and induce growth promotion in tomato (Solanum lycopersicum L.) Microbiol. Res., 228: 126302.

El-Esawi, M.A., I.A. Alaraidh, A.A. Alsahli, et al., 2018. Bacillus firmus (SW5. augments salt tolerance in soybean (Glycine max L.) by modulating root system architecture, antioxidant defense systems and stress-responsive genes expression. Plant Physiol. Bioch., 132: 375-384.

Eljounaidi, K., S.K. Lee, and H.H. Bae, 2016. Bacterial endophytes as potential biocontrol agents of vascular wilt diseases-Review and future prospects. Biol. Control, 103: 62-68.

Elkoca, E., F. Kantar, and F. Sahin, 2008. Influence of nitrogen fixing and phosphorus solubilizing bacteria on the nodulation, plant growth, and yield of chickpea. J. Plant Nutr., 31: 157-171.

Elliott, E.T., 1986. Aggregate structure and carbon, nitrogen and phosphorus in native and cultivated soils. Soil Sci. Soc. Am. J., 50:627-633.

Emami, S., H.A. Alikhani, A.A. Pourbabaei, et al., 2019. Effect of rhizospheric and endophytic bacteria with multiple plant growth promoting traits on wheat growth. Environ. Sci. Pollut. Res., 26: 1980419813.

Emerson, W.W., 1959. The structure of soil crumbs. J. Soil Sci., 10:235-244.

Etesami, H., and S.M. Adl, 2020. Plant growth-promoting rhizobacteria (PGPR) and their action mechanisms in availability of nutrients to plants, In: Kumar M, Kumar V, Prasad R. (Eds): PhytoMicrobiome in Stress Regulation. Singapore: Springer, 147-203.

Etesami, H., S. Emami, and H.A. Alikhani, 2017. Potassium solubilizing bacteria (KSB): Mechanisms, promotion of plant growth, and future prospects-a review. J. Soil Sci. Plant Nutr., 17: 897-911.

Fadiji AE, and O.O. Babalola, 2020. Metagenomics methods for the study of plant-associated microbial communities: A review. J. Microbiol. Meth., 170: 105860.

Fageria, N., F. Zimmermann, and V. Baligar, 1995. Lime and phosphorus interactions on growth and nutrient uptake by upland rice, wheat, common bean and corn in an oxisol. J. Plant Nutr., 18: 25192532.

Falkowski, P.G., T. Fenchel, and E.F. Delong, 2008. the microbial engines that drive Earth's biogeochemical cycles. Science, 320: $1034-1039$.

Fan, B., C. Wang, X.F. Song, et al., 2018. Bacillus velezensis FZB42 in 2018: The gram-positive model strain for plant growth promotion and biocontrol. Front Microbiol., 9: 2491.

FAO, 2009. Food and Agriculture Organization of the United Nations. How to feed the World in 2050. www.fao.org/fileadmin/.)./How to Feed the World in 2050.pdf, website assessed 3 March 2015.

FAO, 2012. Food and Agriculture Organization of the United Nations. Current worldfertilizer trends and outlook to 2016. ftp:// ftp. fao. org/ ag/ agp /docs /cwfto 16. pdf, website assessed $10 \mathrm{March}$ 2015.

Farzaneh, M., S. Wichmann, H. Vierheilig, and H.P. Kaul, 2009. The effects of arbuscular mycorrhiza and nitrogen nutrition on growth of chickpea and barley. Pflanzenbauwissenschaften, 13: 15-22.

Feller, C., and M.H. Beare, 1997. Physical control of soil organic matter dynamics in the tropics. Geoderma 79:69-116 
Feller, C., C. Franc, ois, G. Villemin, J.M. Portal, F. Toutain, and J.L. Morel, 1991. Nature des mati`eres organiques associ'ees aux fractions argileuses d'un sol ferrallitique. CRAcad Sci., 312:14911497.

Ferrando L, and A. Fernández-Scavino, 2013. Functional diversity of endophytic bacteria. In: Aroca R. (Ed): Symbiotic Endophytes. Heidelberg: Springer, 195-211.

Figueiredo, M.V.B., C.R. Martinez, H.A. Burity, and C.P. Chanway, 2008. Plant growth-promoting rhizobacteria for improving nodulation and nitrogen fixation in the common bean (Phaseolus vulgaris L.) World J. Microbiol. Biotechnol., 24: 1187-1193.

Figueiredo, M.V.B., L. Seldin, F.F. de Araujo, and R.L.R. Mariano, 2011a. Plant growthpromoting rhizobacteria: fundamentals and applications. In: Plant Growth andHealth Promoting Bacteria. Springer, p. 21-43.

Figueiredo, M.V.B., L. Seldin, F.F. de Araujo, and R.L.R. Mariano, 2011b. Plant growthpromoting rhizobacteria: fundamentals and applications. In: Maheshwari, D.K. (Ed.): Plant Growth and Health Promoting Bacteria, vol. 18. Springer, BerlinHeidelberg, 21-43.

Fillion, M., 2008. Do transgenic plants affect rhizobacteria populations? Microb. Biotechnol. 1,463475.

Flores-Felix, J.D., E. Menendez, L.P. Rivera, et al., 2013. Use of Rhizobium legumin Sarum as a potential biofertilizer for Lactuca sativa and Daucus carota crops. J. Plant Nutr. Soil Sc., 176: 876882.

Flores-Felix, J.D., L.R. Silva, L.P. Rivera, et al., 2015. Plants probiotics as a tool to produce highly functional fruits: the case of Phyllobacterium and vitamin $\mathrm{C}$ in strawberries. PLoS One, 10: e0122281.

Fonte, S.J., M. Nesper, D. Hegglin, J.E. Velásquez, B. Ramirez, I.M. Rao, S.M. Bernasconi, E.K. Bünemann, E. Frossard, and A. Oberson, 2014. Pasture degradation impacts soil phosphorus storage via changes to aggregate-associated soil organic matter in highly weathered tropical soils. Soil Biol. Biochem., 68:150-157.

Foster, R., 1981. Localization of organic materials in situ in ultrathin sections of natural soil fabrics using cytochemical techniques. In: Bisdom EBA (ed. Working group on submicroscopy, Wageningen, The Netherlands, 309-319.

Freitas, M.A., F.H.V. Medeiros, I.S. Melo, et al., 2019. Stem inoculation with bacterial strains Bacillus amyloliquefaciens (GB03. and Microbacterium imperiale (MAIIF2a. mitigates Fusarium root rot in cassava. Phytoparasitica, 47: 135-142.

Frey, S.D., E.T. Elliott, and K. Paustian, 1999. Bacterial and fungal abundance and biomass in conventional and no-tillage agroecosystems along two climatic gradients. Soil Biol. Biochem., 31:573-585.

Fujisaki, K., A.-S. Perrin, T. Desjardins, M. Bernoux, L.C. Balbino, and M. Brossard, 2015. From forest to cropland and pasture systems: a critical review of soil organic carbon stocks changes in Amazonia. Glob. Change Biol., 21: 2773-2786.

Galloway, J.N., A.R. Townsend, J.W. Erisman, M. Bekunda, Z. Cai, J.R. Freney, L.A. Martinelli, S.P. Seitzinger, and M.A. Sutton, 2008. Transformation of the nitrogen cycle: recent trends, questions, and potential solutions. Science, 320(5878): 889-892.

Garcia-Fraile, P., L. Carro, M. Robledo, et al., 2012. Rhizobium promotes non-legumes growth and quality in several production steps: towards a biofertilization of edible raw vegetables healthy for humans. PLoS One, 7: e38122

Gijsman, A.J., and R.J. Thomas, 1995. Aggregate size distribution and stability of an Oxisol under legume-based and pure grass pastures in the Eastern Colombian savannas. Aust. J. Soil Res., 33:153-165.

Gilbert Koskey, W.M. Simon, A. Richard, M.N. Ezekiel and M.M. John, 2021. Potential Use of Beneficial Microorganisms for Soil Amelioration, Phytopathogens Biocontrol, and Sustainable Crop Production in Smallholder Agro ecosystems, Frontiers in Sustainable Food Systems www.frontiersin.org, 5: 606308.

Glick, B.R., 2020. Introduction to plant growth-promoting bacteria. beneficial Plant-Bacterial Interactions. Springer, Cham, 1-37.

Glick, B.R., 1995. The enhancement of plant growth by free-living bacteria. Can. J. Microbiol., 41 (2): 109-117. 
Glick, B.R., 2012. Plant growth-promoting bacteria: mechanisms and applications. Scientifica 2012.

Glick, B.R., 2015. Introduction to Plant Growth-promoting Bacteria. BeneficialPlant-Bacterial Interactions. Springer, 1-28.

Godfray, H.C.J., J.R. Beddington, I.R. Crute, L. Haddad, D. Lawrence, J.F. Muir, J. Pretty, S. Robinson, S.M. Thomas, and C. Toulmin, 2010. Food Security. The Challenge of Feeding 9 Billion People. Science, 327 (5967): 812-818.

Goldstein, A.H., 1994. Involvement of the quinoprotein glucose dehydrogenase in the solubilization of exogenous phosphates by gram-negative bacteria. In: Torriani-Gorini A, Yagil E, Silver S (eds. Phosphate in microorganisms: cellular and molecular biology. ASM, Washington, DC, 197-203.

Goldstein, A.H., 1994. Involvement of the quinoprotein glucose dehydrogenase inthe solubilization of exogenous phosphates by gram-negative bacteria. In:Phosphate in Microorganisms: Cellular and Molecular Biology. ASM Press, Washington, DC, 197-203.

Gorai, P.S., S.K. Gond, and N.C. Mandal, 2020. Endophytic microbes and their role to overcome abiotic stress in crop plants. Microbial. Serv. Restor. Ecol., 109-122.

Gordon, A.J., F.R. Minchin, L. Skot, and C.L. James, 1997. Stress-induced decline in nitrogen fixation are related to sucrose synthase activity. Plant Physiol., 114: 937-946.

Goswami, D., K. Patel, S. Parmar, H. Vaghela, N. Muley, P. Dhandhukia, and J.N. Thakker, 2015. Elucidating multifaceted urease producing marine Pseudomonas aeruginosa BG as a cogent PGPR and bio-control agent. Plant Growth Regul., 75(1): 253-263.

Goulart, M.C., L.G. Cueva-Yesquén, K.J.H. Martinez, et al., 2019. Comparison of specific endophytic bacterial communities in different developmental stages of Passiflora incarnata using culturedependent and culture-independent analysis. Microbiologyopen, 8: e896.

Graf, F., and M. Frei, 2013. Soil aggregate stability related to soil density, root length, and mycorrhiza using site-specific Alnus incana and Melanogaster variegatus sl.Ecol. Eng., 57: 314-323.

Granada, C.E., L.M.P. Passaglia, E.M. de Souza, et al., 2018. Is phosphate solubilization the forgotten child of plant growth-promoting rhizobacteria? Front Microbiol., 9: 2054.

Gray, E.J., and D.L. Smith, 2005. Intracellular and extracellular PGPR: commonalities and distinctions in the plant-bacterium signaling processes. Soil Biol. Biochem., 37: 395-412.

Griffiths, E., 1965. Microorganisms and soil structure. Biol. Rev., 40:129-142

Griffiths, S.M., M. Galambao, J. Rowntree, et al., 2020. Complex associations between cross-kingdom microbial endophytes and host genotype in ash dieback disease dynamics. J. Ecol., 108: 291-309.

Groffman, P., 2012. Terrestrial denitrifi cation: challenges and opportunities. Ecol. Proc., 1: 1-11

Grover, M., S.Z. Ali, V. Sandhya, et al., 2011. Role of microorganisms in adaptation of agriculture crops to abiotic stresses. World J. Microb. Biot., 27: 1231-1240.

Guggenberger, G., E.T. Elliott, S.D. Frey, J. Six, and K. Paustian, 1999. Microbial contributions to the aggregation of a cultivated grassland soil amended with starch. Soil Biol. Biochem., 3:407-419

Gupta, C., P. Dhan, and G. Sneh, 2014. Role of microbes in combating global warming, International Journal of Pharmaceutical Sciences Letters, 4: 359-363.

Gupta, G., J. Panwar, and P.N. Jha, 2013. Natural occurrence of Pseudomonas aeruginosa, a dominant cultivable diazotrophic endophytic bacterium colonizing Pennisetum glaucum (L.) R. Br. Appl Soil Ecol., 64: 252-261

Gupta V, and JJ Germida, 1988. Distribution of microbial biomass and its activity in different soil aggregate size classes as affected by cultivation. Soil Biol. Biochem., 20:777-786

Gupta, V.V.S.R., and J.J. Germida, 2015. Soil aggregation: influence on microbial biomass and implications for biological processes. Soil Biol. Biochem., 80 (0):A3-A9.

Gyaneshwar, P., G.N. Kumar, L. Parekh, and P. Poole, 2002. Role of soil microorganisms in improving P nutrition of plants. In: Food Security in Nutrient-Stressed Environments: Exploiting Plants' Genetic Capabilities. Springer, 133-143.

Halvorson, H., A. Keynan, and H. Kornberg, 1990. Utilization of calcium phosphates formicrobial growth at alkaline pH. Soil Biol. Biochem., 22 (7): 887-890.

Hamblin, A., 1985. The influence of soil structure on water movement, crop growth, and water uptake. Adv. Agron., 38:95-158

Han, H., and K. Lee, 2005. Phosphate and potassium solubilizing bacteria effect on mineral uptake, soil availability and growth of eggplant. Res. J. Agric. Biol. Sci., 176-180. 
Harris, R.F., O.N. Allen, G. Chesters, and O.J. Attoe, 1963. Evaluation of microbial activity in soil aggregate stabilization and degradation by the use of artificial aggregates. Soil Sci. Soc. Am. Proc., 27:542-545.

Harrison, J.G., and E.A. Griffin, 2020. The diversity and distribution of endophytes across biomes, plant phylogeny and host tissues: how far have we come and where do we go from here? Environ Microbiol., 22: 2107-2123.

Hashem, A., B. Tabassum, and E. Fathi Abd_Allah, 2019. Bacillus subtilis: A plant-growth promoting rhizobacterium that also impacts biotic stress. Saudi J. Biol. Sci., 26: 1291-1297.

Haynes, R.J., and M.H. Beare, 1997. Influence of six crop species on aggregate stability and some labile organic matter fractions. Soil Biol. Biochem., 29:1647-1653.

Haynes, R.J., and R.S. Swift, 1990. Stability of soil aggregates in relation to organic constituents and soil water content. J. Soil Sci., 41:73-83.

Haynes, R.J., R.S. Swift, and R.C. Stephen, 1991. Influence of mixed cropping rotations (pasturearable. on organic matter content, stable aggregation and clod porosity in a group of soils. Soil Tillage Res., 19:77-87.

He, L.Y., Y.F. Zhang, H.Y. Ma, L.N. Su, Z.J. Chen, Q.Y. Wang, Q. Meng, and S.X. Fang, 2010. Characterization of copper resistant bacteria and assessment of bacterial communities in rhizosphere soils of copper-tolerant plants. Appl. Soil Ecol., 44:49-55.

Heath, K.D., and M.A. Grillo 2016. Rhizobia: tractable models for bacterial evolutionary ecology. Environmental Microbiology, 18: 4307-4311.

Herridge, D.F., M.B. Peoples, and R.M. Boddey, 2008. Global inputs of biological nitrogen fixation in agricultural systems. Plant Soil, 311: 1-18.

Hietz, P., 2005. Conservation of vascular epiphyte diversity in Mexican coffee plantations. Conserv Biol., 19:391-399

Hoffmann, M.C., A. Müller, M. Fehringer, et al., 2014. Coordinated Expression of fdxD and molybdenum nitrogenase genes promotes nitrogen fixation by Rhizobacteria capsulatus in the presence of oxygen. J. Bacteriol., 196: 633-640.

Hogh-Jensen, H., J.K. Schjoerring, and J.F. Soussana, 2002. The influence of phosphorus deficiency on growth and nitrogen fixation of white clover plants. Ann. Bot. 90: 745-753.

Holland, E.A., and D.C. Coleman, 1987. Litter placement effects on microbial and organic matter dynamics in an agrosystem. Ecology, 68:425-433

Hollowell, A.C., J.U. Regus, D. Turissini, K.A. Gano-Cohen, R. Bantay, A. Bernardo, D. Moore, J. Pham, and J.L. Sachs 2016. Metapopulation dominance and genomic island acquisition of Bradyrhizobium with superior catabolic capabilities. Proceedings of the Royal Society of London B: Biological Sciences, 283.

Hong, C.E., J.U. Kim, J.W. Lee, et al., 2019. Metagenomic analysis of bacterial endophyte community structure and functions in Panax ginseng at different ages. 3 Biotech., 9: 300.

Hubbell, D.H., and G. Kidder, 2009. Biol. Nitrogen Fixation, 1-4.

Ibijbijen, J., S. Urquiaga, M. Ismaili, B. Alves, and R. Boddey, 1996. Effect of arbuscular mycorrhizal fungi on growth, mineral nutrition and nitrogen fixation of threevarieties of common beans (Phaseolus vulgaris. New Phytol., 134 (2):353-360.

Igual, J.M., A. Valverde, E. Cervantes, and E. Velázquez, 2001. Phosphate-solubilizingbacteria as inoculants for agriculture: use of updated molecular techniques intheir study. Agronomie, 21 (67): 561-568.

Illmer, P., and F. Schinner, 1992. Solubilization of inorganic phosphates by microorganisms isolated from forest soils. Soil Biol. Biochem., 24 (4): 389-395.

Indiragandhi, P., R. Anandham, M. Madhaiyan, and T. Sa, 2008. Characterization of plant growthpromoting traits of bacteria isolated from larval guts of diamondback moth Plutella xylostella (Lepidoptera: Plutellidae. Curr. Microbiol., 56 (4): 327-333.

Israel, D.W., 1987. Investigation of the role of phosphorus in symbiotic dinitrogen fixation. Plant Physiol., 84: 835-840.

Jama B., J.K. Ndufa, R.J. Buresh, and K.D. Shepherd, 2013. Vertical Distribution of Roots and Soil Nitrate: Tree Species and Phosphorus Effects. Soil Science Society of America Journal, 62: 280286. 
Jamir, E., R.D. Kangabam, K. Borah, et al., 2019. Role of soil microbiome and enzyme activities in plant growth nutrition and ecological restoration of soil health. In: Kumar A, Sharma S. (Eds): Microbes and enzymes in soil health and bioremediation. Singapore: Springer, 16: 99-132.

Jastrow, J.D., R.M. Miller, and J. Lussenhop, 1998. Contributions of interacting biological mechanisms to soil aggregate stabilization in restored prairies. Soil Biol. Biochem., 30:905-916

Jha, C.K., D. Patel, N. Rajendran, et al., 2010. Combinatorial assessment on dominance and informative diversity of PGPR from rhizosphere of Jatropha curcas L. J. Basic Microbiol., 50: 211-217.

Jiang, C.Y., X.F. Sheng, M. Qian, and Q.Y. Wang, 2008. Isolation and characterization of a heavy metal resistant Burkholderia sp. From heavy metal-contaminated paddy field soil and its potential in promoting plant growth and heavy metal accumulation in metal polluted soil. Chemosphere, $72: 157-164$

Jiao, R., S. Munir, P.F. He, et al., 2020. Biocontrol potential of the endophytic Bacillus amyloliquefaciens YN201732 against tobacco powdery mildew and its growth promotion. Biol. Control, 143: 104160.

Jiefei, M., G.J.N. Klaas, C.D. Stefan, W.D. Louis and C. Baoliang, 2019. Understanding the mechanisms of soil water repellency from nanoscale to ecosystem scale: a review, Journal of Soils and Sediments, 19:171-185.

Jocteur, M.L., J.N. Ladd, R.W. Fitzpatrick, R.C. Foster, and M. Raupach, 1991. Components and microbial biomass content of size fractions in soils of contrasting aggregation. Geoderma, 49:3762 .

Jones, D.L., and E. Oburger, 2011. Solubilization of phosphorus by soil microorganisms. In: Phosphorus in Action. Springer, 169-198.

Jung, B.K., S.J. Hong, G.S. Park, et al., 2018. Isolation of Burkholderia cepacia JBK9 with plant growth-promoting activity while producing pyrrolnitrin antagonistic to plant fungal diseases. Appl. Biol. Chem., 61: 173-180.

Kabir, M., J.L. Chotte, M. Rahman, R. Bally, and M.L. Jocteur, 1994. Distribution of soil fractions and location of soil bacteria in a vertisol under cultivation and perennial grass. Plant Soil, 163:243255118.

Kanchan, V., K. Nitin, Sh. Chitrakshi, M. Swati, and B.A.V. Sahil, 2020. Revisiting Plant-Microbe Interactions and Microbial Consortia Application for Enhancing Sustainable Agriculture: A Review. Frontiers in Microbiology www.frontiersin.org, 11:560406.

Kannapiran, E., and V.S. Ramkumar, 2011. Inoculation effect of nitrogen fixing and phosphatesolubilizing bacteria to promote growth of black gram (Phaseolus mungo Roxb ; Eng. Ann. Biological Res., 2: 615-621.

Karivaradharajan S., Y. Vandana, T. Deepti, W.D. Dolly, K. Annapurna and K. Shiv, 2020. Significance of Plant Growth Promoting Rhizobacteria in Grain Legumes: Growth Promotion and Crop Production. Plants, 9: 1596.

Kaschuk, G., P.A. Leffelaar, K.E. Giller, O. Alberton, M. Hungria, and T.W. Kuyper, 2010. Responses of legumes to rhizobia and arbuscular mycorrhizal fungi: ameta-analysis of potential photosynthate limitation of symbioses. Soil Biol. Biochem., 42 (1): 125-127.

Kemper, W.D., and R.C. Rosenau, 1986. Methods of soil analysis. Part 1. In: Physical andMineralogical Methods. American Society of Agronomy, Inc.

Khalid, A., M. Arshad, B. Shaharoona, et al., 2009. Plant Growth Promoting Rhizobacteria and Sustainable Agriculture. Microbial Strategies for Crop Improvement: Berlin: Springer, 133-160.

Khaliq, A., and M.K. Abbasi, 2015. Improvements in the physical and chemical characteristics of degraded soils supplemented with organic-inorganic amendments in the Himalayan region of Kashmir, Pakistan. CATENA, 126: 209-219.

Khan, M.A., S. Asaf, and A.L. Khan, 2020. Extending thermotolerance to tomato seedlings by inoculation with SA1 isolate of Bacillus cereus and comparison with exogenous humic acid application. PLoS One, 15: e0232228.

Khan, M.A., S. Asaf, A.L. Khan, et al., 2020. Thermotolerance effect of plant growth-promoting Bacillus cereus SA1 on soybean during heat stress. BMC Microbiol., 20: 175.

Khan, M.S., A. Rizvi, S. Saif, et al., 2017. Phosphate-solubilizing microorganisms in sustainable production of wheat: Current perspective. Probiotics in Agroecosystem. Singapore: Springer, 5181 . 
Khan, A.G., 2005. Role of soil microbes in the rhizospheres of plants growing on trace metal contaminated soils in phytoremediation. J. Trace Ele. Med. Biol., 18(4): 355-364.

Khare, E., and A. Yadav, 2017. The role of microbial enzyme systems in plant growth promotion. Clim Change Environ Sustain 5: 122-145.

Kim, N., H.W. Jeon, M. Mannaa, et al., 2019. Induction of resistance against pine wilt disease caused by Bursaphelenchus xylophilus using selected pine endophytic bacteria. Plant Pathol., 68: 434444.

Kim, S.W., M. Miyahara, S. Fushinobu, T. Wakagi, and H. Shoun, 2010. Nitrous oxide emission from nitrifying activated sludge dependent on denitrifi cation by ammonia-oxidizing bacteria. Bioresour Technol., 101: 3958-3963.

Kim, J., and D.C. Rees, 1994. Nitrogenase and biological nitrogen fixation. Biochemistry33 (2): 389397.

Kiss, T., and E. Farkas, 1998. Metal-binding ability of desferrioxamine B. J. Incl.Phenom. Mol. Recognit. Chem. 32 (2-3): 385-403.

Kneip, C., C.P. Lockhart, C. Voß, and U.G. Maier, 2007. Nitrogen fixation in eukaryotes-new models for symbiosis C. BMC Evol. Biol. 7 (1): 55.

Kohler-Milleret, R., B. Le, R.-C. Ayon, C. Chenu, J.-M. Gobat, P. Boivin, 2013.Impact of two root systems, earthworms and mycorrhizae on the physical properties of an unstable silt loam Luvisol and plant production. Plant Soil, 370(1-2): 251-265.

Kong, P., and C.X. Hong, 2020. Endophytic Burkholderia sp. SSG as a potential biofertilizer promoting boxwood growth. Peer, $J$ 8: e9547.

Kononova, M.M., 2013. Soil organic matter: Its nature, its role in soil formation andin soil fertility. Elsevier.

Kopittke, P.M., N.W. Menzies, P. Wang, et al., 2019. Soil and the intensification of agriculture for global food security. Environ Int 132: 105078.

Koskey, G., S.W. Mburu, J.M. Kimiti, et al., 2018. Genetic characterization and diversity of Rhizobium isolated from root nodules of mid-altitude climbing bean (Phaseolus vulgaris L.) Varieties. Front Microbiol., 9: 968.

Koskey, G., S.W. Mburu, E.M. Njeru, et al., 2017. Potential of native rhizobia in enhancing nitrogen fixation and yields of climbing beans (Phaseolus vulgaris L.) in contrasting environments of Eastern Kenya. Front Plant Sci., 8: 443.

Kour, D., K.L. Rana, A.N. Yadav, et al., 2020. Microbial biofertilizers: Bioresources and eco-friendly technologies for agricultural and environmental sustainability. Biocatal. Agric. Biotechnol., 23: 101487.

Kour, D., K.L. Rana, N. Yadav, et al., 2019. Rhizospheric microbiomes: Biodiversity, mechanisms of plant growth promotion, and biotechnological applications for sustainable agriculture. In: Kumar A, Meena V. (Eds): Plant growth promoting rhizobacteria for agricultural sustainability. Singapore: Springer, 19-65.

Kraaijvanger, R., and T. Veldkamp, 2014. Grain productivity, fertilizer response and nutrient balance of farming systems in Tigray, Ethiopia: A multi-perspective view in relation to soil fertility degradation. Land Degrad. Dev. 26 (7): 701-710.

Kristine A.N. and J.H. Jonathan, 2013. Roles of Biology, Chemistry, and Physics in Soil Microaggregates Formation and Stabilization, The Open Agriculture Journal, 7: 107-117

Krober, M., D. Wibberg, R. Grosch, et al., 2014. Effect of the strain Bacillus amyloliquefaciens FZB42 on the microbial community in the rhizosphere of lettuce under field conditions analyzed by whole metagenome sequencing. Front Microbiol., 5: 252.

Ku, Y.S., H.M. Rehman, and H.M. Lam, 2019. Possible roles of rhizospheric and endophytic microbes to provide a safe and affordable means of crop biofortification. Agronomy 9: 764.

Kucey, R.M.N., 1983. Phosphate-solubilizing bacteria and fungi in various cultivated and virgin Alberta soils. Can. J. Soil Sci., 63: 671-678.

Kucey, R.M.N., H.H. Janzen, and M.E. Leggett, 1989. Microbially mediated increases in plantavailable phosphorus. Adv. Agron., 42: 199-228.

Kumar, A., I. Bahadur, and B.R. Maurya, 2015. Does a plant growth-promoting rhizobacteria enhance agricultural sustainability, J. Pure. Appl. Microbiol., 9: 715-724. 
Kumar, A., and J.P. Verma, 2018. Does plant-Microbe interaction confer stress tolerance in plants: A review? Microbiol Res., 207: 41-52.

Kumar, J., D. Singh, P. Ghosh, et al., 2017. Endophytic and epiphytic modes of microbial interactions and benefits. Plant-microbe interactions in agro-ecological perspectives. Singapore: Springer, $255-771$.

Kumar, K., G. Pal, A. Verma, et al., 2020. Seed inhabiting bacterial endophytes of finger millet (Eleusine coracana L.) promote seedling growth and development, and protect from fungal disease. S. Afr. J. Bot., 134: 91-98.

Kumar, K.V., S. Srivastava, N. Singh, and H.M. Behl, 2009. Role of metal resistant plant growth promoting bacteria in ameliorating fly ash to the growth of Brassica juncea. J. Hazard Mater, 170:51-57.

Kumar, V., L. Jain, S.K. Jain, et al., 2020. Bacterial endophytes of rice (Oryza sativa L.) and their potential for plant growth promotion and antagonistic activities. S. Afr. J. Bot., 134: 50-63.

Kumar, J., S. Divya, G. Paushali , and K. Ashok, 2017. Endophytic and Epiphytic Modes of Microbial Interactions and Benefits, chapter, Springer Nature Singapore Pte. Ltd.

Kumar, V., M. Sarma, K. Saharan, R. Srivastava, L. Kumar, V. Sahai, V. Bisaria, and A. Sharma, 2012. Effect of formulated root endophytic fungus Piriformosporaindica and plant growth promoting rhizobacteria fluorescent pseudomonadsR62 and R81 on Vigna mungo. World J. Microbiol. Biotechnol., 28 (2): 595-603.

Kunda, P., P.K. Dhal, and A. Mukherjee, 2018. Endophytic bacterial community of rice (Oryza sativa L.) from coastal saline zone of West Bengal: 16S rRNA gene-based metagenomics approach. Meta Gene., 18: 79-86.

Kwon, S.W., J.Y. Park, J.S. Kim, et al., 2005. Phylogenetic analysis of the genera Bradyrhizobium, Mesorhizobium, Rhizobium and Sinorhizobium on the basis of 16S rRNA gene and internally transcribed spacer region sequences. Int. J. Syst. Evol. Microbiol., 55: 263-270.

Lal, R., 2015. Restoring soil quality to mitigate soil degradation. Sustainability 7: 5875-5895.

Lally, R.D., P. Galbally, A.S. Moreira, et al., 2017. Application of endophytic pseudomonas fluorescens and a bacterial consortium to Brassica napus can increase plant height and biomass under greenhouse and field conditions. Front Plant Sci., 8: 2193.

Larimer, A.L., J.D. Bever, and K. Clay, 2010. The interactive effects of plant microbialsymbionts: a review and meta-analysis. Symbiosis, 51 (2): 139-148.

Lazali, M., and A. Bargaz, 2017. "Examples of belowground mechanisms enabling legumes to mitigate phosphorus deficiency," in Legume Nitrogen Fixation in Soils with Low Phosphorus Availability, ed. L.-S.P. Sulieman (Trans.) (Berlin: Springer International Publishing): 135-152.

Lazcano C, and J. Dominguez, 2011. The use of vermicompost in sustainable agriculture: impact on plant growth and soil fertility. In: Miransari M (ed. Soil nutrients. Nova Science, New York, pp 123.

Le Cocq, K., S.J. Gurr, P.R. Hirsch, et al., 2017. Exploitation of endophytes for sustainable agricultural intensification. Mol. Plant Pathol., 18: 469-473.

Leifheit, E., E. Verbruggen, and M. Rillig, 2015. Arbuscular mycorrhizal fungi reducedecomposition of woody plant litter while increasing soil aggregation. SoilBiol. Biochem., 81: 323-328.

Leifheit, E., S. Veresoglou, A. Lehmann, E.K. Morris, and M. Rillig, 2014. Multiple factors influence the role of arbuscular mycorrhizal fungi in soil aggregation-ameta-analysis. Plant Soil 374 (12): 523-537.

Leite, J., D. Fischer, L.F.M. Rouws, et al., 2017. Cowpea nodules harbor non-rhizobial bacterial communities that are shaped by soil type rather than plant genotype. Front Plant Sci., 7: 2064.

Lesueur, D., R. Deaker, L. Herrmann, et al., 2016. The production and potential of biofertilizers to improve crop. Bioformulations: For sustainable agriculture. In: Arora N, Mehnaz S, Balestrini R. (Eds): New Delhi: Springer, 71-92.

Letey, J., 1985. Relationship between soil physical properties and crop production. In: Stewart BA (ed. Advance in soil science. Springer, Berlin Heidelberg New York, 277.

Liana T.B., 2020. Evolving together, evolving apart: measuring the fitness of rhizobial bacteria in and out of symbiosis with leguminous plants, New Phytologist, 228: 28-34 
Linquist, B.A., L. Liu, C. van Kessel, and K.J. van Groenigen, 2013. Enhanced efficiency nitrogen fertilizers for rice systems: meta-analysis of yield and nitrogen uptake. Field Crops Res. 154: 246254.

Liotti, R.G., M.I. da Silva Figueiredo, G.F. da Silva, et al., 2018. Diversity of cultivable bacterial endophytes in Paullinia cupana and their potential for plant growth promotion and phytopathogen control. Microbiol Res., 207: 8-18.

Lisette, J., C. Xavier, and J.J. Germida, 2003. Selective interactions between arbuscular mycorrhizal fungi and Rhizobium leguminosarum bv, Viceae enhance pea yield and nutrition. Biol. Fertil. Soil, 37: 261-267.

Liu, H.W., L.C. Carvalhais, M. Crawford, et al., 2017. Inner plant values: Diversity, colonization and benefits from endophytic bacteria. Front Microbiol., 8: 2552.

Lourenço, K.S., N.A. Cassman, A.S. Pijl, et al., 2018. Nitrosospira sp. govern nitrous oxide emissions in a tropical soil amended with residues of bioenergy crop. Front Microbiol., 9: 674.

Lubbers, I.M., G. van, K.J. roenigen, S.J. Fonte, J. Six, L. Brussaard, G. van, J.W. Roenigen, 2013. Greenhouse-gas emissions from soils increased byearthworms. Nat. Clim. Change, 3 (3): 187-194.

Lugtenberg, B., and F. Kamilova, 2009. Plant-growth-promoting rhizobacteria. Ann. Rev. Microbiol., 63: 541-556.

Lynch, J.M., and E. Bragg, 1985. Microorganisms and soil aggregate stability. Adv. Soil Sci., 2:134170

Ma, Y., M.N.V. Prasad, M. Rajkumar, and H. Freitas, 2011. Plant growth promoting rhizobacteria and endophytes accelerate phytoremediation of metalliferous soils. Biotechnol. Adv., 29:248-258

Ma, Y., M. Rajkumar, C. Zhang, and H. Freitas, 2016. Beneficial role of bacterial endophytes in heavy metal phytoremediation. J. Environ. Manag., 174:14-25.

Ma, J.F., 2005. Plant root responses to three abundant soil minerals: silicon, aluminum and iron. Crit. Rev. Plant Sci., 24 (4): 267-281.

Ma, Y., M. Rajkumar, and H. Freitas, 2009. Inoculation of plant growth promoting bacterium Achromobacter xylosoxidans strain Ax10 for the improvement ofcopper phytoextraction by Brassica juncea. J. Environ. Manag., 90 (2): 831-837.

Maaß, S., T. Caruso, and M.C. Rillig, 2015. Functional role of microarthropods in soil aggregation. Pedobiologia. soil microbial communities and plant traits in a species-rich grassland under longterm climate change. Ecology and Evolution, 7: 855-862.

Macedo-Raygoza, G.M., B. Valdez-Salas, F.M. Prado, et al., 2019. Enterobacter cloacae, an endophyte that establishes a nutrient-transfer symbiosis with banana plants and protects against the black sigatoka pathogen. Front Microbiol., 10: 804.

Machuca, A., G. Pereira, A. Aguiar, and A. Milagres, 2007. Metal-chelating compoundsproduced by ectomycorrhizal fungi collected from pine plantations. Lett. Appl.Microbiol., 44 (1): 7-12.

Mahmood, A., K. Takagi, K. Ito, et al., 2019. Changes in endophytic bacterial communities during different growth stages of cucumber (Cucumis sativus L.) World J. Microbiol Biotechnol., 35: 104.

Majeed, A., M.K. Abbasi, S. Hameed, et al., 2015. Isolation and characterization of plant growthpromoting rhizobacteria from wheat rhizosphere and their effect on plant growth promotion. Front Microbiol., 6: 198.

Malik, K., M. Mirza, U. Hassan, S. Mehnaz, G. Rasul, J. Haurat, R. Bally, and P. Normand, 2002. The role of plant-associated beneficial bacteria in rice-wheat cropping system. Biofertilizers in action Rural industries research and development Corporation. Canberra, 73-83.

Malusá, E., and N. Vassilev, 2014. A contribution to set a legal framework for biofertilizers. Appl Microbiol Biotechnol., 98: 6599-6607.

Malusa, E., L. Sas Paszt, W. Popi Òska, and E. Wurawicz, 2007. The effect of a substrate containing arbuscular mycorrhizal fungi and rhizosphere microorganisms (Trichoderma, Bacillus, Pseudomonas and Streptodornase. and foliar fertilization on growth response and rhizosphere $\mathrm{pH}$ of three strawberry cultivars. Int. J. Fruit Sci., 6: 25-41.

Malusa, E., L. Sas-Paszt, and J. Ciesielska, 2012. Technologies for beneficial microorganisms inocula used as biofertilizers. Sci. World J., 2012:491206.

Mansfeld-Giese, K., J. Larsen, and L. Bødker, 2002. Bacterial populations associated with mycelium of the arbuscular mycorrhizal fungus Glomus intraradices. FEMS Microbiol. Ecol., 41 (2): 133140 . 
Marques, J.M., T.F. da Silva, R.E. Vollu, A.F. Blank, G.-C. Ding, L. Seldin, and K. Smalla, 2014. Plant age and genotype affect the bacterial community composition in the tuber rhizosphere of feldgrown sweet potato plants. FEMS Microbiol. Ecol., 88(2):424-435.

Marshner, H., 1995. Mineral nutrition of higher plants. Academic Press, New York San Diego, Ltd.

Martin, S., S. Mooney, M. Dickinson, and H. West, 2012. The effects of simultaneous root colonisation by three Glomus species on soil pore characteristics. Soil Biol. Biochem., 49: 167-173.

Martinez-Viveros, O., M. Jorquera, D.E. Crowley, G. Gajardo, and M.L. Mora, 2010. Mechanisms and practical considerations involved in plant growth promotion by rhizobacteria. J. Soil Sci. Plant Nutr., 10: 293-319.

Masood, S., and A. Bano, 2016. Mechanism of potassium solubilization in the agricultural soils by the help of soil microorganisms. In: Meena V, Maurya B, Verma J. et al., (Eds): Potassium solubilizing microorganisms for sustainable agriculture. New Delhi: Springer, 137-147.

Mathesius, U., H.R.M. Schlaman, H.P. Spaink, C. Sautter, B.G. Rolfe, and M.A. Djordjevic, 1998. Auxin transport inhibition precedes root nodule formation in white clover roots and is regulated by flavonoids and derivatives of chitin oligosaccharides. Plant J., 14: 23-34

Mathur, A., A. Koul, and J. Hattewar, 2019. Plant growth-promoting rhizobacteria (pgprs): significant revolutionary tools for achieving long-term sustainability and combating the biotic stress caused by the attack of pathogens affecting crops in agriculture, In: Sayyed R. (Ed): Plant growth promoting rhizobacteria for sustainable stress management. Singapore: Springer, 379-388.

Mburu, S.W., G. Koskey, and J.M. Kimiti, et al., 2016. Agrobiodiversity conservation enhances food security in subsistence-based farming systems of Eastern Kenya. Agric. Food Secur., 5: 19.

Mburu SW, G Koskey, EM Njeru, et al., 2020. Differential response of promiscuous soybean to local diversity of indigenous and commercial Bradyrhizobium inoculation under contrasting agroclimatic sones. Int. J. Plant Prod., 14: 578-582.

Medina, A., A. Roldán, and R. Azcón, 2010. The effectiveness of arbuscular-mycorrhizalfungi and Aspergillus niger or Phanerochaete chrysosporium treated organic amendments from olive residues upon plant growth in a semi-arid degradedsoil. J. Environ. Manage., 91 (12): 2547-2553.

Medina, A., M. Vassileva, F. Caravaca, A. Roldán, and R. Azcón, 2004. Improvement of soil characteristics and growth of Dorycnium pentaphyllum by amendment with agrowastes and inoculation with AM fungi and/or the yeast Yarowialipolytica. Chemosphere, 56 (5): 449-456.

Meena, V.S., I. Bahadur, B.R. Maurya, et al., 2016. Potassium-solubilizing microorganism in evergreen agriculture: An overview. Potassium solubilizing microorganisms for sustainable agriculture. New Delhi: Springer, 1-20.

Meena, V.S., B.R. Maurya, and J.P. Verma, 2014. Does a rhizospheric microorganism enhance K and availability in agricultural soils? Microbiol. Res., 169: 337-347.

Meena, V.S., B. Maurya, and J.P. Verma, 2014. Does a rhizospheric microorganism enhance K and availability in agricultural soils? Microbiol. Res., 169 (5):337-347.

Meng, L., A. Zhang, F. Wang, X. Han, D. Wang, and S. Li, 2015. Arbuscular mycorrhizal fungi and Rhizobium facilitate nitrogen uptake and transfer in soybean/maize intercropping system. Front. Plant Sci., 13:339.

Mengual, C., A. Roldán, F. Caravaca, and M. Schoebitz, 2014a. Advantages of inoculation with immobilized rhizobacteria versus amendment with olive-mill waste in the afforestation of a semiarid area with Pinus halepensis Mill. Ecol. Eng., 73: 1-8.

Mengual, C., M. Schoebitz, R. Azcón, and A. Roldán, 2014b. Microbial inoculants andorganic amendment improves plant establishment and soil rehabilitation under semiarid conditions. J. Environ. Manage. 134: 1-7.

Miethke, M., and M.A. Marahiel, 2007. Siderophore-based iron acquisition and pathogen control. Microbiol. Mol. Biol. Rev., 71 (3): 413-451.

Miller, R., and J. Jastrow, 2000. Mycorrhizal fungi influence soil structure. Arbuscularmycorrhizas: physiology and function. Springer, 3-18.

Miller, S.H., P. Browne, C. Prigent-Combaret, E. Combes-Meynet, J.P. Morrissey, F. O'Gara, 2010. Biochemical and genomic comparison of inorganic phosphate solubilization in Pseudomonas species. Environ. Microbiol. Rep., 2 (3): 403-411.

Minden, V., and H.O. Venterink, 2019. Plant traits and species interactions along gradients of N, P and K availabilities. Funct. Ecol., 33: 1611-1626. 
Minerdi, D., R. Fani, R. Gallo, A. Boarino, and P. Bonfante, 2001. Nitrogen fixation genes in an endosymbiotic Burkholderia strain. Appl. Environ. Microbiol., 67(2): 725-732.

Ming, B.Y., Z.X. Min, and D.L. Smith, 2003. Enhanced soybean plant growth resulting from coinoculation of Bacillus strains with Brady rhizobium japonicum. Crop Sci., 43: 1774-1781.

Mirminachi, F., A. Zhang, and M. Roehr, 2002. Citric acid fermentation and heavymetal ions: II. The action of elevated manganese ion concentrations. Acta Biotechnol., 22 (3-4): 375-382.

Misra, N., G. Gupta, and P.N. Jha, 2012. Assessment of mineral phosphate solubilizing properties and molecular characterization of zinc tolerant bacteria. J. Basic Microbiol., 52:549-558

Mitran, T., R.S. Meena, R. Lal, et al., 2018. Role of soil phosphorus on legume production. In: Meena R, Das A, Yadav G, et al., (Eds): Legumes for soil health and sustainable management. Singapore: Springer, 487-510.

Moawad, H., W.M. Abd El-Rahim, D. Abd El-Aleem, et al., 2005. Persistence of two Rhizobium etli inoculant strains in clay and silty loam soils. J. Basic Microbiol., 45: 438-446.

Monreal, C.M., M. Schnitzer, H.R. Schulten, C.A. Campbell, and D.W. Anderson, 1995. Soil organic structures in macro and microaggregates of a cultivated brown chernozem. Soil Biol Biochem $27: 845-853$.

Montanarella, L., and R. Vargas, 2012. Global governance of soil resources as a necessary condition for sustainable development. Curr. Opin. Environ. Sustain., 4: 559-564.

Montgomery, D.R., 2007. Soil erosion and agricultural sustainability. Proc. Natl.Acad. Sci. U.S.A., 104 (33): 13268-13272.

Mortimer, P., M. Pérez-Fernández, and A. Valentine, 2008. The role of arbuscular mycorrhizal colonization in the carbon and nutrient economy of the tripartitesymbiosis with nodulated Phaseolus vulgaris. Soil Biol. Biochem., 40 (5):1019-1027.

Mrkovacki, N., and V. Milic, 2001. Use of Azotobacter chroococcum as potentially useful in agricultural application. Ann. Microbiol., 51 (2): 145-158.

Msimbira, L.A., and D.L. Smith, 2020. The roles of plant growth promoting microbes in enhancing plant tolerance to acidity and alkalinity stresses. Front Sustain Food Syst., 4: 106.

Nadeem, S.M., Z.A. Zahir, M. Naveed, and M. Arshad, 2009. Rhizobacteria containing A CCdeaminase confer salt tolerance in maize grown on salt-affected fields. Can. J. Microbiol., 55 (11): 1302-1309

Nag, P., S. Shriti, and S. Das, 2020. Microbiological strategies for enhancing biological nitrogen fixation in nonlegumes. J. Appl. Microbiol., 129: 186-198.

Nagpal, S., P. Sharma, A. Sirari, et al., 2020. Coordination of Mesorhizobium sp. and endophytic bacteria as elicitor of biocontrol against fusarium wilt in chickpea. Eur. J. Plant Pathol., 158: 143161.

Nasto, M.K., S. Alvarez-Clare, Y. Lekberg, B.W. Sullivan, A.R. Townsend, and C.C. Cleveland, 2014. Interactions among nitrogen fixation and soil phosphorusacquisition strategies in lowland tropical rain forests. Ecol. Lett., 17 (10):1282-1289.

Nayak, A.K., S.S. Panda, A. Basu, et al., 2018. Enhancement of toxic Cr (VI): Fe, and other heavy metals phytoremediation by the synergistic combination of native Bacillus cereus strain and Vetiveria zizanioides L. Int. J. Phytoremediation, 20: 682-691.

Neelipally, R.T.K.R., A.O. Anoruo, and S. Nelson, 2020. Effect of Co-Inoculation of Bradyrhizobium and Trichoderma on growth, development, and yield of Arachis hypogaea L. (Peanut. Agronomy 10: 1415.

Neubauer, U., G. Furrer, A. Kayser, and R. Schulin, 2000. Siderophores, NTA, and citrate: potential soil amendments to enhance heavy metal mobility in phytoremediation. Int. J. Phytorem., 2 (4): $353-368$.

Nguyen, N., and T. Bruns, 2015. The microbiome of pinus muricata ectomycorrhiza: community assemblages, fungal species effects, and burkholderia as importantbacteria in multipartnered symbioses. Microb. Ecol., 1-8.

Nielsen, K.L., A. Eshel, and J.P. Lynch, 2001. The effect of phosphorus availability on carbon economy of contrasting common bean (Phaseolus vulgaris L.) genotypes. J. Exp. Bot., 52: 329-339.

Njeru, E.M., M. Muthini, and M.M. Muindi, 2020. Exploiting arbuscular mycorrhizal fungirhizobialegume symbiosis to increase smallholder farmers' crop production and resilience under a 
changing climate. In: Singh B, Safalaoh A, Amuri N, et al., (Eds): Climate impacts on agricultural and natural resource sustainability in Africa. Springer, Cham, 471-488.

Nyamwange, M.M., E.M. Njeru, M. Mucheru-Muna, et al., 2018. Soil management practices affect arbuscular mycorrhizal fungi propagules, root colonization and growth of rainfed maize. AIMS Agric. Food, 3: 120-134.

Nyoki, D., and P.A. Ndakidemi, 2014a. Effects of Brady rhizobium japonicum inoculation and supplementation with phosphorus on macronutrients uptake in cowpea (Vigna unguiculata (L.) Walp. Am. J. Plant Sci. 5: 442-451.

Nziguheba, G., S. Zingore, J. Kihara, R. Merckx, S. Njoroge, and A. Otinga, 2016. Phosphorus in smallholder farming systems of sub-Saharan Africa: implications for agricultural intensification. Nutr. Cycl. Agroecosys., 104: 321-340.

Oades, J.M., and A.G. Waters, 1991. Aggregate hierarchy in soils. Aust. Soil Res., 29:815-828

Oldeman, L., Ru. Hakkeling, and W.G. Sombroek, 1990. World map of the status of human-induced soil degradation: an explanatory note, International Soil Reference and Information Centre.

Ortiz, N., E. Armada, E. Duque, A. Roldán, and R. Azcón, 2015. Contribution of arbuscular mycorrhizal fungi and/or bacteria to enhancing plant droughttolerance under natural soil conditions: Effectiveness of autochthonous orallochthonous strains. J. Plant Physiol., 174: 87-96.

Olubukola O, O.C. Babalola, B.S. Emmanuel, K.A. Adeleke, B. Odelade ', C. Nwachukwu, · E.A. Oluwatobi , T.A. Taofeek, and O.I. Nicholas , 2021. Rhizosphere Microbiome Cooperation: Strategies for Sustainable Crop Production. Current Microbiology, 78:1069-1085.

Omomowo, O.I., and O.O. Babalola, 2019. Bacterial and fungal endophytes: Tiny giants with immense beneficial potential for plant growth and sustainable agricultural productivity. Microorganisms 7: 481.

Ong, K.S., Y.K. Aw, L.H. Lee, et al., 2016. Burkholderia paludis sp. nov., an antibiotic-siderophore producing novel Burkholderia cepacia complex species, isolated from Malaysian Tropical Peat Swamp Soil. Front Microbiol., 7: 2046.

Orozco-Mosqueda, M.D.C., M.D.C. Rocha-Granados, B.R. Glick, et al., 2018. Microbiome engineering to improve biocontrol and plant growth-promoting mechanisms. Microbiol. Res., 208: $25-31$.

Orr, C.H., A. James, C. Leifert, J.M. Cooper, S.P. Cummings, et al., 2011. Diversity and activity of free-living nitrogen-fi xing bacteria and total bacteria in organic and conventionally managed soils. Appl. Environ. Microbiol., 77: 911-919

Osman, K.T., 2014. Soil degradation, conservation and remediation. Springer. DOI: https://doi.org/10.1007/978-94-007-7590-9.

Osorio, N.W., and M. Habte, 2001. Synergistic influence of an arbuscular mycorrhizal fungus and P solubilizing fungus on growth and plant $\mathrm{P}$ uptake of Leucaena leucocephala in an Oxisol. Arid Land. Res. Manage., 15: 263-274.

Oves, M., M.S. Khan, and A. Zaidi, 2013. Chromium reducing and plant growth promoting novel strain Pseudomonas aeruginosa OSG41 enhance chickpea growth in chromium amended soils. Eur J Soil Biol., 56:72-83

Owen, D., A.P. Williams, G.W. Griffith, and P.J.A. Withers, 2015. Use of commercial bio-inoculants to increase agricultural production through improved phosphrous acquisition. Appl. Soil Ecol. 86 (0): 41-54.

Pandey, P.K., R. Samanta, and R.N.S. Yadav, 2019. Inside the plant: addressing bacterial endophytes in biotic stress alleviation. Arch. Microbiol. 201: 415-429.

Panigrahi, S., S. Mohanty, and C.C. Rath, 2019. Characterization of endophytic bacteria Enterobacter cloacae MG00145 isolated from Ocimum sanctum with Indole Acetic Acid (IAA. production and plant growth promoting capabilities against selected crops. S. Afr. J. Bot., 134: 17-26.

Par'e, T., H. Dinel, A.P. Moulin, and L. Townley-Smith, 1999. Organic matter quality and structural stability of a Black Chernozemic soil under different manure and tillage practices. Geoderma 91:311-326.

Parmar, P., and S. Sindhu, 2013. Potassium solubilization by rhizosphere bacteria: influence of nutritional and environmental conditions. J. Microbiol. Res. 3 (1):25-31.

Parnell, J.J., R. Berka, H.A. Young, et al., 2016. From the lab to the farm: An industrial perspective of plant beneficial microorganisms. Front Plant Sci 7: 1110. 
Parton, W.J., D.S. Ojima, C.V. Cole, and D.S. Schimel, 1994. "A general model for soil organic matter dynamics: sensitivity to litter chemistry, texture and management," in Quantitative Modelling of Soil Forming Processes, eds R. B Bryant and R. W. Arnold (Madison, WI: Soil Science Society of America): 147-167.

Parul, R., S. Rupali, M. Gourav, S.R. Mohanty and T. Archana, 2013. Biogeochemical Aspect of Atmospheric Methane and Impact of Nanoparticles on Methanotrophs. J. Environ. Anal. Toxicol., 3: $2-10$

Patel, J.S., A. Singh, H.B. Singh, and B.K. Sarma , 2015. Plant genotype, microbial recruitment and nutritional security. Front Plant Sci., 6:608-608.

Patel, P., G. Trivedi, and M. Saraf, 2018. Iron biofortification in mungbean using siderophore producing plant growth promoting bacteria. Environ Sustain, 1: 357-365.

Paul, E., and R. Kucey, 1981. Carbon flow in plant microbial associations. Science 213(4506): 473474.

Paustian, K., J. Lehmann, S. Ogle, D. Reay, G.P. Robertson, and P. Smith, 2016. Climate-smart soils. Nature, 532: 49-57.

Peng, S., T. Guo, and G. Liu, 2013. The effects of arbuscular mycorrhizal hyphal networks on soil aggregations of purple soil in southwest China. Soil Biol. Biochem. 57: 411-417.

Penn, C.J., and J.J. Camberato, 2019. A critical review on soil chemical processes that control how soil ph affects phosphorus availability to plants. Agriculture, 9: 120.

Peoples, M.B., J. Brockwell, D.F. Herridge, I.J. Rochester, B.J.R. Alves, S. Urquiaga, 2009. The contributions of nitrogen-fixing crop legumes to the productivity of agricultural systems. Symbiosis, 48: 1-17.

Peoples, M.B., J.K. Ladha, and D.F. Herridge, 1995. Enhancing legume N2 fixation through plant and soil management. Plant Soil, 174: 83-101.

Pereg, L., and M. McMillan, 2015. Scoping the potential uses of beneficial microorganisms for increasing productivity in cotton cropping systems. Soil Biol. Biochem., 80: 349-358

Pérès, G., D. Cluzeau, S. Menasseri, J.-F. Soussana, H. Bessler, C. Engels, M. Habekost, G. Gleixner, A. Weigelt, and W.W. Weisser, 2013. Mechanisms linking plant community properties to soil aggregate stability in an experimental grass land plant diversity gradient. Plant Soil, 373 (1-2): 285-299.

Pérez, C.A., F.M. Thomas, W.A. Silva, B. Segura, B. Gallardo, and J.J. Armesto, 2014.Patterns of biological nitrogen fixation during 60000 years of forest development on volcanic soils from south-central Chile. N. Z. J. Ecol., 38 (2):189-200.

Pérez-Montano, F., C. Alías-Villegas, R.A. Bellogín, P. del Cerro, M.R. Espuny, I. Jiménez-Guerrero, F.J. López-Baena, F.J. Ollero, and T. Cubo., 2014. Plant growth promotion in cereal and leguminous agricultural important plants: From microorganism capacities to crop production. Microbiological Research 169, 325-336

Phetcharat, P., and A. Duangpaeng, 2012. Screening of endophytic bacteria from organic rice tissue for indole acetic acid production. Procedia Eng., 32:177-183

Pii, Y., T. Mimmo, N. Tomasi, et al., 2015. Microbial interactions in the rhizosphere: beneficial influences of plant growth-promoting rhizobacteria on nutrient acquisition process. A review. Biol Fertil Soils, 51: 403-415.

Postgate, J.R., 1982. The fundamentals of nitrogen fixation, CUP Archive. Prajapati, K., Sharma, M., Modi, H., 2012. Isolation of two potassium solubilizing fungi from ceramic industry soils. Life Sci. Leaflets, 5: 71-75.

Postgate, J.R., 1998. Nitrogen Fixation. Cambridge University Press, Cambridge, UK.

Prakamhang, J., P. Tittabutr, N. Boonkerd, K. Teamtisong, T. Uchiumi, M. Abe, and N. Teaumroong, 2015. Proposed some interactions at molecular level of PGPRcoinoculated with Bradyrhizobium diazoefficiens USDA110 and B. japonicumTHA6 on soybean symbiosis and its potential of field application. Appl. SoilEcol., 85: 38-49.

Pramanik, P., G.K. Ghosh, P.K. Ghosal, and P. Banik, 2007. Changes in organic-C, N, P and K and enzyme activities in vermicompost of biodegradable organic wastes under liming and microbial inoculants. J Bioresour Technol., 98:2485-2494

Prasad, M., R. Srinivasan, M. Chaudhary, et al., 2019. Plant growth promoting rhizobacteria (PGPR. for sustainable agriculture. PGPR Amelior Sustain Agric., 129-157. 
Prasanna, K.M.K., H.B. Mahesh, R.U. Desai, et al., 2020. Metagenome sequencing of finger milletassociated microbial consortia provides insights into structural and functional diversity of endophytes. 3 Biotech., 10: 15.

Prosser, J.I., 2007. Microorganisms cycling soil nutrients and their diversity. In: Modern Soil Microbiology, ed. by Van Elsas JD, Jansson JK and Trevors JT. CRC Press, New York, NY, 237261.

Puget, P., D.A. Angers, and C. Chenu, 1999. Nature of carbohydrates associated with water-stable aggregates of two cultivated soils. Soil Biol Biochem., 31:55-63

Puget, P., C. Chenu, and J Balesdent, 2000. Dynamics of soil organic matter associated with particlesize fractions of water-stable aggregates. Eur. J. Soil Sci., 51:595-605

Puppi, G., R. Azcón, and G. Höflich, 1994. Management of positive interactions ofarbuscular mycorrhizal fungi with essential groups of soil microorganisms. In: Impact of Arbuscular Mycorrhizas on Sustainable Agriculture and Natural Ecosystems. Springer, 201-215.

Qin, G.-K.P., M. Tignor, S.K. Allen, J. Boschung, A. Nauels, Y. Xia, V. Bex, and P.M. Midgley (Cambridge, UK; New York, NY: Cambridge University Press): 465-570.

Qu'en'eherv'e, P., and J.L. Chotte, 1996. Distribution of nematodes in vertisol aggregates under a permanent pasture in Martinique. Appl. Soil Ecol., 4:193-200

Qureshi, M.A., A. Iqbal, N. Akhtar, M.A. Shakir, and A. Khan, 2012. Coinoculation of phosphate solubilizing bacteria and rhizobia in the presence of L-tryptophan for the promotion of mash bean (Vigna mungo L.) Soil Environ., 31: 47-54.

Rabiey, M., L.E. Hailey, S.R. Roy, et al., 2019. Endophytes vs tree pathogens and pests: can they be used as biological control agents to improve tree health? Eur. J. Plant Pathol., 155: 711-729.

Raffi, M.M., and P.B.B.N. Charyulu, 2021. Azospirillum-biofertilizer for sustainable cereal crop production: Current status. Recent developments in applied microbiology and biochemistry. Elsevier, 193-209.

Rajkumar, M., N. Ae, and H. Freitas, 2009. Endophytic bacteria and their potential to enhance heavy metal phytoextraction. Chemosphere, 77:153-160

Rajput, R.S., R.M. Ram, A. Vaishnav, et al., 2019. Microbe-based novel bio stimulants for sustainable crop production. In: Satyanarayana T, Das S, Johri B. (Eds): Microbial diversity in ecosystem sustainability and biotechnological applications. Singapore: Springer, 2: 109-144.

Rania, A.B.A., H. Jabnoun-Khiareddine, A. Nefzi, et al., 2016. Endophytic bacteria from Datura metel for plant growth promotion and bio protection against Fusarium wilt in tomato. Biocontrol Sci Technol., 26: 1139-1165.

Rao, D.L.N., 2014. Recent advances in biological nitrogen fixation in agricultural systems. Proc. Indian Natl. Sci. Acad., 80: 359-378.

Rashid, S., T.C. Charles, and B.R. Glick, 2012. Isolation and characterization of new plant growthpromoting bacterial endophytes. Appl. Soil Ecol., 61: 217-224.

Rashid, M.I., R.G. de Goede, L. Brussaard, and E.A. Lantinga, 2013. Home field advantage of cattle manure decomposition affects the apparent nitrogen recovery in production grasslands. Soil Biol. Biochem., 57, 320-326.

Rashid, M.I., R.G. de Goede, G.A.C. Nunez, L. Brussaard, and E.A. Lantinga, 2014b. Soil pH and earthworms affect herbage nitrogen recovery from solid cattle manure in production grassland. Soil Biol. Biochem., 68: 1-8.

Rashid, M.I., R.G.M. de Goede, L. Brussaard, J. Bloem, and E.A. Lantinga, 2014a.Productionecological modelling explains the difference between potential soilN mineralisation and actual herbage N uptake. Appl. Soil Ecol., 84: 83-92.

Raza, A., A. Razzaq, S.S. Mehmood, et al., 2019. Impact of climate change on crops adaptation and strategies to tackle its outcome: A Review. Plants, 8: 34.

Reddy, C. A., and R.S. Saravanan, 2013. Polymicrobial multi-functional approach for enhancement of crop productivity. Adv. Appl. Microbiol. 82, 53-113.

Reed, S.C., C.C. Cleveland, and A.R. Townsend, 2007. Controls over leaf litter and soil nitrogen fixation in two lowland tropical rain forests. Biotropica, 39 (5):585-592.

Reed, S.C., C.C. Cleveland, and A.R. Townsend, 2011. Functional ecology of free-living nitrogen fixation: a contemporary perspective. Ann. Rev. Ecol. Evol. Syst. 42,489-512. 
Regina, L.W., A.A. Jayde, T.R. Scott, B.S. Matthew, E.G. David, M.P. Eric, D.Z. Olivier, V.P. Anthony, and A.E. Dwayne, 2019. Soil Aggregate Microbial Communities: Towards Understanding Microbiome Interactions at Biologically Relevant Scales, Applied and Environmental Microbiology, 85: 14 e00324-19.

Reichow, S.L., D.M. Clemens, J.A. Freites, K.L. Németh-Cahalan, M. Heyden, D.J. Tobias, J.E. Hall, and T. Gonen, 2013. Allosteric mechanism of water channel gating by $\mathrm{Ca} 2$ and -calmodulin. Nat Struct Mol Biol., 20:1085- 1092

Rengel, Z., 2002. Breeding for better symbiosis. Plant Soil, 245 (1): 147-162.

Rfaki, A., O. Zennouhi, F.Z. Aliyat, et al., 2020. Isolation, selection and characterization of rootassociated rock phosphate solubilizing bacteria in moroccan wheat (Triticum aestivum L.) Geomicrobiol., J., 37: 230-241.

Rice, W.A., G.W. Clayton, P.E. Olsen, and N.Z. Lupwayi, 2000. Rhizobial inoculant formulations and soil $\mathrm{pH}$ influence field pea nodulation and nitrogen fixation. Can. J. Soil Sci. 80, 395-400

Richardson, A.E., J-M. Barea, A.M. McNeill, and C. Prigent - Combaret, 2009. Acquisition of phosphorus and nitrogen in the rhizosphere and plant growth promotion by microorganisms. Plant Soil, 321: 305-339.

Riggs, P.J., M.K. Chelius, A.L. Iniguez, S.M. Kaeppler, and E.W. Triplett, 2001. Enhanced maize productivity by inoculation with diazotrophic bacteria. Funct. Plant Biol., 28 (9): 829-836.

Rillig, M.C., and P.D. Steinberg, 2002. Glomalin production by an arbuscular mycorrhizal fungus: a mechanism of habitat modification? Soil Biol. Biochem., 34:1371-1374

Rillig, M.C., C.A. Aguilar-Trigueros, J. Bergmann, E. Verbruggen, S.D. Veresoglou, and A. Lehmann, 2015. Plant root and mycorrhizal fungal traits for understanding soil aggregation. New Phytol., 205 (4): 1385-1388.

Rillig, M.C., D.L. Mummey, P.W. Ramsey, J.N. Klironomos, and J.E. Gannon, 2006.Phylogeny of arbuscular mycorrhizal fungi predicts community composition of symbiosis-associated bacteria. FEMS Microbiol. Ecol., 57 (3): 389-395.

Rillig, M.C., S.F. Wright, and V.T. Eviner, 2002. The role of arbuscular mycorrhizal fungi and glomalin in soil aggregation: comparing effects of five plant species. Plant Soil 238 (2): 325-333.

Robert, M., and C. Chenu, 1992. Interactions between soil minerals and microorganisms. In: Stotzky G, Bollag JM (eds. Soil biochemistry, vol 7. Dekker, New York, 307-404.

Rodri'iguez, H., and R. Fraga, 1999. Phosphate solubilizing bacteria and their role implant growth promotion. Biotechnol. Adv. 17 (4): 319-339.

Rodriguez, H., T. Gonzalez, I. Goire, and Y. Bashan, 2004. Gluconic acid production andphosphate solubilization by the plant growth-promoting bacterium Azospirillum spp. Naturwissenschaften 91 (11): 552-555.

Rogers, S.L., and R.G. Burns, 1994. Changesin aggregate stability nutrient status, in digenousmicrobial populations, and seedling emergence following inoculation with Nostoc muscorum. Biol Fertil Soils, 18:219-215.

Roldan, A., J. Albaladejo, and J.B. Thornes, 1996. Aggregate stability changes in a semiarid soil after treatment with different organic amendments. Arid. Soil Res. Rehabil., 10:139-148

Römheld, V., and E.A. Kirkby, 2010. Research on potassium in agriculture: needs andprospects. Plant Soil, 335 (1-2): 155-180.

Ryan, R.P., K. Germaine, A. Franks, D.J. Ryan, and D.N. Dowling, 2008. Bacterial endophytes: recent developments and applications. FEMS Microbiol. Lett., 278:1-9.

Sabaté, D.C., C.P. Brandan, G. Petroselli, et al., 2017. Decrease in the incidence of charcoal root rot in common bean (Phaseolus vulgaris L.) by Bacillus amyloliquefaciens B14, a strain with PGPR properties. Biol Control., 113: 1-8.

Sachs, J.L., K.W. Quides, and C.E. Wendlandt, 2018. Legumes versus rhizobia: a model for ongoing conflict in symbiosis. New Phytologist, 219: 1199-1206.

Sajjad, A., A.K. Muhammad, K. Abdul Latif, W. Muhammad, Sh. Raheem, K. Ah-Yeong, K. Sang-Mo and L. In-Jung, 2017. Bacterial endophytes from arid land plants regulate endogenous hormone content and promote growth in crop plants an example of Sphingomonas sp. and Serratia marcescens. journal of plant interactions, 12(1): 31-38 
Sánchez-Díaz, M., M. Pardo, M. Antolin, J. Pena, and J. Aguirreolea, 1990. Effect of water stress on photosynthetic activity in the Medicago-Rhizobium-Glomus symbiosis. Plant Sci., 71 (2): 215221.

Santoyo, G., G. Moreno-Hagelsieb, M.O.-M. del Carmen, et al., 2016. Plant growth-promoting bacterial endophytes. Microbiol. Res., 183: 92-99.

Sarhan, M.S., M.A. Hamza, H.H. Youssef, et al., 2019. Culturomics of the plant prokaryotic microbiome and the dawn of plant-based culture media-A review. J. Adv. Res., 19: 15-27.

Sasirekha, B., and S. Srividya, 2016. Siderophore production by Pseudomonas aeruginosa FP6, a biocontrol strain for Rhizoctonia solani and Colletotrichum gloeosporioides causing diseases in chilli. Agric. Nat. Resour., 50: 250-256

Sayer, E.J., A.E. Oliver, J.D. Fridley, A.P. Askew, R.T.E. Mills, et al, 2017. Links between

Schalk, I.J., M. Hannauer, and A. Braud, 2011. New roles for bacterial siderophores inmetal transport and tolerance. Environ. Microbiol., 13 (11): 2844-2854.

Schlecht-Pietsch, S., U. Wagner, and T.H. Anderson, 1994. Changes in composition of soil polysaccharides and aggregate stability after carbon amendments to different textured soils. Appl. Soil Ecol., 1:145-154

Schlemper, T.R., M.R. Dimitrov, F.A.O.S. Gutierrez, et al., 2018. Effect of Burkholderia tropica and Herbaspirillum frisingense strains on sorghum growth is plant genotype dependent. Peer, J. e5346.

Schulze, J., 2004. How are nitrogen fixation rates regulated in legumes? J. Plant Nutr. Soil Sci. 167, $125-137$.

Schulze, J., and J.J. Drevon, 2005. P-deficiency increases the O2 uptake per N2 reduced in alfalfa. J. Exp. Bot. 56: 1779-1784.

Sendi, Y., T. Pfeiffer, E. Koch, et al., 2020. Potential of common bean (Phaseolus vulgaris L.) root microbiome in the biocontrol of root rot disease and traits of performance. J. Plant Dis. Prot. 127: 453-462.

Seneviratne, G., A. Jayasekara, S. De, M. Ilva, and U. Abeysekera, 2011. Developedmicrobial biofilms can restore deteriorated conventional agricultural soils. SoilBiol. Biochem., 43 (5): 1059-1062.

Seneviratne, G., J. Zavahir, W. Bandara, and M. Weerasekara, 2008. Fungal-bacterialbiofilms: their development for novel biotechnological applications. World J. Microbiol. Biotechnol., 24 (6): 739-743.

Serraj, R., and J. Adu-Gyamfi, 2004. Role of symbiotic nitrogen fixation in the improvement of legume productivity under stressed environments. West Afr. J. Appl. Ecol. 6: 95-109.

Shah, G.M., M.I. Rashid, G.A. Shah, J.C.J. Groot, and E.A. Lantinga, 2013. Mineralizationand herbage recovery of animal manure nitrogen after application to varioussoil types. Plant Soil, 365 (1-2): 69-79.

Sharaf, H., R.R. Rodrigues, and J.Y. Moon, et al., 2019. Unprecedented bacterial community richness in soybean nodules vary with cultivar and water status. Microbiome, 7: 63.

Sharma, A., B. Johri, A. Sharma, and B. Glick, 2003. Plant growth-promoting bacteriumPseudomonas sp: strain GRP 3 influences iron acquisition in mung bean (Vignaradiata L.) Wilzeck. Soil Biol. Biochem. 35 (7): 887-894.

Shaviv, A., 2000. Advances in controlled release of fertilizers. Adv. Agron., 71: 1-49.

Shelobolina E., E. Roden, J. Benzine, and M.Y. Xiong, 2014. Using phyllosilicate-fe (ii)-oxidizingsoil bacteria to improve fe and K plant nutrition: Google Patents.

Sheng, X.F., and L.Y. He, 2006. Solubilization of potassium-bearing minerals by awild-type strain of Bacillus edaphic us and its mutants and increased potassium uptake by wheat. Can. J. Microbiol., 52 (1): 66-72.

Shifa, H., C. Gopalakrishnan, and R. Velazhahan, 2014. Efficacy of Bacillus subtilis G-1 in suppression of stem rot caused by Sclerotium rolfsii and growth promotion of groundnut. Int J Agric Environ Biotechnol., 8: 111.

Shindell, D., J.C. Kuylenstierna, E. Vignati, V.R. Dingenen, M. Amann, et al, 2012. Simultaneously mitigating near-term climate change and improving human health and food security. Science, 335:183-189.

Shrivastava, M., P.C. Srivastava, and S.F. D'souza, 2016. KSM soil diversity and mineral solubilization, in relation to crop production and molecular mechanism. In: Meena V, Maurya B, 
Verma J. et al., (Eds): Potassium solubilizing microorganisms for sustainable agriculture. New Delhi: Springer, 221-234.

Sieverding, E., G.A. da Silva, R. Berndt, and F. Oehl, 2014. Rhizoglomus, a new genus of the Glomeraceae. Mycotaxon, 129 (2): 373-386.

Sinclair, T., R. Muchow, J. Bennett, and L. Hammond, 1987. Relative sensitivity of nitrogen and biomass accumulation to drought in field-grown soybean. Agron. J. 79 (6): 986-991.

Singh, A., M. Kumar, S. Verma, et al., 2020. Plant microbiome: Trends and prospects for sustainable agriculture. In: Varma A, Tripathi S, Prasad R. (Eds): Plant microbe symbiosis. Springer, Cham, $129-151$.

Singh, B.K., R.D. Bardgett, P. Smith, and S.R. Dave, 2010. Microorganisms and climate change: terrestrial feedbacks and mitigation options. Nat Rev Microbiol., 8: 779-790.

Singh, D., N. Geat, M.V.S. Rajawat, et al., 2018. Prospecting endophytes from different Fe or Zn accumulating wheat genotypes for their influence as inoculants on plant growth, yield, and micronutrient content. Ann Microbiol., 68: 815-833.

Singh, M., A. Kumar, R. Singh, et al., 2017. Endophytic bacteria: a new source of bioactive compounds. 3 Biotech 7: 316.

Singh, R.K., and S. Kundu, 2014. Review on Changing Natural Nitrogen Cycle: Special Reference to Kingdom of Saudi Arabia. International Journal of Engineering Science Invention Research \& Development, 1: 73-80

Singh, Y., P.W. Ramteke, and P.K. Shukla, 2013. Isolation and characterization of heavy metal resistant Pseudomonas spp. and their plant growth promoting activities. Adv Appl Sci Res 4:269-272

Singh, J.S., 2014. Cyanobacteria: a vital bio-agent in eco-restoration of degraded lands and sustainable agriculture. Clim. Change Environ. Sustain., 2 (2):133-137.

Singh, J.S., 2015. Microbes. The chief ecological engineers in reinstating equilibrium in degraded ecosystems. Agric. Ecosyst. Environ., 203: 80-82.

Singh, B.K., P. Millard, A.S. Whiteley, and J.C. Murrell, 2004. Unravelling rhizosphere-microbial interactions : opportunities and limitations. Trends Microbiol., 12: 386-393.

Sinha, R.K., S. Herat, and D.B. Valani, 2009. Earthworms: the 'unheralded soldiers of mankind' and 'farmer's friend' working day and night under the soil: reviving the dreams of Sir Charles Darwin for promoting sustainable agriculture. Am-Euras J. Agric Environ., Sci., 5(S):1-55

Six, J., A. Carpentier, C.V. Kessel, R. Merckx, D. Harris, W.R. Horwath, and A. Lüscher, 2001. Impact of elevated $\mathrm{CO} 2$ on soil organic matter dynamics as related to changes in aggregate turnover and residue quality. Plant Soil 234:27-36 Importance of Microorganisms for Soil Aggregation, 119.

Six, J., H. Bossuyt, S. Degryze, and K. Denef, 2004. A history of research on the link between (micro. aggregates, soil biota, and soil organic matter dynamics. Soil Tillage Res., 79 (1): 7-31.

Smil, V., 2000. Phosphorus in the environment: natural flows and human interferences. Annu. Rev. Energy Environ., 25 (1): 53-88.

Smith, S.E., and D.J. Read, 2010. Mycorrhizal Symbiosis. Academic press, Cambrige.

Soenens, A., and J. Imperial, 2020. Biocontrol capabilities of the genus Serratia. Phytochem. Rev., 19: $577-587$.

Song, X., M. Liu, D. Wu, B.S. Griffiths, J. Jiao, H. Li, and F. Hu, 2015. Interaction matters: Synergy between vermicompost and PGPR agents improves soil quality, crop quality and crop yield in the field. Appl. Soil Ecol., 89: 25-34.

Sonnleitner, R., E. Lorbeer, and F. Schinner, 2003. Effects of straw, vegetable oil and whey on physical and microbiological properties of a chernozem. Appl. Soil Ecol., 22:195-204

Sørensen, J. and A. Sessitsch, 2007. "Plant-associated bacteria-life style and molecular interactions, "in Modern Soil Microbiology, 2ndEdn, eds J.D.V.Elsas, J.K.Jansson and J.T.T revors (Boca Raton, FL: CRC Press): 211-236.

Spaccini, R., J.S.C. Mbagwu, C.A. Igwe, P. Conte, and A. Piccolo, 2003. Carbohydrates and aggregation in lowland soils of Nigeria as influenced by organic inputs. Soil Tillage Res., 75:161172

Sparks, D.L., and P.M. Huang, 1985. Physical Chemistry of Soil Potassium. In: Munson,R.D. (Ed.): Potassium in Agriculture American Society of Agronomy, Crop Science Society of America, Soil Science Society of America Madison, WI, 201-276.

Sprent J., M. Sutherland, and S. De Faria, 1989. Structure and function of nodules from woodylegumes. 
Srinivasarao, C., B. Venkateswarlu, R. Lal, A. Singh, S. Kundu, K. Vittal, J. Patel, and M. Patel, 2014. Long-term manuring and fertilizer effects on depletion of soil organic carbon stocks under pearl millet-cluster bean-castor rotation in western India. Land Degr. Dev. 25 (2): 173-183.

Stacey, G., 2007. The Rhizobium-legume nitrogen-fixing symbiosis. In: Biology of the Nitrogen Cycle. Elsevier, London, 147.

Stella, M., M. Theeba, Z.I. Illani, et al., 2019. Organic fertilizer amended with immobilized bacterial cells for extended shelf-life. Biocatal. Agric. Biotechnol., 20: 101248.

Sulieman, S., and L.S. Tran, 2015. Phosphorus homeostasis in legume nodules as an adaptive strategy to phosphorus deficiency. Plant Sci., 239: 36-43.

Suman, A., A.N. Yadav, and P. Verma, 2016. Endophytic microbes in crops: Diversity and beneficial impact for sustainable agriculture. In: Singh D, Singh H, Prabha R. (Eds): Microbial inoculants in sustainable agricultural productivity. New Delhi: Springer, 1: 117-143.

Sun, T., Q. Chen, Y. Chen, R. Cruse, X. Li, C. Song, Y. Kravchenko, and X. Zhang, 2014.A novel soil wetting technique for measuring wet stable aggregates. SoilTillage Res., 141, 19-24.

Swati, T., S. Ramesh and J. Shaily, 2014. Effect of Climate Change on Plant-Microbe Interaction: An Overview. European Journal of Molecular Biotechnology, 5: 149-156.

Tagele, S.B., S.W. Kim, H.G. Lee, et al., 2019. Potential of novel sequence Type of Burkholderia cenocepacia for biological control of root rot of maize (Zea mays L.) Caused by Fusarium temperatum. Int. J. Mol. Sci., 20: 1005.

Tairo, E.V., and P.A. Ndakidemi, 2014. Macronutrient's uptake in soybean as affected by Bradyrhizobium japonicum Inoculation and phosphorus (P. supplements. Am. J. Plant Sci. 5), 488496.

Tajkhorshid, E., P. Nollert, M.Ø. Jensen, L.J.W. Miercke, J. O’Connell, R.M. Stroud, and K. Schulten, 2002. Control of the selectivity of the aquaporin water channel family by global orientational tuning. Science, 296: 525-530

Tak, N., and H.S. Gehlot, 2019. Diversity of nitrogen-fixing symbiotic rhizobia with special reference to indian thar desert, In: Satyanarayana T, Das S, Johri B. (Eds): Microbial diversity in ecosystem sustainability and biotechnological applications. Singapore: Springer, 31-55.

Tang, J., E.S.P. Bromfield, N. Rodrigue, S. Cloutier, and J.T. Tambong, 2012. Microevolution of symbiotic Bradyrhizobium populations associated with soybeans in east North America. Ecology and Evolution, 2: 2943-2961

Tang, J., Y. Mo, J. Zhang, and R. Zhang, 2011. Influence of biological aggregating agentsassociated with microbial population on soil aggregate stability. Appl. Soil Ecol., 47 (3): 153-159.

Tao, G.-C., S.-J. Tian, M.-Y. Cai, and X. Guang-Hui, 2008. Phosphate-solubilizing and-mineralizing abilities of bacteria isolated from soils. Pedosphere, 18 (4):515-523.

Taylor, B.N., E.L. Simms, and K.J. Komatsu, 2020. More than a functional group: Diversity within the legume-rhizobia mutualism and its relationship with ecosystem function. Diversity, 12: 50.

Teotia, P., V. Kumar, M. Kumar, et al., 2016. Rhizosphere microbes: Potassium solubilization and crop productivity-present and future aspects. In: Meena V, Maurya B, Verma J, et al., (Eds): Potassium solubilizing microorganisms for sustainable agriculture. New Delhi: Springer, 315-325.

Tewari, S., and N.K. Arora, 2016. Fluorescent Pseudomonas sp. PF17 as an efficient plant growth regulator and biocontrol agent for sunflower crop under saline conditions. Symbiosis, 68: 99-108.

Tewari, S., V.L. Shrivas, and P. Hariprasad, et al., 2019. Harnessing endophytes as biocontrol agents. In: Ansari R, Mahmood I. (Eds): Plant Health Under Biotic Stress. Singapore: Springer, 189-218.

Thiergart T, P Durán, T Ellis, et al., 2020. Root microbiota assembly and adaptive differentiation among European Arabidopsis populations. Nat. Ecol. Evol., 4: 122-131.

Thiery, J.P., 1967. Mise en 'evidence des polysaccharides sur coupes fines en microscopie 'electronique. J. Microsc, 6:987-1017

Thomas, P., and A.C. Sekhar, 2017. Cultivation versus molecular analysis of banana (Musa sp.) Shoottip tissue reveals enormous diversity of normally uncultivable endophytic bacteria. Microb Ecol 73: 885-899.

Tian, G., C.-Y. Chiu, A.J. Franzluebbers, O.O. Oladeji, T.C. Granato, A.E. Cox, 2015.Biosolids amendment dramatically increases sequestration of cropresidue-carbon in agricultural soils in western Illinois. Appl. Soil Ecol., 85: 86-93. 
Tiessen, H., E. Cuevas, and P. Chacon, 1994. The role of soil organic matter insustaining soil fertility. Nature, 371 (6500): 783-785.

Tilman, D., C. Balzer, J. Hill, and B.L. Befort, 2011. Global food demand and thesustainable intensification of agriculture. Proc. Natl. Acad. Sci. U. S. A. 108 (50):20260-20264.

Timmusk, S., L. Behers, J. Muthoni, et al., 2017. Perspectives and challenges of microbial application for crop improvement. Front Plant Sci 8: 49.

Tisdall, J.M., B. Cockroft, and N.C. Uren, 1978. The stability of soil aggregates as affected by organic materials, microbial activity and physical disruption. Aust. J. Soil Res., 10:9-18

Tisdall, J.M., and J.M. Oades, 1982. Organic matter and water stable aggregates in soils. J. Soil Sci., 33:141-163.

Tisdall, J., 1994. Possible role of soil microorganisms in aggregation in soils. Plant Soil, 159 (1): 115121.

Trenkel, M.E., 2010. Slow-and Controlled-release and Stabilized Fertilizers: An Option for Enhancing Nutrient Use Efficiency in Agriculture. Paris: International Fertilizer Industry Association. doi: 10.1007/s00284-007-9058-8

Tully, K., C. Sullivan, R. Weil, et al., 2015. The state of soil degradation in sub-saharan Africa: baselines, trajectories, and solutions. Sustainability, 7: 6523-6552.

Tytova, L.V., I.S. Brovko, A.K. Kizilova, I.K. Kravchenko, and G.A. Iutynska, 2013. Effectof complex microbial inoculants on the number and diversity of rhizosphericmicroorganisms and the yield of soybean. Int. J. 4 (3): 267-274.

Udaya K.V., R. Jina, L.P. Singha, S. Lakkakula, A. Hemasundar, D.V.N.S. Pamidimarri, C. Sushma, R. Rambabu, S. Vanisri , B.M. Pranab and P. Piyush, 2021. The Endophytic Microbiome as a Hotspot of Synergistic Interactions, with Prospects of Plant Growth Promotion. Biology, 10, 101.

Udaya, S.A.C., S.C. Nayaka, S. Niranjan-Raj, et al., 2009. Rhizobacteria-mediated resistance against the blackeye cowpea mosaic strain of bean common mosaic virus in cowpea (Vigna unguiculata . Pest Manag. Sci., 65: 1059-1064.

Ullah, A., M. Nisar, H. Ali, et al., 2019. Drought tolerance improvement in plants: an endophytic bacterial approach. Appl. Microbiol. Biotechnol., 103: 7385-7397.

Umesha, S., P.K. Singh, and R.P. Singh, 2018. "Microbial biotechnology and sustainable agriculture," in Biotechnology for Sustainable Agriculture, Chap. 6, eds R. L. Singh and S. Monda (Sawston: Woodhead Publishing): 185-205.

Upadhayay, A., and S. Srivastava, 2012. Evaluation of multiple plant growth promoting traits of an isolate of Pseudomonas fluorescens strain Psd. Indian J. Exp. Biol., 48:601-609.

Uroz, S., C. Calvaruso, M.-P. Turpault, and P. Frey-Klett, 2009. Mineral weathering bybacteria: ecology, actors and mechanisms. Trends Microbiol., 17 (8): 378-387.

Utuk, I.O., and E.E. Daniel, 2015. land degradation: a threat to food security: a global assessment. J. Environ. Earth Sci. 5 (8): 13-21.

Van der Heijden, M.G., R.D. Bardgett, and N.M. Van Straalen, 2008. The unseen majority: soil microbes as drivers of plant diversity and productivity in terrestrial ecosystems. Ecol. Lett. 11 (3): 296-310.

Van Lynden, L., and G. Odeman, 1998. The Assessment of the Status of Human-induced Soil Degradation in South and Southeast Asia. ISRIC.

Van Noorden, G.E., J.J. Ross, J.B. Reid, B.G. Rolfe, and U. Mathesius, 2006. Defective long-distance auxin transport regulation in the Medicago truncatula super numeric nodules mutant 1[W]. Plant Physiol., 140: 1494-1506.

Van Vuuren, D.P., A. Bouwman, and A. Beusen, 2010. Phosphorus demand for the1970-2100 period: a scenario analysis of resource depletion. Glob. Environ. Change, 20 (3): 428-439.

Vandenberghe, L.P., C.R. Soccol, A. Pandey, and J.-M. Lebeault, 1999. Microbial production of citric acid. Braz. Arch. Biol. Technol., 42 (3): 263-276.

Vanlauwe, B., K. Descheemaeker, K.E. Giller, et al., 2014. Integrated soil fertility management in subSaharan Africa. Soil Discuss, 1: 1239-1286.

Vanlauwe, B., M. Hungria, F. Kanampiu, et al., 2019. The role of legumes in the sustainable intensification of African smallholder agriculture: Lessons learnt and challenges for the future. Agric. Ecosyst. Environ., 284: 106583. 
Vansuyt, G., A. Robin, J.-F. Briat, C. Curie, and P. Lemanceau, 2007. Iron acquisition from Fepyoverdine by Arabidopsis thaliana. Mol. Plant Microbe Interact., 20(4): 441-447.

Vardharajula, S., A. SkZ, P. Krishna S.S. Vurukonda, et al., 2017. Plant growth promoting endophytes and their interaction with plants to alleviate abiotic stress. Curr. Biotechnol., 6.

Vardien, W., E.T. Steenkamp, and A.J. Valentine, 2016. Legume nodules from nutrient-poor soils exhibit high plasticity of cellular phosphorus recycling and conservation during variable phosphorus supply. J. Plant Physiol., 191: 73-81.

Vargas, L., A.B.S. Brígida, J.P. Mota Filho, et al., 2014. Drought tolerance conferred to sugarcane by association with Gluconacetobacter diazotrophicus: A transcriptomic view of hormone pathways. PLoS One 9: e114744.

Vassilev, N., M. Vassileva, A. Lopez, V. Martos, A. Reyes, and I. Maksimovic, 2015. Unexploited potential of some biotechnological techniques for biofertilizer production and formulation. Appl. Microbiol. Biotechnol., 99: 4983-4996

Velázquez, E., L. Carro, J.D. Flores-Félix, et al., 2017. The legume nodule microbiome: A source of plant growth-promoting bacteria. In: Kumar V, Kumar M, Sharma S, et al., (Eds): Probiotics and plant health. Singapore: Springer, 41-70.

Veresoglou, S.D., B. Chen, and M.C. Rillig, 2012. Arbuscular mycorrhiza and soil nitrogen cycling. Soil Biol. Biochem., 46: 53-62.

Verma, M., J. Mishra, and N.K. Arora, 2019. Plant growth-promoting rhizobacteria: Diversity and applications. In: Sobti R, Arora N, Kothari R. (Eds): Environmental Biotechnology: For Sustainable Future. Singapore: Springer, 129-173.

Verma, V.C., S.K. Singh, and S. Prakash, 2011. Bio-control and plant growth promotion potential of siderophore producing endophytic Streptomyces from Azadirachta indica A. Juss. J Basic Microb., 51: 550-556.

Vigani, G., E. Rolli, R. Marasco, et al., 2019. Root bacterial endophytes confer drought resistance and enhance expression and activity of a vacuolar $\mathrm{H}$ and -pumping pyrophosphatase in pepper plants. Environ Microbiol., 21: 3212-3228.

Vitousek, P.M., D.N.L. Menge, S.C. Reed, and C.C Cleveland, 2013. Biological nitrogen fi xation: rates, patterns and ecological controls in terrestrial ecosystems, P. T. Roy. Soc. B, 368, 20130119.

Walia, A., S. Guleria, A. Chauhan, et al., 2017. Endophytic bacteria: role in phosphate solubilization, In: Maheshwari D, Annapurna K. (Eds): Endophytes: Crop productivity and protection. Springer, Cham., 16: 61-93.

Wang, C.J., Y.Z. Wang, Z.H. Chu, et al., 2020. Endophytic Bacillus amyloliquefaciens YTB1407 elicits resistance against two fungal pathogens in sweet potato (Ipomoea batatas (L.) Lam.) J Plant Physiol., 253: 153260.

Wang, L., Y. Cao, E.T. Wang, et al., 2016. Biodiversity and biogeography of rhizobia associated with common bean (Phaseolus vulgaris L.) in Shaanxi Province. Syst. Appl. Microbiol., 39: 211-219.

Wang, T., F. Li, Q. Lu, et al., 2020. Studies on diversity, novelty, antimicrobial activity, and new antibiotics of cultivable endophytic actinobacteria isolated from psammophytes collected in Taklamakan Desert. J. Pharm Anal. In Press.

Wang, Y.B., W.X. Zhang, C.J. Ding, et al., 2019. Endophytic communities of transgenic poplar were determined by the environment and niche rather than by transgenic events. Front Microbiol., 10: 588.

Wang, J., F.-J. Zhao, A.A. Meharg, A. Raab, J. Feldmann, and S.P. McGrath, 2002. Mechanisms of arsenic hyperaccumulation in Pteris vittata. Uptake kinetics, interactions with phosphate, and arsenic speciation. Plant Physiol., 130 (3):1552-1561.

Wang, X., Q. Pan, F. Chen, X. Yan, and H. Liao, 2011. Effects of co-inoculation with arbuscular mycorrhizal fungi and rhizobia on soybean growth as related to root architecture and availability of N and P. Mycorrhiza, 21: 173-181.

Ward, B.B., 2011. Measurement and distribution of nitrify cation rates in the oceans. Methods Enzymol., 486: 307-323

Weiman, S, 2015. Microbes help to drive global carbon cycling and climate change. Microbe Mag., 10: 233-238. 
Weyens, N., D. van der Lelie, S. Taghavi, L. Newman, and J. Vangronsveld, 2009. Exploiting plantmicrobe partnerships to improve biomass production and remediation. Trends Biotechnol., 27:591-598.

Wright, S.F., 2000. A fluorescent antibody assay for hyphae and glomalin from arbuscular mycorrhizal fungi. Plant Soil, 226:171-177

Wright, S.F., M. Franke-Snyder, J.B. Morton, and A. Upadhyaya, 1996. Time-course study and partial characterization of a protein on hyphae of arbuscular mycorrhizal fungi during active colonization of roots. Plant Soil, 181:193-203

Wright, S.F., and A. Upadhyaya, 1996. Extraction of an abundant and unusual protein from soil and comparison with hyphae protein of arbuscular mycorrhizal fungi. Soil Sci., 161:575-586

Wright, S.F., and A. Upadhyaya, 1998. A survey of soils for aggregate stability and glomalin, a glycoprotein produced by hyphae of arbuscular mycorrhizal fungi. Plant Soil, 198:97- 1007.

Wu, S.H., G.Q. Zhuang, Z.H. Bai, et al., 2018. Mitigation of nitrous oxide emissions from acidic soils by Bacillus amyloliquefaciens, a plant growth-promoting bacterium. Glob. Chang Biol., 24: 23522365.

Wu, Q.-S., M.-Q. Cao, Y.-N. Zou, and X.-h He, 2014. Direct and indirect effects of glomalin, mycorrhizal hyphae, and roots on aggregate stability in rhizosphereof trifoliate orange. Sci. Repo. 4.

Wu, S.C., Z.H. Caob, Z.G. Lib, K.C. Cheunga, and M.H. Wonga, 2005. Effects of biofertilizer containing N-fixer, $\mathrm{P}$ and $\mathrm{K}$ solubilizers and AM fungi on maize growth: a greenhouse trial. Geoderma 125, 155-166.

Wu, S., Z. Cao, Z. Li, K. Cheung, and M. Wong, 2005. Effects of biofertilizer containing N-fixer, P and $\mathrm{K}$ solubilizers and AM fungi on maize growth: a greenhouse trial.Geoderma 125 (1): 155-166.

Wunderlin, P., J. Mohn, A. Joss, L. Emmenegger, and H. Siegrist, 2012. Mechanisms of N2O production in biological wastewater treatment under nitrifying and denitrifying conditions. Water Res., 46: 1027-1037.

$\mathrm{Xu}, \mathrm{S} ., \mathrm{X} . \mathrm{W}$. Xie, Y.R. Zhao, et al., 2020. Whole-genome analysis of Bacillus velezensis ZF2, a biocontrol agent that protects cucumis sativus against corynespora leaf spot diseases. 3 Biotech 10: 186.

Xu, P., L.Z. Liang, X.Y. Dong, and R.F. Shen, 2015. Effect of arbuscular mycorrhizal fungion aggregate stability of a clay soil inoculating with two different host plants.Acta Agric. Scand., Section BSoil Plant Sci., 65 (1): 23-29.

Yadav, J., J.P. Verma, D.K. Jaiswal, and A. Kumar, 2014. Evaluation of PGPR and different concentration of phosphorus level on plant growth, yield and nutrient content of rice (Oryza sativa. Ecol. Eng., 62: 123-128.

Yaish, M.W., I. Antony, and B.R. Glick, 2015. Isolation and characterization of endophytic plant growth-promoting bacteria from date palm tree (Phoenix dactylifera $\mathrm{L}$.) and their potential role in salinity tolerance. Antonie Van Leeuwenhoek, 107: 1519-1532.

Yaniv, S., E. Benjamin, N.T. Tü nde, L. Guy, L. Varda, S. Gadi, and A. Noam, 2021 . NADPH performs mediated electron transfer in cyanobacterial-driven bio-photo electrochemical cells. IScience 24, 101892, January 22, $2021^{\text {a }} 2020$ the Author(s.

Yasmeen, S., and A. Bano, 2014. Combined effect of phosphate-solubilizing microorganisms, Rhizobium and Enterobacter on root nodulation and physiology of soybean (Glycine max L.) Commun. Soil Sci. Plant Anal., 45: 2373-2384.

Yasmin, H., S. Naeem, M. Bakhtawar, et al., 2020. Halotolerant rhizobacteria Pseudomonas pseudoalcaligenes and Bacillus subtilis mediate systemic tolerance in hydroponically grown soybean (Glycine $\max \mathrm{L}$.) against salinity stress. PLoS One 15: e0231348.

Yasmin, S., F.Y. Hafeez, M.S. Mirza, et al., 2017. Biocontrol of Bacterial Leaf Blight of rice and profiling of secondary metabolites produced by rhizospheric Pseudomonas aeruginosa BRp3. Front Microbiol., 8: 1895.

Yergeau, E., S. Bokhorst, S. Kang, J. Zhou, C.W. Greer et al, 2012. Shifts in soil microorganisms in response to warming are consistent across a range of Antarctic environments. The ISME Journal, 6: $692-702$.

Yoon, V., G. Tian, J.K. Vessey, et al., 2016. Colonization efficiency of different sorghum genotypes by Gluconacetobacter diazotrophicus. Plant Soil, 398: 243-256. 
Zadorova, T., O. Jak`sík, R. Kode`sová, and V. Penízzek, 2011. Influence of terrain attributes and soil properties on soil aggregate stability. Soil Water Res., 6 (3):111.

Zahedi, H., 2016. Growth-promoting effect of potassium-solubilizing microorganisms on some crop species, In: Meena V, Maurya B, Verma J. et al., (Eds): Potassium solubilizing microorganisms for sustainable agriculture. New Delhi: Springer, 31-42.

Zaidi, A., M. Ahemad, M. Oves, E. Ahmad, and K.M. Saghir, 2010. "Role of phosphate-solubilizing bacteria in legume improvement," in Microbes for Legume Improvement, eds. Khan, A. Zaidi and J. Musarrat (Vienna: Springer). 273-292.

Zancarini, A., C. Mougel, A.-S. Voisin, M. Prudent, C. Salon, and N. Munier-Jolain, 2012. Soil nitrogen availability and plant genotype modify the nutrition strategies of $\mathrm{M}$. truncatula and the associated rhizosphere microbial communities. PLoS ONE, 7(10): e47096.

Zarjani, J.K., N. Aliasgharzad, S. Oustan, M. Emadi, and A. Ahmadi, 2013. Isolation andcharacterization of potassium solubilizing bacteria in some Iranian soils. Arch.Agron. Soil Sci., 59 (12): 1713-1723.

Zhalnina, K., K.B. Louie, Z. Hao, et al., 2018. Dynamic root exudate chemistry and microbial substrate preferences drive patterns in rhizosphere microbial community assembly. Nat. Microbiol., 3: 470480.

Zhang, Q., G. Lambert, D. Liao, H.K. Robin, et al, 2011b. Acceleration of emergence of bacterial antibiotic resistance in connected microenvironments. Science, 333:1764-1767.

Zhang, Y., X.X. Yu, W.J. Zhang, et al., 2019. Interactions between endophytes and plants: Beneficial effect of endophytes to ameliorate biotic and abiotic stresses in plants. J. Plant Biol., 62: 1-13.

Zhang, J., C. Müller, and Z. Cai, 2015. Heterotrophic nitrification of organic N and its contribution to nitrous oxide emissions in soils. Soil Biol. Biochem. 84: 199-120.

Zhang, L., J. Fan, X. Ding, X. He, F. Zhang, and G. Feng, 2014. Hyphosphereinteractions between an arbuscular mycorrhizal fungus and a phosphate solubilizing bacterium promote phytate mineralization in soil. Soil Biol. Biochem., 74: 177-183.

Zheng, W., E.K. Morris, and M.C. Rillig, 2014. Ecto mycorrhizal fungi in association with Pinus sylvestris seedlings promote soil aggregation and soil water repellency.Soil Biol. Biochem. 78, $326-331$.

Zhou, J., K. Xue, J. Xie, Y. Deng, W. Liyou, et al., 2011. Microbial mediation of carbon-cycle feedbacks to climate warming. NATURE CLIMATE CHANGE. 1-5.

Zhu, Q., W.J. Riley, J. Tang, and C.D. Koven, 2016. Multiple soil nutrient competition between plants, microbes, and mineral surfaces: model development, parameterization, and example applications in several tropical forests. Biogeosciences, 13: 341-363.

Zimmerman, L., and B. Labonte, 2015. Climate change and the microbial methane banquet. Climate Alert, 27. 